\title{
WestVirginiaUniversity
}

THE RESEARCH REPOSITORY @ WVU

Graduate Theses, Dissertations, and Problem Reports

2014

\section{Evaluation of Hydrotreated Biofuels for Use in Naval Diesel Engines}

Cory J. Morgan

Follow this and additional works at: https://researchrepository.wvu.edu/etd

\section{Recommended Citation}

Morgan, Cory J., "Evaluation of Hydrotreated Biofuels for Use in Naval Diesel Engines" (2014). Graduate Theses, Dissertations, and Problem Reports. 7333.

https://researchrepository.wvu.edu/etd/7333

This Thesis is protected by copyright and/or related rights. It has been brought to you by the The Research Repository @ WVU with permission from the rights-holder(s). You are free to use this Thesis in any way that is permitted by the copyright and related rights legislation that applies to your use. For other uses you must obtain permission from the rights-holder(s) directly, unless additional rights are indicated by a Creative Commons license in the record and/ or on the work itself. This Thesis has been accepted for inclusion in WVU Graduate Theses, Dissertations, and Problem Reports collection by an authorized administrator of The Research Repository @ WVU. For more information, please contact researchrepository@mail.wvu.edu. 


\title{
Evaluation of Hydrotreated Biofuels for Use in Naval Diesel Engines
}

\author{
Cory J. Morgan \\ Thesis submitted \\ to the College of Engineering and Mineral Resource \\ at West Virginia University \\ in partial fulfillment of the requirements for the degree of \\ Master of Science in \\ Mechanical Engineering \\ Dr. Gregory Thompson, Chair \\ Dr. Andrew Nix \\ Dr. Hailin Li \\ Department of Mechanical Engineering
}

Morgantown, West Virginia

2014

Keywords: Diesel Engines, Biofuels, Combustion, Emissions

Copyright 2014 Cory Morgan 


\begin{abstract}
All rights reserved
INFORMATION TO ALL USERS

The quality of this reproduction is dependent upon the quality of the copy submitted.

In the unlikely event that the author did not send a complete manuscript and there are missing pages, these will be noted. Also, if material had to be removed, a note will indicate the deletion.
\end{abstract}

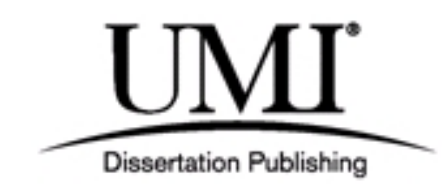

UMI 1555320

Published by ProQuest LLC (2014). Copyright in the Dissertation held by the Author.

Microform Edition (c) ProQuest LLC.

All rights reserved. This work is protected against unauthorized copying under Title 17, United States Code

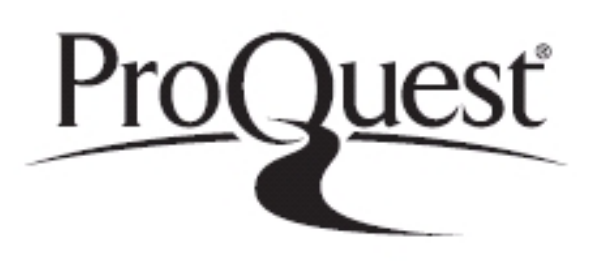

ProQuest LLC.

789 East Eisenhower Parkway

P.O. Box 1346

Ann Arbor, MI 48106 - 1346 


\title{
Abstract \\ Evaluation of Hydrotreated Biofuels for Use in Naval Diesel Engines
}

\author{
Cory J. Morgan
}

In recent years the U.S. Navy has developed several energy goals to displace foreign petroleumderived fuels. One of these goals involves replacing existing fuels with alternative hydrotreated biofuels. Hydrotreated biofuels are a second generation renewable diesel fuel and generally have similar fuel properties and characteristics as petroleum-derived fuels. The U.S Navy is currently investigating several alternative biofuels including HRJ5, HRD76, DSH76, and HDCD76. To ensure these fuels perform similarly to or better than petroleum fuels, the U.S. developed a fuel specification program. Part of this program involves preliminary evaluations of the alternative biofuels in a laboratory environment to identify negative combustion characteristics and allow a down-select of fuels before they are evaluated in the field such as on-board Navy vessels. The overall objective of this study is to identify any negative combustion characteristics of refinery-based hydrotreated renewable diesel fuels targeted for Navy use. To fulfill this objective, the biofuels were compared in neat and blended ratios against existing U.S. Navy Fuels JP-5 and F-76. Additionally, the engine performance and fuel consumption of the biofuels were evaluated as well as the regulated gaseous and particulate matter exhaust emissions to provide additional assessment information.

To evaluate the performance of these refinery-based hydrotreated biofuels each was tested in the following ratios: Neat HRJ5, 50/50 JP5/HRJ5, Neat HRD76, 50/50 F76/HRD76, Neat DSH76, 50/50 F76/DSH76, 80/20 F76/DSH76, and 80/20 F76/HDCD76. The fuels were investigated on a 1992 DDC Series 60 engine equipped with a sensor for in-cylinder pressure measurement and combustion process analysis. The engine was test on a 15 mode steady state and a transient idle to full power step test (for JP-5 fuels only). The biofuels, depending on the blend ratios and base fuel, showed reductions in heat release rate and maximum in-cylinder pressure and temperature. The biofuels also demonstrated retarded injection timing, shorter ignition delay, shorter premix combustion, and longer diffusion combustion. The only biofuel that did not follow these trends was 80/20 F76/HDCD76. These result suggested significant effect of fuel properties, such as cetane number, aromatic content, density, and heating value, on combustion parameters.

The biofuels also showed favorable emission results. Brake specific emissions of $\mathrm{NOx}, \mathrm{HC}, \mathrm{CO}, \mathrm{CO}_{2}$, and PM were measured to determine the effect of different fuels, and hence fuel properties, on exhaust emissions. Significant reductions in $\mathrm{NOx}, \mathrm{CO}_{2}$, and $\mathrm{PM}$ were achieved, while only slight reductions in $\mathrm{HC}$ and $\mathrm{CO}$ were achieved with operation of the biofuels. Reductions in emissions were attributed to the lower fuel density, lower aromatic content, and higher cetane number of the biofuels. The 80/20 F76/HDCD76 blend higher emissions values due to its higher fuel density, aromatic content, and lower cetane number compared to the F76. 


\section{Acknowledgments}

First and foremost, I would like to offer my deepest thanks to everyone involved in my undergraduate and graduate studies and my research project and thesis.

This thesis would not have been possible without Dr. Gregory Thompson. Dr. Thompson assisted me in pursuing my Masters degree in many ways ranging from offering me employment and a research position, to final revisions to my thesis and everything in between. The help and guidance I received from Dr. Thompson has been invaluable and has helped me to become the engineer I am today. I would also like to thank my committee members, Dr. Andrew Nix and Dr. Hailin Li, for the insight and expertise they provided that helped me complete my Masters.

A special acknowledgement goes to Bradley Ralston for educating me about the WVU CAFEE and engine and emissions testing. Without the time and energy Bradley spent in the test cell during our test program I would not have been able to acquire the data to complete this thesis. I would like to show gratitude a specific group of friends and colleagues that had a large role in my success throughout my studies; Ryan Shields, Kevin Shields, Jr Lucas, Michael Wise, and my brother Derrick.

Finally, I thank my friends and family for their continued support and guidance through all of my studies and for encouraging me to pursue my Masters degree. I am indebted greatly to my parents and offer a special thank you for the amount of support and encouragement they have provided in my schooling and throughout my life. They have offered financial, emotional, and physical support for many things that helped me earn my degrees and I can never begin to repay them for that. 


\section{Table of Contents}

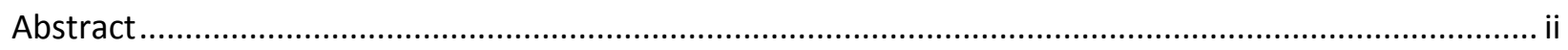

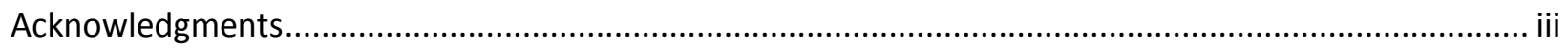

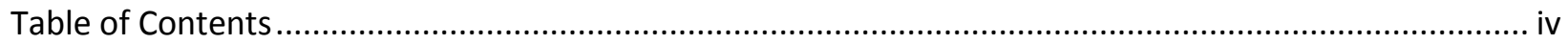

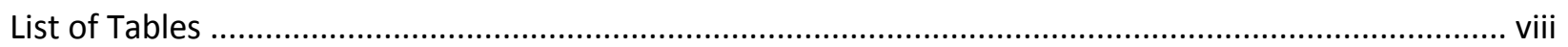

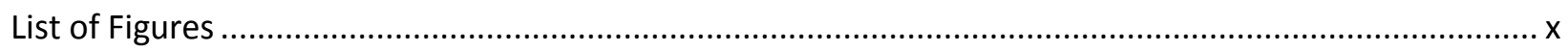

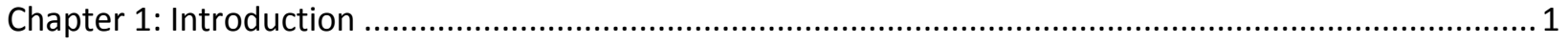

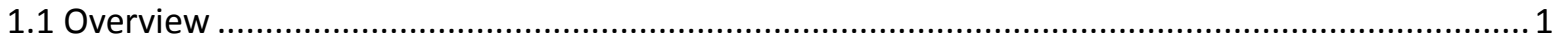

1.2 Transesterification Based Refining Methods ............................................................................... 2

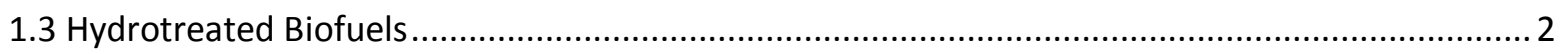

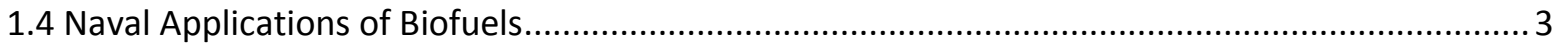

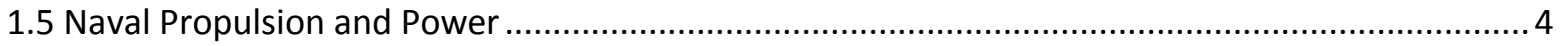

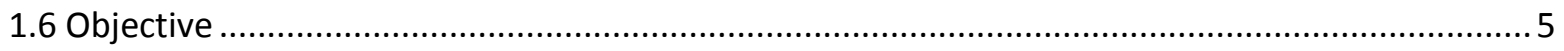

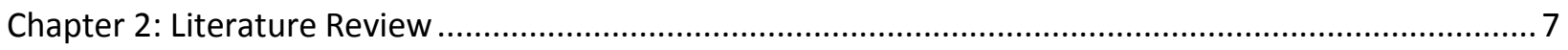

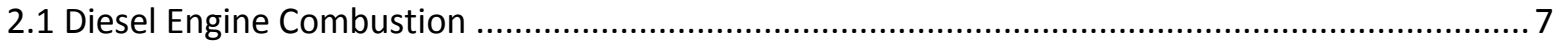

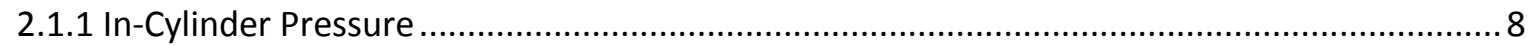

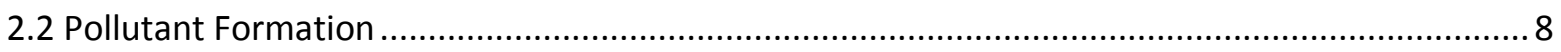

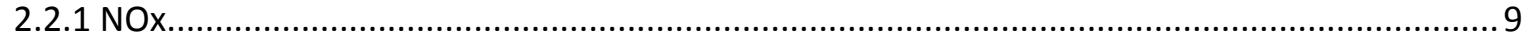

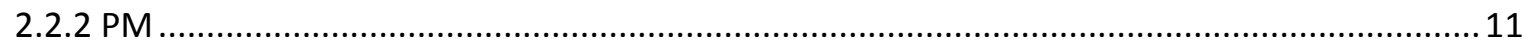

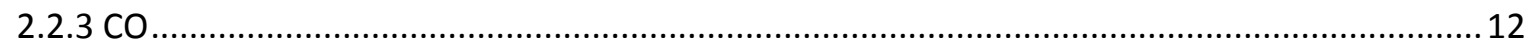

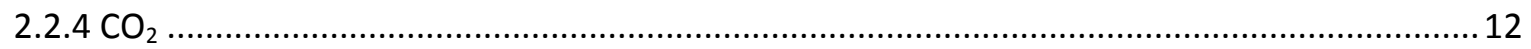

2.2.5 HC

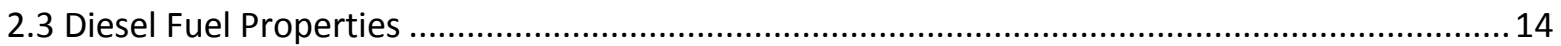

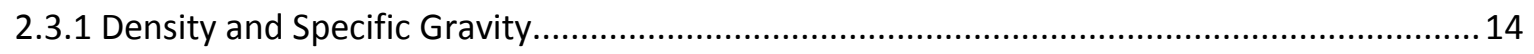

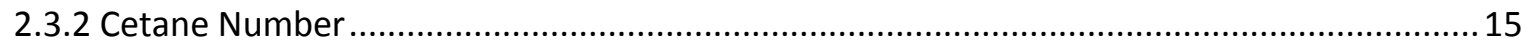

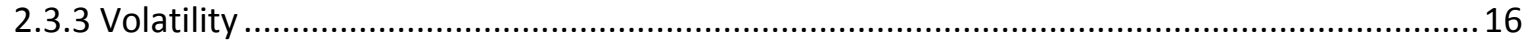

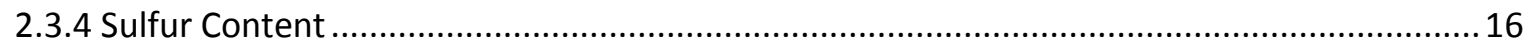

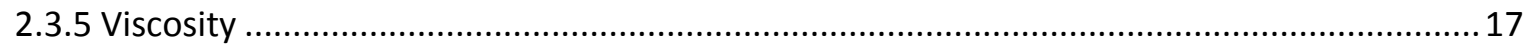

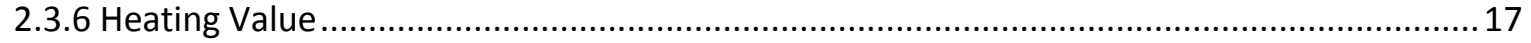

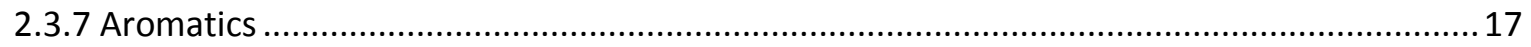

2.4 Application of Hydrotreated Fuels to $\mathrm{Cl}$ Engines ...................................................................... 18 


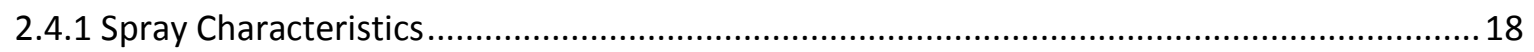

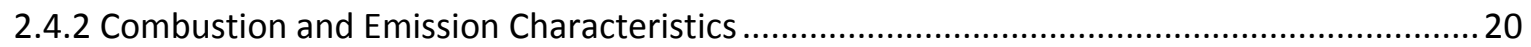

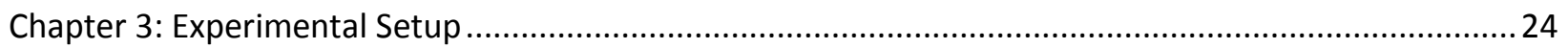

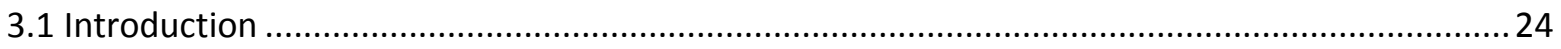

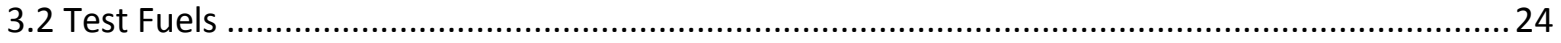

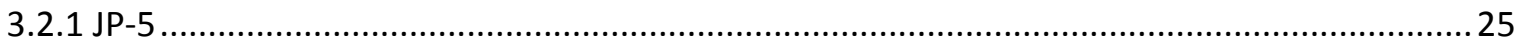

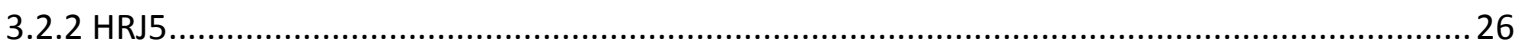

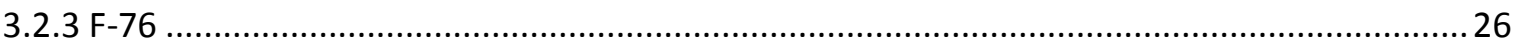

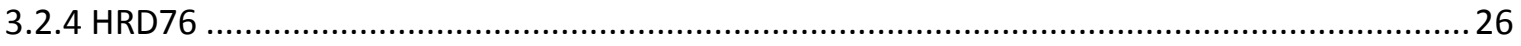

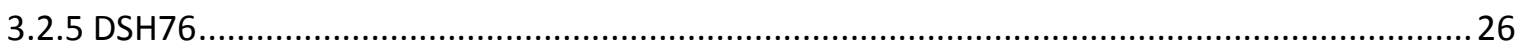

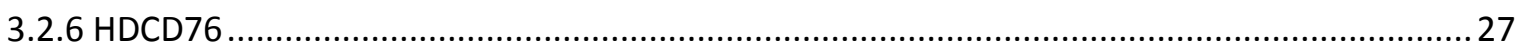

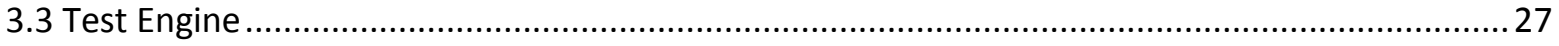

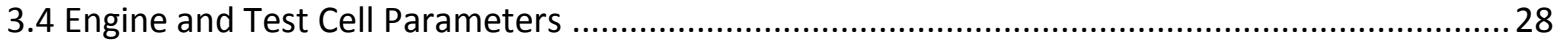

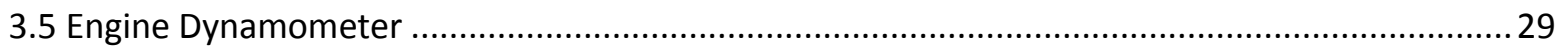

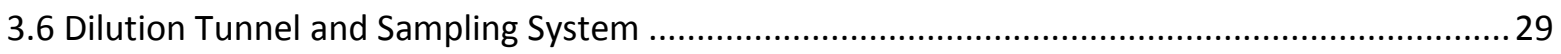

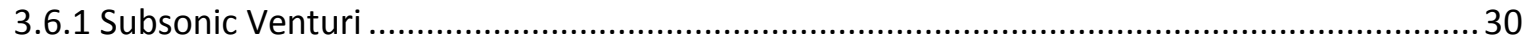

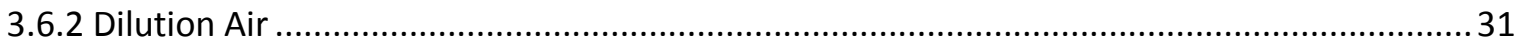

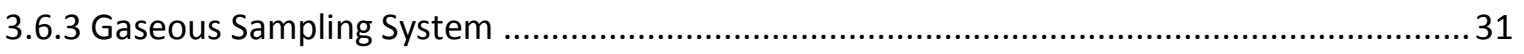

3.6.4 Particulate Matter Sampling System …….......................................................................... 31

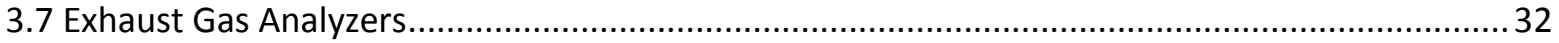

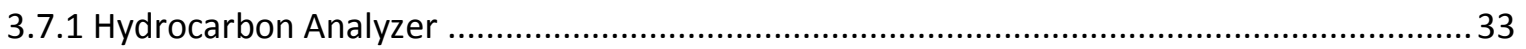

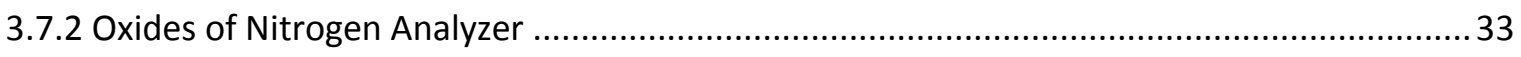

3.7.3 Carbon Monoxide and Carbon Dioxide Analyzers …............................................................. 34

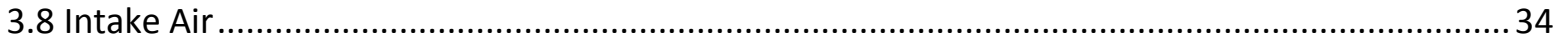

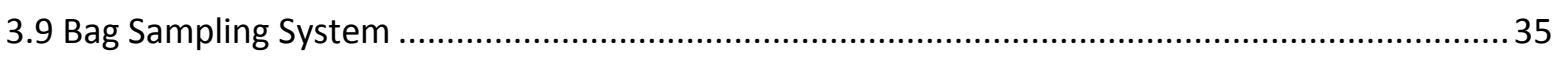

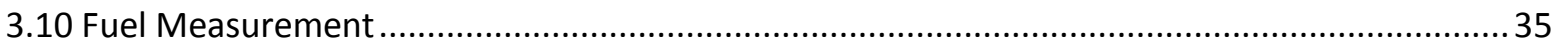

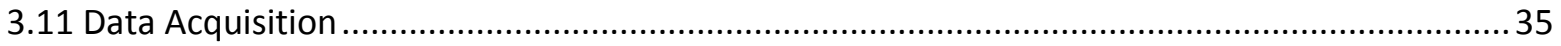

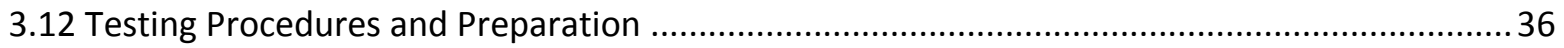

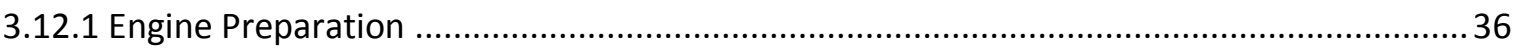

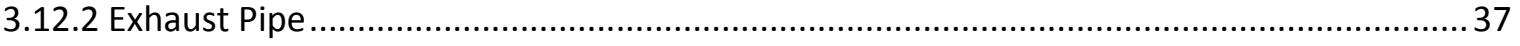

3.12.3 Dynamometer Load Cell Calibration .............................................................................. 37

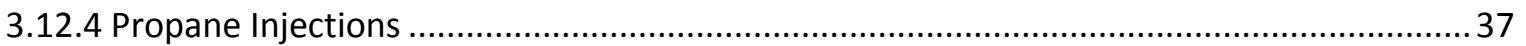




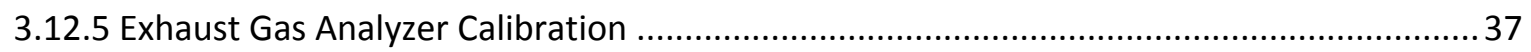

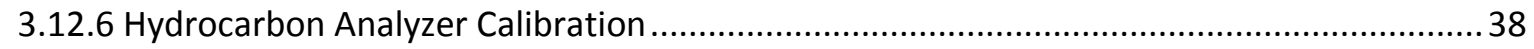

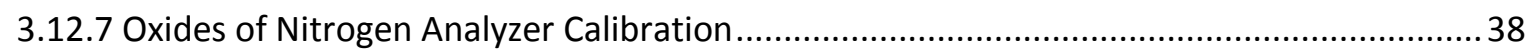

3.12.8 Carbon Monoxide and Carbon Dioxide Analyzer Calibration ............................................ 38

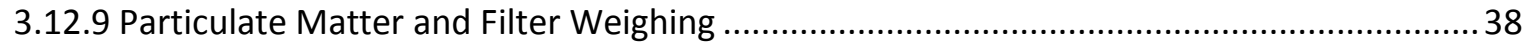

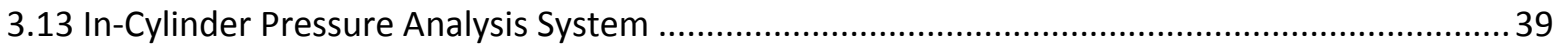

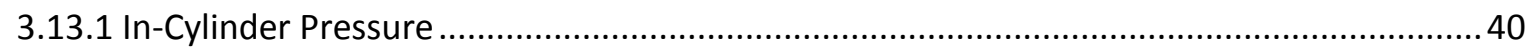

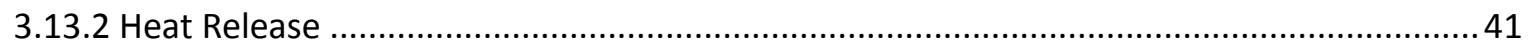

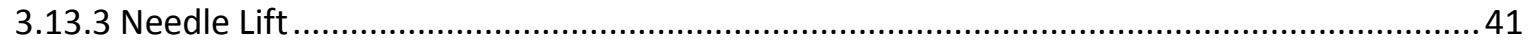

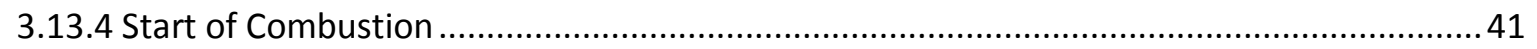

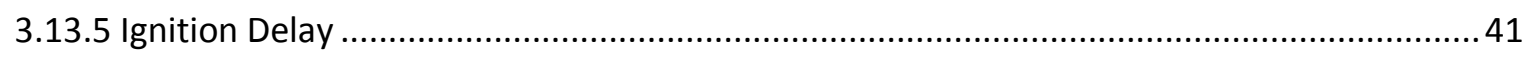

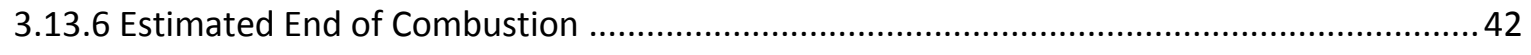

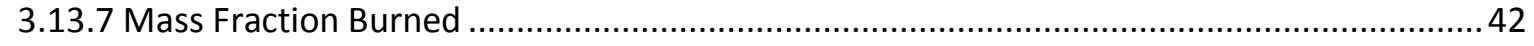

3.13.8 Indicated and Brake Mean Effective Pressure ................................................................. 42

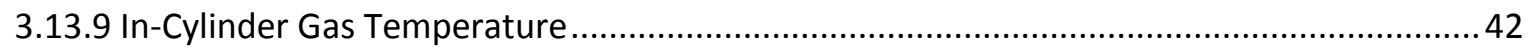

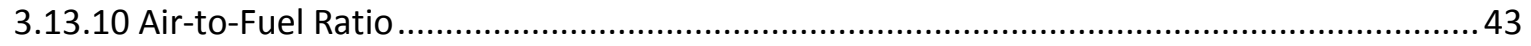

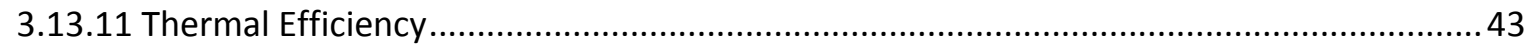

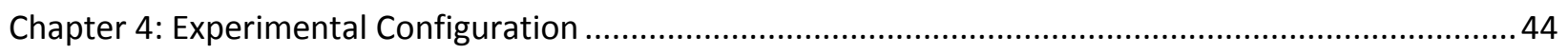

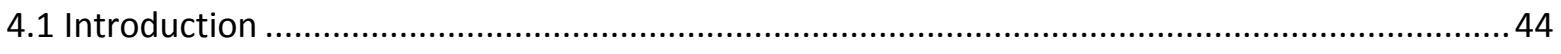

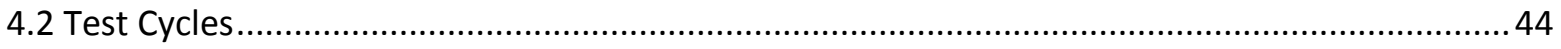

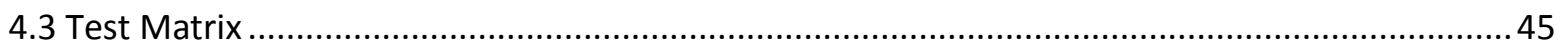

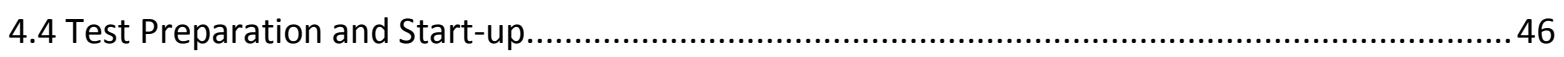

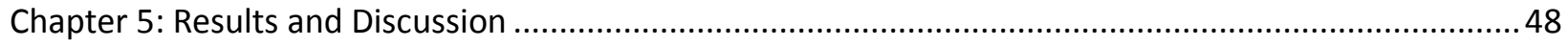

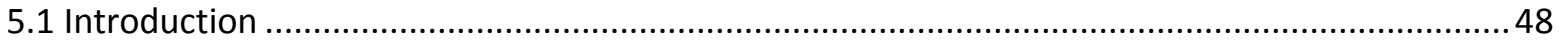

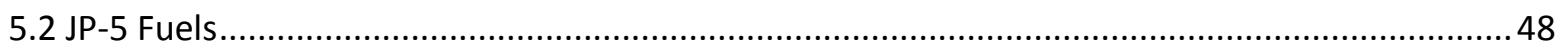

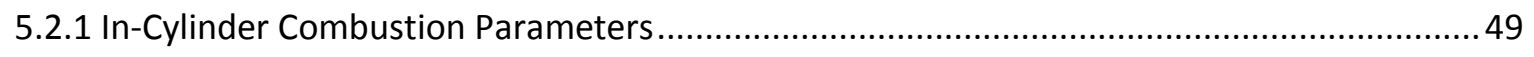

5.2.1.1 Heat Release and Heat Release Rate .......................................................................... 50

5.2.1.2 In-Cylinder Pressure and Pressure Rise Rate ................................................................. 53

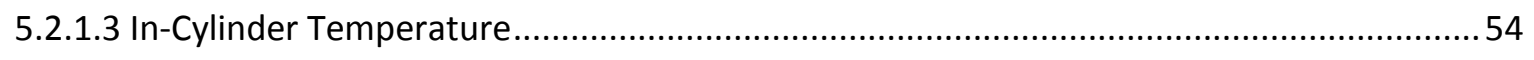

5.2.1.4 Start of Fuel Injection and Ignition Delay ................................................................... 56

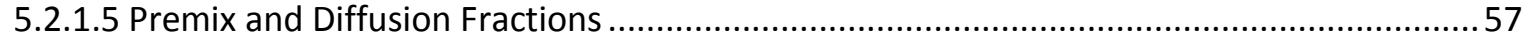

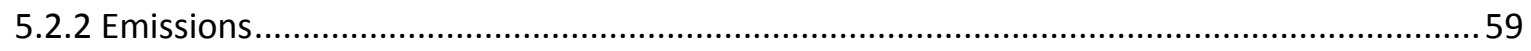


5.2.2.1 HC

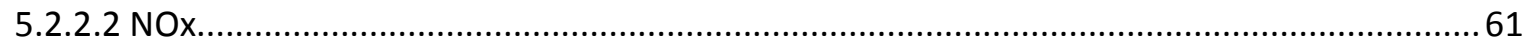

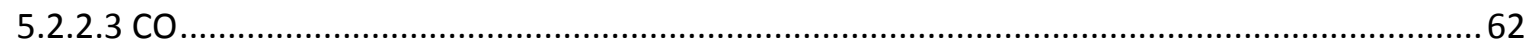

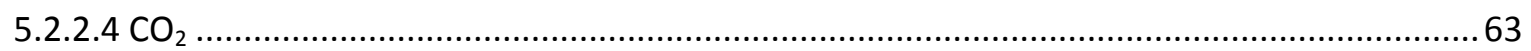

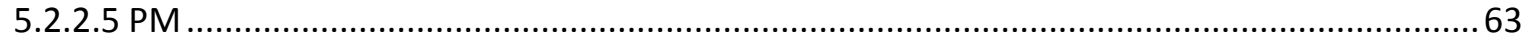

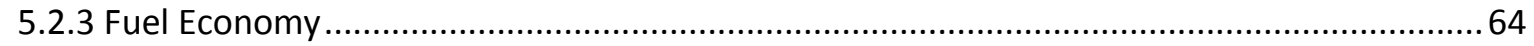

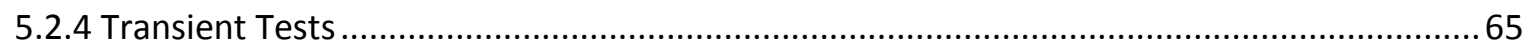

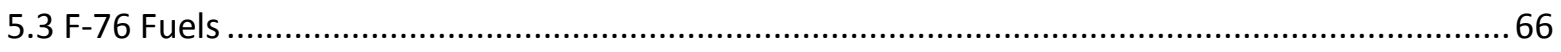

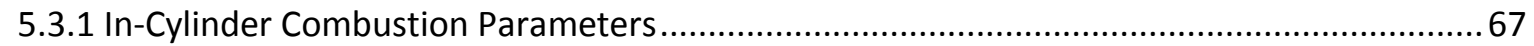

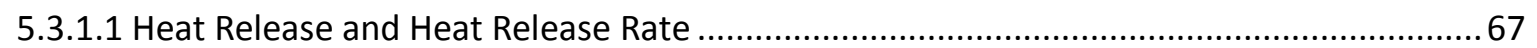

5.3.1.2 In-Cylinder Pressure and Pressure Rise Rate ............................................................... 70

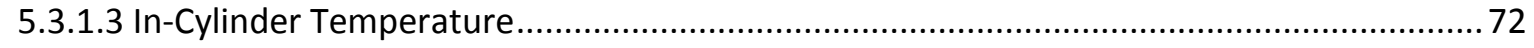

5.3.1.4 Start of Fuel Injection and Ignition Delay ...................................................................... 74

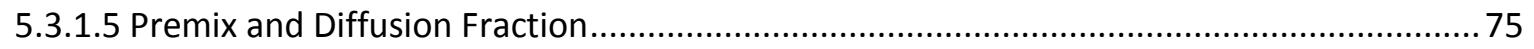

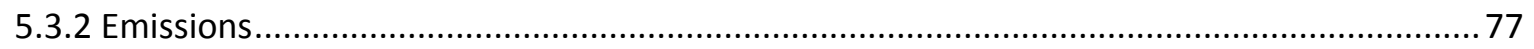

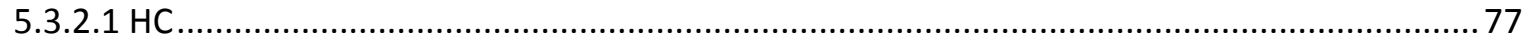

5.3.2.2 NOx

5.3.2.3 CO

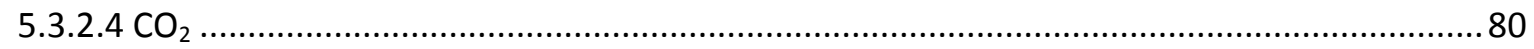

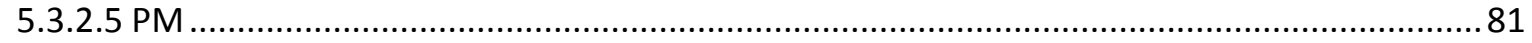

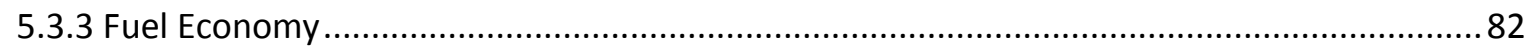

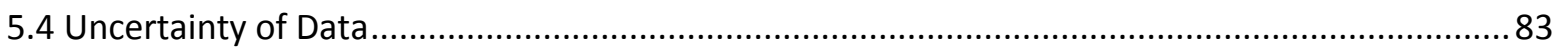

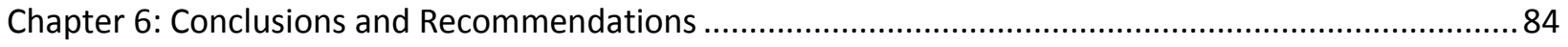

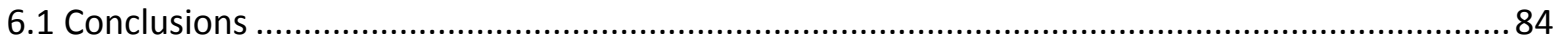

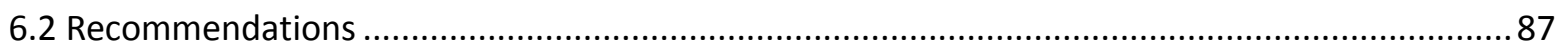

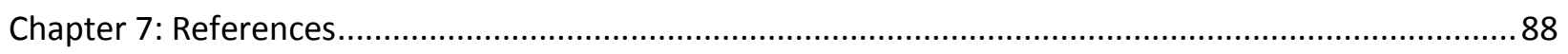

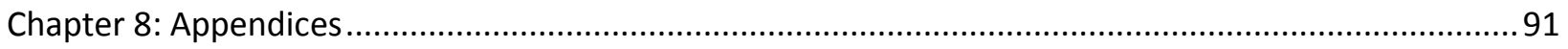

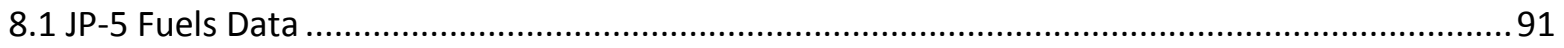

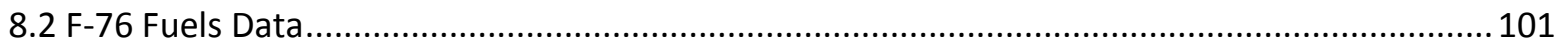




\section{List of Tables}

Table 2-1: Typical fuel properties of HVO, EN 590, GTL, and FAME [6] ............................................ 18

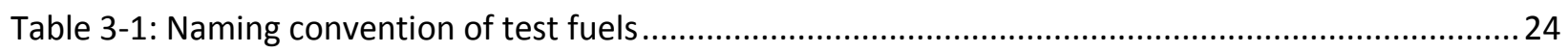

Table 3-2: Fuel property comparison of JP-5-based fuels per MIL-DTL-5624V .......................................25

Table 3-3: Fuel property comparison of F-76-based fuels per MIL-DTL-16884M.......................................25

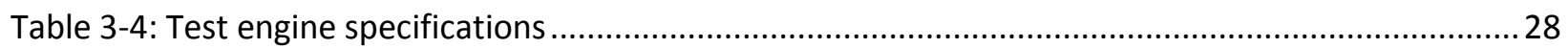

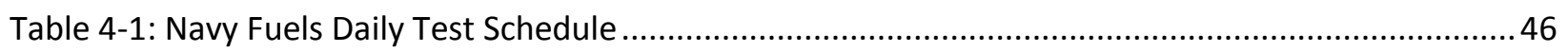

Table 5-1: Relationship between BMEP and modal set points for JP-5 steady state test cycle ................48

Table 5-2: Relationship between BMEP and modal set points for F-76 test cycle ..................................67

Table 8-1: Effects of fuel density, cetane number, and aromatic content on maximum heat release rate

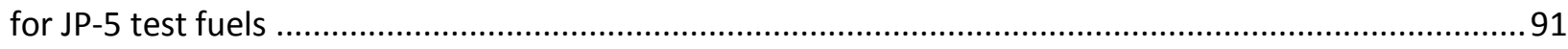

Table 8-2: Effects of fuel density, cetane number, and aromatic content on net heat released for JP-5 test fuels

Table 8-3: Effects of fuel density, cetane number, and aromatic content on maximum in-cylinder pressure for JP-5 test fuels.

Table 8-4: Effects of fuel density, cetane number, and aromatic content on maximum pressure rise rate for JP-5 test fuels

Table 8-5: Effects of fuel density, cetane number, and aromatic content on maximum in-cylinder temperature for JP-5 test fuels.

Table 8-6: Effects of fuel density, cetane number, aromatic content, and viscosity on start of fuel injection for JP-5 test fuels

Table 8-7: Effects of fuel density, cetane number, and aromatic content on start of combustion for JP-5 test fuels.

Table 8-8: Effects of fuel density, cetane number, and aromatic content on premix fraction length for JP-

5 test fuels.

Table 8-9: Effects of fuel density, cetane number, and aromatic content on diffusion fraction length for JP-5 test fuels .95 Table 8-10: Effects of fuel density, cetane number, and aromatic content on bsHC emissions for JP-5 test fuels .96

Table 8-11: Effects of fuel density, cetane number, and aromatic content on bsNOx emissions for JP-5 test fuels.

Table 8-12: Effects of fuel density, cetane number, and aromatic content on bsCO emissions for JP-5 test fuels

Table 8-13: Effects of fuel density, cetane number, and aromatic content on $\mathrm{bsCO}_{2}$ emissions for JP-5 test fuels

Table 8-14: Effects of fuel density, cetane number, and aromatic content on bsPM emissions for JP-5 test fuels......

Table 8-15: Effects of fuel density, cetane number, and aromatic content on bsFC for JP-5 test fuels..... 98

Table 8-16: Transient Combustion Data for JP-5 Test Fuels ................................................................99

Table 8-17: Transient Emissions Data for JP-5 Test Fuels 100 
Table 8-18: Effects of fuel density, cetane number, and aromatic content on maximum heat release rate for F-76 test fuels

Table 8-19: Effects of fuel density, cetane number, and aromatic content on net heat released for F-76 test fuels 101

Table 8-20: Effects of fuel density, cetane number, and aromatic content on maximum in-cylinder pressure for F-76 test fuels 101

Table 8-21: Effects of fuel density, cetane number, and aromatic content on maximum pressure rise rate for F-76 test fuels 102

Table 8-22: Effects of fuel density, cetane number, and aromatic content on maximum in-cylinder temperature for F-76 test fuels 102

Table 8-23: Effects of fuel density, cetane number, aromatic content, and viscosity on start of fuel injection for F-76 test fuels 102

Table 8-24: Effects of fuel density, cetane number, and aromatic content on start of combustion for F-76 test fuels 103

Table 8-25: Effects of fuel density, cetane number, and aromatic content on premix fraction length for F76 test fuels. 103

Table 8-26: Effects of fuel density, cetane number, and aromatic content on diffusion fraction length for F-76 test fuels. 103

Table 8-27: Effects of fuel density, cetane number, and aromatic content on bsHC emissions for F-76 test fuels.

Table 8-28: Effects of fuel density, cetane number, and aromatic content on bsNOx emissions for F-76 test fuels 104

Table 8-29: Effects of fuel density, cetane number, and aromatic content on bsCO emissions for F-76 test fuels

Table 8-30: Effects of fuel density, cetane number, and aromatic content on $\mathrm{bsCO}_{2}$ emissions for F-76 test fuels 105

Table 8-31: Effects of fuel density, cetane number, and aromatic content on bsPM emissions for F-76 test fuels 105

Table 8-32: Effects of fuel density, cetane number, and aromatic content on bsFC for F-76 test fuels .. 105 


\section{List of Figures}

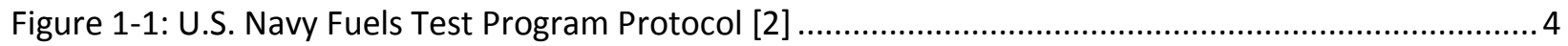

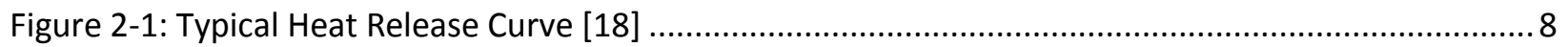

Figure 2-2: Emissions from a Typical Diesel Fuel Spray [17] .............................................................. 9

Figure 2-3: Schematic of Diesel Spray Pattern Showing Equivalence Ratio [17] .................................... 13

Figure 2-4: Effect of Cetane Number on Exhaust Emissions [20] ..................................................... 16

Figure 2-5: Schematic of Diesel Fuel Spray [17] ............................................................................... 19

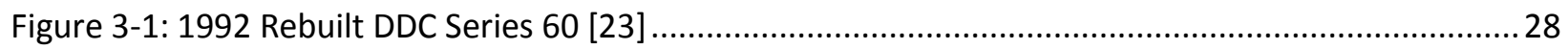

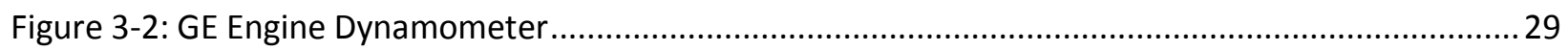

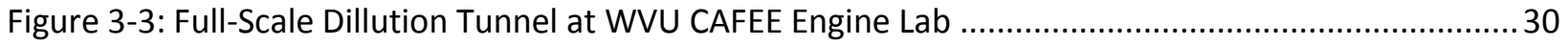

Figure 3-4: PM Sampling Box at WVU CAFEE Engine Lab ................................................................... 32

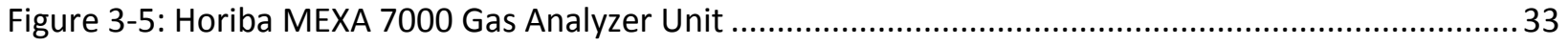

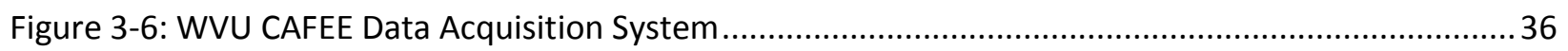

Figure 3-7: Kistler 6125B In-Cylinder Pressure Transducer [18] ........................................................... 40

Figure 4-1: Steady State Test Cycle (JP-5 Fuels) with Mode Order ....................................................... 45

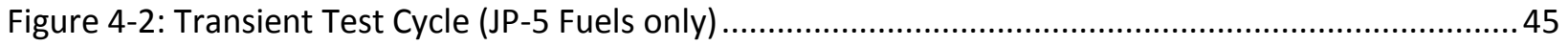

Figure 5-1: Engine Map and Set Points for JP-5 Test Fuels ..................................................................... 49

Figure 5-2: Heat Release Rate Curve at Mode 5 (25\% Engine Load and 1430 rpm) for JP-5 Test Fuels..... 50

Figure 5-3: Heat Release Rate Curve at Mode 12 (75\% Engine Load and 1649 rpm) for JP-5 Test Fuels... 51

Figure 5-4: Maximum Heat Release Rate at all Test Modes for JP-5 Test Fuels ......................................51

Figure 5-5: Effect of Cetane Number of Maximum Heat Release Rate ...................................................5 52

Figure 5-6: Net Heat Released at each Test Mode for JP-5 Test Fuels ...................................................52

Figure 5-7: In-Cylinder Pressure Curve at Mode 5 for JP-5 (25\% Engine Load and 1430 rpm) Test Fuels . 53

Figure 5-8: In-Cylinder Pressure Curve at Mode 12 (75\% Engine Load and 1649 rpm) for JP-5 Test Fuels

Figure 5-9: Maximum Pressure Rise Rate at Each Test Mode for JP-5 Test Fuels ..................................5 54

Figure 5-10: In-Cylinder Temperature Curve at Mode 5 (25\% Engine Load and 1430 rpm) for JP-5 Test

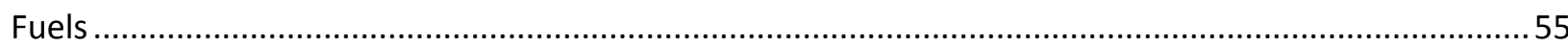

Figure 5-11: In-Cylinder Temperature Curve at Mode 12 (75\% Engine Load and 1649 rpm) for JP-5 Test

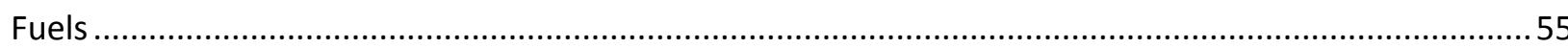

Figure 5-12: Heat Release Rate Curve at Mode 5 Indicating Start of Fuel Injection and Start of

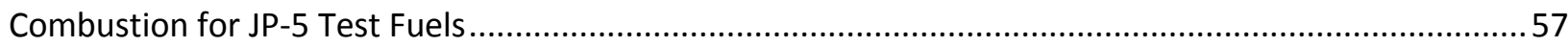

Figure 5-13: Heat Release Rate Curve at Mode 12 Indicating Start of Fuel Injection and Start of

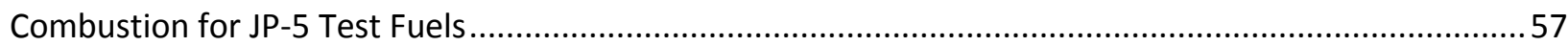

Figure 5-14: Premix Fraction Length of each Test Mode for JP-5 Test Fuels...........................................58

Figure 5-15: Diffusion Fraction Length of each Test Mode for JP-5 Test Fuels ......................................59

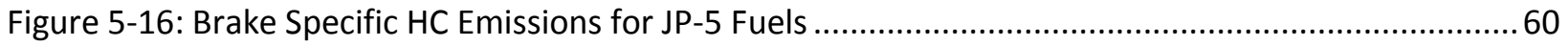

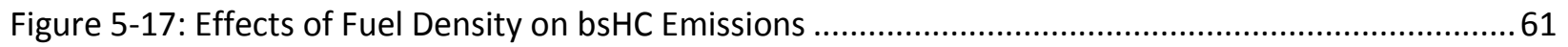

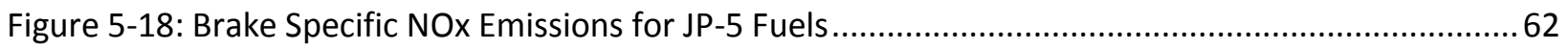

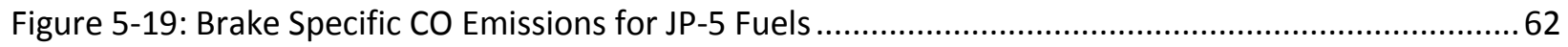

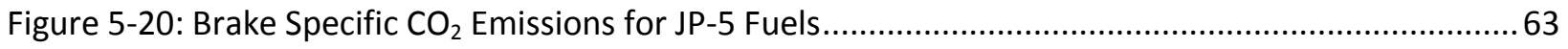


Figure 5-21: Brake Specific PM Emissions for JP-5 Fuels

Figure 5-22: Brake Specific Fuel Consumption for JP-5 Fuels

Figure 5-23: Engine Map and Set Points for F-76 Test Fuels

Figure 5-24: Heat Release Rate Curve at Mode 5 (25\% Engine Load and 1416 rpm) for F-76 Test Fuels .. 68

Figure 5-25: Heat Release Rate Curve at Mode 12 (75\% Engine Load and 1644 rpm) for F-76 Test Fuels 69

Figure 5-26: Maximum Heat Release Rate at each Test Mode for F-76 Test Fuels.

Figure 5-27: Net Heat Released for F-76 Test Fuels.

Figure 5-28: In-Cylinder Pressure Curve at Mode 5 (25\% Engine Load and 1430 rpm) for F-76 Test Fuels71

Figure 5-29: In-Cylinder Pressure Curve at Mode 12 (75\% Engine Load and 1644 rpm) for F-76 Test Fuels

Figure 5-30: Maximum Pressure Rise Rate for F-76 Test Fuels

Figure 5-31: In-Cylinder Temperature Curve at Mode 5 (25\% Engine Load and 1430 rpm) for F-76 Test

Fuels

Figure 5-32: In-Cylinder Temperature Curve at Mode 12 (75\% Engine Load and 1644 rpm) for F-76 Test

Fuels

Figure 5-33: Heat Release Rate Curve at Mode 5 Indicating Start of Fuel Injection and Start of Combustion for F-76 Test Fuels

Figure 5-34: Heat Release Rate Curve at Mode 12 Indicating Start of Fuel Injection and Start of Combustion for F-76 Test Fuels .75

Figure 5-35: Length of Premix Fraction for F-76 Test Fuels .................................................................. 76

Figure 5-36: Length of Diffusion Fraction for F-76 Test Fuels............................................................ 77

Figure 5-37: Brake Specific HC Emisions for F-76 Test Fuels ............................................................. 78

Figure 5-38: Brake Specific NOx Emissions for F-76 Test Fuels............................................................... 79

Figure 5-39: Brake Specific Emissions of CO for F-76 Test Fuels.......................................................... 80

Figure 5-40: Brake Specific Emissions of $\mathrm{CO}_{2}$ for F-76 Test Fuels ..................................................... 81

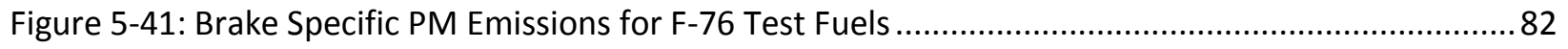

Figure 5-42: Brake Specific Fuel Consumption for F-76 Test Fuels ..................................................... 83 


\section{Chapter 1: Introduction}

\subsection{Overview}

In an effort to reduce dependency on foreign oil, the U.S. Navy is exploring the use of fuels produced via non-conventional methods, or alternative fuels. In 2009, Secretary of the Navy (SECNAV) Ray Mabus announced five energy goals to reduce the Department of the Navy's energy consumption, decrease its reliance on foreign oil sources, and increase its use of alternative energy [1]. One of the goals is to deploy a "Great Green Fleet," a carrier strike group fueled by alternative sources of energy. Prior to its 2016 deployment, the "Great Green Fleet," operating on 50 percent biofuels, participated in the Rim of the Pacific (RIMPAC) maritime exercise in July 2012 [1,2,3]. Following a successful demonstration during the RIMPAC exercise, outlining the goals of the program, Mabus stated, "It shows that we can make big strides toward energy security; it shows that we can make big strides toward energy independence; it shows that we can reduce our vulnerability that we currently have because of our dependence on foreign sources of oil [3]."

One such fuel that has been examined as an alternative fuel for the U.S. Navy, and commercial, fleet is biodiesel. Biodiesel is an alternative fuel derived from plant oils, animal fats, or recycled cooking oils. Biodiesel is renewable, energy efficient, non-toxic, biodegradable, and it can reduce harmful emissions as well as displace petroleum-derived diesel fuel [4]. In modern diesel engines, blends of up to $20 \%$ biodiesel can be used with little or no modifications to the engine or fuel system. Higher blends and neat biodiesel can also be utilized in diesel engines but may require additional modifications over the stock diesel configuration.

However, the physical properties of neat biodiesel, B100, that characterize engine-related performance can be significantly different from that of petroleum diesel. For this reason, biodiesel is typically blended with conventional diesel to minimize these differences while maintaining some of the benefits of B100. Blends up to $20 \%$ biodiesel and $80 \%$ petroleum diesel, or B20, are found in the United States, and other countries, commercial markets; however, blends as low as $2 \%$ biodiesel, B2, are also utilized. All biodiesel and blends of biodiesel must meet the ASTM D6751 specification in the United States [5].

Biodiesel can be produced through a process called transesterification in which the raw oils or fats are reacted with a short-chain alcohol (methanol) in the presence of a catalyst, usually sodium hydroxide or potassium hydroxide. This process produces new chemical compounds called fatty acid 
methyl esters (FAME) with glycerin as a bi-product. The transesterification process does not result in a fuel that meets the ASTM D6751 standard and further downstream refining is typically necessary before the fuel will meet the ASTM D6751 standard. More recently, hydrotreating of vegetable oils and animal fats has emerged as an alternative process to esterification for producing biobased diesel fuels $[6,7,8]$. Fuels produced through hydrotreating are typically referred to as "renewable diesel fuels" opposed to "biodiesel" which generally refers to FAME.

\subsection{Transesterification Based Refining Methods}

Refining of the biodiesel downstream of the transesterification process is carried out through various methods. The first step usually involves the separation of the biodiesel and glycerin through techniques such as gravitational settling or centrifugation. After separation, the biodiesel is washed with hot de-ionized water to remove soap, excess alcohol, and residual catalyst. Water washing provides a means for acid addition to neutralize any remaining catalyst. Once settled, the mixture is heated to remove residual water. The removal of methanol, via a vacuum flash process, is also desirable downstream of transesterification. Methanol removal can be performed pre- or post-washing. In addition to water washing, washing with acids or solid absorbents and ether can be used for purification. Acid washing neutralizes the catalyst and decomposes the soap formed. Solid absorbents and ether are used to absorb hydrophilic materials such as glycerol. However, these processes are still followed by water washing. Reports show that washing with distilled water at $50^{\circ} \mathrm{C}$ is considered to be the best method to separate and purify biodiesel $[9,10]$. The main disadvantage of the washing process is the production of waste water containing small amounts of methanol, soap, and free glycerol [11].

New developments in membrane based separation technology presents several advantages for refining of biodiesel over conventional methods. Some of the most effective methods for biodiesel separation and purification include membrane reactors and seperative ceramic membranes. In these separation processes, after the removal of methanol, the biodiesel is directly filtered by a microporous ceramic membrane to remove the residual glycerol, catalyst, and soap to obtain the final product [11]. The advantages of membrane separation methods are the simplification of the biodiesel refining process and no production of waste water from washing.

\subsection{Hydrotreated Biofuels}

Hydrotreated biofuels are a second generation renewable diesel fuel made by a refinery-based process converting bio-based feedstocks to paraffinic hydrocarbon [6]. Since these fuels are liquid hydrocarbons, they will generally meet ASTM D975 [12] requirements for conventional petroleumderived diesel. The "biodiesel" specifications, ASTM D6751, do not apply for "renewable diesel fuel" or 
"hydrotreated renewable diesel" (HRD). HRD can be produced from various kinds of vegetable oil as well as non-food oils such as jathropa and algae oil. In the production process, oxygen is removed from the triglyceride via hydrogenation. Further processing is necessary in order to get a pure hydrocarbon (primarily $\mathrm{C}_{11}-\mathrm{C}_{21}$ normal and isoparaffins) suitable for use as jet fuel or naval distillate. HRD is practically free of sulfur, oxygen, nitrogen, or aromatics. It also has a high cetane number and a heating value similar to petroleum diesel [6,7]. Overall, hydrotreated fuels generally have more similar fuel properties and characteristics of petroleum-derived diesel fuels than that of first generation FAME fuels. Hydrotreated fuels have received considerable attention for ground, marine, and aviation applications, especially from the U.S. Navy.

\subsection{Naval Applications of Biofuels}

In recent years the U.S. Navy has taken steps to increase its use of alternative hydrocarbon fuels. Beginning in 2001, the use of B20 was implemented to operate non-tactical vehicles and other equipment at military bases and installations. In late 2003, the U.S. Navy began producing its own biodiesel in a demonstration project at the Naval Facilities Engineering Services Center. By June 1, 2005, all Navy and Marine Corps non-tactical diesel vehicles were required to operate on B20 fuel [13]. However, biodiesel (FAME) is currently banned from use in all deployable, tactical DOD military assets [14]. As a result, Fischer-Tropsch liquids and hydrotreated renewable oils are being investigated for use in deployable, tactical DOD assets. In October 2009, SECNAV committed the Navy and Marine Corps to creating a "Green Strike Group" by 2012 and deploying it by 2016. The "Green Strike Group," also known as the "Great Green Fleet," consisting of five warships and 71 aircraft set sail in July 2012 for the RIMPAC exercises $[3,15]$. The ships were powered using a 50-50 blend of hyrdoprocessed renewable diesel (HRD76) and marine diesel (F-76). Similarly, the aircrafts burned a 50-50 blend of hydroprocessed renewable jet fuel (HRJ5) and aviation fuel (JP-5) [15]. Hydroprocessed fuels for the U.S. Navy are designated to be "feedstock neutral," meaning the fuel can be produced from a variety of feedstocks. The U.S. Navy requires that these fuels must be derived from either plant or algae oils and produced in the U.S.A. By 2020, the U.S. Navy's goal is to generate 50\% of its power from alternative sources [2].

The U.S. Navy is currently investigating several biofuels as drop-in replacements for current marine diesel (F-76) and aviation (JP-5) fuels. Candidate alternative fuels include HRJ5, HRD76, DSH76, and HDCD76. These fuels must follow existing military specifications for JP-5 (MIL-DTL5624V) and F-76 (MIL-DTL-16884M), respectively, until new specifications are developed. To ensure these fuels perform similarly to or better than petroleum fuels, the U.S. Navy developed a fuel specification plan [2]. Figure 1-1 shows the fuel qualification process developed by the U.S. Navy. Included in the program are fit for purpose (FFP) property tests. The FFP tests comprise parameters 
important to the U.S. Navy that are not included in specifications because they always fall within the acceptable range with regard to petroleum. Testing includes component, full-scale, platform, and field testing to ensure compatibility with current U.S. Navy fuels and fuel logistics, material compatibility, fire safety, and long-term storage requirements. The goal is to ensure that any new drop-in replacement fuel will not require any modifications to existing infrastructure or propulsion hardware [2].

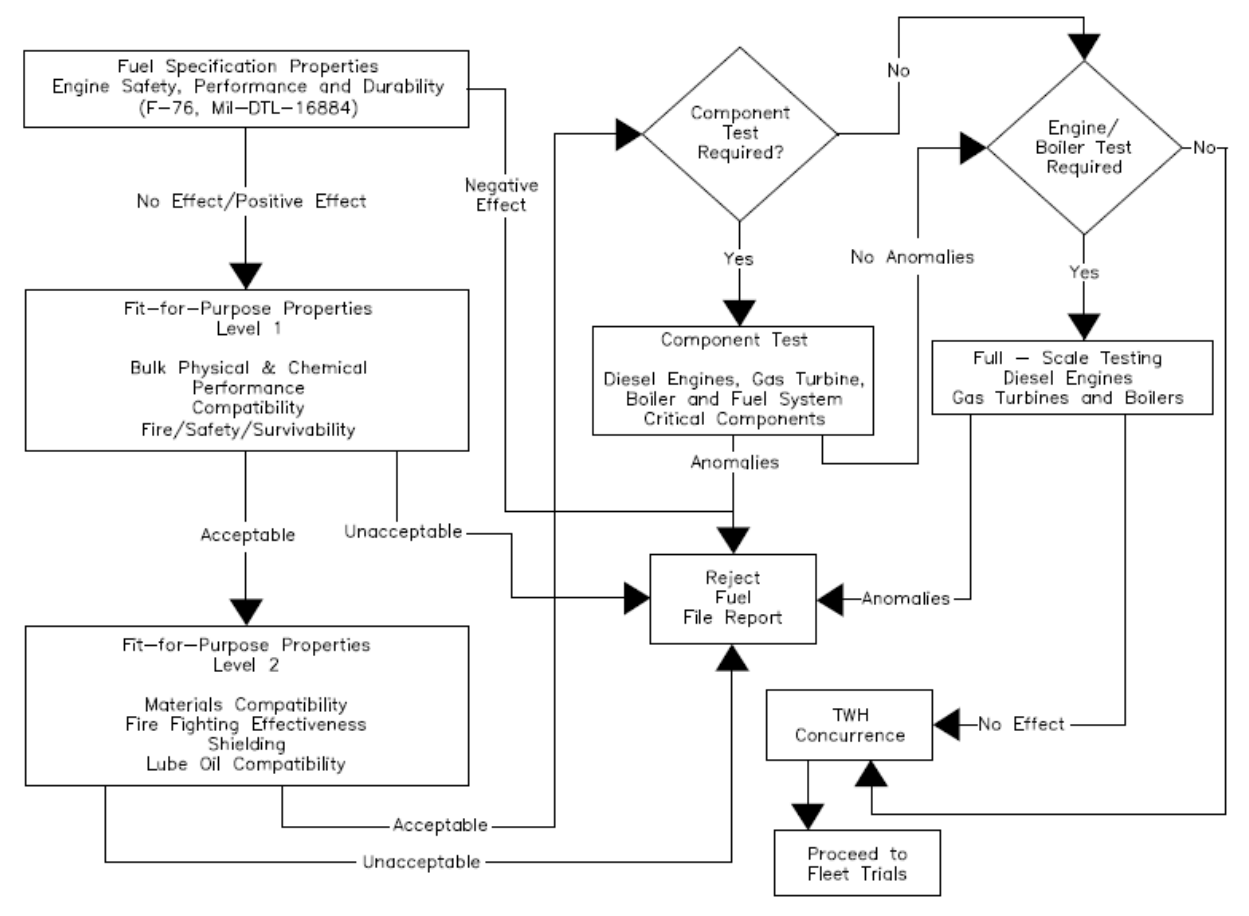

Figure 1-1: U.S. Navy Fuels Test Program Protocol [2]

\subsection{Naval Propulsion and Power}

Diesel engines have become an integral part of the U.S. Navy's propulsion and auxiliary power systems. Propulsion systems employ many different arrangements of engines, shafts, reducing gears, and propellers to suit the requirements of the given vessel, vehicle, or aircraft. For example, while it is possible to use a single large engine ( $\sim 50,000 \mathrm{bhp})$ for vessel propulsion, combinations of smaller engines are typically utilized to increase economy and operational flexibility [16]. Although the exact arrangement of the propulsion system can vary from ship to ship, most vessels have a twin shaft system with a single or multiple main propulsion diesel engines (MPDEs) on each shaft depending on the size and propulsion requirements of the vessels. Rated power for MPDEs can range from $\sim 600 \mathrm{bhp}$ for smaller vessels to $\sim 17,000 \mathrm{bhp}$ for larger vessels [16]. Auxiliary power is provided from the ship's service diesel generators (SSDGs). Vessels usually employ two to four SSDGs, which consist of a diesel engine coupled with a generator. Depending on the size, capabilities, and operations of the ship the rated 
power per generator can range from $\sim 150 \mathrm{~kW}$ to $\sim 2000 \mathrm{~kW}[16]$. The engines used for propulsion and auxiliary power can be, and often are, the same or a similar engine.

Diesel engines, in general, are designed to operate on various fuels within a certain range of properties. However, engines for naval applications operate on NATO F-76, which has more strict specifications than commercially available fuels. The strict specifications are mainly due to stability and storage requirements for on-board use and storage of U.S. Navy fuels. These requirements also apply to JP-5 due to its use in aircrafts aboard Navy vessels. While the proposed fuels have similar properties to and may even meet current specifications for F-76 and JP-5, subtle differences in fuel properties may cause unknown operational differences.

Due to the size of the engines used in U.S. Navy vessels, on-board testing becomes expensive because of the amount of fuel needed. Also, the proposed fuels are currently not mass produced and, therefore, are more expensive than currently used U.S. Navy fuels. For this reason, among others, smallscale testing is advantageous. Small-scale testing enables pre-screening of the fuels to determine which fuels should be investigated further. Other advantages of small-scale testing include: less fuel consumed, more controlled testing, in-cylinder combustion analysis, accurately quantify emissions, catastrophic failure is less expensive, and U.S. Navy assets and vessels are not occupied. Among the advantages of small-scale testing, in-cylinder combustion analysis is particularly important. In-cylinder combustion analysis makes it possible to determine combustion parameters that may indicate adverse operating characteristics of a fuel that could lead to engine damage or malfunction. Should these parameters exceed the operational limits of the engine, piston and cylinder damage is likely and could lead to premature engine component failure.

\subsection{Objective}

The global objective of this study is to explore the use of hydrotreated fuels in the U.S. Navy fleet. Because of the large displacement, and hence large power, engines in the U.S. Navy Fleet targeted for alternative fuel use, exploratory testing of bio-derived fuels becomes very expensive. Preliminary evaluation of candidate alternative fuels in a smaller displacement engine, and hence lower fuel consumption, may identify negative combustion characteristics and allow a down-select of fuels that are evaluated on-board U.S. Navy vessels. The overall objective of this study is to identify any negative combustion characteristics of refinery-based hydrotreated renewable diesel fuels targeted for U.S Navy use. To fulfill this objective, the refinery-based biofuels will be compared in neat and blended ratios against existing Navy fuels JP-5 and F76. Additionally, the engine performance (torque and power) and 
fuel consumption of the refinery-based biofuels will be evaluated as well as the regulated gaseous and particulate matter (PM) exhaust emissions to provide additional assessment information. 


\section{Chapter 2: Literature Review}

The following sections will review topics related to the performance of diesel engines and hydrotreated fuels. The diesel combustion process will be explained as well as the formation of pollutants, such as, $\mathrm{NOx}, \mathrm{HC}, \mathrm{CO}, \mathrm{CO}_{2}$, and PM. Diesel fuel properties will be discussed and their effects on combustion, emissions, and engine performance explained. Previous studies of the application of hydrotreated fuels in diesel engines will be reviewed to present their general effect on engine performance.

\subsection{Diesel Engine Combustion}

The combustion process of a compression-ignition or diesel engine is summarized as follows. A fresh charge of air is introduced into the combustion chamber through the intake value. The intake valve closes and the air is compressed. Near the end of the compression stroke when the piston is near top dead center, fuel is injected into the engine cylinder, just before the desired start of combustion. The liquid fuel, usually injected at high velocity and pressure, atomizes into small droplets and penetrates into the combustion chamber. The fuel mixes with the high-temperature and high-pressure air in the cylinder, absorbs heat and vaporizes. Since the air temperature and pressure are above the fuel's ignition point, spontaneous ignition of portions of the already-mixed fuel and air occurs after a delay of a few crank angle degrees [17]. Injection continues until the desired amount of fuel has entered the cylinder. Atomization, vaporization, fuel-air mixing, and combustion continue until essentially all the fuel has passed through each process [17]. Combustion in diesel engines is generally characterized as a two-stage process, illustrated by Figure 2-1. The premixed combustion stage is the sudden burning, characterized by high heat release rates, of the premixed air-fuel mixture formed during the ignition delay period. Premixed combustion could be a high percentage of the total combustion at low load but a relatively small percentage at high load. Diffusion combustion is controlled by the rate of fuel-air mixing. It is usually a small percentage of the total combustion at low load but a high percentage of the total combustion at high load. Heat release rates are usually lower in this phase and decrease as the phase progresses [17]. During fuel injection, a delay occurs before combustion and is identified in the heat release rate curve as the negative value illustrated in Figure 2-1. Combustion phasing, heat release rate, mass fraction burned, and several other combustion properties can be determined through analysis of the measured in-cylinder pressure. 


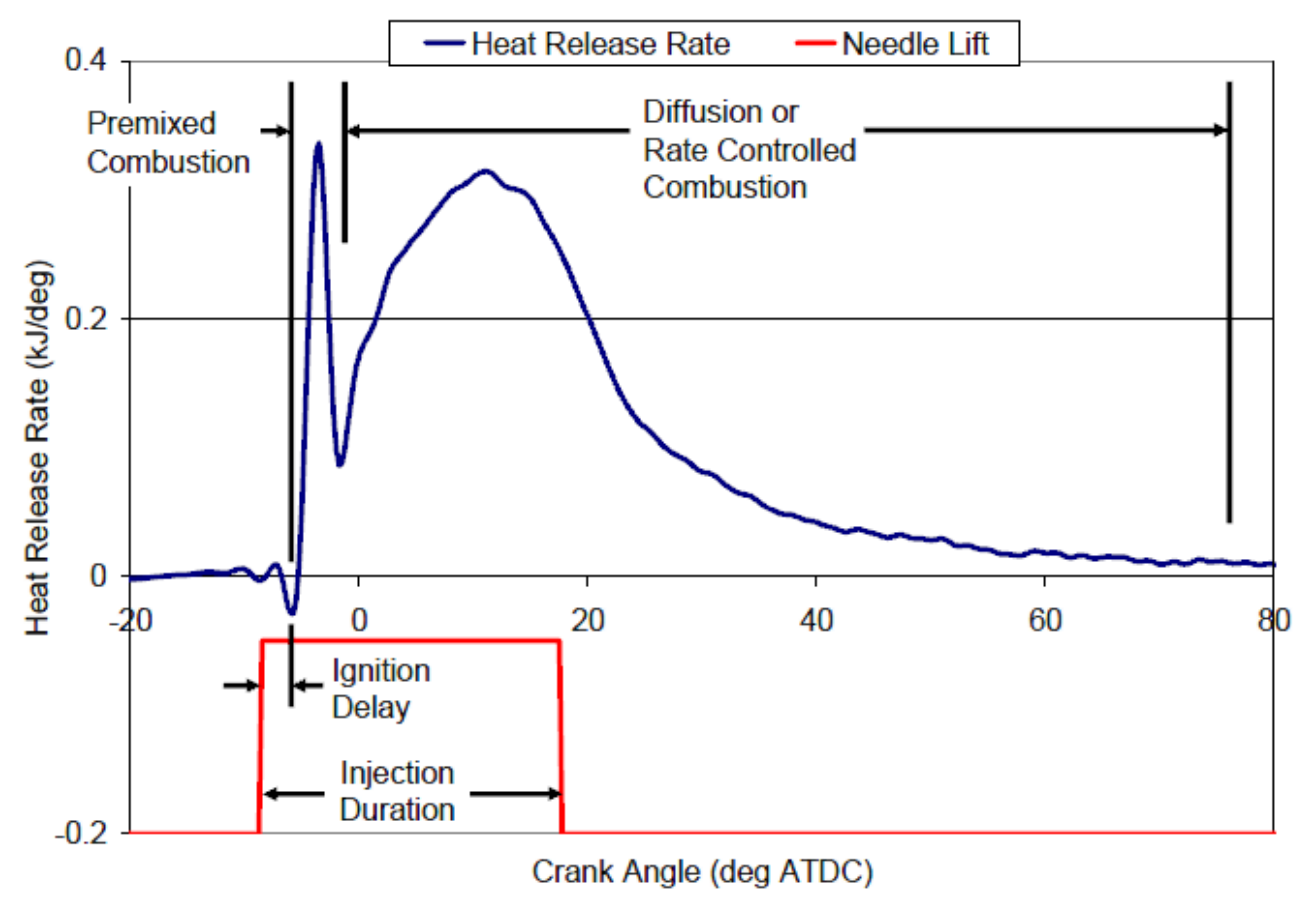

Figure 2-1: Typical Heat Release Curve [18]

\subsubsection{In-Cylinder Pressure}

Measuring in-cylinder pressure provides the means to analyze the combustion event and determine combustion characteristics described by start of ignition, ignition delay, combustion duration, heat release rate, pressure rise rate, and mass fraction burned [18]. In-cylinder pressure can be measured by a piezoelectric pressure transducer. A piezoelectric pressure transducer enables the measurement of dynamic pressure at a rate to discern the in-cylinder pressure to less than a crank angle resolution [18].

\subsection{Pollutant Formation}

Several factors make the diesel engine the desired device for transportation, powering equipment, and generating electricity more efficiently than any other prime movers in their size range. But the diesel engine is one of the largest contributors to pollution problems worldwide. Diesel emissions can contribute to air, water, and soil pollution, reductions in visibility, and global climate change [19]. Exposure to diesel exhaust (DE) can also contribute to the development of several health problems including cancer and respiratory problems. The current regulated emissions in the US for heavy-duty diesel engines are carbon monoxide (CO), total hydrocarbons (THC) and/or non-methane hydrocarbons (NMHC), oxides of nitrogen (NOx), and particulate matter (PM) [20]. Engines used for on-road use are regulated on a brake-specific mass emissions basis with units of mass per unit of work performed over a defined set of speed and load set points on an engine dynamometer. Typical units used to report the 
emissions are $\mathrm{g} / \mathrm{bhp}-\mathrm{hr}$ or $\mathrm{g} / \mathrm{kW}$-hr. Permitted levels may vary according to engine size, operation, and application. The exact composition of DE depends on operational parameters such as engine load, speed, fuel composition, ambient air temperature, relative humidity, and engine design.

Understanding the way in which each pollutant is formed is important and helps to understand what parameters to optimize to reduce emissions. During combustion, as a result of a chemical reaction, products are formed. Common products of combustion of a hydrocarbon fuel are $\mathrm{CO}$, carbon dioxide $\left(\mathrm{CO}_{2}\right)$, NOx, PM, HC, water $\left(\mathrm{H}_{2} \mathrm{O}\right)$, nitrogen $\left(\mathrm{N}_{2}\right)$, and oxygen $\left(\mathrm{O}_{2}\right)$. Figure 2-2 illustrates the emissions from a typical diesel fuel spray.
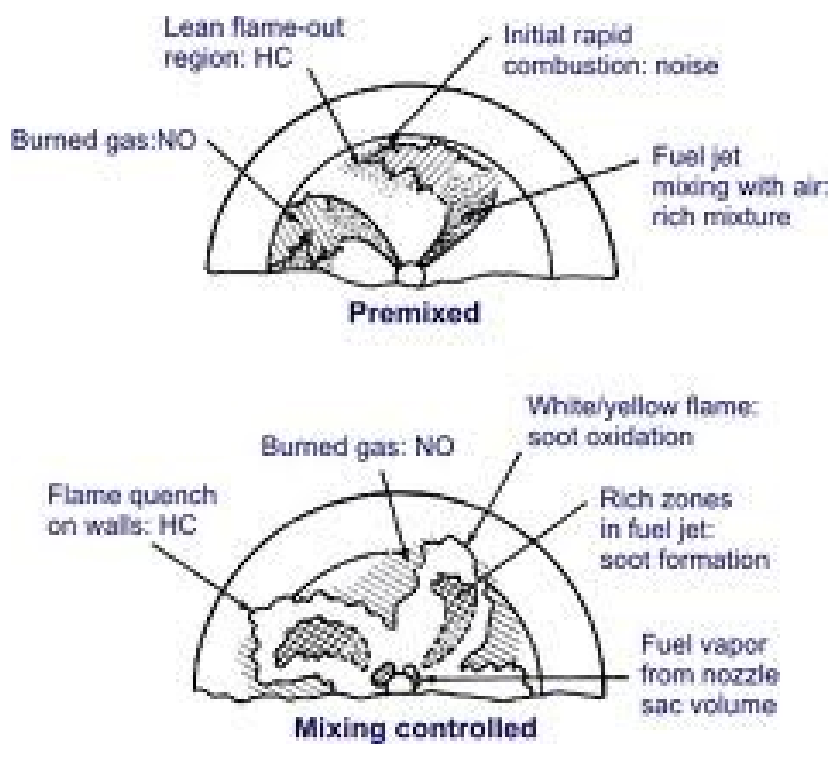

Figure 2-2: Emissions from a Typical Diesel Fuel Spray [17]

\subsubsection{NOx}

Due to environmental restrictions, NOx emissions are being reduced to meet regulations. However, NOx emissions are difficult to control in diesel engines because high combustion temperatures due to high compression ratios lead to higher NOx formation and lower fuel consumption than spark ignition engines [18]. Another main concern is that PM formation is more prevalent in diesel engines compared to spark ignition engines due to the heterogeneous fuel-air mixture and a reduction in NOx usually coincides with an increase in PM. This correlation is called the NOx-PM trade-off.

Understanding NOx formation during the combustion process is essential for NOx control and reduction. While nitric oxide (NO) and nitrogen dioxide $\left(\mathrm{NO}_{2}\right)$ are usually grouped together as $\mathrm{NOx}, \mathrm{NO}$ is the predominant oxide of nitrogen formed inside the engine cylinder [17]. NO usually accounts for 70$90 \%$ of total $\mathrm{NOx}$ while the remaining $10-30 \%$ is $\mathrm{NO}_{2}$ [18]. Oxidation of atmospheric nitrogen and 
oxygen is the principal source of NO. Oxidation of fuel containing nitrogen compounds is an additional source of NO formation. Four mechanisms are attributed to NOx formation: thermal, $\mathrm{N}_{2} \mathrm{O}$-intermediate, prompt, and fuel. From atmospheric $\mathrm{N}_{2}$, the thermal NOx formation occurs by the well-known extended Zeldovich mechanism (Equation 2-1, Equation 2-2, Equation 2-3).

$$
\begin{array}{ll}
\mathrm{O}+\mathrm{N}_{2} \leftrightarrow \mathrm{NO}+\mathrm{N} & \text { Equation 2-1 } \\
\mathrm{N}+\mathrm{O}_{2} \leftrightarrow \mathrm{NO}+\mathrm{O} & \text { Equation 2-2 } \\
\mathrm{N}+\mathrm{OH} \leftrightarrow \mathrm{NO}+\mathrm{H} & \text { Equation 2-3 }
\end{array}
$$

The reactions listed above are a simplification of many different elementary reactions. At high temperatures, dissociation of $\mathrm{N}_{2}$ and $\mathrm{O}_{2}$ can contribute to thermal NOx formation. The reaction rate constants of these reactions tend to be very slow compared to those for combustion, mainly due to the relatively high activation energy values. Thus, NO formation through this mechanism has very strong temperature dependence [17]. The threshold temperature for NO formation is about $1800 \mathrm{~K}$. Thermal NO is generally considered to be formed in the hot bulk mixture such as the combustion products of post flame gases, where high temperature is available. The $\mathrm{N}_{2} \mathrm{O}$-intermediate mechanism consists of molecular nitrogen and oxygen forming $\mathrm{N}_{2} \mathrm{O}$, then reacts with oxygen or hydrogen to form NO. This mechanism involves mainly the following reactions:

$$
\begin{array}{ll}
O+N_{2}+M \leftrightarrow N_{2} O+M & \text { Equation 2-4 } \\
H+N_{2} O \leftrightarrow N O+N H & \text { Equation 2-5 } \\
O+N_{2} O \leftrightarrow N O+N O & \text { Equation 2-6 }
\end{array}
$$

The $\mathrm{N}_{2} \mathrm{O}$-intermediat mechanism has previously been a minor contributor to NOx emissions, but has less dependence on temperature than thermal NOx formation and may have a greater contribution in modern engines [18]. The prompt NOx mechanism is initiated by the reactions of hydrocarbon fuel radicals and molecular nitrogen to form atomic nitrogen and species containing nitrogen elements. Through oxidation these species are converted to NOx. Prompt NOx is usually formed in the initial stage of combustion. Its contribution to NOx emissions in internal combustion engines is very small. The fourth mechanism, fuelborne NOx is formed by nitrogen contained in the fuel, when the nitrogen is oxidized, typically through the prompt NOx mechanism. Fortunately, current levels of nitrogen in diesel fuels are usually not significant. Part of the NO formed by these mechanisms is converted to $\mathrm{NO}_{2}$ during and after the combustion process via:

$$
\mathrm{NO}+\mathrm{HO}_{2} \leftrightarrow \mathrm{NO}_{2}+\mathrm{OH} \quad \text { Equation 2-7 }
$$

The formation reaction of $\mathrm{NO}_{2}$ is to a large extent due to the availability of the $\mathrm{HO}_{2}$ radical. $\mathrm{The} \mathrm{NO}_{2}$ formed can also be destructed and converted back to NO by the following reactions. 


$$
\begin{array}{lr}
\mathrm{NO}_{2}+\mathrm{O} \leftrightarrow \mathrm{NO}+\mathrm{O}_{2} & \text { Equation 2-8 } \\
\mathrm{NO}_{2}+\mathrm{H} \leftrightarrow \mathrm{NO}+\mathrm{OH} & \text { Equation 2-9 }
\end{array}
$$

It has been demonstrated that the presence of $\mathrm{N}_{2}$ and $\mathrm{O}_{2}$ under considerably high temperature is the prerequisite for NOx formation. It is also shown that NOx formation has strong temperature dependence, which can be effected by several design and operation parameters. The most important engine parameters that affect NOx emissions include: equivalence ratio, burned gas fraction, injection timing, and compression ratio. Other factors that affect NOx emissions are exhaust gas recirculation (EGR) rate, engine load, availability of $\mathrm{O}_{2}$, intake humidity level, and intake pressure and temperature.

\subsubsection{PM}

In the last few decades concerns of what effect PM emissions have on the environment as well as potential health effects have grown. Diesel PM consists primarily of combustion generated carbonaceous materials (soot) on which organic compounds have been absorbed [17]. Most PM is the result of incomplete combustion of the hydrocarbon fuel. PM is seen to consist of collections of elemental and organic carbon spherules agglomerated into aggregates (or particles). Organic carbon contributes to PM as the result of unburned fuel, crankcase oil blow-by, and combustion byproducts. Elemental carbon contributes to PM as the residue of burned fuel. These particles become coated with adsorbed and condensed organic compounds. The condensed material also includes inorganic species such as sulfates. PM is typically classified by its size. Any particle from $2.5 \mu \mathrm{m}$ to $10 \mu \mathrm{m}$ in size, known as $\mathrm{PM}_{10}$, is referred to as an "Inhalable Coarse Particle," and any particle smaller than $2.5 \mu \mathrm{m}$, known as $\mathrm{PM}_{2.5}$, is referred to as a "Fine Particle" [21].

Particulate matter undergoes two main processes in diesel engines: formation and growth. PM formation takes place at temperatures between about 1000 and $2800 \mathrm{~K}$, and pressures of 50 to 100 atm [17]. During formation, diesel fuel will undergo pyrolysis, dehydrogenation, and oxidation to form “carbon-rich" products. These products typically include unsaturated hydrocarbons and polycyclic aromatic hydrocarbons (PAH). Both are considered the most likely precursors of soot in flames. The condensation of these products leads to the formation of the first recognizable soot particles, called nuclei [17]. PM nuclei are very small, often less than $2 \mathrm{~nm}$ in diameter. The small nuclei begin to bond together and grow larger particles through surface growth, coagulation, and aggregation.

The bulk of the solid phase material is generated by surface growth. Surface growth involves the deposition of the gas-phase species on the nuclei, increasing the size and mass of individual soot particles. Particle growth also occurs through coagulation, in which the particles collide and coalesce to form larger particles. After surface growth ceases, these larger particles continue to coalesce to form chainlike 
structures. This latter coalescence is known as aggregation [17]. Particle growth can continue in the atmosphere, long after being emitted from the engine, by way of adsorption and condensation. At any stage in the formation and growth process oxidation can occur where PM is burned with oxidizing species to form $\mathrm{CO}, \mathrm{CO}_{2}$, and $\mathrm{HC}$ gases [17].

\subsubsection{CO}

The formation of $\mathrm{CO}$ in diesel engines is attributed to the oxidation of fuel from combustion. The main contributor to $\mathrm{CO}$ formation is insufficient time and oxygen for the oxidation of $\mathrm{CO}$ to $\mathrm{CO}_{2}$ [18]. The emissions of CO from internal combustion engines are primarily controlled by the fuel/air equivalence ratio. For fuel-rich mixtures $\mathrm{CO}$ concentrations increase steadily with increasing equivalence ratio. For fuel-lean mixtures, CO concentrations vary little and are relatively low [17]. Since diesel engines operate on the lean side of stoichiometric, $\mathrm{CO}$ emissions are low and considered to be insignificant and generally fall far below current regulations [17,18].

\subsection{4 $\mathrm{CO}_{2}$}

The emissions of $\mathrm{CO}_{2}$ are a direct product from combustion of a hydrocarbon fuel. The emissions of $\mathrm{CO}_{2}$ form when sufficient time and oxygen is available for oxidation of $\mathrm{CO}$ to $\mathrm{CO}_{2}$. Emissions of $\mathrm{CO}_{2}$ are directly related to fuel consumption in diesel engines. An increase in fuel consumption increases the emissions of $\mathrm{CO}_{2}$. Global warming and climate change has been attributed to $\mathrm{CO}_{2}$. For this reason the EPA and the National Highway Traffic Safety Administration (NHTSA) adopted the first U.S. greenhouse gas (GHG) emission and fuel consumption standards for heavy- and medium-duty vehicles in 2011 [22]. This regulation covers model years (MY) 2014-2018 engines, with the NHTSA fuel economy standard being voluntary in MY 2014-2015.

\subsubsection{HC}

Hydrocarbon emissions are the result of incomplete combustion. The level of unburned HC in the exhaust gases is generally expressed in terms of total hydrocarbons (THC). THC emissions are a useful measure of combustion efficiency; however, it is not necessarily a significant index of pollutant emissions [17]. Hydrocarbons can form and survive in the combustion chamber in many ways such as flame quenching, absorption into engine oil, misfires, crevices, over-leaning, and under-mixing [17]. HC emissions contribute not only to gaseous emissions but also the emissions of PM as discussed previously.

Formation and survival of $\mathrm{HC}$ starts when diesel fuel is injected into the combustion chamber. The fuel is sprayed at an optimized angle for which the fuel vaporize, and mix with air, without hitting the chamber wall. The inner core of the spray pattern is very rich, above the rich combustion limit of the fuel [17]. The fuel becomes increasingly lean from the center of the spray outwards. At the outermost edge of 
the spray the fuel becomes too lean, below the lean limit, to support flame propagation [17]. The fuel at the outside edge will oxidize and become one of the main contributors to $\mathrm{HC}$ emitted. Figure 2-3 illustrates the equivalence ration distribution in the fuel spray at the time of ignition.

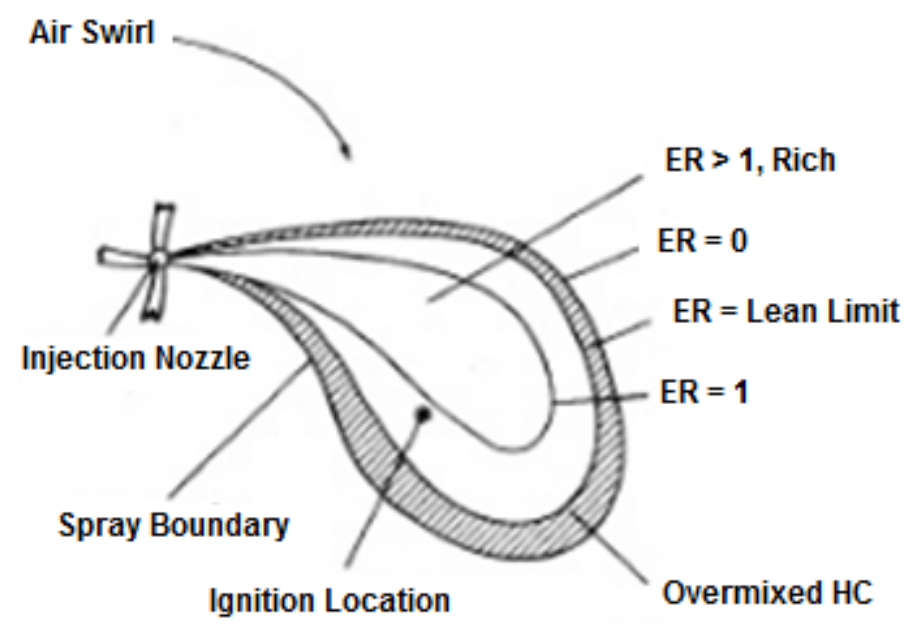

Figure 2-3: Schematic of Diesel Spray Pattern Showing Equivalence Ratio [17]

Along with the unburned fuel in the outermost region of the fuel spray, the fuel in the over-mixed (or over-leaned) region has already mixed beyond the lean limit of combustion and will not auto-ignite. Within this region, unburned fuel, fuel decomposition products, and partial oxidation products (aldehydes and other oxygenates) will exist [17]. However, not all of these products will completely survive the combustion process and leave the cylinder. The magnitude of $\mathrm{HC}$ in the over-lean region is related to the amount of fuel injected during the ignition delay period and the mixing rate with air during this period [17]. Thus, a correlation with unburned $\mathrm{HC}$ and length of ignition delay is expected. As the ignition delay and mixing period increase, the magnitude of $\mathrm{HC}$ in this region and the magnitude of $\mathrm{HC}$ emissions will increase [17].

Under-mixing, or over-fueling, will also result in $\mathrm{HC}$ emissions due to insufficient mixing with air. This is usually a result of fuel that leaves the injector at low velocity, late in the combustion process [17]. The most important source here is excess fuel in the nozzle sac. At the end of the injection process, some fuel will remain in the tip of the injector after the needle seats. These HC emissions depend upon the sac volume; therefore, injectors with small or no sac volume will have lower HC emissions [17]. The fuel in the sac will vaporize as the combustion and expansion process proceed and enter the cylinder at a low velocity through the nozzle holes. This fuel vapor will mix with air and may escape the cylinder during the exhaust stroke. Over-fueling may also occur during transient engine operation as the engine accelerates. Even though the equivalence ratio of the bulk mixture may remain lean, locally rich regions 
may exist in the cylinder. The rich regions allow for the survival of unburned fuel particles that may contribute to $\mathrm{HC}$ emissions. It is important to note that although many hydrocarbons are not burned completely during the main combustion process, not all of them escape in the exhaust. Most of them are still burned off or oxidized in the combustion chamber when mixed with the hot combustion products.

Hydrocarbon emissions have also been found to be sensitive to engine oil and coolant temperatures. $\mathrm{HC}$ emissions are shown to decrease as these temperatures increase [17]. When ignition delay is held constant, the over-mixing phenomena should also remain approximately constant. Therefore, wall (or flame) quenching may also be considered a significant source of HC survival. This will depend upon the amount of spray impingement on the combustion chamber walls [17]. Misfires can also contribute to a rise in $\mathrm{HC}$ emissions; however, complete misfires in a well-designed and adequately controlled engine are unlikely to occur under normal operating conditions [17].

\subsection{Diesel Fuel Properties}

Diesel fuels are complex mixtures of hydrocarbon molecules distilled from crude oil. Various processes exist for refining of fuels to meet the appropriate quality specifications. The standards specifying requirements placed on diesel fuel properties, such as ASTM D975, have evolved in part to environmental considerations and emissions legislation [12]. Parameters specified in these standards that influence emissions as well as combustion include:

- Density

- Cetane Number

- Volatility

- Sulfur Content

- Viscosity

- Heating Value

- Aromatics

A summary of the impact these properties have on combustion and emissions are summarized below.

\subsubsection{Density and Specific Gravity}

Density, an important fuel property, can provide useful information about bulk fuel composition and performance-related characteristics such as ignition quality, power, fuel economy, and lowtemperature properties [20]. A lower density fuel will generally lead to a lower maximum power and lower NOx emissions with an increase in PM and CO [23]. Also, fuel injection equipment operates on a volume metering system, so a change in density will influence engine output properties due to the 
different mass being injected [20]. Due to this effect higher density fuels lead to a decrease in volumetric fuel consumption.

Density may sometimes be expressed as specific gravity. Specific gravity is the ratio of the density of the product being tested to the density of water at a specific temperature. The density can also be expressed as API gravity, which is an arbitrary scale developed by the American Petroleum Institute [20]. API gravity is inversely related to specific gravity, therefore a high API gravity means the material is lower density. Density, specific gravity, and API gravity can all be measured by using either ASTM D287 or ASTM D1298 methods. API gravity is calculated using the following formula:

$$
\text { API gravity }\left(^{\circ}\right)=\frac{141.5}{S G}-131.5 \quad \text { Equation } 2-10
$$

\subsubsection{Cetane Number}

Cetane number is a measure of ignition quality of a fuel defined as the readiness for a fuel to ignite after injected into a diesel engine. Fuels with higher cetane numbers have a higher propensity to ignite and have a higher ignition quality compared to lower cetane number fuels. The cetane number of a fuel is determined using ASTM D613 method, along with a Cooperative Fuels Research (CFR) engine, by comparing its ignition delay of two reference fuels with known cetane numbers under a specified operating condition [20]. The reference fuels are normal cetane (n-hexadecane or $n-\mathrm{C}_{16} \mathrm{H}_{34}$ ), which has a cetane number of 100 , and heptamethyl nonane $\left(\mathrm{C}_{12} \mathrm{H}_{34}\right)$, which is given a value of 15 [20]. The cetane number is calculated by the following formula:

$$
\text { Cetane Number }=\left(\% n-C_{16} H_{34}\right)-0.15\left(\% C_{12} H_{34}\right)
$$

Equation 2-11

Cetane number can affect various engine operation parameters as well as emissions. Higher cetane number fuels have a shorter ignition delay. Lowering the cetane number will lead to a higher pressure rise rate and reduced brake specific fuel consumption (bsfc). This is partially due to the higher heating value of lower cetane number fuels [20]. Figure 2-4 shows the effect of cetane number on emissions of NOx, CO, and $\mathrm{HC}$ from three heavy-duty diesel truck engines [20]. This study was conducted using the Japanese 6-mode test cycle. Emissions of NOx, CO, and HC are all lower when a fuel with a high cetane number is used. PM emissions also tend to decrease as fuel cetane number increases [24]. 


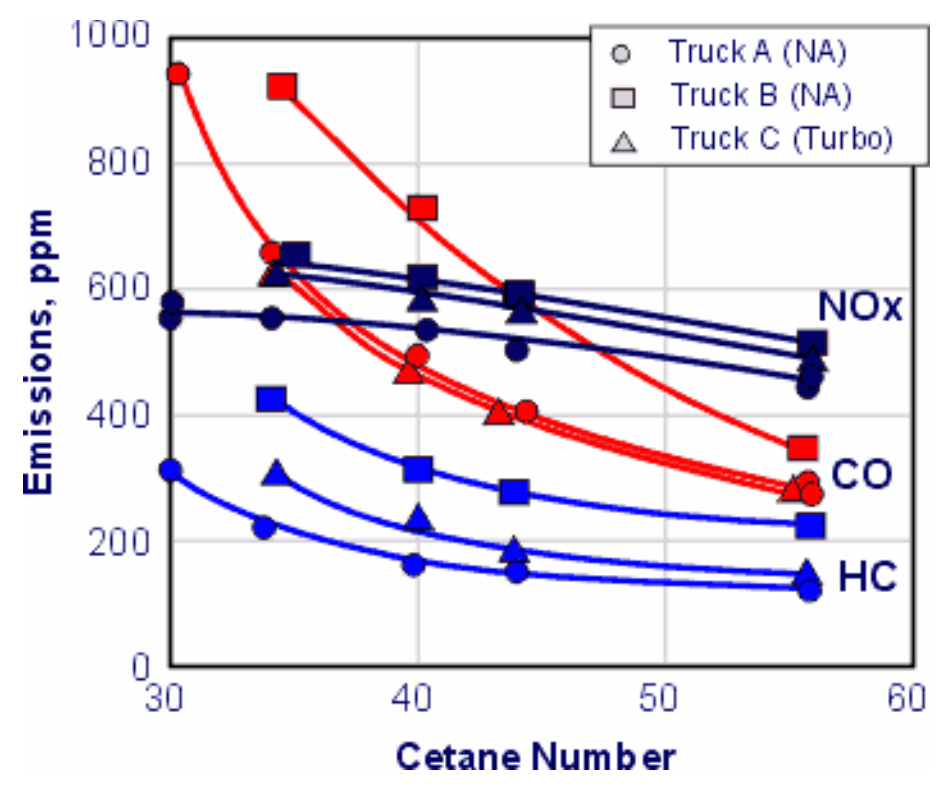

Figure 2-4: Effect of Cetane Number on Exhaust Emissions [20]

\subsubsection{Volatility}

Volatility is a measure of the distillation or boiling range of a fuel. A highly volatile fuel will boil at a low temperature and evaporate quickly [20]. Volatility is expressed in terms of the temperature at which successive portions are distilled from a sample fuel under controlled heating in a standardized apparatus [20]. ASTM D86 is a widely accepted method for distillation. Several factors are recorded during the distillation process, including: initial boiling point (IBP), final boiling point (FBP), percent of condensate recovered, percent residue of non-volatile matter [20]. The $10 \%$ and $90 \%$ or $95 \%$ recovery temperature are often used as more precise indicators of the IBP and FBP, respectively. The distillation range of a fuel will influence other properties such as flash point, viscosity, autoignition temperature, density, and cetane number. Although some differences in engine performance are attributable to variations in volatility, effects are generally modest and far less significant than the influence of individual engine design [20]. The effect of volatility on gaseous emissions is also generally modest and again highly dependent on engine design.

\subsubsection{Sulfur Content}

Sulfur content was the first fuel property to be controlled as a means to limit harmful diesel exhaust emissions [20]. Sulfur is present in all crude oil and, as a result, is present in all diesel fuels to some extent. During combustion, most of the sulfur present in the fuel is converted to sulfur dioxide $\left(\mathrm{SO}_{2}\right)$ and sulfur trioxide $\left(\mathrm{SO}_{3}\right)$. These compounds, together with other gases, also form acidic byproducts and solid compounds such as sulfuric acid $\left(\mathrm{H}_{2} \mathrm{SO}_{4}\right)$ and sulfate particulates. The gaseous emissions will influence the exhaust odor, while the sulfates will contribute to PM emissions [20]. Fuel 
sulfur content directly influences sulfur oxide emissions. Combustion of fuels with high sulfur content produce higher sulfur oxide emissions [24]. It is noted that on-road diesel fuels sold in the United Sates since 2006 have had maximum sulfur content of 15 ppm (termed ULSD) and sulfur-related emissions are generally not a concern.

\subsubsection{Viscosity}

The viscosity of a fluid indicates its resistance to flow. The higher the viscosity of a fluid, the greater the resistance it has to flow. Usually expressed as kinematic viscosity, ASTM D445 is widely used to determine this property of diesel fuels [20]. Viscosity varies inversely with temperature, therefore the temperature at which the viscosity was determined must be noted, usually $20^{\circ} \mathrm{C}$ or $40^{\circ} \mathrm{C}$ for diesel fuels [20]. Viscosity plays a major role in the performance of the fuel injection equipment, which must accurately measure the amount of fuel to be injected. At high temperatures, the viscosity of the fuel is lower and leaking can occur through seals in the fuel injection system if the viscosity if too low. The diesel spray pattern and atomization are also influence by fuel viscosity. On-road diesel fuel specifications impose an upper and lower limit on viscosity to ensure that no problems occur in the fuel injection system or engine [20,23].

\subsubsection{Heating Value}

Heating value (or heat of combustion) is an important fuel property. It is defined as the energy available from a fuel when it is burned, and is the basis for calculating the thermal efficiency of an engine using that fuel [20]. The heating value of a fuel is determined using a bomb calorimeter described by the ASTM D240 method. Heating value does not normally appear in specifications for automotive diesel fuels because it is not controlled during manufacturing [20]. Fuels of varying heating value will produce different power outputs on the same engine, unless other fuel propertiesor fuel injection systems are adjusted.

\subsubsection{Aromatics}

The effects of aromatic content in fuels on engine performance and emissions are highly debated. While most research shows that aromatics have little or no effect on $\mathrm{HC}, \mathrm{CO}$, and PM emissions, some studies show mixed results. A slight decrease in NOx emissions can result from decreasing aromatic content $[20,23]$. This trend can be attributed to the higher combustion temperature of fuels containing aromatics. There are multiple methods to determine content of aromatics in a hydrocarbon fuel, including ASTM D5186. 


\subsection{Application of Hydrotreated Fuels to CI Engines}

Hydrotreated fuels perform similarly to conventional diesel fuel in diesel engines; however, key property differences lead to different combustion and performance characteristics. Fuel properties of hydrotreated fuels that may affect combustion include density, cetane number, heating value, oxygen content, sulfur content, viscosity, and aromatics. Hydrotreated fuels are essentially free of oxygen, sulfur, and aromatics. These fuels also have a high cetane number and a heating value similar to conventional diesel [6,7]. Table 2-1 compares fuel properties of hydrotreated vegetable oil (HVO), EN 590 diesel fuel, gas-to-liquid (GTL) diesel fuel, and FAME. At this point relatively little research exists in literature about the performance of $\mathrm{HVO}$ in diesel engines. However, existing research on the application of HVO to diesel engines is typically related to spray, combustion, and emission characteristics.

Table 2-1: Typical fuel properties of HVO, EN 590, GTL, and FAME [6]

\begin{tabular}{|l|c|c|c|c|}
\hline & HVO & $\begin{array}{c}\text { EN 590 } \\
\text { (summer } \\
\text { grade) }\end{array}$ & GTL & $\begin{array}{c}\text { FAME } \\
\text { (from rape } \\
\text { seed oil) }\end{array}$ \\
\hline Density at $15^{\circ} \mathrm{C}\left(\mathrm{kg} / \mathrm{m}^{3}\right)$ & $775 \ldots 785$ & $\approx 835$ & $770 \ldots 785$ & $\approx 885$ \\
\hline Viscosity at $40^{\circ} \mathrm{C}\left(\mathrm{mm}^{2} / \mathrm{s}\right)$ & $2.5 \ldots 3.5$ & $\approx 3.5$ & $3.2 \ldots 4.5$ & $\approx 4.5$ \\
\hline Cetane number & $\approx 80 \ldots 99$ & $\approx 53$ & $\approx 73 \ldots 81$ & $\approx 51$ \\
\hline Distillation range $\left({ }^{\circ} \mathrm{C}\right)$ & $\approx 180 \ldots 320$ & $\approx 180 \ldots 360$ & $\approx 190 \ldots 330$ & $\approx 350 \ldots 370$ \\
\hline Cloud point $\left({ }^{\circ} \mathrm{C}\right)$ & $-5 \ldots-25$ & $\approx-5$ & $-0 \ldots-25$ & $\approx-5$ \\
\hline Heating value, lower $(\mathrm{MJ} / \mathrm{kg})$ & $\approx 44.0$ & $\approx 42.7$ & $\approx 43.0$ & $\approx 37.5$ \\
\hline Heating value, lower $(\mathrm{MJ} / \mathrm{l})$ & $\approx 34.4$ & $\approx 35.7$ & $\approx 34.0$ & $\approx 33.2$ \\
\hline Total aromatics $(\mathrm{wt}-\%)$ & 0 & $\approx 30$ & 0 & 0 \\
\hline Polyaromatics $(\mathrm{wt}-\%)^{(1)}$ & 0 & $\approx 4$ & 0 & 0 \\
\hline Oxygen content $(\mathrm{wt} \%)$ & 0 & 0 & 0 & $\approx 11$ \\
\hline Sulfur content $(\mathrm{mg} / \mathrm{kg})$ & $<10$ & $<10$ & $<10$ & $<10$ \\
\hline Lubricity HFRR at $60{ }^{\circ} \mathrm{C}(\mu \mathrm{m})$ & $<460^{(2)}$ & $<460^{(2)}$ & $<460^{(2)}$ & $<460$ \\
\hline Storage stability & Good & Good & Good & $\begin{array}{c}\text { Very } \\
\text { challenging }\end{array}$ \\
\hline
\end{tabular}

\subsubsection{Spray Characteristics}

Few studies have been conducted to compare fuel spray characteristics of $\mathrm{HVO}$ and existing petroleum derived diesel fuels. Though research is limited, spray characteristics of HVO have been investigated by Hulkkonen et al. and Legg et al. [25,26]. Physical properties of HVO (Table 2-1) such as density and viscosity will lead to differing spray characteristics of HVO compared to petroleum diesel. Fundamental fuel spray characteristics are presented in Figure 2-5. Spray velocity is defined as the velocity of the leading edge of the spray. The spray penetration is defined as the distance from the nozzle tip to the leading edge of the spray. The length of which the spray disintegrates into droplets is called the break-up length. The spray angle is the angle formed by the intersection of the spray and the tip of the injector [25]. 


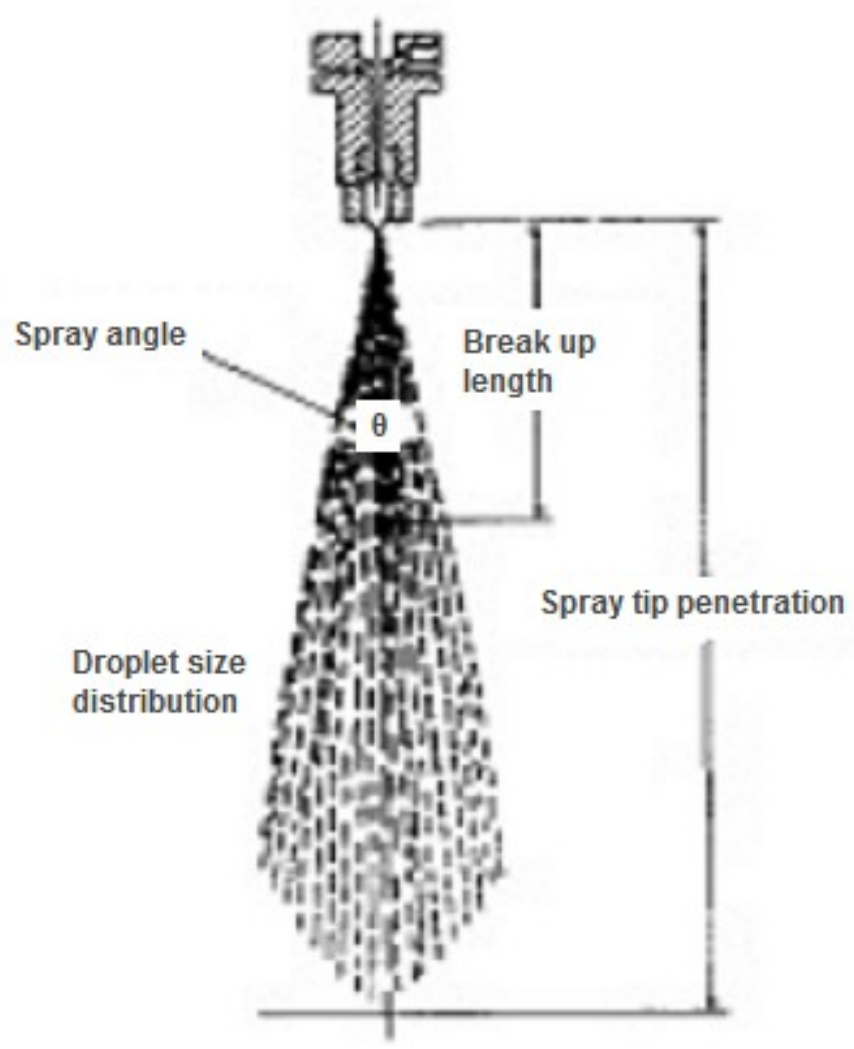

Figure 2-5: Schematic of Diesel Fuel Spray [17]

Hulkkonen et al. investigated macroscopic characteristics such as spray penetration and spray angle of HVO and petroleum diesel for various injection parameters. Two test fuels were used in this study: NExBTL (a HVO produced by Neste Oil Corporation) and summer grade EN 590 diesel fuel. Spray penetration and spray angle were studied for two nozzle orifice diameters $(0.08$ and $0.12 \mathrm{~mm})$ and injection pressures of 450,1000, and 1950 bar. No significant and consistent difference in spray penetration was found between the EN 590 and NExBTL fuels. They found that maximum spray velocity is slightly higher with NExBTL and more pronounced at higher injection pressures. However, these differences were not great enough to cause significant difference in spray penetration. The spray angle was found to be wider when NExBTL was used. As with the general results for petroleum diesel, the spray angle of HVO increases with increase in orifice diameter and decreases with rising injection pressure [25].

In a study conducted by Legg et al. [26], the atomization performance of several fuels was investigated using at twin-fluid airblast atomizer. Five fuels were tested in this study including a 50-50 blend of HRD76 and F-76. Legg et al. found that, relative to conventional diesel, neat F-76 and the 50-50 blend of HRD76 and F-76 have wide spray angles. The effect of a larger spray cone angle would increase 
the exposure of droplets to the surrounding air, improving secondary atomization as well as mixing and heat transfer [26]. The spray angle of the neat F-76 and HRD/F-76 blend was also found to be slightly canted to one side. This study also investigated the Sauter Mean Diameter (SMD) and droplet size distribution for each test fuel. Fuels with similar physical properties such as F-76, HRD/F-76 blend, and conventional \#2 diesel all produced similar results for SMD and droplet size distribution. Differences between values for these fuels were within the experimental error [26].

While differences in physical properties of hydrotreated fuels produce slightly different spray characteristics than conventional diesel, these differences are typically not significant. This suggests that combustion and emission trends of these fuels is not significantly affected by spray characteristics but rather by fuel properties such as cetane number, density, heating value, oxygen content, sulfur content, and viscosity among others.

\subsubsection{Combustion and Emission Characteristics}

Combustion related properties of HVO are primarily better than petroleum derived diesel fuel. HVO has higher cetane number, lower boiling point, and lower adiabatic flame temperature than petroleum diesel. These properties not only allow for more advance combustion strategies but also help reduce regulated and unregulated exhaust emissions. HVO is adaptable in current engine designs; however, adjustment to the engines electronic control unit (ECU) may be necessary for optimal combustion and emission performance. There is a lack of research investigating in-cylinder combustion characteristics of hydrotreated fuels; most studies focus on overall engine performance and emission characteristics.

A study by Caton et al. [27] compared angle of peak pressure (AOP), peak pressure (PP), indicated mean effective pressure (IMEP), and brake mean effective pressure (BMEP) of HRD and conventional diesel. This study used an indirect injection (IDI) 2007 AM General Engine Products 6.5 liter V8 HMMWV (Humvee) turbocharged diesel engine instrumented to measure in-cylinder pressure. AOPs for both HRD and diesel were similar but diesel had higher PPs by about 2-6\% due to shorter combustion duration and greater premixed burn. Over most of the engine operating map the IMEP and BMEP were similar to, or slightly greater, compared to diesel fuel. The slight improvement in IMEP and BMEP was due to the overall longer burn duration of HRD. This provided for a more favorable integrated pressure-volume change effect [27]. Maximum power for diesel and HRD were similar due to similar fuel densities and heating values. Caton et al. also reported results on injection timing, ignition delay, combustion duration, fuel consumption, and $\mathrm{CO}_{2}$ emissions. HRD fuel operation showed a slightly retarded start of injection (SOI) of about 0.5 crank angle degrees (CAD). Ignition delay for HRD was moderately shorter up to $2.5 \mathrm{CAD}$ due to higher cetane number. HRD operation also showed modestly 
longer combustion duration from 0.5 to $1.5 \mathrm{CAD}$. This is a result of the shorter ignition delay which leads to less fuel-air premixing. Brake specific fuel consumption was generally 5-10\% lower with HRD operation and $\mathrm{CO}_{2}$ emissions were consistently lower for $\mathrm{HRD}$, from 5-10\%, compared to the petroleum diesel. This is due to a more favorable $\mathrm{H} / \mathrm{C}$ fuel ratio of $\mathrm{HRD}$ compared to diesel and more efficient combustion phasing of HRD fuel [27].

Several studies $[2,6,7,8,28,29]$ indicate that reductions in regulated and unregulated emissions as well as fuel consumption are possible with operation of hydrotreated fuels. Exhaust emissions of three cars using NExBTL blends were tested and compared with EN 590 and Swedish Environmental Class 1 (EC1) diesel fuels by Rantanen et al. [8]. Fuel blends tested were 5, 15, 20, and 85\% by volume of NExBTL. They found that reductions in $\mathrm{CO}, \mathrm{HC}$, and PM were dependent upon the proportion of NExBTL in the fuel mixture. However, a clear reduction in NOx emissions was not seen in this study. A fuel blend of $85 \%$ NExBTL showed on average $30 \%$ less $\mathrm{CO}$ emissions, $40 \%$ less $\mathrm{HC}$ emissions, $17 \%$ less PM, 4-6\% less $\mathrm{CO}_{2}$, and $<5 \%$ NOx emissions compared to EN 590 reference fuel. Changes in fuel consumption and $\mathrm{CO}_{2}$ emissions were not seen in this study except modest reductions with fuel blend of $85 \%$ NExBTL [8].

Emissions of two heavy duty diesel engines and two city buses operated on HVO and sulfur free EN 590 are presented by Kuronen et al. [6]. One bus was equipped with a urea based SCR (selective catalyst reduction) and the other with EGR and an oxidation catalyst to reduce NOx emissions. The buses were tested using the Braunschweigh City Driving Cycle. Emissions results for two other truck engines are present in this study provided by earlier research. Both European Steady State and Transient test cycles were used for the engines. Reductions in emissions compared to standard sulfur free EN 590 ranged from $28-46 \%$ for PM, 7-14\% for NOx, $0-48 \%$ for $\mathrm{HC}$, and $5-78 \%$ for CO. From this study it is evident that emission reductions can be significant with $\mathrm{HVO} . \mathrm{CO}_{2}$ levels also dropped due to the higher $\mathrm{H} / \mathrm{C}$ ratio in $\mathrm{HVO}$ compared to diesel. A slight decrease in mass based fuel consumption was also noticed for HVO; however, volumetric fuel consumption was slightly higher due to the lower density of HVO [6]. Aatola et al. [28] studied the effect of injection timing on emissions and fuel consumption with HVO fuel. The test engine was a turbocharged 8.4 liter 6-cylinder 4-stroke direct injection diesel engine with common-rail fuel injection and a charge air cooler. Tested fuels were neat HVO, a blend 30vol-\% HVO and 70vol-\% EN 590 diesel fuel. EN 590 was also used as a reference fuel. The engine was run under steady state conditions as three speeds (1000, 1500, and $2200 \mathrm{rev} / \mathrm{min})$ and two load corresponding to $50 \%$ and $100 \%$ load. The main injection timing was varied from six CAD earlier than the default setting and six CAD later than the default setting with intervals of two CAD. Average reductions of all emissions were clear with neat HVO. Smoke was reduced about 35\% and NOx was reduced about 5\%. With the HVO-EN 590 blend fuel smoke was reduced about $11 \%$ but no clear difference in NOx was 
found. The changes in THC and $\mathrm{CO}$ emissions for both fuels were not significant in absolute terms because of the already low absolute values [28]. Mass based fuel consumption was reduced with neat and blended HVO fuels but volumetric fuel consumption increased. At all loads and speeds on each measured injection timings neat HVO lowered both NOx and smoke emissions. These changes were not as apparent with the blended HVO-EN 590 fuel. Specific fuel consumption (SFC) also decreased with neat HVO across the load-speed map at each injection timing, again the decrease with the blended fuel is not that clear. This decrease was attributed to the higher effective heating value of the HVO [28]. A slight increase in engine efficiency was also observed with both neat HVO and the HVO-EN 590 blend, possibly due to the higher cetane number and shorter ignition delay. When NOx emission of the engine was kept equal with all test fuels; the use of neat HVO led to $37 \%$ lower smoke and to $6 \%$ lower SFC than the diesel fuel studied. In addition, with constant SFC of the engine for all fuels, the application of neat HVO led to $16 \%$ lower NOx and to $23 \%$ lower smoke than the use of diesel fuel. The results of this study suggest that even more significant reduction in emissions can be achieved with optimized injection parameters for $\mathrm{HVO}$ [28].

The effects of HVO on combustion and emission characteristics were investigated by Sugiyama et al. [29] using an engine dynamometer and vehicle tests. The test engine was an inline 4-cylinder direct injection turbocharged diesel engine with common rail fuel injection. The test vehicle was a production model passenger car with a six-speed manual transmission; the engine had the same specifications as the engine for dynamometer tests. It was found that the same torque and brake specific energy consumption (BSEC) could be obtained with HVO as with the diesel. This is partially due to the higher (approximately $3 \%$ ) injection quantity of HVO. First a test with single fuel injection was performed and then a test with pilot injections. During the test with single fuel injection, combustion noise, HC, and NOx were all lower with HVO than diesel fuel. As a result of the shorter ignition delay of HVO, the heat release rate (HRR) advances. This difference was most prominent at low loads. With pilot injections the reduction in NOx and combustion noise was not observed; $\mathrm{HC}$ and smoke were lower in all load ranges. Also, the advancement of HRR was decreased with pilot injections. Vehicle tests were conducted with neat HVO, diesel fuel, and diesel fuel blended with $20 \%$ and $40 \%$ of HVO. As with the engine dynamometer tests, vehicle emissions in chassis dynamometer tests produced less HC and CO with neat HVO and the dieselHVO blends. NOx levels were similar for each fuel. A decrease in PM was also observed and was more pronounce with higher proportions of HVO. Optimization of engine performance utilizing the characteristics of HVO was also investigated in this study. They found that slight advancing the main injection of HVO fuel, fuel consumption could be decreased by $4-5 \%$ without significantly effecting beneficial emission trends. It was also found that it will be possible to further decrease emissions and fuel 
consumption by taking advantage of the high cetane number of HVO to optimize combustion by decreasing the quantity of pilot injection [29].

A study performed by Ghosh and Risley [2] compared engine performance and emission data of a 50/50 blend of ULSD/HRD to ULSD on a 4-stroke marine diesel engine from a Stalwart class vessel. Emissions were measured at stable operation loads of 100, 75, 50, 25, and 10\%. The operation of the engine on the ULSD/HRD blend resulted in reductions of $10 \%$ for $\mathrm{NOx}, 18 \%$ for $\mathrm{CO}, 5 \%$ for $\mathrm{CO}_{2}$, and $25 \%$ for PM. Improved fuel economy at intermediate loads was also observed with the 50/50 blend, while differences in fuel economy at low and high loads were not significant. They concluded that HRD has the potential to substantially reduce pollutant emissions without engine or vessel infrastructure modification.

These studies $[2,6,7,8,27,28,29$,] have shown that HVO generally reduce exhaust emissions and fuel consumption, though NOx reductions are not always clearly seen. Hydrotreated fuels have the potential to replace conventional diesel fuel due to fuel properties that lead to similar combustion characteristics and engine performance. Fuel injection system may require recalibration to further optimize performance of $\mathrm{HVO}$, but more research is necessary to fully understand the effect of injection timing on HVO. 


\section{Chapter 3: Experimental Setup}

\subsection{Introduction}

The experimental equipment and procedures used in this study were conducted at West Virginia University's Center for Alternative Fuels, Engines, and Emissions (CAFEE). Where applicable, CAFEE operates in compliance with CFR 40, Parts 1036 (highway engines), 1042 (marine engines), and 1065 (test procedures). The objective of this investigation was to identify possible positive and negative attributes of eight proposed alternative fuels on a smaller compression ignition engine than is used for propulsion engines in the existing Navy fleet. Testing was carried out on a 1992 rebuilt Detroit Diesel Corporation Series 60 engine coupled to a General Electric DC dynamometer. Emissions data were characterized with the use of a full scale dilution tunnel system.

\subsection{Test Fuels}

There were eight proposed alternative fuels being evaluated for the U.S. Navy in this program. The proposed fuels were compared against their respective reference fuel, either JP-5 or F-76. Each candidate alternative is a hydrotreated biofuel and was tested as a neat and/or blended fuel. Table 3-1 contains the naming convention of the fuels. Table 3-2 and Table 3-3 contain fuel properties compared to reference fuel properties of JP-5 and F-76 [27,30,31]. Fuel properties for JP-5 and F-76 are based on standard military specifications MIL-DTL-5624V [30] and MIL-DTL-16884M [31], respectively. Detailed property tables and fuel specifications are found in the Appendix. Fuel properties for 80/20 F76/DSH76 were not available because the fuel was mixed on-site and chemical and physical properties were not determined.

Table 3-1: Naming convention of test fuels

\begin{tabular}{|l|l|}
\hline Reference Fuel & \multicolumn{1}{|c|}{ Candidate Fuel } \\
\hline \multirow{3}{*}{ JP-5 } & $50 / 50$ JP5/HRJ5 \\
\cline { 2 - 2 } & Neat HRJ5 \\
\hline \hline \multirow{5}{*}{ F-76 } & Neat HRD76 \\
\cline { 2 - 2 } & $50 / 50$ F76/HRD76 \\
\cline { 2 - 2 } & Neat DSH76 \\
\cline { 2 - 2 } & $50 / 50$ F76/DSH76 \\
\cline { 2 - 2 } & $80 / 20$ F76/DSH76 \\
\cline { 2 - 2 } & $80 / 20$ F76/HDCD76 \\
\hline
\end{tabular}


Table 3-2: Fuel property comparison of JP-5-based fuels per MIL-DTL-5624V

\begin{tabular}{|l|l|c|c|c|}
\hline \multicolumn{1}{|c|}{ Property } & \multicolumn{1}{c|}{ Unit } & JP-5 & HRJ-5 & $\begin{array}{c}50 / 50 \\
\text { JP5/HRJ5 }\end{array}$ \\
\hline Density at $15^{\circ} \mathrm{C}$ & $\mathrm{kg} / \mathrm{m}^{3}$ & $814.8^{\#}$ & $766.5^{\#}$ & $790.7^{\#}$ \\
\hline Viscosity at $-20^{\circ} \mathrm{C}$ & $\mathrm{mm}^{2} / \mathrm{s}$ & $5.3^{*}$ & 8 & 5.9 \\
\hline Cetane Number & --- & $44^{*}$ & 62 & 51 \\
\hline Freezing Point & ${ }^{\circ} \mathrm{C}$ & $-50^{*}$ & -50 & -55 \\
\hline Heating Value (by mass @ 15 C) & $\mathrm{MJ} / \mathrm{kg}$ & $42.6(\mathrm{~min})$ & 44 & 43.5 \\
\hline Heating Value (by volume @ 15 C) & $\mathrm{MJ} / \mathrm{L}$ & $33.5(\mathrm{~min})$ & 33.748 & 34.365 \\
\hline Aromatics & $\mathrm{Vol} \%$ & $19.2^{*}$ & 0.2 & 9.8 \\
\hline Flash Point & ${ }^{\circ} \mathrm{C}$ & $62^{*}$ & 63 & 64 \\
\hline Hydrogen Content & $\mathrm{Mass} \%$ & $13.6^{*}$ & 15 & 14.2 \\
\hline Sulfur Content & Mass \% & 0.3 (max) & report & 0.1 \\
\hline Thermal Stability (Pressure Drop) & $\mathrm{mm} \mathrm{Hg}$ & $0^{*}$ & 0.0 & 0.1 \\
\hline \#Fuel density measured at WVU CAFEE \\
*Fuel properties measured by Fuels Division of Naval Air Systems Command [27] \\
\hline
\end{tabular}

Table 3-3: Fuel property comparison of F-76-based fuels per MIL-DTL-16884M

\begin{tabular}{|c|c|c|c|c|c|c|c|c|}
\hline Property & Unit & F-76 & HRD-76 & $\begin{array}{c}50 / 50 \\
\text { F76/HRD76 }\end{array}$ & DSH-76 & \begin{tabular}{|c|}
$50 / 50$ \\
F76/DSH76 \\
\end{tabular} & HDCD & $\begin{array}{c}80 / 20 \\
\text { F76/HDCD7 }\end{array}$ \\
\hline Density at $15^{\circ} \mathrm{C}$ & $\mathrm{kg} / \mathrm{m}^{3}$ & $845.8^{\#}$ & $777.9^{\#}$ & $812.6^{\#}$ & $772.9^{\#}$ & $808.5^{\#}$ & $928^{\#}$ & $862.1^{\#}$ \\
\hline Viscosity at $40^{\circ} \mathrm{C}$ & $\mathrm{mm}^{2} / \mathrm{s}$ & $3.8^{*}$ & 2.3 & 2.3 & 2.4 & 2.5 & 5.4 & 3.3 \\
\hline Cetane Number & --- & $43 *$ & 70 & 59 & 58 & 55 & 28 & 44 \\
\hline Cloud Point & ${ }^{\circ} \mathrm{C}$ & $-16^{*}$ & -3 & -11 & -82 & -28 & $<-81$ & -14 \\
\hline Heating Value (by mass @ 15 C) & $\mathrm{MJ} / \mathrm{kg}$ & $43(\mathrm{~min})$ & 43.9 & 43.3 & 44 & 43.442 & 42.1 & 42.8 \\
\hline Heating Value (by volume @ 15C) & $\mathrm{MJ} / \mathrm{L}$ & 34 (min) & 34 & 34.9 & 34.2 & 35.4 & 36 & 36.6 \\
\hline Aromatics & vol \% & $17.3^{*}$ & 1 & 11 & report & 12 & 20 & 22 \\
\hline Flash Point & ${ }^{\circ} \mathrm{C}$ & $62 *$ & 64 & 65 & 106 & 81 & 96 & 76 \\
\hline Pour Point & ${ }^{\circ} \mathrm{C}$ & $-24^{*}$ & -9 & -18 & $<-75$ & -48 & -48 & -18 \\
\hline Hydrogen Content & Mass $\%$ & $12.7^{*}$ & 15 & 14 & 14.8 & 13.9 & 11.9 & 12.8 \\
\hline Sulfur Content & Mass $\%$ & $0.34^{*}$ & $\mathrm{~N} / \mathrm{A}$ & 0.06 & report & report & NR & 0.2 \\
\hline Lubricity & $\mu \mathrm{m}$ & 460 (max) & NR & NR & 540 & 460 & 190 & 410 \\
\hline Storage Stability & $\mathrm{mg} / 100 \mathrm{~mL}$ & $1 *$ & 0.0 & 0.5 & 1.0 & 0.6 & 0.7 & 2.3 \\
\hline \multicolumn{9}{|c|}{ *Fuel properties measured by Fuels Division of Naval Air Systems Command, Patuxent River, MD and US Naal Academy [27] } \\
\hline \#Fuel density measured at WVU CA & & & & & & & & \\
\hline
\end{tabular}

\subsubsection{JP-5}

JP-5 is a yellow kerosene-based jet fuel developed in 1952 for use in aircraft stationed aboard aircraft carriers. JP-5 is a complex mixture of hydrocarbons containing alkanes, naphtenes, and aromatic hydrocarbons. This fuel requires military-unique additives that are necessary in military weapon systems, engines, and missions. It is intended for use in aircraft turbine engines, but in some cases, may be burned in diesel engines. Jet fuel is often used in ground support vehicles at airports instead of diesel. However, jet fuel tends to have poor lubricating abilities compared to diesel. JP-5 is covered by the military 
specification MIL-DTL-5624V [30]. Properties of JP-5 are shown in Table 3-2. In this experiment JP-5 was operated as a reference fuel for neat HRJ5 and 50/50 JP5/HRJ5 proposed alternative fuels.

\subsubsection{HRJ5}

HRJ5 is a hydroprocessed renewable jet fuel and a possible replacement for JP-5. It is a paraffinic-type hydrocarbon with no aromatics and a normal jet cut carbon chain length distribution. Under MIL-DTL-5624V [30] it can be blended up to 50\% with JP-5, limited by density and minimum aromatic content. HRJ5 is not dependent upon feedstock. Relative to JP-5, HRJ5 has lower density, aromatic content, and volumetric heating value. It also has a higher cetane number and hydrogen content. In this experiment, HRJ5 was operated as neat HRJ5 and a blend of 50/50 JP5/HRJ5 and compared to JP5 reference fuel.

\subsubsection{F-76}

F-76 is the military specified distillate fuel normally used in shipboard diesel engines, gas turbines, and boilers for propulsion and auxiliary power. It has stringent specifications and storage/handling requirements covered in MIL-DTL-16884M [31]. Older naval engineering terminology referred to F-76 as Diesel Fuel Marine (DFM). Current practice no longer uses "DFM' as a name for F76 and to avoid confusion, F-76 fuel should only be referred to as "F-76." F-76 is a clear, never dyed fuel. Table 3-3 shows fuel properties of F-76. In this experiment F-76 was operated as a reference fuel for the neat alternative HRD76, DSH76, HDCD76, and their respective blends, fuels.

\subsubsection{HRD76}

HRD76 (Hydroprocessed Renewable Diesel) is another paraffinic-type hydrocarbon fuel with no aromatics. It has a normal diesel-cut carbon chain length distribution with various degrees of hydrocarbon branching at all chain lengths. Similar to HRJ5, it is feedstock independent and can be operated in blends up to $50 \%$, limited by density and minimum aromatic content under MIL-DTL16884M [31]. Relative to F-76, it has lower density, aromatic content, volumetric heating value and higher cetane number and hydrogen content. HRD76 was operated as neat HRD76 and a blend of 50/50 F76/HRD76 in this experiment.

\subsubsection{DSH76}

DSH76 is a direct sugar to hydrocarbon fuel. First, the sugar is fermented to produce farnesene, which is then hydroprocessed to produce farnesane. Farnesane is a single-molecule C-15 paraffin. DSH76 has no distribution of chain length or isomerization. It can used in blends up to $50 \%$ before it meets the limit of density and minimum aromatic content set by MIL-DTL-16884M [31]. Relative to F76, DSH76 has a relatively flat boiling point curve, lower density, aromatic content, and volumetric 
heating value as well as higher cetane number and hydrogen content. DSH76 was operated in three ratios in this experiment: Neat DSH76, 50/50 F76/DSH76, and 80/20 F76/DSH76.

\subsubsection{HDCD76}

HDCD76 (or Hydrotreated Depolymerized Cellulosic Diesel) is an aromatic and cycloparaffinic rich hydrocarbon. Its chemistry is primarily defined by catalytic cracking of cellulosic biomass, which is followed by downstream hydrotreating. It has a normal distribution of aromatic and cycloparaffinic molecules. Blending of HDCD76 is limited to $20 \%$ because of limits on cetane number, maximum density, hydrogen content, and viscosity [31]. Unlike the other candidate fuels, HDCD76 has higher aromatic content, density, viscosity, and volumetric heating value as well as lower cetane number and hydrogen content compared to F-76. HDCD76 was only operated as an 80/20 F76/HDCD76 blend in this experiment.

\subsection{Test Engine}

Evaluation of the test fuels is conducted using a 1992 rebuilt Detroit Diesel Corporation Series 60 engine. In order for this engine to be tested in a laboratory environment some changes were made in order for the engines to be accommodated. The radiator found in typical on-road vehicles was replaced with a liquid-to-liquid heat exchanger, and the intercooler replaced with a liquid-to-air intercooler. All accessories such as the fan and air conditioning unit were either removed or disengaged. Intake air was conditioned by the CAFEE heating, ventilation, and air conditioning system and the intake filter was replaced with a laboratory filter. An exhaust back pressure valve on the exhaust pipe took the place of the exhaust muffler.

The 1992 DDC S60 was rebuilt in 2006 to the original 1992 DDC specifications. It has been used in previous tests to examine effects of fuel additives on in-cylinder pressure and emission characteristics reported by Nuszkowski [18] and Tincher [23]. The specifications for this engine can be found in Table 3-4, and the engine can be seen in Figure 3-1. This engine can be considered a pristine laboratory engine suitable for emissions testing and in-cylinder pressure analysis. The engine was previously fitted with two in-cylinder pressure transducers (cylinder No. 3 and No. 5) located in the engine head by the Detroit Diesel Corporation. The fuel injector in cylinder No. 3 was also fitted with a needle lift sensor to obtain injection timing data. An encoder attached to the drive shaft of the engine provided the timing for data acquisition with a low to high voltage at every 0.25 crank angle degree. The voltage change triggered the DAQ card to acquire a measurement for in-cylinder pressure. 
Table 3-4: Test engine specifications

\begin{tabular}{|l|c|}
\hline Engine Manufacturer & Detroit Diesel Corporation \\
\hline Engine Model, Year & Rebuilt DDC Series 60, 1992 \\
\hline Model Number & 6067GU60 \\
\hline Serial Number & 06R0105610 \\
\hline Configuration & Inline 6 Cylinder \\
\hline Displacement (L) & 12.7 \\
\hline Power Rating (hp) & 360 @ 1810 rpm \\
\hline Torque Rating (ft-lbs) & 1450 @ 1200 rpm \\
\hline Compression Ratio & $15: 1$ \\
\hline Bore X Stroke (mm x mm) & 135 X 165 \\
\hline Air Handling & Turbocharged, Aftercooled \\
\hline Exhaust Gas Recirculation & N/A \\
\hline
\end{tabular}

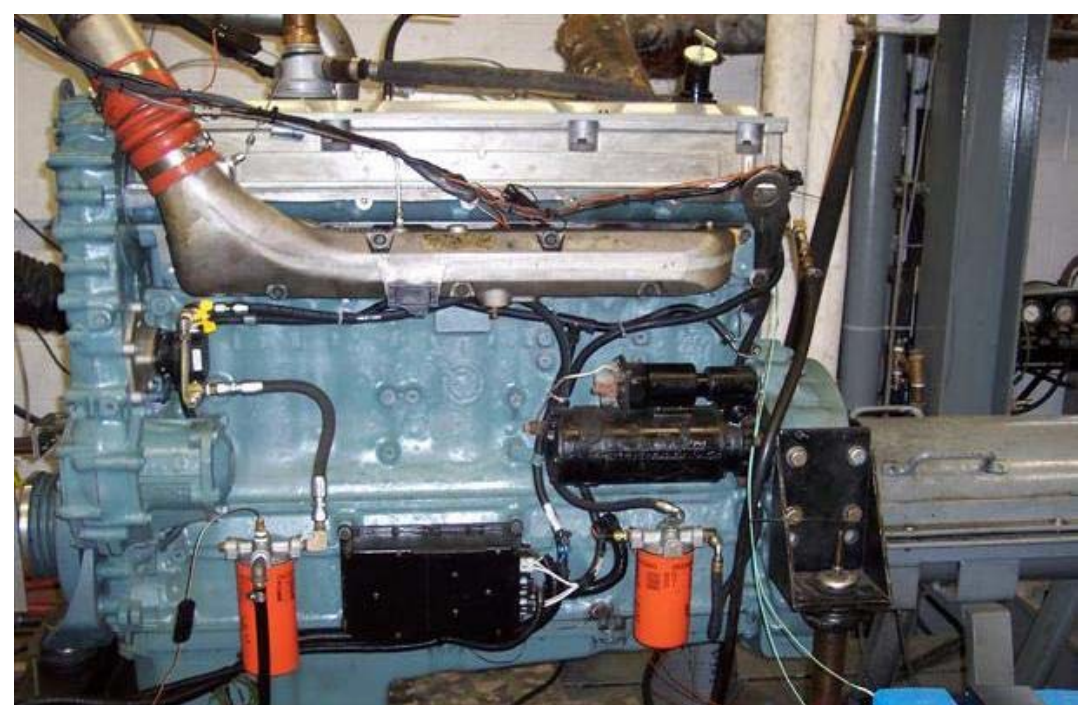

Figure 3-1: 1992 Rebuilt DDC Series 60 [23]

\subsection{Engine and Test Cell Parameters}

During engine testing, several parameters were recorded to ensure proper engine and test cell operation. Recorded engine parameters included: coolant temperature, oil temperature, exhaust temperature, exhaust back pressure, manifold air temperature and pressure, and intake depression. Other parameters were also recorded to ensure the test cell was functioning properly and included: fuel temperature, intake air temperature, intake air humidity, and inlet and outlet temperatures for each of the heat exchangers. Along with several other measurements, the parameters listed above were required for the calculation of in-cylinder pressure and emission data. After each test, all of these parameters were checked in order to validate the test. 


\subsection{Engine Dynamometer}

The dynamometer used for testing during this study was a General Electric direct current model DYC 243 and can be seen in Figure 3-2. This dynamometer was capable of delivering up to 500hp and absorbing 550hp. The engine was coupled to the dynamometer using a Vulkan damper and drive shaft coupling. A load cell mounted on the dynamometer measured the force, used to calculate the engine torque, and a digital encoder attached to the dynamometer was used to determine engine speed. The dynamometer was calibrated to be in compliance with CFR 40 Part 1065.310 [32].

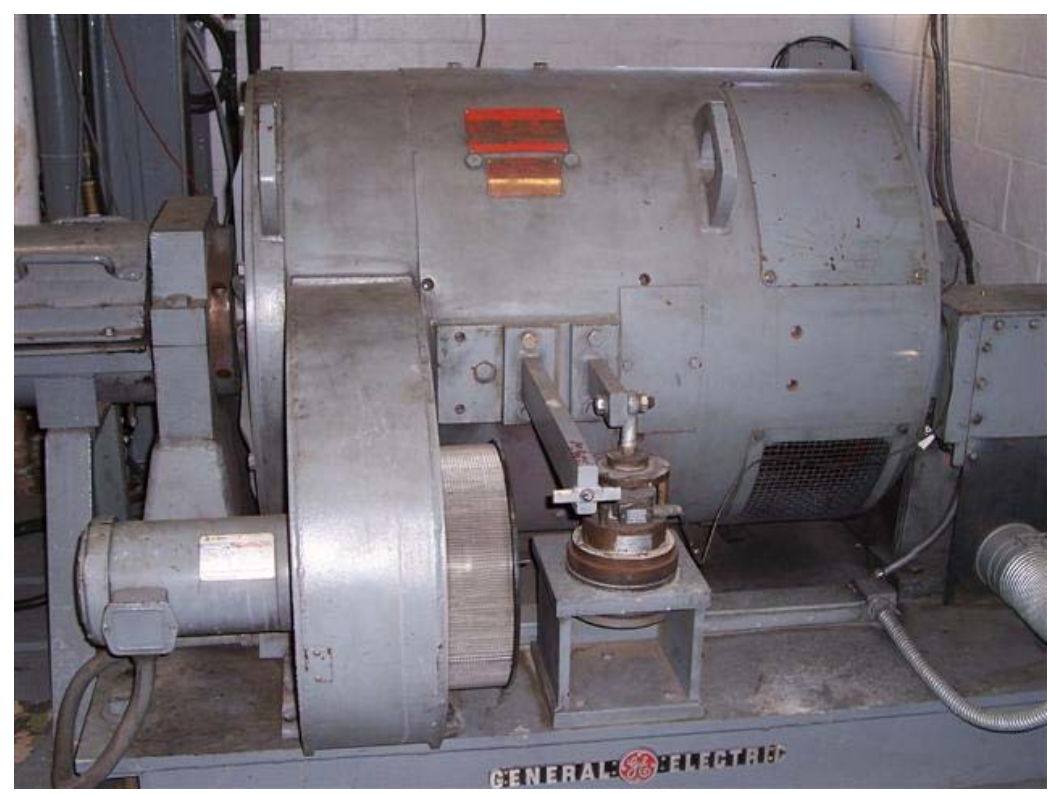

Figure 3-2: GE Engine Dynamometer

\subsection{Dilution Tunnel and Sampling System}

Emission testing at CAFEE was conducted using a full-scale dilution tunnel, shown in Figure 3-3, in order to measure the effects of exhaust emissions on a simulated real world environment. The system was designed to meet CFR 40 Part 1065 specifications. The dilution tunnel enables mixing of engine exhaust and ambient air, which allows a multitude of reactions to occur replicating reactions experienced once exhaust gas enters the atmosphere. The primary purpose of the dilution tunnel was to allow for particulate matter formation, but measurement of gaseous emissions was also simplified for transient tests.

A constant volume sampling system (CVS) was used with the dilution tunnel. In order to satisfy CFR 40 Part 1065.240, the total volume of exhaust and dilution air must be measure and a continuously proportioned volume of sample must be collected for analysis [32]. A subsonic venturi (SSV) was used 
to measure the dilute exhaust mixture. An electric blower, located after all emission probes and the venturi, was used to pull the air mixture through the CVS system.

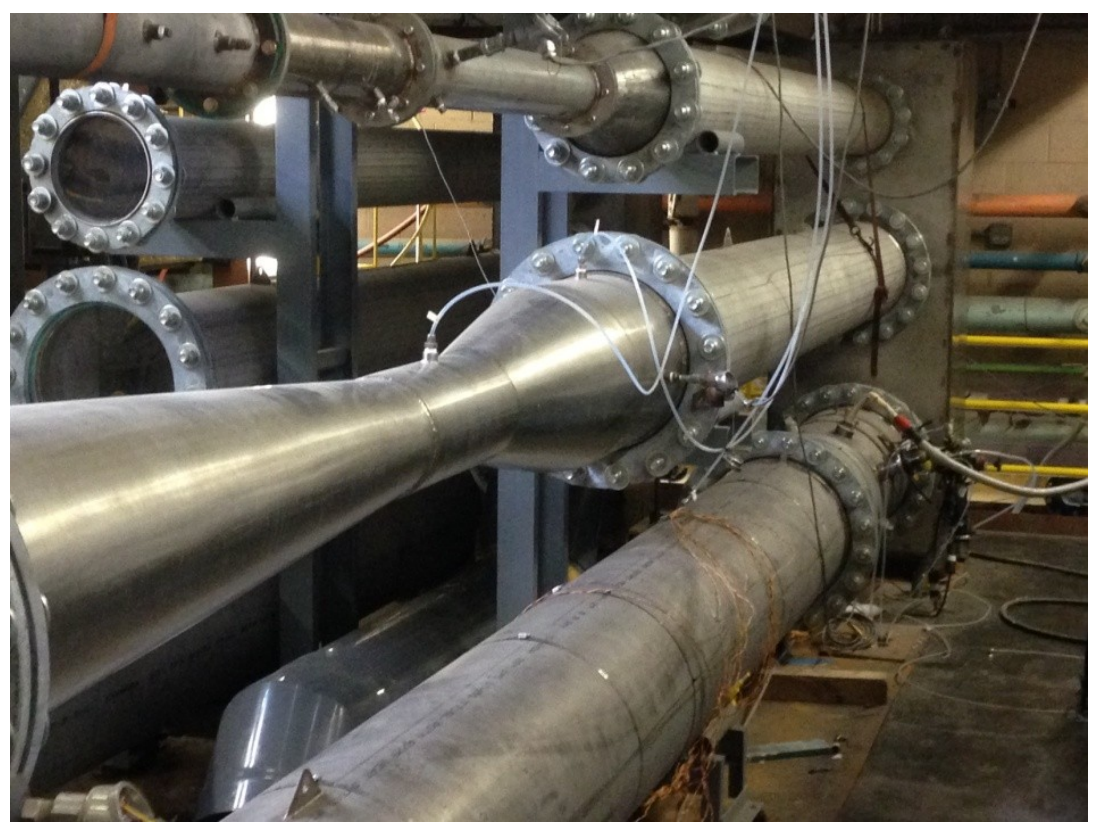

Figure 3-3: Full-Scale Dillution Tunnel at WVU CAFEE Engine Lab

\subsubsection{Subsonic Venturi}

As specified in CFR 40 Part 1065.240 [32], the CVS system consisted of a subsonic venturi capable of accurately measuring flow being pulled through it. The SSV was used to measure the flow rate of the exhaust and dilution air mixture and sustain a continuous flow rate through the dilution system. The venturi flow rate can be determined using Equation 3-1.

$$
Q_{v}=\frac{Q_{m}}{\rho_{s}}=\frac{K_{q}}{\rho_{s}}\left(\frac{C_{d^{*} Y * d^{2}}}{\sqrt{1-\beta^{4}}}\right) \sqrt{\rho_{i} * \Delta P} \quad \text { Equation 3-1: Venturi Flow Rate }
$$

Where, $\mathrm{Q}_{\mathrm{v}}(\mathrm{SCFM})$ is the standard volumetric flow rate through the venture

$\mathrm{K}_{\mathrm{q}}$ is a known constant

$\rho_{\mathrm{s}}$ is the density at standard conditions

$\mathrm{C}_{\mathrm{d}}$ is the coefficient of discharge (or Actual Air Flow/Theoretical Air Flow)

$\mathrm{Y}$ is the expansion factor

$\mathrm{d}$ is the throat diameter

$\beta$ is the ratio of the throat diameter to inlet pipe diameter

$\rho_{\mathrm{i}}$ is the density at inlet conditions

$\Delta \mathrm{P}$ is the differential pressure (or pressure drop) between the throat and inlet 


\subsubsection{Dilution Air}

The dilution tunnel is designed to simulate the effects of exhaust gas entering the atmosphere. In order to reduce variability in the engine performance and the resulting emissions, the intake and dilution air streams were temperature and humidity controlled. This allowed all tests to be evaluated on the same basis. Outside ambient air was passed through a HEPA filter to remove PM found in the air. HEPA filters have an initial collection specification of $99.97 \%$. The air was then conditioned to fall in the 20 to $30^{\circ} \mathrm{C}$ range with an approximate dew point of $14.5^{\circ} \mathrm{C}$ as per CFR 40 Part 1065.140 [32].

\subsubsection{Gaseous Sampling System}

The gaseous sampling system at the WVU CAFEE consisted of heated sampling lines, heated pumps, heated filters, exhaust gas analyzers, a chiller unit, and an exhaust system. The sampling probes were located downstream of the dilution air mixing and upstream of the SSV. All sampling probes and lines were heated to prevent condensation; individual temperatures were dependent upon the emission species. Samples were taken more than 10 diameters downstream of the exhaust and dilution air mixing. Samples were taken for the following gases: $\mathrm{CO}, \mathrm{CO}_{2}, \mathrm{NOx}$, and THC. To satisfy CFR 40 Part 1065.145 [32], sample lines and probes for $\mathrm{CO}, \mathrm{CO}_{2}$, and $\mathrm{NOx}$ were all maintained at $235 \pm 20^{\circ} \mathrm{F}$. THC sampling probes and lines were kept at $375 \pm 20^{\circ} \mathrm{F}$. $\mathrm{CO} / \mathrm{CO}_{2}$ samples were passed through a chiller unit to remove water from the sample line. The gas samples were then pumped to a MEXA-7000 analyzer consisting of different exhaust gas analyzers, which are explained in more detail in Section 3.7.

\subsubsection{Particulate Matter Sampling System}

A gravimetric-based collection method was used to collect particulate matter emissions. A slipstream was taken from the main dilution tunnel for TPM measurements on the order of 1-2 scfm. The slipstream passed through a stainless steel sample line connected to the PM sampling box, shown in Figure 3-4. After entering the PM sampling box, the exhaust gas first passed through a particulate cyclone with a cut size of $10 \mu \mathrm{m}$. The exhaust gas then passed through a $47 \mathrm{~mm}$ TX40 filter being held in a stainless steel filter holder in which PM was collected. A digital mass flow controller measured and controlled the amount of exhaust gas passing over filter face. The filter face was maintained at a nominal $125^{\circ} \mathrm{F}$ to prevent the PM from changing due to condensation.

The $47 \mathrm{~mm}$ TX40 filters are made of pure borosilicate glass microfibers reinforced with woven glass clothe and bonded with PTFE (polytetrafluoroethylene). The TX40 filters have a manufacturer rated efficiency of $99.9 \%$. In accordance with CFR 40 Part 1065.170 [32], the use of one filter is permissible so long as the minimum initial collection efficiency is at least $99.7 \%$ as specified by the 
manufacturer's product ratings. All filters were pre-conditioned and weighed prior to and after testing in a controlled clean room environment following standards set by CFR 40 Part 1065.190 [32].

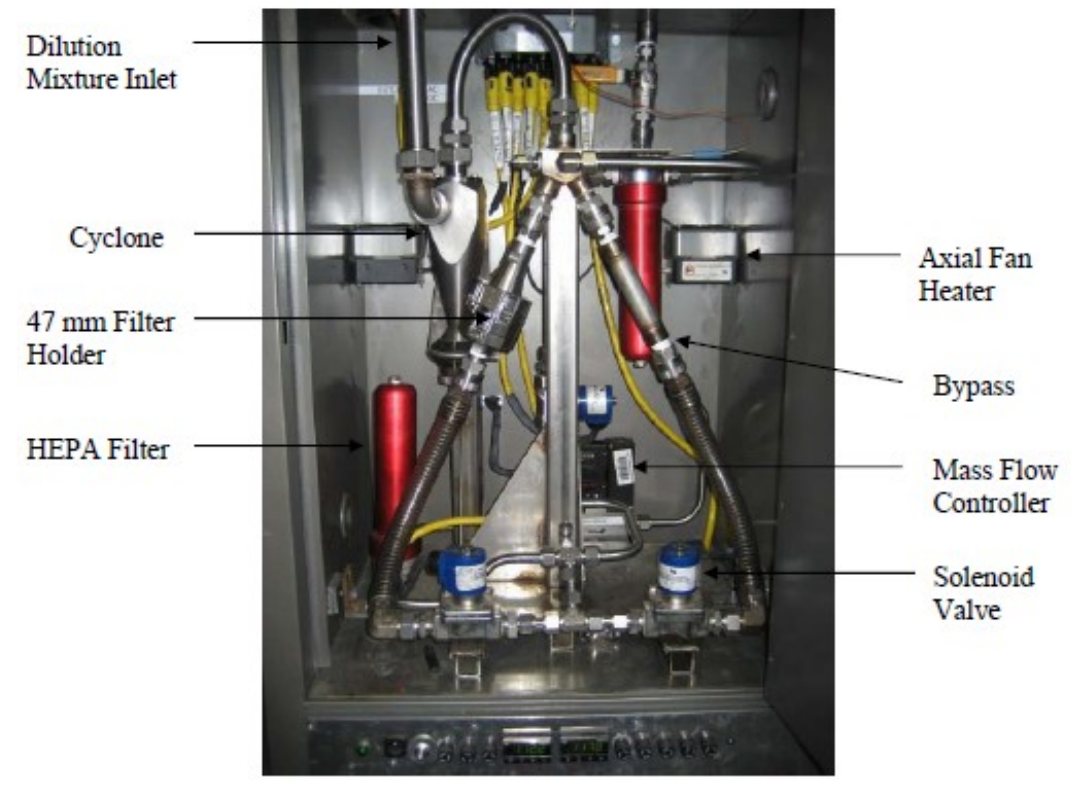

Figure 3-4: PM Sampling Box at WVU CAFEE Engine Lab

\subsection{Exhaust Gas Analyzers}

Emissions at WVU CAFEE were measured during testing using a Horiba MEXA-7000 gas analyzer unit, shown in Figure 3-5. This unit utilizes a chemiluminescent analyzer for oxides of nitrogen, a heated flame ionization detector (HFID) for total hydrocarbons, and infrared analyzers for carbon monoxide and carbon dioxide. Each of these analyzers was calibrated using NIST-traceable gases and set to a range appropriated to the emissions from the engine. Calibrations occurred at the beginning of the test program. 


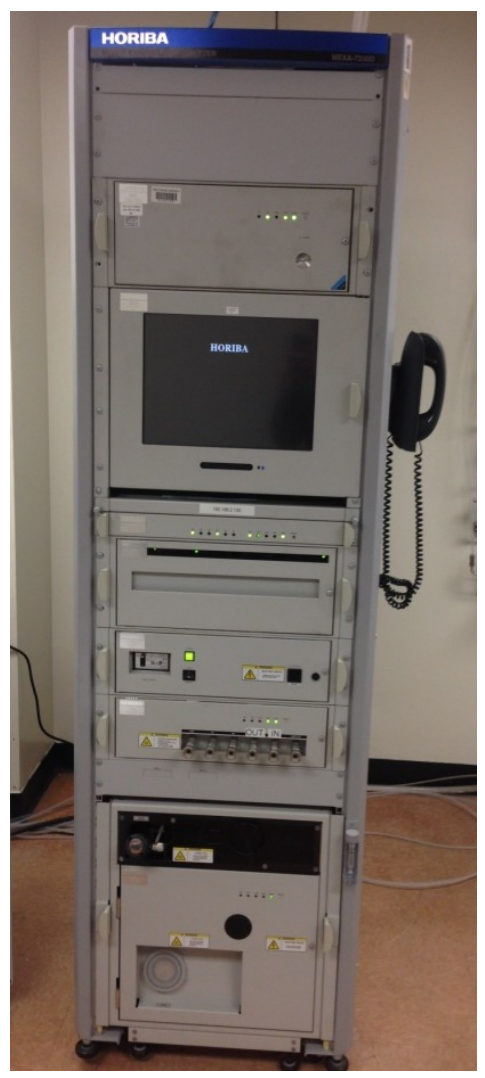

Figure 3-5: Horiba MEXA 7000 Gas Analyzer Unit

\subsubsection{Hydrocarbon Analyzer}

A HFID analyzer (Horiba Model FIA-721HA) was used to measure the total hydrocarbon concentration in the gaseous exhaust. An HFID has a heated oven which contains a burner with a heated pump [23]. A regulated flow of $40 \%$ hydrogen $/ 60 \%$ helium sustained the flame within the analyzer. As hydrocarbons passed through the flame positive ions were formed. The positive ions were collected by a split ring analyzer with polarized electrodes. When the sample is passed through the flame the electrostatic field generates as small current between electrodes. The measured current is directly proportional to the concentration of total hydrocarbons in the sample. A secondary hydrocarbon analyzer (Horiba Model FIA-725A) was used as a quality assurance/quality control (QA/QC) device. Both devices have linearity within $\pm 1 \%$ of full scale and repeatability within $\pm 0.5 \%$ of full scale.

\subsubsection{Oxides of Nitrogen Analyzer}

Oxides of nitrogen were measured with two separate analyzers, both worked on the principle of chemiluminescence. Chemiluminescence is the chemical reaction that produces light. The primary NOx analyzer was a Horiba Model CLA-720MA, and a Horiba Model CLA-720A, which acted as a QA/QC device. First, the sample gas is passed through a $\mathrm{NO}_{2}$ to $\mathrm{NO}$ converter to convert all $\mathrm{NO}_{2}$ to $\mathrm{NO}$. The $\mathrm{NO}$ 
is then mixed with ozone $\left(\mathrm{O}_{3}\right)$ in which the $\mathrm{NO}$ is oxidized to $\mathrm{NO}_{2}$, a small portion of the $\mathrm{NO}_{2}$ formed is in an excited state. In order to reach a stable, non-excited state the excited $\mathrm{NO}_{2}$ released a photon in the form of light. The released photons were then detected by a photon detector; the number of detected photons is directly proportional to the number of NO molecules in the exhaust sample. The total level of NOx in the exhaust gas was detected by the device that responded proportionally to the NO in the sample and the $\mathrm{NO}$ formed from $\mathrm{NO}_{2}$ dissociation [23]. Both analyzers have linearity within $\pm 1 \%$ of full scale and repeatability within $\pm 0.5 \%$ of full scale.

\subsubsection{Carbon Monoxide and Carbon Dioxide Analyzers}

A Horiba AIA-721A and a Horiba AIA-722 were used to measure $\mathrm{CO}$ and $\mathrm{CO}_{2}$ emissions, respectively. Both analyzers used the non-dispersive infrared (NDIR) principle to detect $\mathrm{CO}$ and $\mathrm{CO}_{2}$ concentrations. NDIR is based on the ability of certain gases' to absorb infrared radiation. The absorbed energy is measured and used to determine the concentration of specific gases in the gaseous sample. Prior to being sent to the analyzer the sample must be sent through a chiller unit for water to be condensed out because NDIR is sensitive to water vapor.

\subsection{Intake Air}

Intake air flow was measure using a laminar flow element (LFE), manufactured by Meriam Instruments (Model No. 50MC2-6), and conditioned to meet CFR 40 Part 1065.125 specifications [32]. The intake air was taken from outside and passed through an air handling unit where it was cooled to remove moisture, if necessary. It was then passed through a HEPA filter to remove any particulate matter from the ambient air. The HEPA filter also helped to ensure test repeatability. The air was then heated and humidified in a heat exchanger to fall within the 20 to $30^{\circ} \mathrm{C}$ range.

The differential pressure across the LFE was measured using an Omege differential pressure transducer. An absolute pressure transducer was used to correct back to standard conditions. Inlet temperature to the LFE was measured using a resistance temperature device. The actual volumetric flow rate was calculated using the inlet temperature and the differential pressure. A GE sensor hygrometer, with a sample line located in the intake pipe after the LFE, was used to measure intake air humidity via dew point temperature. This sensor was used to reduce laboratory data for the NOx correction factor. A second hygrometer, an EdgeTech DewPrime II, was used to calibrate the GE hygrometer and as a QA/QC device to verify intake air temperature and humidity. 


\subsection{Bag Sampling System}

For emissions analysis, the concentration of $\mathrm{CO}, \mathrm{CO}_{2}, \mathrm{NOx}$, and $\mathrm{THC}$ in the dilution air needs to be known. This was completed with the use of the exhaust gas analyzers previously mentioned and two 80-liter Tedlar bags. A background bag sample was taken throughout the test cycle upstream of the dilution tunnel before exhaust gases were mixed with the dilution air. A second sample, the dilute bag sample was taken downstream of the exhaust gas and dilution air mixing. Contents of each bag were analyzed separately and the values recorded. After each test cycle and analysis period each bag was completely evacuated in preparation for the next test. To account for gas concentrations in the ambient air the background bag values were subtracted from the continuous sample or dilute bag values.

\subsection{Fuel Measurement}

Three methods were used at the WVU CAFEE to measure and calculate the amount of fuel consumed during testing. The first method was a carbon balance method in which the amount of carbon measured in the diluted exhaust was proportional to the amount of combusted fuel. To determine the amount of fuel consumed with this method the following parameters needed to be known: specific gravity of the test fuel, the hydrogen-to-carbon $(\mathrm{H} / \mathrm{C})$ ratio and oxygen-to-carbon ratio of the test fuel, and the mass of $\mathrm{HC}, \mathrm{CO}$, and $\mathrm{CO}_{2}[23]$.

The second method used a fuel metering system to measure the fuel flow into the engine. The fuel metering unit was a Max Machinery Model 710 fuel conditioning system. The measurement system consisted of a fuel tank, fuel meter, fuel pump, supply and return lines, and a heat exchanger. The heat exchange allowed the fuel to be maintained at near-constant temperature before it entered the engine. The output signal from the fuel metering system was recorded as counts, which was used to calculate the mass flow rate of fuel into the engine.

The last method was a gravimetric method which used a fuel scale that measured the mass of the test fuel in a 16-gallon fuel barrel. The fuel weight was measured prior to the start and at the end of the test cycle and continuously throughout the cycle to determine overall and modal fuel consumption.

\subsection{Data Acquisition}

Laboratory measurements were recorded with a computer-controlled National Instruments SCXI 1001 data acquisition (DAQ) system, shown in Figure 3-6. Output signals, usually voltages, from measurement devices such as thermocouples or transducers are proportional to some physical measurement. Some devices transmit a current that was proportional to a physical measurement, since the DAQ records voltage these signals must be converted to a voltage. The DAQ system takes the 
voltages provided by the measurement devices and converts them in to a physical measurement in engineering units through calibration files. If an error was found in the calibration, data was able to be rereduced. Signal conditioning, such as a low pass filter was used to account for variations.

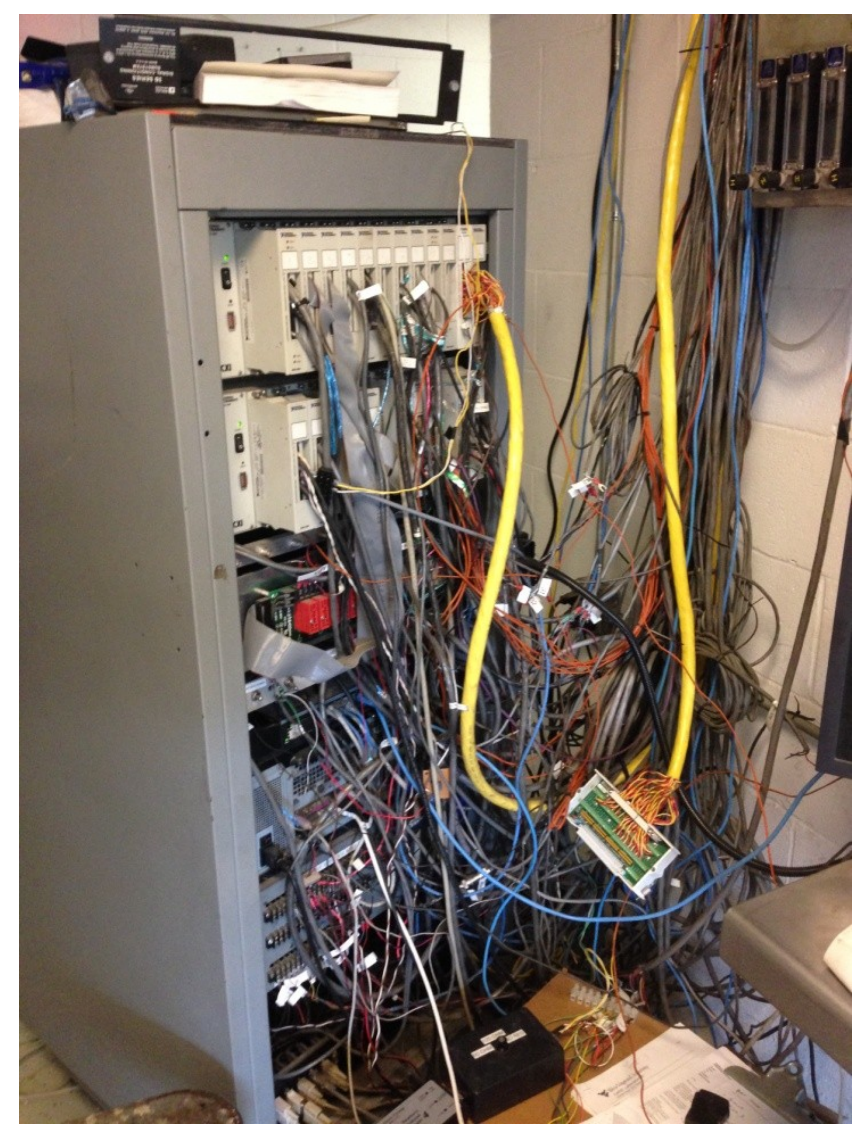

Figure 3-6: WVU CAFEE Data Acquisition System

\subsection{Testing Procedures and Preparation}

All laboratory system checks and equipment operations were carried out with respect to specifications set by Title 40 Part 1065 of the CFR. Several calibrations and system checks were done prior to testing to ensure repeatability and accurate results. These checks include: analyzer calibrations, propane injections, and dynamometer calibrations amongst others.

\subsubsection{Engine Preparation}

For this study, no hardware changes were made to the test engine that would affect its performance. However, the 1992 Rebuilt DDC S60 had been instrumented with in-cylinder pressure hardware for a previous study by Nuszkowski [18]. The hardware, combustion analysis code, and software described by Nuszkowski were also used in this study to examine the combustion characteristics of the various test fuels. Prior to testing, engine oil and filters, engine coolant and filters, and fuel filters 
were replaced to ensure optimal engine performance. Preliminary tests were done with available diesel fuel to condition the engine oil and to ensure the engine and laboratory systems were operating properly. Engine oil and coolant temperatures and levels were monitored throughout the test procedure to ensure proper operating levels were maintained.

\subsubsection{Exhaust Pipe}

The exhaust system used consisted of a 5 inch diameter steel pipe. Specifications for this system were in accordance with CFR 40 Part 1065.130 [32]. The steel pipe was insulated with 1 inch layer of fiber glass insulation to prevent heat loss in the exhaust gas. A butterfly valve was fitted into the pipe to simulate the appropriate exhaust backpressure on the engine. All connections were either taped with exhaust tape and clamped or welded in order to prevent leaks.

\subsubsection{Dynamometer Load Cell Calibration}

Prior to testing the dynamometer load torque cell was calibrate in accordance with CFR 40 Part 1065.310 [32]. This procedure involved hanging a series of calibration weight in $50 \mathrm{lb}$ increments from the calibration arm. The load cell response was recorded at ten points and a curve fit created to relate the response to the torque.

\subsubsection{Propane Injections}

In accordance with CFR 40 Part 1065.341 [32], propane injections were done to ensure the accuracy of the dilution tunnel and to detect any leaks or losses in the system. Propane was injected into the dilution tunnel at a known rate via a propane injection kit. Only the injected propane and dilution air were flowing through the tunnel during propane injections. The propane concentration in the tunnel was measured by the $\mathrm{HC}$ analyzer. The propane recovered during injections had to fall within $\pm 2 \%$ of the amount of propane injected in order for the test to pass. Tests were conducted until three consecutive tests were within $\pm 0.5 \%$ of each other, all of which must have been within the $\pm 2 \%$ range of the amount of propane injected, this criteria is a WVU CAFEE requirement.

\subsubsection{Exhaust Gas Analyzer Calibration}

Each exhaust gas analyzer was calibrated in accordance with Title 40 Part 1065 of the CFR. Each calibration gas bottle concentration and pressure was noted. Analyzer calibrations were performed prior to the start of testing; each calibration consisted of a 10-point non-zero calibration curve. Calibration gases were chosen based on the specific emissions output of the specific test engine. 


\subsubsection{Hydrocarbon Analyzer Calibration}

Hydrocarbon analyzer calibration was conducted in accordance with CFR 40 Part 1065.360 and Part 1065.365 [32]. The CFR requires that a calibration curve be conducted using a minimum of 6 points. WVU CAFEE uses 10 points for calibration. Propane was used as the test gas with zero air as the reference gas. Test points were evaluated starting at 100\% propane and decreasing the propane concentration by $10 \%$ in between each calibration point. Prior to each calibration, the zero and span (100\% propane) was checked to ensure its value for calibration. The calibration gas was then varied from $90 \%$ to $0 \%$ using a Horiba gas divider. The DAQ system recorded the ADC value for each point and plotted these points against the set point. A line of best-fit was created to evaluate the accuracy of each point. The best-fit line needed to be within $\pm 2 \%$ of the value at each non-zero point and within $\pm 0.3 \%$ of full scale on the zero point [32]. An $\mathrm{R}^{2}$ value of $1 \pm 0.0001$ or better was required to ensure the response from the analyzer was linear [32].

\subsubsection{Oxides of Nitrogen Analyzer Calibration}

The oxides of nitrogen analyzer was calibrated in a similar fashion as the hydrocarbon analyzer explained above. CFR 40 Part 1065.370 [32] requires a minimum of 9 calibration points; again 10 points were used at WVU CAFEE. As with the $\mathrm{HC}$ analyzer a specific $\mathrm{R}^{2}$ was required to ensure the linearity of the analyzer. Since the NOx analyzer relied on $\mathrm{NO}_{2}$ to $\mathrm{NO}$ conversion for the chemiluminescent detector to properly measure the amount of NOx in the exhaust sample, a monthly converter efficiency test was done to verify proper converter operation. In order to verify proper converter operation, the $\mathrm{NO}_{2}$ to $\mathrm{NO}$ converter must allow for measuring at least $95 \%$ of the total $\mathrm{NO}_{2}$ at the maximum expected concentration of $\mathrm{NO}_{2}[32]$.

\subsubsection{Carbon Monoxide and Carbon Dioxide Analyzer Calibration}

Unlike the $\mathrm{NOx}$ and $\mathrm{HC}$ analyzers, the $\mathrm{CO}$ and $\mathrm{CO}_{2}$ analyzers had a non-linear curve-fit. As with the $\mathrm{HC}$ and NOx analyzer a 10 point calibration curve was used for the $\mathrm{CO}$ and $\mathrm{CO}_{2}$ analyzers. However, in this case the $\mathrm{R}^{2}$ value was used to ensure the higher order polynomial was within the error limits of each non-zero point. Along with calibration, the $\mathrm{CO}$ analyzer had to be checked to ensure no water or $\mathrm{CO}_{2}$ interference as per CFR 40 Part 1065.355 [32]. Likewise, the $\mathrm{CO}_{2}$ analyzer had to be checked to verify no water interference with the analyzer as per CFR 40 Part 1065.350 [32]. This ensured the functionality of the chiller unit and the analyzers.

\subsubsection{Particulate Matter and Filter Weighing}

Prior to testing, PM filters were pre-conditioned in a clean room as specified in CFR 40 Part 1065.190 [32]. Filters were stored in glass Petri dishes to avoid possible contamination of ambient 
particles. After the pre-conditioning period and filters were in equilibrium with the clean room environment, three reference filters were created. These reference filters were used throughout the testing process to measure the amount of variation in the repeated weighing of these three filters for the entire test period. Prior to use in an engine test cycle, filters were pre-weighed and associated to the respective reference filters. After a test cycle, the filters were brought back into the clean room for postconditioning. After this conditioning the filters were post-weighed. Filters were pre- and post-weighed using a Sartorius SE 2-F balance meeting specification of CFR 40 Part 1065.290 [32]. The difference in mass between pre- and post-weights are a portion of what determines how much PM was created during a test. The other portion is determined by the amount of PM in the dilution air. This is determined by taking a background filter during a 20 minute test without the engine running. The background PM weight could then be subtracted from all test filter weights; however, in this case background PM was not included in the determination of PM emission for this work. Balance verifications and weighing process verifications were carried out in accordance with CFR 40 Part 1065.390 [32]. During this study one PM filter was used for each of the 15 test modes. For the transient step test cycle a single filter was used for the entire test cycle.

\subsection{In-Cylinder Pressure Analysis System}

In-cylinder pressure data was recorded using a piezoelectric type pressure transducer. The pressure transducer measures dynamic pressure within the cylinder. The pressure transducer was connected to a charge amplifier to amplify the piezoelectric voltage so that the pressure signal can be read by the DAQ system. The 1992 DDC test engine utilized a Kistler quartz transducer model 6125B, shown in Figure 3-7. A low-pass filter was applied to the measured in-cylinder pressure to minimize fluctuations caused by the pressure wave. The low-pass filter had a cut-off frequency of $2500 \mathrm{~Hz}$ to reduce high frequency combustion noise. The low-pass filter is of averaging type, which may cause a reduction in the premix pressure spike. Since this averaging was applied to all data equally, the relative difference between fuels should not be significantly impacted [18]. 


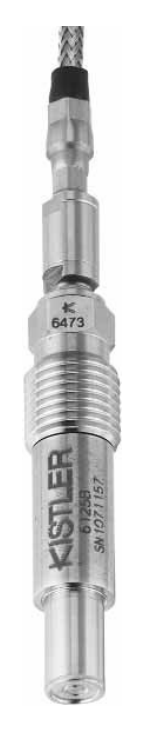

Figure 3-7: Kistler 6125B In-Cylinder Pressure Transducer [18]

To acquire the in-cylinder pressure data, DAQ software developed by Nuszkowski [18] was used. The software allows real-time processing of the acquired pressure data into the heat release and derived combustion characteristics data. Calculated combustion characteristics can then be determined and recorded. The combustion analysis system used a stand-alone computer from the rest of the laboratory system due to computational requirements.

Although the in-cylinder combustion DAQ software provided some real-time measured and calculated parameters; the acquired pressure data was sent to Dr. Nuszkowski at the University of North Florida to reanalyze the data. The data was reanalyzed using a Matlab program written by Nuszkowski [18]. Parameters were directly calculated using the in-cylinder pressure. Engine speed was used to align the measured and calculated parameters during a test to the laboratory data.

\subsubsection{In-Cylinder Pressure}

The maximum in-cylinder pressure and its location were calculated from the direct measurement of the in-cylinder pressure. The maximum pressure provides an indication of engine load. Typically, higher pressure indicates higher engine loads.

Since the pressure transducer measured dynamics pressure, a reference pressure was needed to determine an absolute pressure. The method used for this study was a constant polytropic constant [18]. This method was recommended by Brunt et al. [33] for combustion studies because it is more accurate than measuring the manifold air pressure (MAP). The corrected pressure was averaged from the calculated pressures over a 60 crank angle degree window during the compression stroke between 120 
and 60 degrees BTDC [18]. The MAP was obtained from the in-cylinder pressure data at the location of intake valve closing.

\subsubsection{Heat Release}

Heat release rate data was processed directly from the measured in-cylinder pressure data in realtime. Calculated heat release parameters include: maximum heat release rate, location of maximum heat release rate, net heat released during combustion period, gross heat released during combustion period, heat released during premix combustion, and heat released during diffusion combustion. The net and gross heat released is the summation of the heat released during each crank angle resolution from the start of combustion to the end of combustion.

\subsubsection{Needle Lift}

The test engine was instrumented with a needle lift sensor inside a single injector. The sensor was a Hall Effect sensor, which provided a voltage signal proportional to the height of the fuel injection needle at a response frequency of $25 \mathrm{kHz}$. Similar to the pressure transducer, the instrumented injector was installed into cylinder no. 3. The needle lift sensor provided data indicating the start and end of fuel injection. This was important to examine any injection and resulting ignition differences between the test fuels.

\subsubsection{Start of Combustion}

The start of combustion (SOC) is defined as the first measureable quantity of combustion in the cylinder. Some researchers have used the point at which the pressure deviates from the motoring curve or the point at which $5 \%$ of the total energy has been released. In this study the location of $5 \%$ mass fraction burned was defined as the SOC. When comparing several fuels on the same engine at the same set points, the start of combustion is an indication of ignition delay.

\subsubsection{Ignition Delay}

Ignition delay is defined as the crank angle or time period from the start of fuel injection to the start of combustion. Ignition delay provides an indication of the combustibility of the fuel injected and the mixing of the air and fuel. A long ignition delay indicates a low cetane fuel or the need for higher pressures and temperatures within the cylinder for combustion. High cetane fuels have shorted ignition delay and therefore more fuel is burned during the diffusion burn. A shorter ignition delay can indicate longer combustion duration and therefore a lower maximum temperature, potentially resulting in lower NOx emissions. 


\subsubsection{Estimated End of Combustion}

Combustion duration is the crank angle or time period from the start of combustion to the end of combustion (EOC). Combustion duration can be longer when a greater amount of fuel is injected. Long combustion duration can indicate that too much fuel has been injected, which can cause incomplete combustion. In this study the EOC was estimated from the location of the maximum heat released over ten crank angle degrees and adding twenty degrees [18]. The heat released after the EOC should remain the same for tens of degrees, therefore over estimation of the EOC should be a better assumption than under estimation [18]. This is especially important when the mass fraction burned is of concern.

\subsubsection{Mass Fraction Burned}

The mass fraction burned (MFB) is the ratio of the fuel mass burned at a given crank angle, usually measured as a percentage of the total mass of the injected fuel. Values of interest in this study were the locations of 5, 10,50,90, and 95\% MFB, as well as the MFB below $950 \mathrm{~K}$. Calculating the location of various levels of MFB provides insight to the phasing of the combustion process. The duration, in crank angle degrees, of SOC to $10 \%$ or $50 \%$ MFB indicates the strength of the premix combustion; the duration from $50 \%$ to $90 \%$ or $95 \%$ indicates the intensity of the diffusion burn [18]. In this study the mass fraction burned was calculated by normalizing the gross heat release at each crank angle to the total heat released.

$$
m f b_{\theta}=\frac{\sum_{i=s o c}^{\theta} d Q_{i, g r o s s}}{Q_{\text {gross }}} \quad \text { Equation 3-2 }
$$

\subsubsection{Indicated and Brake Mean Effective Pressure}

Indicated mean effective pressure (IMEP) is the cylinder work normalized by the cylinder displacement volume. It can also be thought of as the average in-cylinder pressure over the engine cycle. IMPE is the work delivered to the piston over the compression and expansion stroke, per cycle per unit displace volume [17]. IMEP is a useful combustion parameter because it allows for the comparison of an engines ability to do work regardless of engine size. In this study brake mean effective pressure (BMEP) was also used for comparison purposes.

\subsubsection{In-Cylinder Gas Temperature}

The mean bulk gas temperature in the cylinder was calculated at each crank angle by making the ideal gas assumption with a known reference location and temperature [18]. This allowed for the estimation of the maximum in-cylinder pressure and its location along with the average temperature over the cycle. The temperature at the start of combustion, the intake gas temperature, and the exhaust gas temperature were also recorded. The in-cylinder temperature is important because pollutant formation, 
especially NOx, is strongly temperature dependant. Typically, NOx emissions increase with higher incylinder gas temperatures.

\subsubsection{Air-to-Fuel Ratio}

The air-to-fuel ratio (AFR) strongly influences combustion conditions and emission characteristics. The AFR was calculated based on the intake air and the fuel flow. The AFR can be reported on a mass and/or molar basis, in this study the mass AFR was calculated. AFR varies based on engine load but typically diesel engines operate on an AFR lower than the stoichiometric AFR. Common values for the AFR of a diesel engine usually fall within the 18 to 70 range [17].

\subsubsection{Thermal Efficiency}

Calculating the thermal efficiency indicated how much power was converted from the energy in the fuel for each combustion event. This provides insight to whether differing properties of the various test fuels changed the efficiency of combustion. The energy conversion efficiency was calculated based on the lower heating value of the test fuel and the fuel flow and power from the in-cylinder combustion parameters.

$$
\eta_{\text {eff }}=\frac{\text { Power }}{\dot{m}_{\text {fuel }} \text { LLHV }^{-}} \quad \text { Equation 3-3 }
$$




\section{Chapter 4: Experimental Configuration}

\subsection{Introduction}

In the following sections the test cycles, test matrix, and test preparations are discussed in detail. Two test cycles were conducted: a 15 mode steady state test, for all fuels, and a transient idle to full power step tests for the JP-5-based fuels only. Set points of the test cycles were based on engine maps of the reference fuels (JP-5 and F-76) and care should be taken when examining the data to ensure the appropriate reference set point file is used. The test matrix followed a daily schedule throughout the program. Test preparations included: software start-up, fuel purging, engine warming, in-cylinder pressure data acquisition encoder verification, and PM filter preparation.

\subsection{Test Cycles}

Test cycles were computer controlled using engine speed and engine load (torque) as input values. For each fuel the engine was operated at set points to bring the coolant and oil to operating conditions. The engine was then mapped at least twice; once as a warm map and again as a hot map. For all fuels a 15 mode steady state test, illustrated in Figure 4-1, was conducted. It should be noted that Figure 4-1 shows the set points for the JP-5 fuels only, the engine map for F-76 fuels followed the same general map but set point values were slightly different due to the differences in fuel properties. The 15 steady state mode points consist of the 13 mode points of the heavy duty supplemental emissions test (SET) and two additional low speed modes at $900 \mathrm{rpm}$ and 25\% and 50\% load. The 15 modes were ordered by ascending power to minimize stabilization time from mode to mode and overall test cycle time. It is important to note that the SET mode order is not important for this work since emissions are not a primary concern. The SET modes were used in this work because they provide known operating conditions in the engine and emissions research community and they provide a wide range of speed-load

points for the effect of fuel properties on combustion to be examined. Each steady state mode had 300, or more, cycles averaged together; therefore, mode length was adjusted to allow ample time for enough cycles to occur. Mode length was also affected by the time needed for gaseous exhaust and PM sampling. A transient step test between idle and rated power was also conducted for fuels being compared to JP-5. The transient test is shown inFigure 4-2. During the transient test, the engine operated at each mode for 30 seconds and cycled between the idle and full power modes 10 times. This test was selected based on sponsor input. 


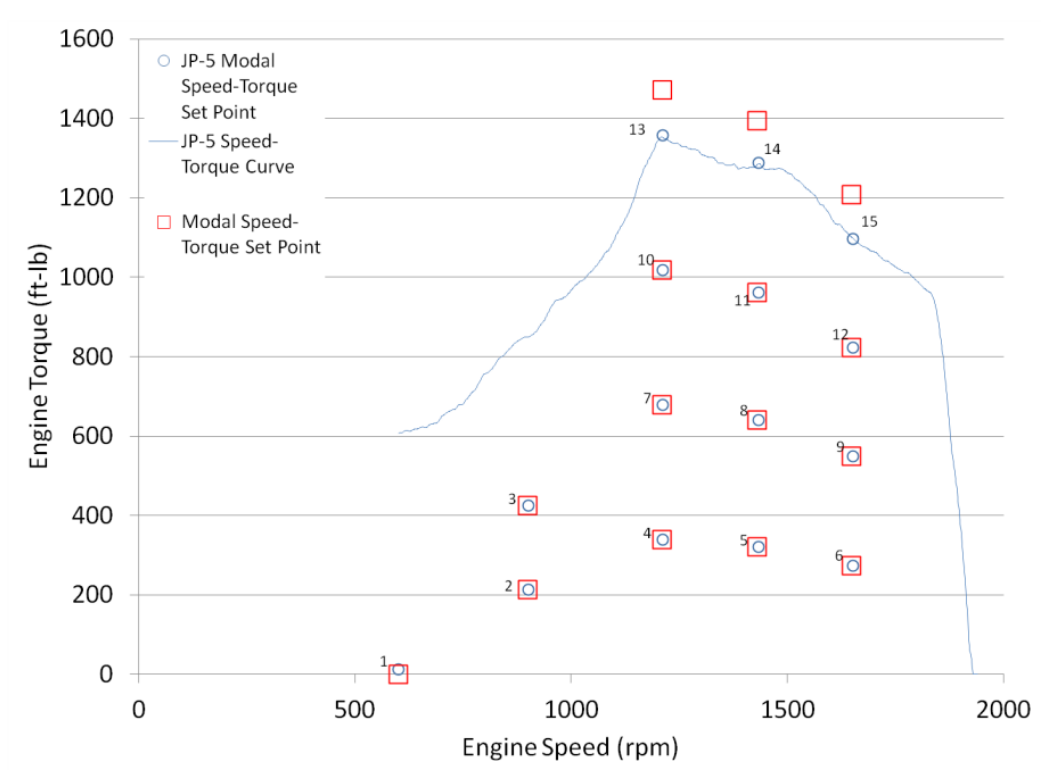

Figure 4-1: Steady State Test Cycle (JP-5 Fuels) with Mode Order

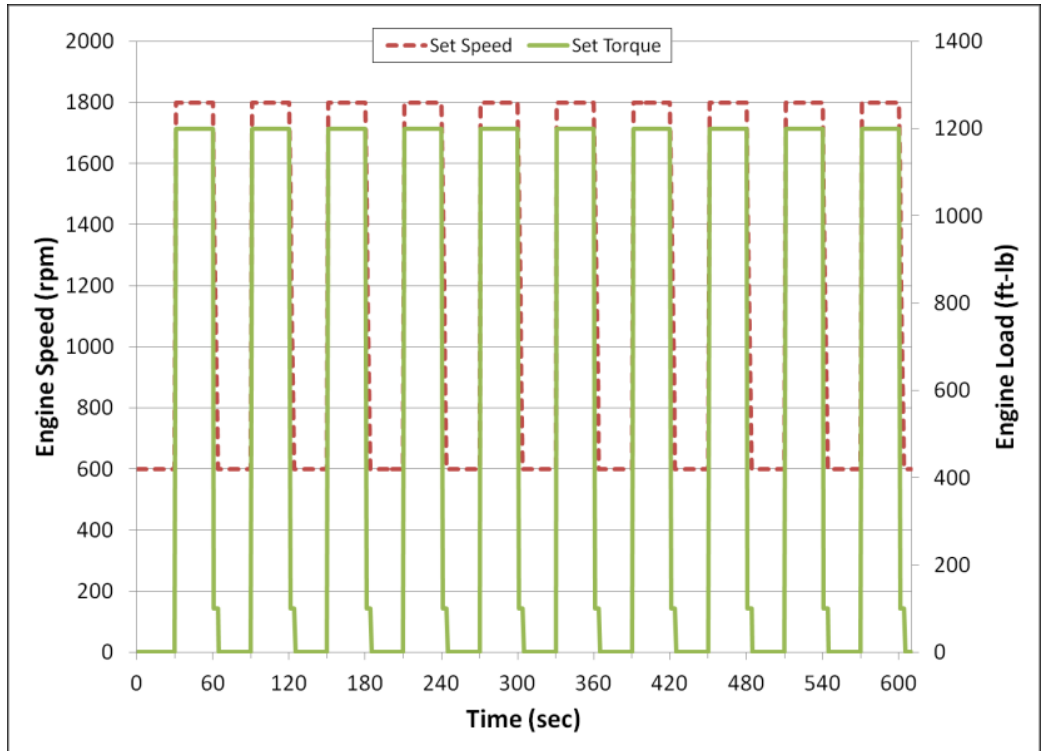

Figure 4-2: Transient Test Cycle (JP-5 Fuels only)

\subsection{Test Matrix}

The investigated fuels are shown in Table 3-1. The 1992 DDC engine was evaluated with these fuels to identify any adverse combustion effects as well as quantify emissions of the alternative Navy fuels. A seven-day test schedule was utilized; however, additional days were required for troubleshooting and retests. The daily test schedule, shown in Table 4-1, consisted of multiple steady state tests for each fuel. During the laboratory startup and preparation the engine was warmed with the reference fuel (JP-5 or F-76), the engine was mapped before testing. If necessary, the fuel system was purged prior to 
warming the engine. After a fuel switch, the fuel was purged to remove any residual fuel left from previous tests to ensure only the desired fuel under test was being evaluated. It is important to note that transient idle to rated power tests were conducted for JP-5-based fuels only.

Table 4-1: Navy Fuels Daily Test Schedule

\begin{tabular}{|r|l|l|}
\hline \multicolumn{1}{|c|}{ Time Description } & \multicolumn{1}{c|}{ Fuel } \\
\hline 7:00 & Fuel Purge, Lab Startup, Preparation, Engine Warmup & Reference Fuel (JP-5 or F-76) \\
\hline $8: 00$ & Engine Map (Warm and Hot) & Reference Fuel (JP-5 or F-76) \\
\hline $8: 20$ & Idle-Full Power Transient Test (JP-5 Fuels Only) & Reference Fuel (JP-5 Fuels Only) \\
\hline $8: 50$ & Steady State Test & Reference Fuel (JP-5 or F-76) \\
\hline 9:50 & Steady State Test & Reference Fuel (JP-5 or F-76) \\
\hline $10: 50$ & Fuel Switch and Engine Warmup & Candidate Navy Fuel \\
\hline 11:50 & Engine Map (Warm and Hot) & Candidate Navy Fuel \\
\hline 12:10 & Idle-Full Power Transient Test (JP-5 Fuels Only) & Candidate Navy Fuel (JP-5 Fuels Only) \\
\hline 12:40 & Steady State Test & Candidate Navy Fuel \\
\hline $13: 40$ & Steady State Test & Candidate Navy Fuel \\
\hline $14: 40$ & Steady State Test & Candidate Navy Fuel \\
\hline 15:40 & Fuel Switch and Engine Warmup & Reference Fuel (JP-5 or F-76) \\
\hline 16:10 & Steady State Test & Reference Fuel (JP-5 or F-76) \\
\hline 17:10 & Engine Cooldown and Lab Shutdown & Reference Fuel (JP-5 or F-76) \\
\hline
\end{tabular}

\subsection{Test Preparation and Start-up}

Prior to starting a test cycle several laboratory and DAQ systems needed to be prepared to accurately measure engine performance. This included creating appropriate file names for: ECU, incylinder pressure, and laboratory DAQ data. The ECU logger and in-cylinder pressure software operated on separate computers from the laboratory DAQ software. ECU data was continuously recorded for every test cycle and had to be started and stopped manually at the beginning and end of the test cycle. Note that the ECU data was not used nor analyzed in this work. In-cylinder pressure data was also recorded for every test cycle; however, the data for transient and steady state tests were recorded differently. In-cylinder pressure data was recorded continuously as a single mode for transient tests and was started manually at the beginning of the test cycle. Pressure data for steady state tests was recorded so that each individual mode would have its own data set. This was done by setting the number of modes to match that of the test cycle and applying a stop trigger at the end of each mode. This allowed for automatic recording of unique data sets for each mode based on a digital signal sent from the laboratory DAQ.

When fuel changes were required, the fuel was purged to remove any residual fuel left in the engine and fuel lines to ensure only the desired candidate fuel was being tested. This was done by 
running the fuel pump with a bypass in the fuel line before the engine and emptying the fuel into a collection bucket. Also the fuel return line was removed from the fuel barrel drained into a collection bucket to remove the rest of the fuel. The engine and fuel lines held approximately one gallon of fuel; two to three gallons of the fuel was purged to ensure complete fuel purge of the previous fuel. Once the fuel system was purged, the engine was warmed for several minutes with the new fuel to bring the engine oil and coolant to operation levels. The engine was then mapped at least twice prior to the start of the first test cycle. This process is outlined in Table 4-1.

Other laboratory start-up and preparations included turning on and warming the MEXA gas analyzer unit, ensuring all laboratory water and fuel pumps and the dynamometer skid had power, incylinder crank shaft encoder was referenced to top dead center, and preparing PM filters for each test. During steady state testing PM filters were changed during the stabilization period between each mode while the transient test only utilized one filter for this test. 


\section{Chapter 5: Results and Discussion}

\subsection{Introduction}

The following sections will provide test data for all relative tests and fuels. The global objective of this research was to explore the use of hydrotreated fuels in the U.S. Navy fleet. The overall objective of this study was to identify any negative combustion characteristics of the alternative candidate biofuels through in-cylinder pressure analysis. Additionally, the engine performance and fuel consumption as well as the regulated gaseous and particulate matter emissions were evaluated to provide additional assessment information. The combustion and emission results consisted of modal steady state tests for all fuels and transient tests for JP-5 fuels. Using the in-cylinder pressure data, several combustion characteristics were calculated to aid the understanding of the performance of each fuel. The data presentation has been divided between the two fuel sets (JP-5 and F-76) and between the combustion and emission data. Modes 5 and 12 have been chosen to be discussed in detail because they provide insight to operational conditions at both low and high power engine operation. Mode 5 operated at $25 \%$ engine load and $1430 \mathrm{rpm}$, for JP5, and $1416 \mathrm{rpm}$, for F-76, engine speeds and mode 12 operated at 75\% engine load and $1649 \mathrm{rpm}$, for JP5, and 1644 rpm, for F-76, engine speeds.

\subsection{JP-5 Fuels}

Two alternative candidate biofuels (50/50 JP5/HRJ5 and Neat HRJ5) were examined and compared to the reference fuel (JP-5). The engine was mapped to yield a full power torque curve on the reference fuel. This baseline torque curve was used throughout the test program for the JP-5 fuels only. The test program consisted of a 15 mode steady state test and an idle to rated power transient step test. Figure 5-1 shows the engine map for each fuel along with the set points for each mode. It is noted that the three full load set points were increased by $100 \mathrm{ft}-1 \mathrm{~b}$ to ensure that full power was reached for each fuel. Note that there were small run-to-run differences for modes 1 through 12 due to normal run-to-run and day-to-day variations but there were larger differences in maximum torque values due to differences in fuel properties. The data is presented below as heat release rate, in-cylinder pressure and temperature curves for both mode 5 and 12. Data are presented as a function of BMEP, in ascending order, to illustrate performance differences at other modes. Table 5-1 shows the relationship of BMEP to mode number and test cycle set points.

Table 5-1: Relationship between BMEP and modal set points for JP-5 steady state test cycle

\begin{tabular}{|c|c|c|c|c|c|c|c|c|c|c|c|c|c|c|c|}
\hline BMEP (bar) & 0.17 & 2.86 & 3.68 & 4.31 & 4.54 & 5.73 & 7.37 & 8.60 & 9.09 & 11.04 & 12.91 & 13.64 & 14.37 & 16.88 & 17.81 \\
\hline Mode (-) & 1 & 2 & 6 & 5 & 4 & 3 & 9 & 8 & 7 & 12 & 11 & 10 & 15 & 14 & 13 \\
\hline Set Speed (rpm) & 601 & 900 & 1649 & 1430 & 1210 & 900 & 1649 & 1430 & 1210 & 1649 & 1430 & 1210 & 1649 & 1430 & 1210 \\
\hline Set Torque (ft-lb) & 0 & 213 & 274 & 321 & 339 & 426 & 549 & 641 & 678 & 823 & 962 & 1018 & 1208 & 1395 & 1471 \\
\hline
\end{tabular}




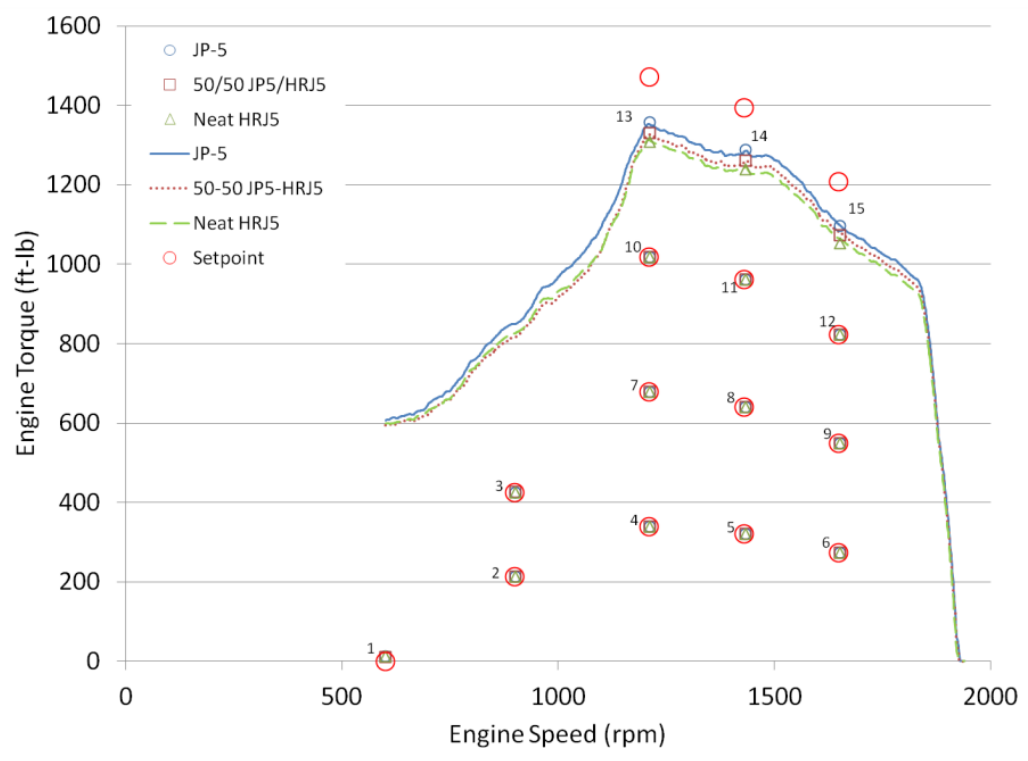

Figure 5-1: Engine Map and Set Points for JP-5 Test Fuels

\subsubsection{In-Cylinder Combustion Parameters}

Several in-cylinder combustion parameters were recorded and calculated through the in-cylinder pressure analysis. The following sections will present the data for: heat release and heat release rate, incylinder pressure and temperature, fuel injection, ignition delay, and combustion phasing for each JP-5 test fuel. The values for a given parameter were obtained by averaging the values for each mode from each repeat test for each fuel. The candidate biofuels were compared to the reference fuel (JP-5) using a percent difference and/or an absolute difference. A percent difference was used for non-crank angle parameters; a negative percent difference indicated a reduction in a particular parameter and a positive percent difference showed an increase. Absolute difference was used for values related to crank angle location, such as injection timing, combustion phasing, locations of maximum values, etc. A positive difference showed retardation and a negative difference showed advancement in location compared to JP5. An absolute difference was used for crank angle-related parameters since many of these values were at or near zero and may lead to large percent differences that would not be indicative of the relative differences. The effects of fuel density, cetane number, and aromatic content of the test fuels on the discussed combustion parameters were also examined, and are reported in the following sections. Each parameter for each mode were comparedagainst fuel density, cetane number, and aromatic content; a linear curve fit was applied to determine the $\mathrm{m}$ (slope), $\mathrm{b}$ (y-intercept), and $\mathrm{R}^{2}$ values. A negative slope indicates a decrease in a given parameter as the respective fuel property increases and a positive slope indicates an increase. 


\subsubsection{Heat Release and Heat Release Rate}

The experimental heat release parameters were calculated and/or measured for each combustion cycle during steady state and transient testing. An investigation into parameters, such as net heat released, maximum heat release rate and its location, as well as heat released during premix and diffusion helped to understand the performance changes between fuels. Figure 5-2 and Figure 5-3 illustrate the heat release rate (HRR) for mode 5 and 12, respectively. At both modes the maximum HRR was significantly lower for both candidate biofuels. A shorter ignition delay was also noticed; ignition delay is indicated by the negative value in the HRR curve. The other test modes show a similar reduction in maximum HRR as shown in Figure 5-4. The variation bars in Figure 5-4 represent one standard deviation of the repeat data for each test fuel. Over the entire test cycle the maximum HRR for 50/50 JP5/HRJ5 was $\sim 3$ to $25 \%$ lower than that of JP-5 and $\sim 3$ to $43 \%$ lower for Neat HRJ5. At most modes the maximum HRR occurred during the premix spike; however, as power and engine load increased the maximum HRR shifted to the diffusion fraction, this can be seen in Figure 5-3 for Neat HRJ5. The effects of fuel density, cetane number, and aromatic content on maximum heat release rate are presented in Table 8-1. A graphical example of the regression is illustrated in Figure 5-5, which shows that as cetane number increases maximum HRR decreases. Table 8-1 indicates that reductions in maximum HRR can also be attributed to lower fuel density and aromatic content.

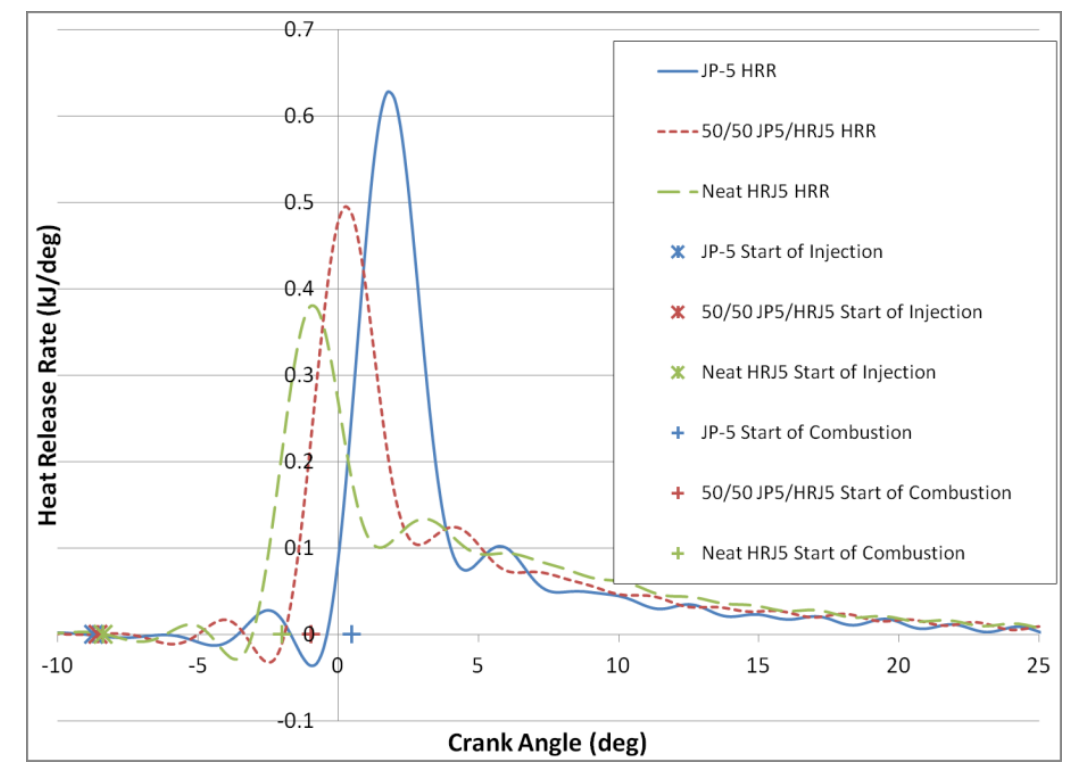

Figure 5-2: Heat Release Rate Curve at Mode 5 (25\% Engine Load and $1430 \mathrm{rpm}$ ) for JP-5 Test Fuels 


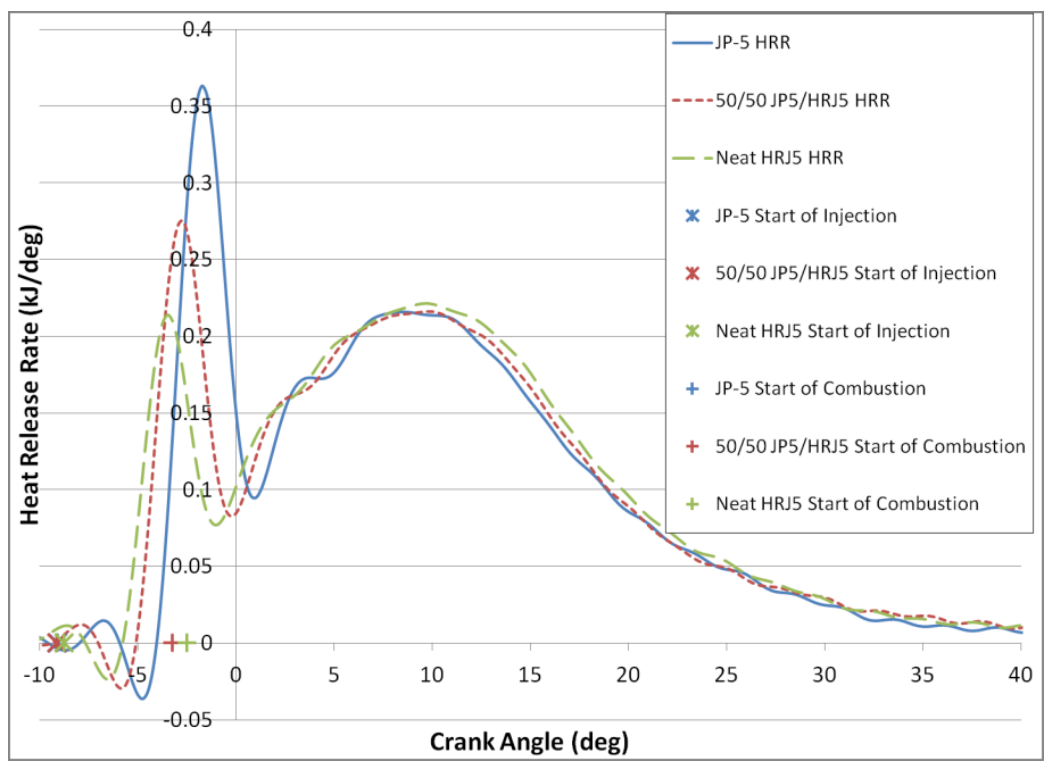

Figure 5-3: Heat Release Rate Curve at Mode 12 (75\% Engine Load and 1649 rpm) for JP-5 Test Fuels

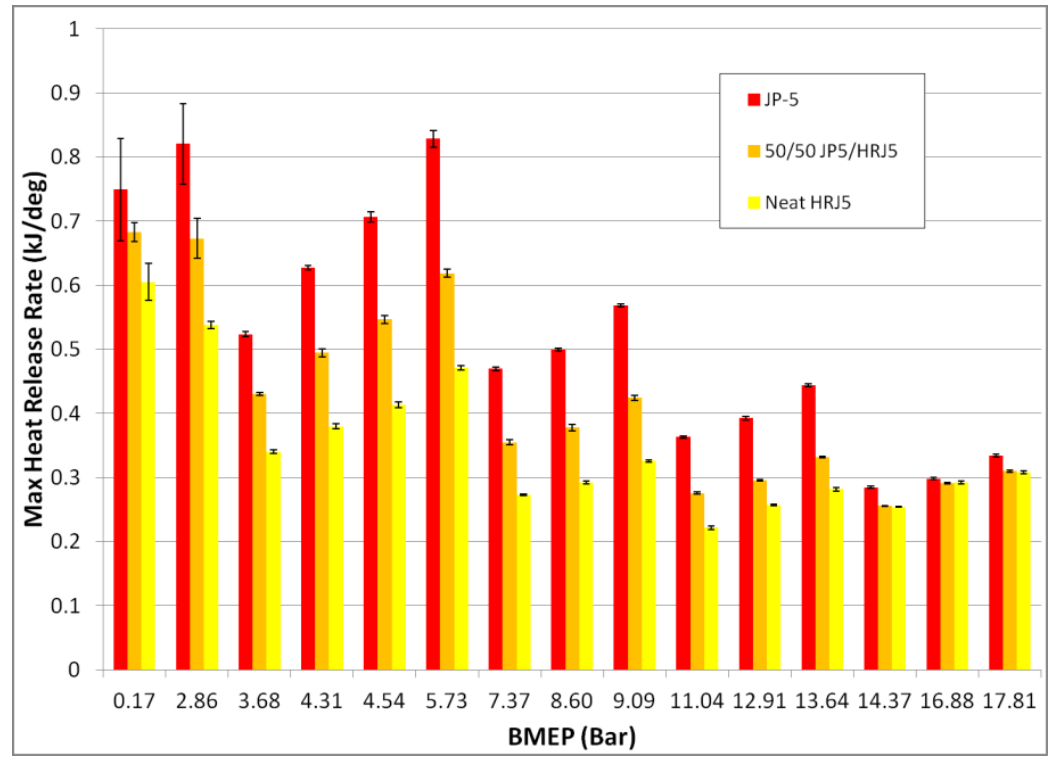

Figure 5-4: Maximum Heat Release Rate at all Test Modes for JP-5 Test Fuels 


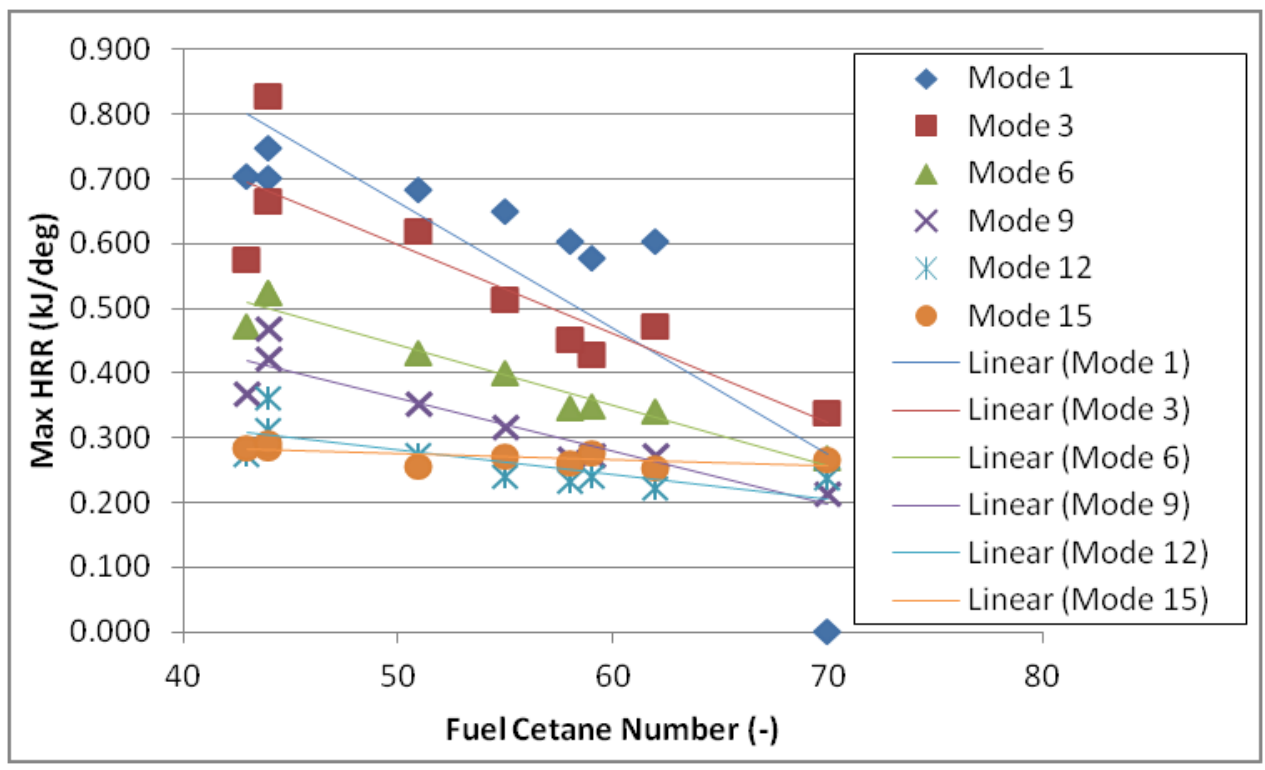

Figure 5-5: Effect of Cetane Number of Maximum Heat Release Rate

It was also noticed that the net heat released in Figure 5-6 for the two candidate biofuels (50/50 JP5/HRJ5 and Neat HRJ5) is slightly lower than the reference fuel (JP-5) for most modes. The most significant difference was seen at the last three modes, where the net heat released for 50/50 JP5/HRJ5 is $\sim 2 \%$ to $2.5 \%$ lower and $\sim 2.75$ to $4 \%$ lower for Neat HRJ 5 due to lower energy and density of the fuel injected. The fuel density, cetane number, and aromatic content do not appear to have any significant effect on net heat released as indicated by the small slope or "m" values in Table 8-2.

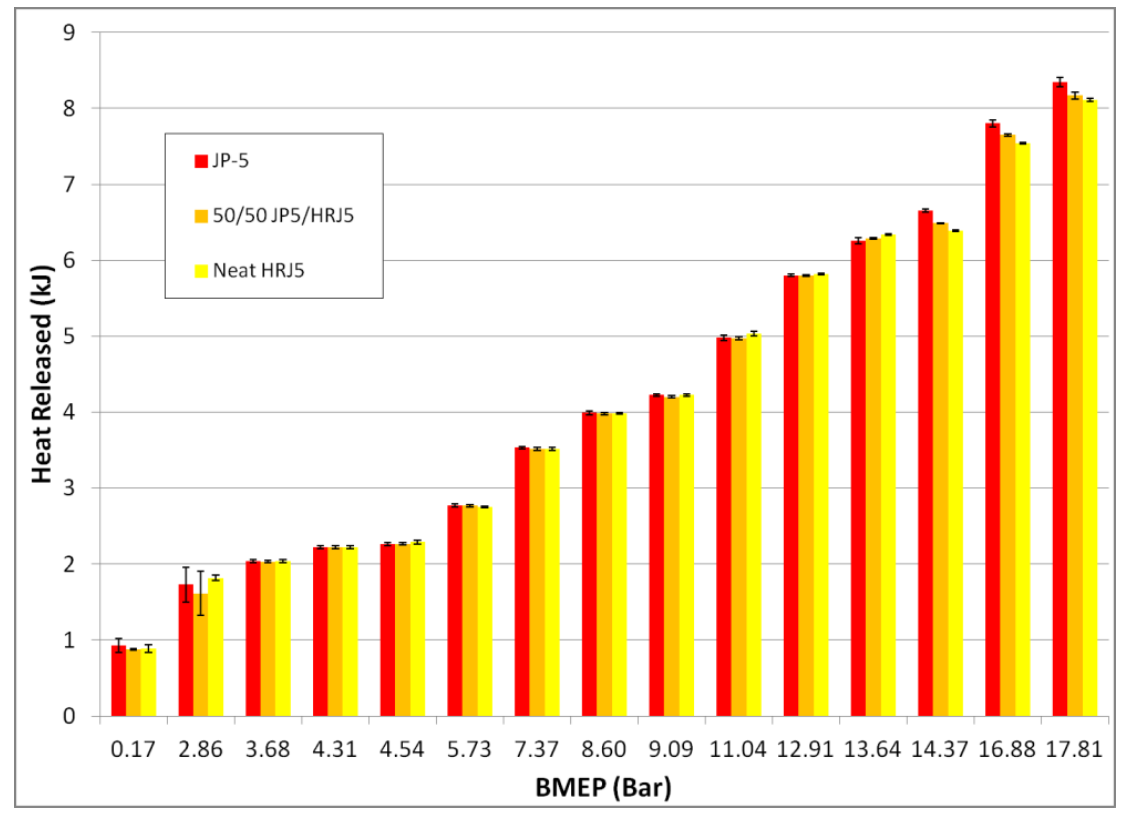

Figure 5-6: Net Heat Released at each Test Mode for JP-5 Test Fuels 


\subsubsection{In-Cylinder Pressure and Pressure Rise Rate}

In-cylinder pressure data were used to determine the maximum pressure and pressure rise rate in the cylinder as well as other in-cylinder parameters discussed earlier in this chapter. These parameters are important because they provide an indication of engine load and in-cylinder temperature. The maximum pressure typically increases with engine load. Figure 5-7 and Figure 5-8 illustrate the in-cylinder pressure for modes 5 and 12, respectively. It was noticed that the maximum pressure for the two candidate biofuels was slightly lower at all modes compared to JP-5. The maximum pressure for 50/50 JP5/HRJ5 was $\sim 1$ to $5 \%$ lower and $\sim 1.5$ to $7 \%$ lower for Neat HRJ5 over the entire test cycle compared to JP-5. Neat HRJ5 and 50/50 JP5/HRJ5 also showed lower maximum pressure rise rates (Figure 5-9) across the test cycle: $\sim 6$ to $22 \%$ for 50/50 HRJ5/JP5 and $\sim 16$ to $39 \%$ for Neat HRJ5. The reductions in maximum in-cylinder pressure are consistent with the literature [27]. In-cylinder pressure can be significantly affected by fuel density, cetane number, and aromatic content; this is evident in

Table 8-3, indicated by the large slope or " $m$ " values. As the fuel density and aromatic content increased maximum in-pressure increased and while cetane number increased maximum in-cylinder pressure decreased. Therefore the reductions in maximum in-cylinder pressure were attributed to the lower fuel density, lower aromatic content, and higher cetane number of the biofuels. The effects of density, cetane number, and aromatic content on pressure rise rate followed a similar trend as for maximum in-cylinder pressure as indicate in Table 8-4.

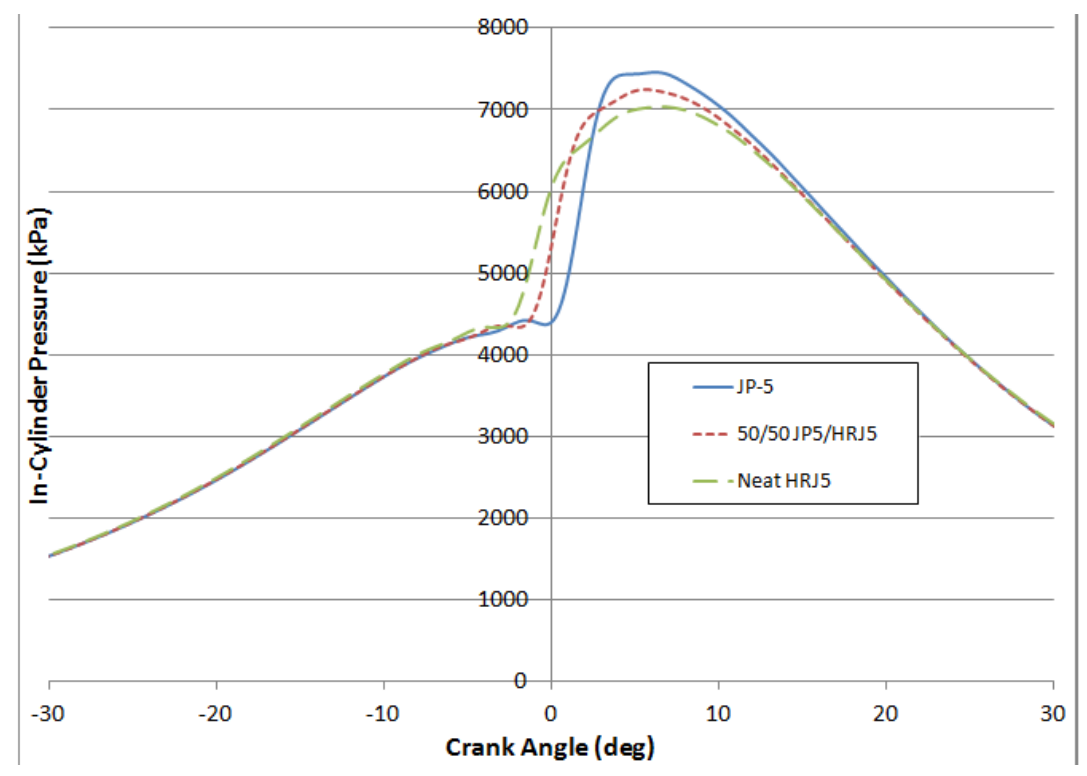

Figure 5-7: In-Cylinder Pressure Curve at Mode 5 for JP-5 (25\% Engine Load and 1430 rpm) Test Fuels 


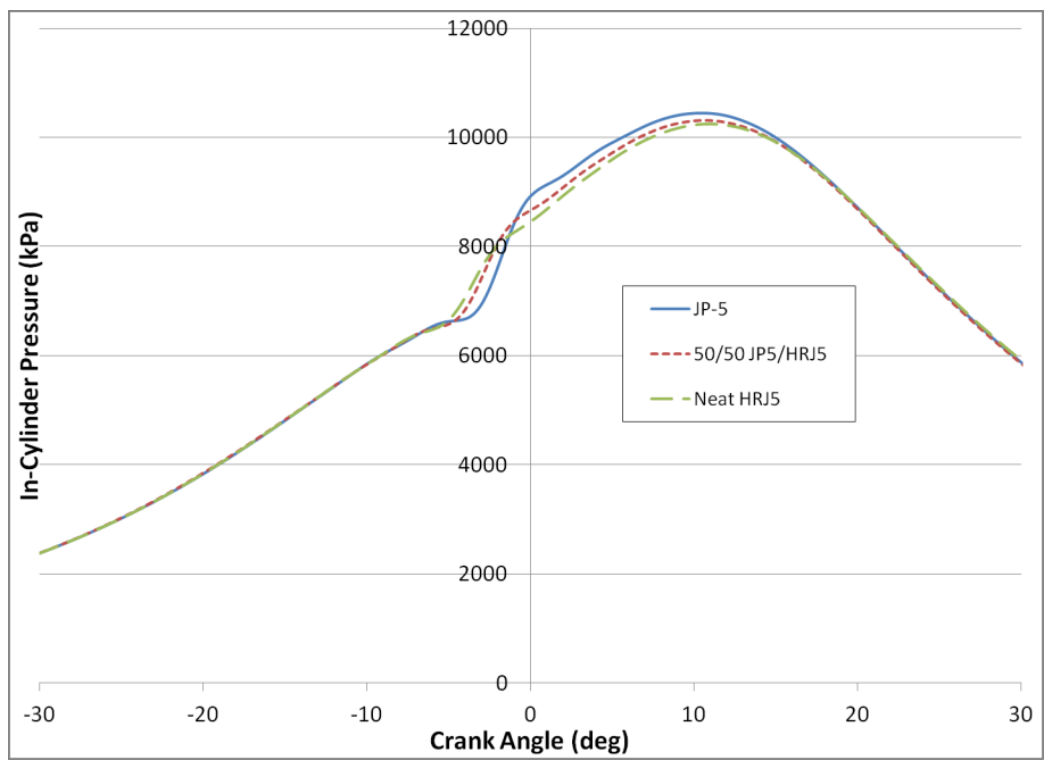

Figure 5-8: In-Cylinder Pressure Curve at Mode 12 (75\% Engine Load and 1649 rpm) for JP-5 Test Fuels

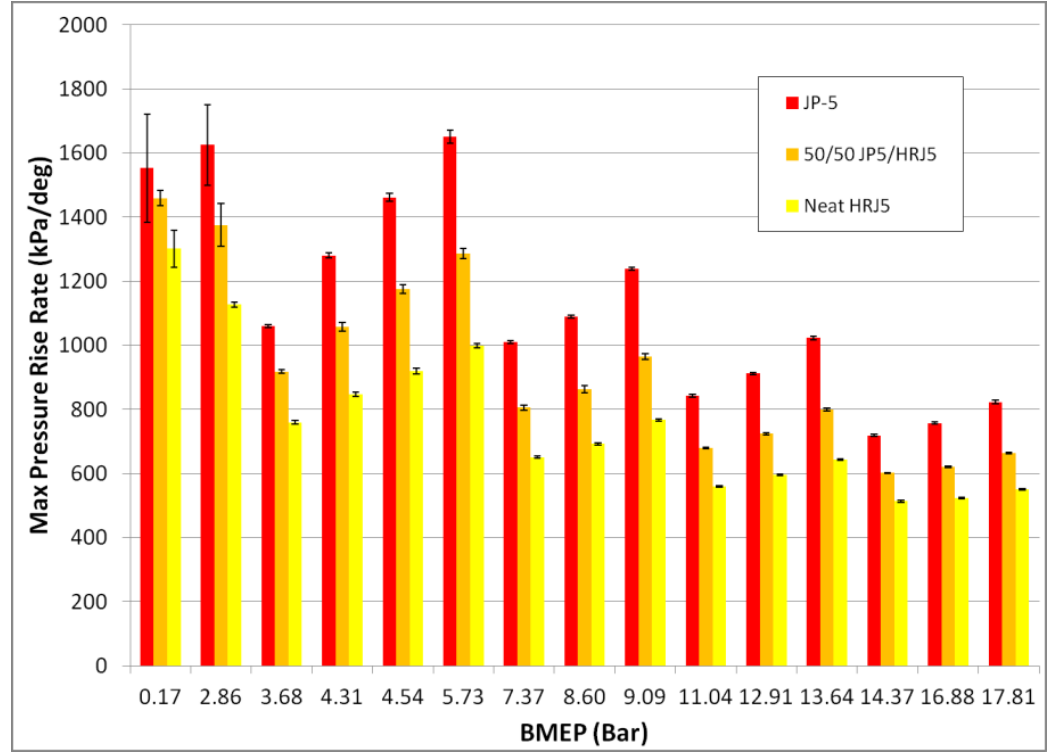

Figure 5-9: Maximum Pressure Rise Rate at Each Test Mode for JP-5 Test Fuels

\subsubsection{In-Cylinder Temperature}

The in-cylinder temperature typically increases as the pressure increases, due to compression and combustion, and has a similar curve shape. Figure 5-10 shows that the maximum averaged in-cylinder temperature at mode 5 was slightly lower for both candidate biofuels compared to JP-5. However, as the power and engine load increased the difference in maximum in-cylinder temperature decreased. This is evident in Figure 5-11, where the temperature of the biofuels is nearly the same throughout the compression and combustion period. At any mode the maximum reduction in maximum in-cylinder 
temperature for either fuel was just under $4.5 \%$; this was relatively insignificant to engine performance but may have a significant impact on emission formation, especially NOx. Table 8-5illustrates the effects of density, cetane number, and aromatic content on maximum in-cylinder temperature. A previous study [18] indicated that as cetane number increases maximum in-cylinder temperature decreases. This study showed similar results. The lower fuel density and aromatic content may have also helped to reduce the temperature.

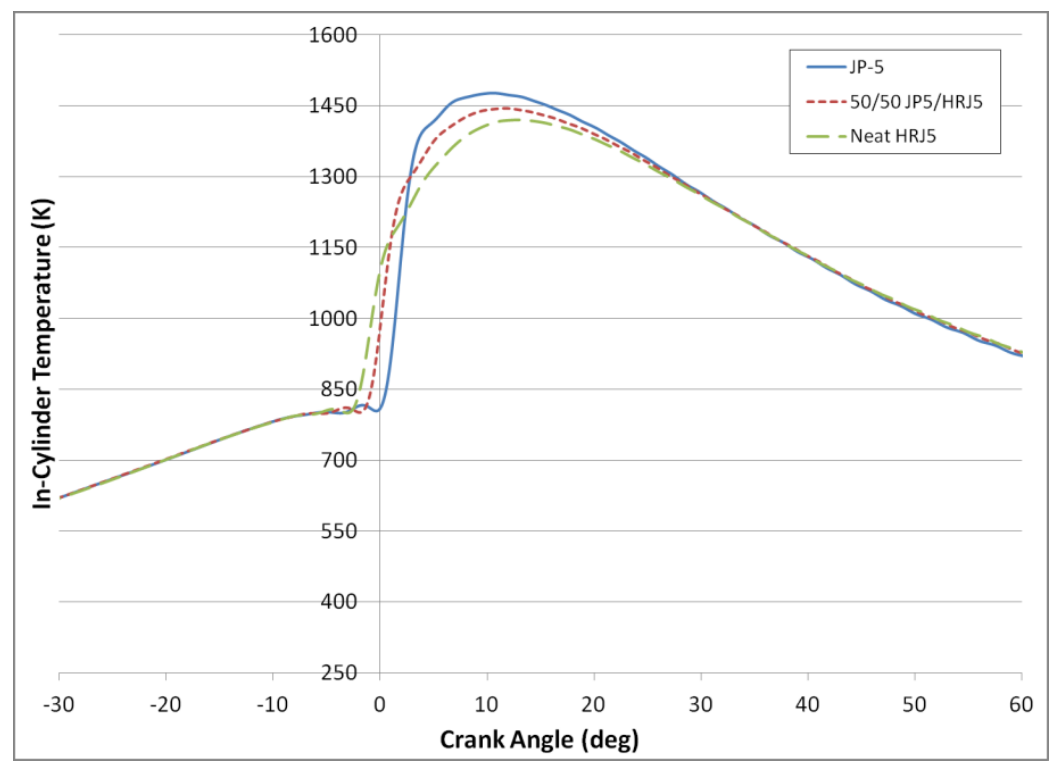

Figure 5-10: In-Cylinder Temperature Curve at Mode 5 (25\% Engine Load and 1430 rpm) for JP-5 Test Fuels

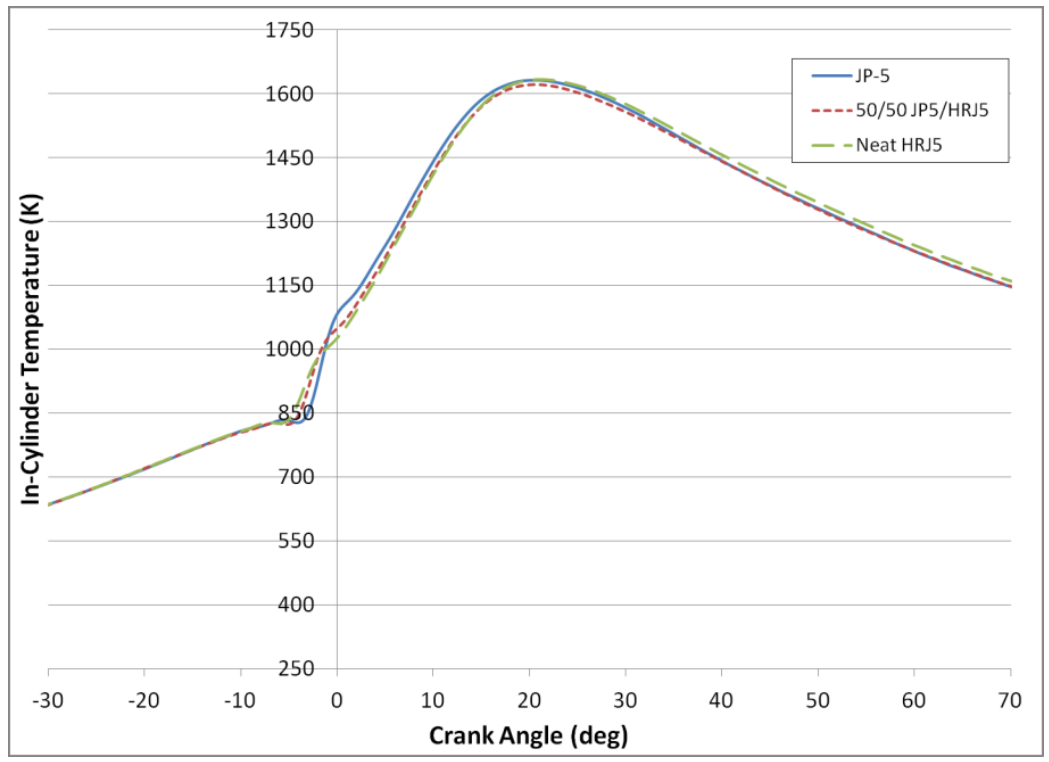

Figure 5-11: In-Cylinder Temperature Curve at Mode 12 (75\% Engine Load and 1649 rpm) for JP-5 Test Fuels 


\subsubsection{Start of Fuel Injection and Ignition Delay}

Start of fuel injections was recorded to examine differences in fuel injection patterns between the fuels. Figure 5-12 and Figure 5-13 show a region of the heat release curve of modes 5 and 12, respectively, which indicate the start of fuel injection and start of combustion. Start of combustion was determined based on the location of 5\% mass fraction burned. The crank angle period between the start of fuel injection and start of combustion is the ignition delay. The encoder used to trigger the pressure DAQ had a resolution of 0.25 degrees so anything less than 0.25 degrees was within the pressure DAQ resolution and care must be used to infer significance to any changes in crank angle less than 0.25 degrees. At mode 5 (Figure 5-12), fuel injection was slightly retarded by $\sim 0.3$ and $\sim 0.15$ degrees for Neat HRJ5 and 50/50 JP5/HRJ5, respectively; and start of combustion was advanced by 2.5 and 1.5 degrees for Neat HRJ5 and 50/50 JP5/HRJ5, respectively. Therefore, the ignition delay for Neat HRJ5 and 50/50 JP5/HRJ5 was approximately 2.8 degrees shorter and 1.6 degrees shorter, respectively. Mode 12 (Figure 5-13) showed slight ( 0.25 degree) retardation in start of injection for Neat HRJ5 while start of injection of 50/50 JP5/HRJ5 was too similar to notice a difference; due to the resolution of the pressure DAQ system it was difficult to draw a conclusion about fuel injection for this fuel at this mode. Start of combustion at mode 12 was the same for Neat HRJ5 and JP-5 and was advanced by 0.75 degrees for 50/50 JP5/HRJ5. Despite the similarities in start of fuel injection (JP-5 and 50/50 JP5/HRJ5) and start combustion (JP-5 and Neat HRJ5), the ignition delay of both candidate biofuels is shorter by $\sim 0.3$ and 0.7 degrees for Neat HRJ5 and 50/50 JP5/HRJ5, respectively. Across the entire test cycle start of injection was consistently retarded by $\sim 0.2$ to 0.59 degrees for Neat HRJ5. The 50/50 JP5/HRJ5 blend also showed slightly retarded injection timing $(<0.25$ degrees) except for modes 1,6 , and 9 . The start of injection for modes 1 and 9 were less than -0.05 degrees different than JP- 5 and mode 6 was only advanced by about -0.2 degrees or less. Differences in fuel injection were attributed to different fuel viscosity and density of the candidate biofuels. Start of combustion for the biofuels was consistently advanced compared to JP-5 across the entire test cycle; indicating a shorter ignition delay for both candidate biofuels at all test modes. Shorter ignition delay with these fuels is consistent with the literature [20,27].

The effects of fuel density, cetane number, and aromatic content on start of injection and start of combustion are presented in Table 8-6andTable 8-7. The effects of fuel viscosity were also examined for start of fuel injection. The literature [27] suggests that fuel injection is slightly retarded due to higher viscosities. This study found similar results indicated by the positive slope or " $\mathrm{m}$ " values for viscosity inTable 8-6. Retarded fuel injection could also be attributed to the lower fuel density and change of compressibility of the biofuels. The advanced start of combustion is most likely attributed to the higher 
cetane number of the biofuels. This is indicated by the negative slope or "m" values for cetane number in Table 8-6.

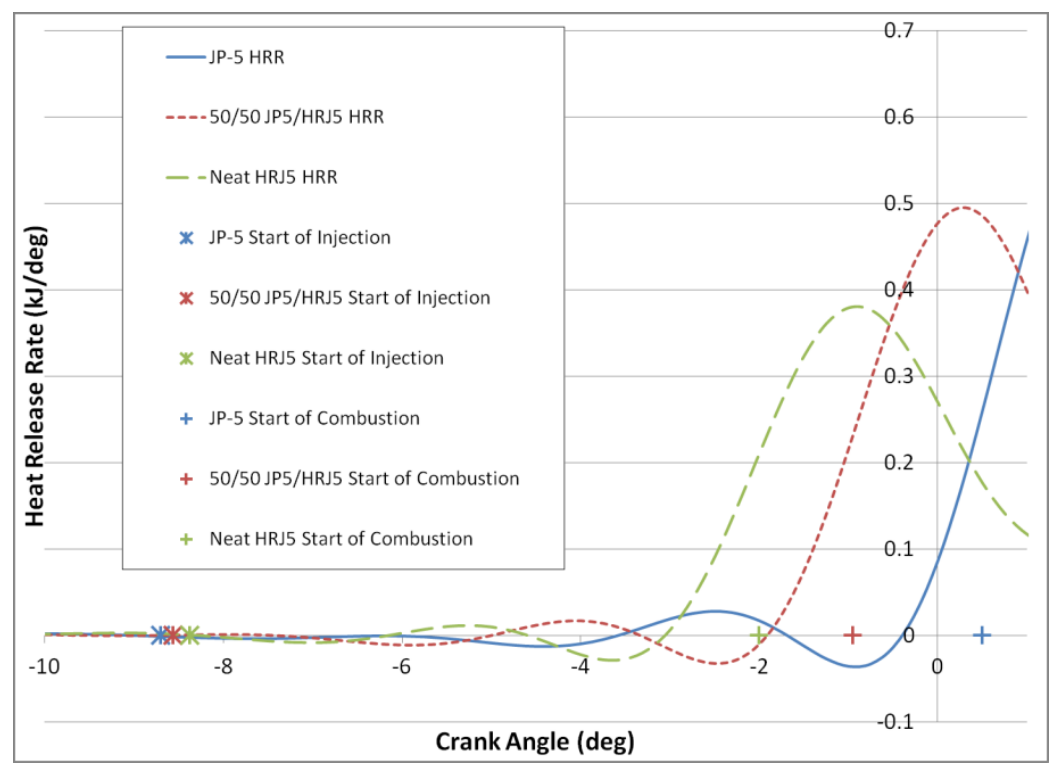

Figure 5-12: Heat Release Rate Curve at Mode 5 Indicating Start of Fuel Injection and Start of Combustion for JP-5 Test Fuels

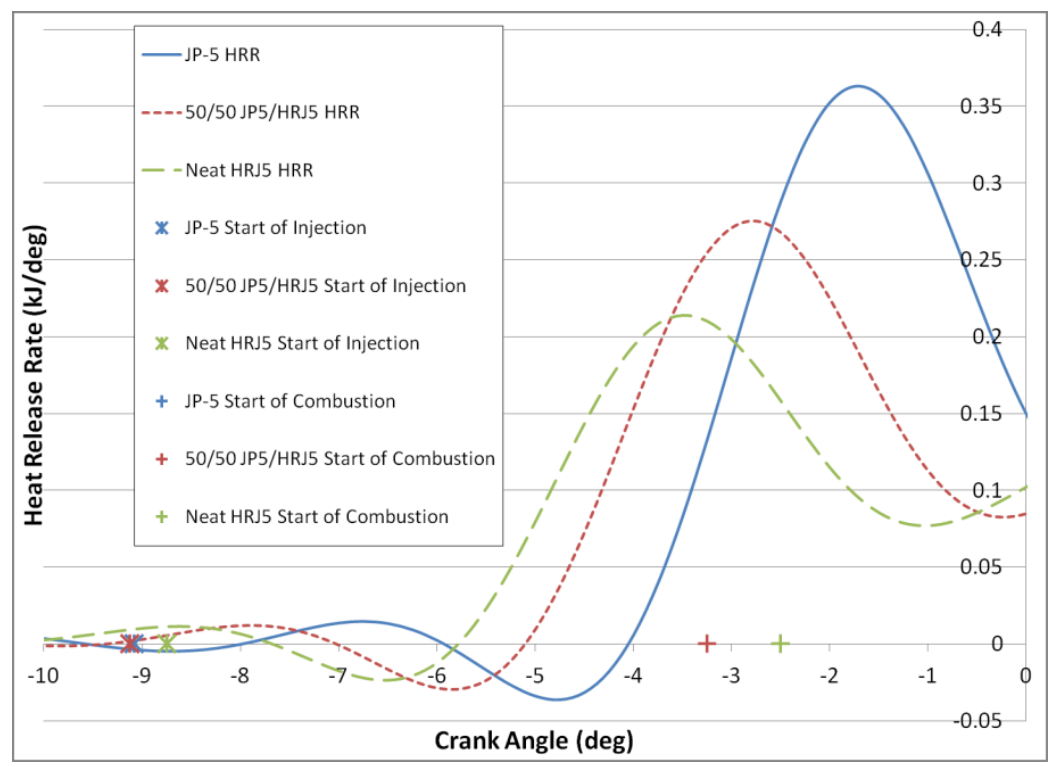

Figure 5-13: Heat Release Rate Curve at Mode 12 Indicating Start of Fuel Injection and Start of Combustion for JP-5 Test Fuels

\subsubsection{Premix and Diffusion Fractions}

Premix and diffusion fraction lengths vary with engine load and, typically, premix is a high percentage of the combustion period at low load and a low percentage at high low load for this era engine design. Generally, diffusion is a low percentage of the combustion period at low load and a high percentage at high load. Premix fraction is characterized by sudden and high heat release rates and 
diffusion is characterized by lower more controlled heat release rates. This is evident in Figure 5-2, where the combustion period is predominantly premix fraction, and Figure 5-3, where the premix fraction is only a small portion of the combustion period compared to the diffusion fraction. Figure 5-14 and Figure 5-15 illustrate the premix and diffusion fraction lengths of all test modes across the test cycle. The net heat released during both fractions is directly related to its length; a shorter premix fraction indicates less heat released and a longer diffusion fraction indicates more heat released. The shorter premix fraction was attributed to the lower fuel density, aromatic content, and cetane number (Table 8-8); however, these effects were very small. Table 8-9 indicates that the lower density, aromatic content, and cetane number increased the length of the diffusion fraction. The fuel property effects on diffusion fraction length were more significant than the effects on premix fraction length.

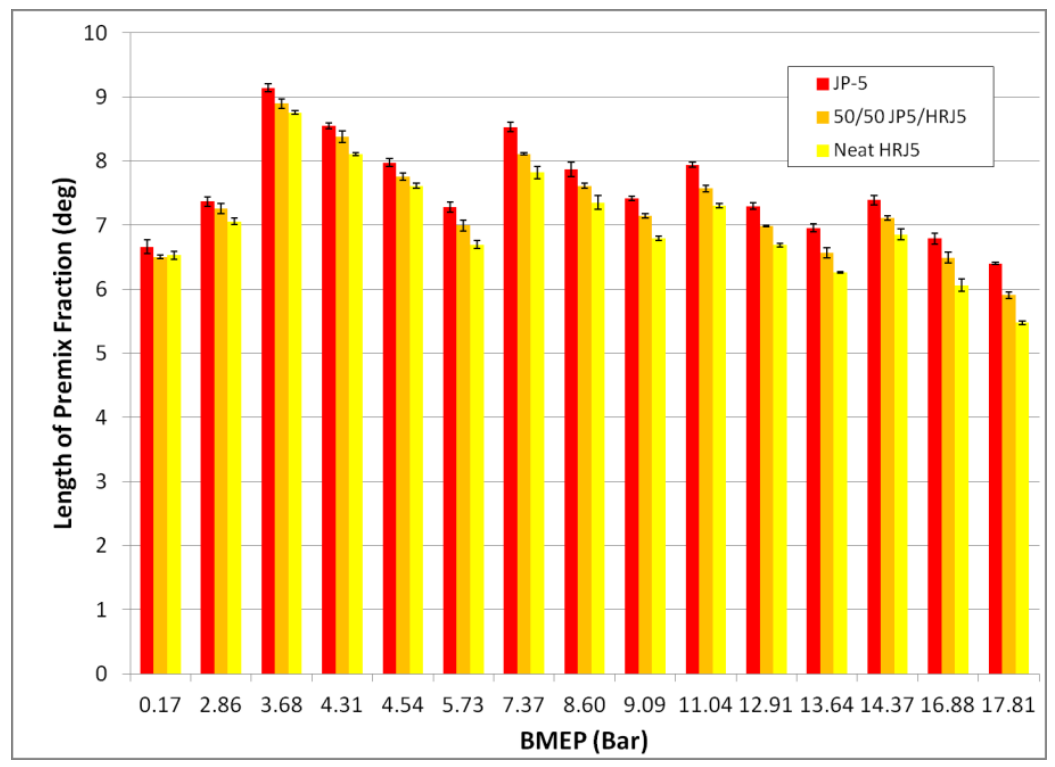

Figure 5-14: Premix Fraction Length of each Test Mode for JP-5 Test Fuels 


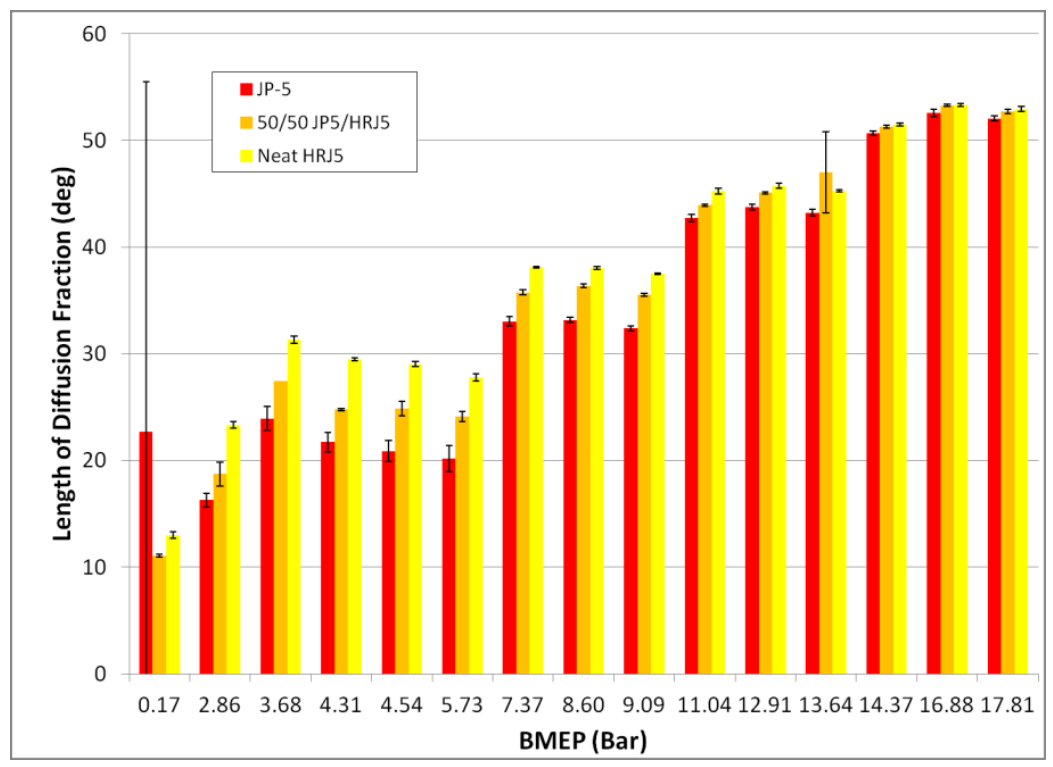

Figure 5-15: Diffusion Fraction Length of each Test Mode for JP-5 Test Fuels

\subsubsection{Emissions}

Complex physical and chemical reactions, such as ignition, combustion, vaporization and atomization, all occur during normal diesel combustion. Each test fuel brought about changes in operating conditions, and each of these changes determined how exhaust emissions would be effected. An increase NOx emissions was usually attributed to an increase of in-cylinder temperature. Gaseous HC in the exhaust was normally attributed to high or low air-to-fuel ratios, and overfueling. Incomplete combustion would lead to increased $\mathrm{CO}$ emissions; known to be a dissociation product of $\mathrm{CO}_{2}$. $\mathrm{PM}_{\text {was }}$ composed of organic and inorganic substances found in the fuel and air.

The emission results for the steady state and transient tests are presented in the following sections. These results include the brake specific mass emissions of $\mathrm{HC}, \mathrm{NOx}, \mathrm{CO}, \mathrm{CO}_{2}$, and PM, as well as brake specific fuel consumption. The brake specific values were obtained by averaging the data for each mode of all the tests for a given fuel. The candidate biofuels were compared to the reference fuel by using a percent difference. A negative percent difference shows a reduction in a particular emission constituent from the reference fuel and a positive percent difference shows an increase. Note that variations in small numbers may show up as a large percent difference. Some of this variation in small values could be attributed to the emissions analyzer ranges. It is important to note that variations also occurred at mode 1 (idle), so this information must be taken lightly since all the data for the idle mode were small due to the selected tunnel flow rate and analyzer full-scale range selected to capture the highest concentrations during testing. Also note that the idle mode, mode 1, data is provided on a mass rate basis while the other 14 modes are on a brake-specific mass basis. Effects of fuel density, cetane 
number, and aromatic content of the test fuels on emission constituents were also examined, and are reported in the following sections. Each brake specific mass emission constituent for each mode was plotted against fuel density, cetane number, and aromatic content; a linear curve fit was applied to determine the $\mathrm{m}$ (slope), $\mathrm{b}$ (y-intercept), and $\mathrm{R}^{2}$ values. A negative slope indicates a decrease in a given emission constituent as the respective fuel property increases and a positive slope indicates an increase.

\subsubsection{HC}

Brake specific HC emissions for JP-5 test fuels are displayed in Figure 5-16 for each of the 15 modes. Large percent reductions in bsHC emissions were noticed; however, this is partially due to the relatively low magnitude of $\mathrm{HC}$ emissions. Figure 5-17 provides an example on the analysis of fuel property effects on exhaust emissions; this specific figure illustrates the effects of changing fuel density on HC emissions. Table 8-10 provides a detailed analysis on effects of fuel density, cetane number, and aromatic content on bsHC emissions. Figure 5-17 (density impact) and Table 8-10 show that there is no significant effect of density, cetane number, or aromatic content on bsHC emissions; this is indicated by the small slope or " $m$ " values in Table 8-10.

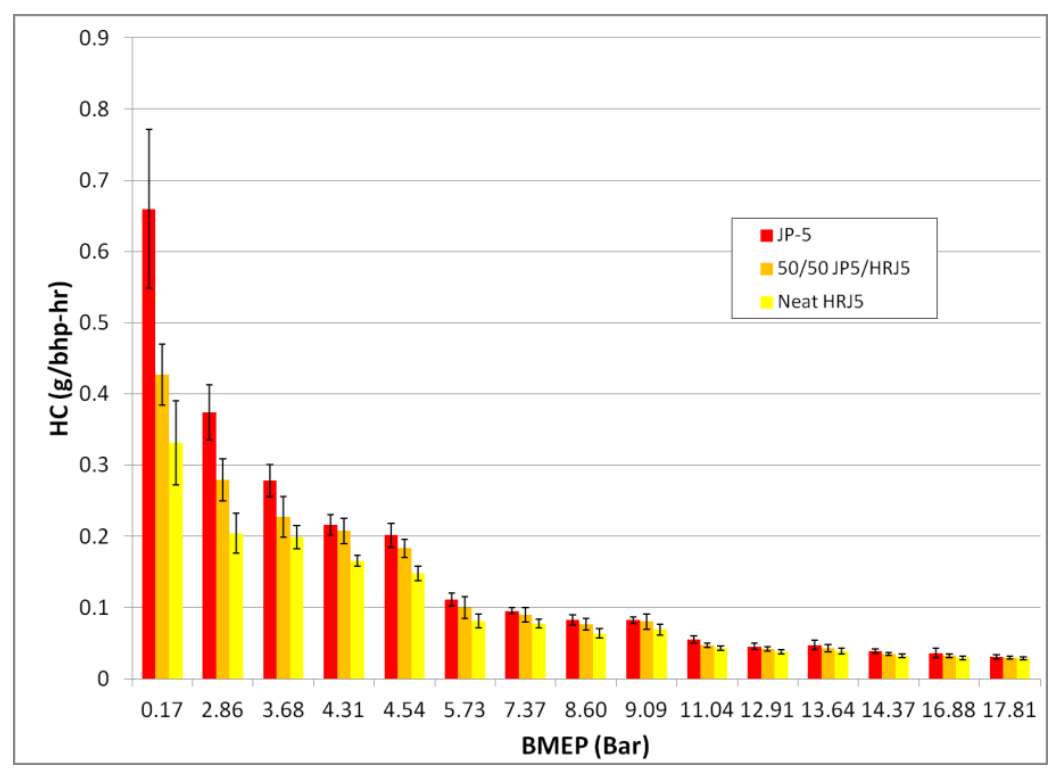

Figure 5-16: Brake Specific HC Emissions for JP-5 Fuels 


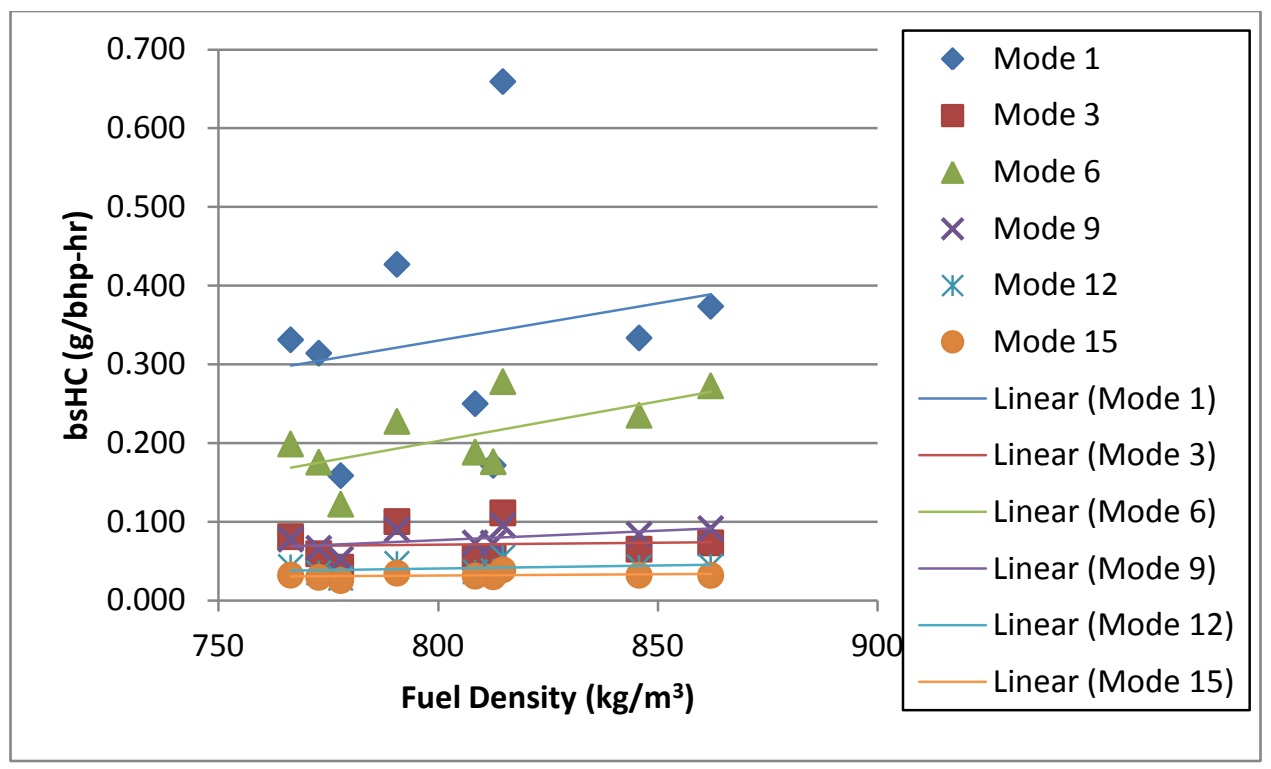

Figure 5-17: Effects of Fuel Density on bsHC Emissions

\subsubsection{NOx}

Figure 5-18 illustrates the brake specific NOx emissions for the JP-5 test fuels at each test mode. It is clearly shown that there is a NOx reduction in all modes for both candidate fuels. The most significant differences are noticed at $25 \%$ engine load and become less significant as engine load and BMEP increase. At $25 \%$ load, reductions up to $\sim 19 \%$ are seen for $50 / 50 \mathrm{JP} 5 / \mathrm{HRJ} 5$ and $\sim 31 \%$ for Neat HRJ5. The percent difference in reduction steadily decreases to $\sim 2.5 \%$ for JP5/HRJ5 and $\sim 7 \%$ for Neat HRJ5 as the engine load and BMEP increase. Effects of fuel density, cetane number, and aromatics on bsNOx emissions are present in Table 8-11. At every mode bsNOx emissions decreased as cetane number increased due to the shorter premix and longer diffusion fractions caused by higher cetane numbers. As fuel density and aromatic content increased bsNOx emissions increased. The relation between NOx emissions and cetane number is consistent with previous studies [18,20]. At high engine loads the change in bsNOx brought on by a change in fuel properties was less significant than at low loads. 


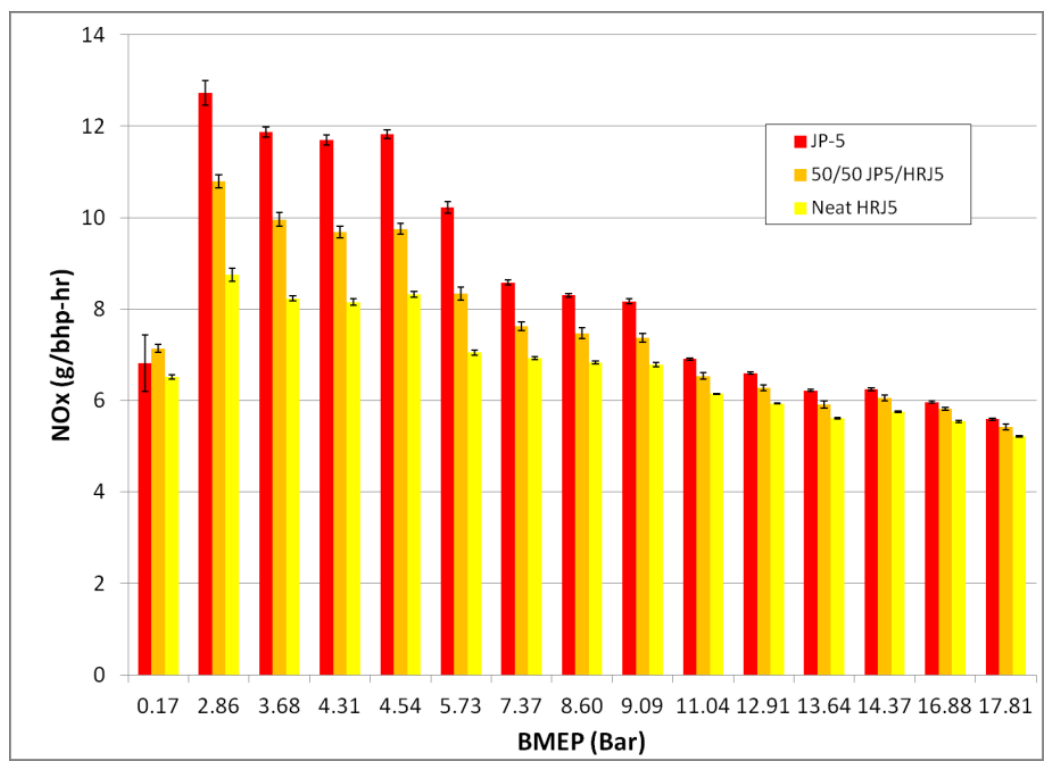

Figure 5-18: Brake Specific NOx Emissions for JP-5 Fuels

\subsubsection{CO}

Brake specific CO emissions are display in Figure 5-19. Reductions in CO emissions were noticed at all modes. It is difficult to determine if the reductions were significant due to the relatively low magnitude $\mathrm{CO}$ emissions. Generally, $\mathrm{CO}$ emissions fall far below regulated level and are considered insignificant in diesel engines due to the lean operation $[17,18]$. There also seemed to be no significant effects of differences in density, cetane number, or aromatics on bsCO emissions. This was determined based on the low slope or "m" values in Table 8-12.

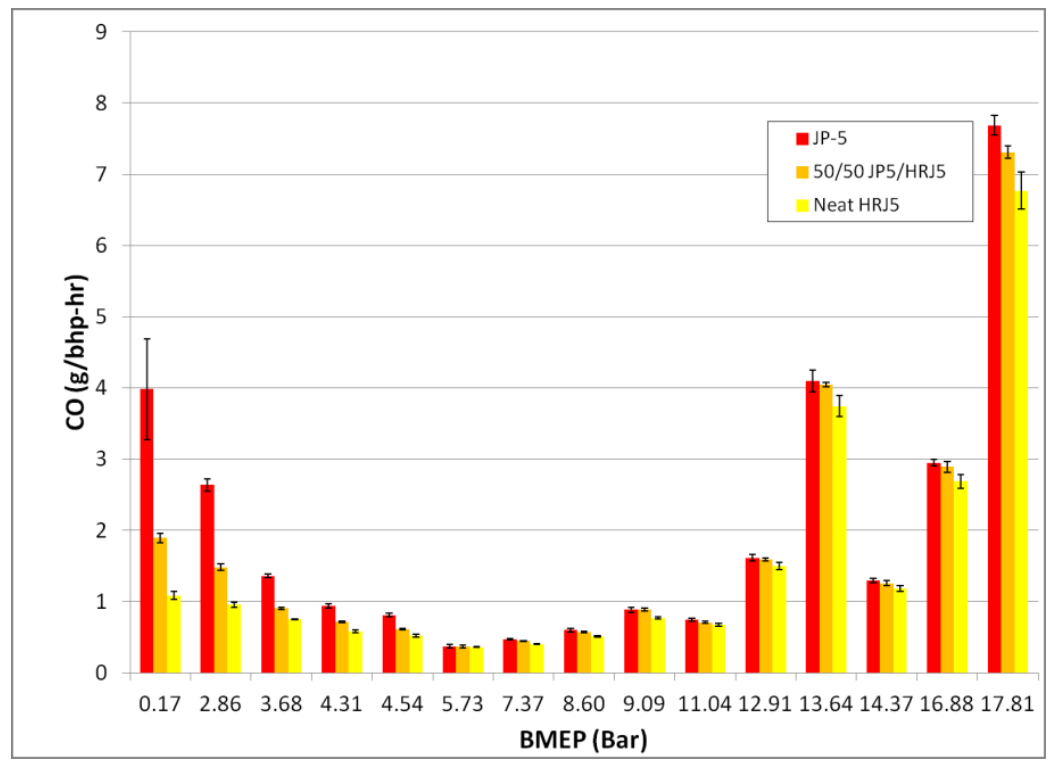

Figure 5-19: Brake Specific CO Emissions for JP-5 Fuels 


\subsubsection{4 $\mathrm{CO}_{2}$}

As shown in Figure 5-20, reductions in $\mathrm{CO}_{2}$ emissions were noticed for both biofuels. Since $\mathrm{CO}_{2}$ emissions are directly related to fuel consumption it was concluded that reductions in fuel consumption would also be noticed. Reductions were consistently within 1.5 and 3\% for 50/50 JP5/HRJ5 and around 4 to $5 \%$ for Neat HRJ5. Although the percent difference is relatively low, these reductions are considered moderate due to the relative large magnitude of $\mathrm{CO}_{2}$ emissions. This is attributed to a higher $\mathrm{H} / \mathrm{C}$ ratio of the biofuels, which leads to more efficient combustion phasing [27]. Cetane number indirectly affected $\mathrm{CO}_{2}$ emissions by affecting the combustion process; its affect is presented in Table 8-13.

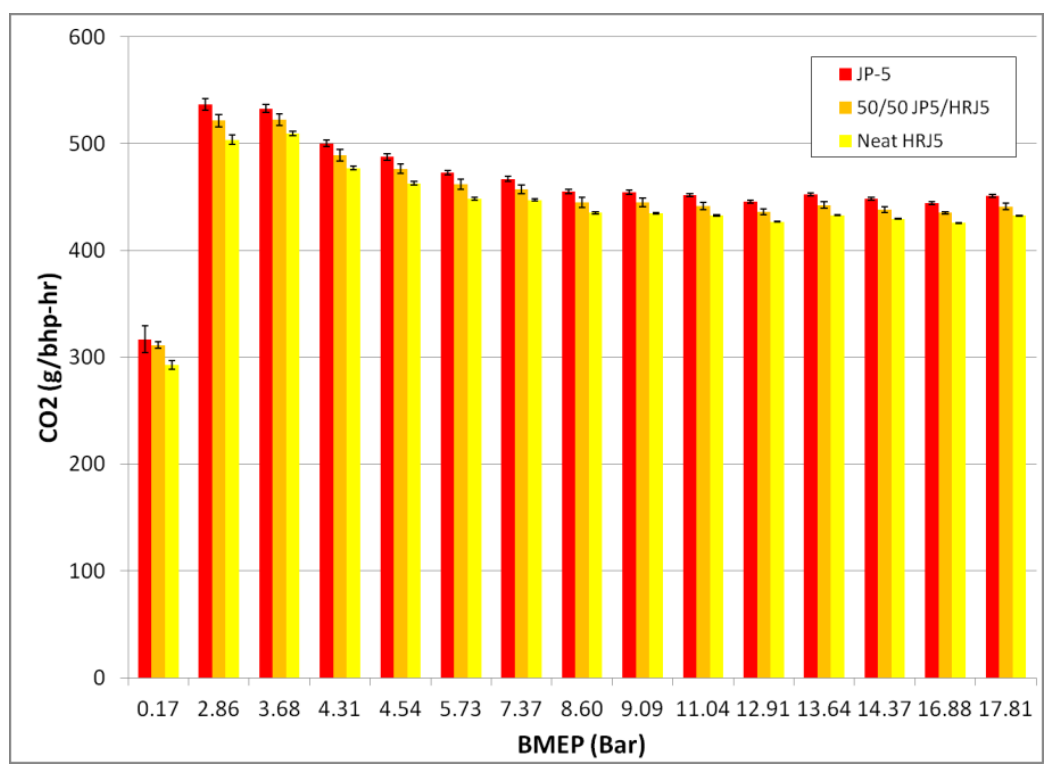

Figure 5-20: Brake Specific $\mathrm{CO}_{2}$ Emissions for JP-5 Fuels

\subsubsection{PM}

Particulate matter emissions were reported as a brake specific constituent in Figure 5-21. Contrary to the literature $[6,7,24,29]$, multiple low engine load (25\%) modes showed a significant increase in bsPM for 50/50 JP5/HRJ5, while other modes showed slight to moderate reduction. This trend is interesting because operation of Neat HRJ5 showed significant ( $\sim 15$ to $30 \%$ ) consistent reductions in bsPM. Care must be taken when examining the data at the low power modes since data collection times were not long enough to collect a desired amount of PM on the filter. This is exhibited by the relatively large run-to-run variation bars in this figure for the low power modes. The mode duration was a tradeoff between allowing for repeat tests and providing maximum signal output. Although the gaseous emissions also were subject to relatively low signal output at these low power modes, the gaseous analyzers were able to capture these signals in a more repeatable manner. It was known that a priori that PM sample times were not as long as desired but were set to satisfy time and fuel 
constraints. Table 8-14 indicates that reductions in bsPM are attributed to higher cetane number and an increase is attributed to an increase in fuel density or aromatic content.

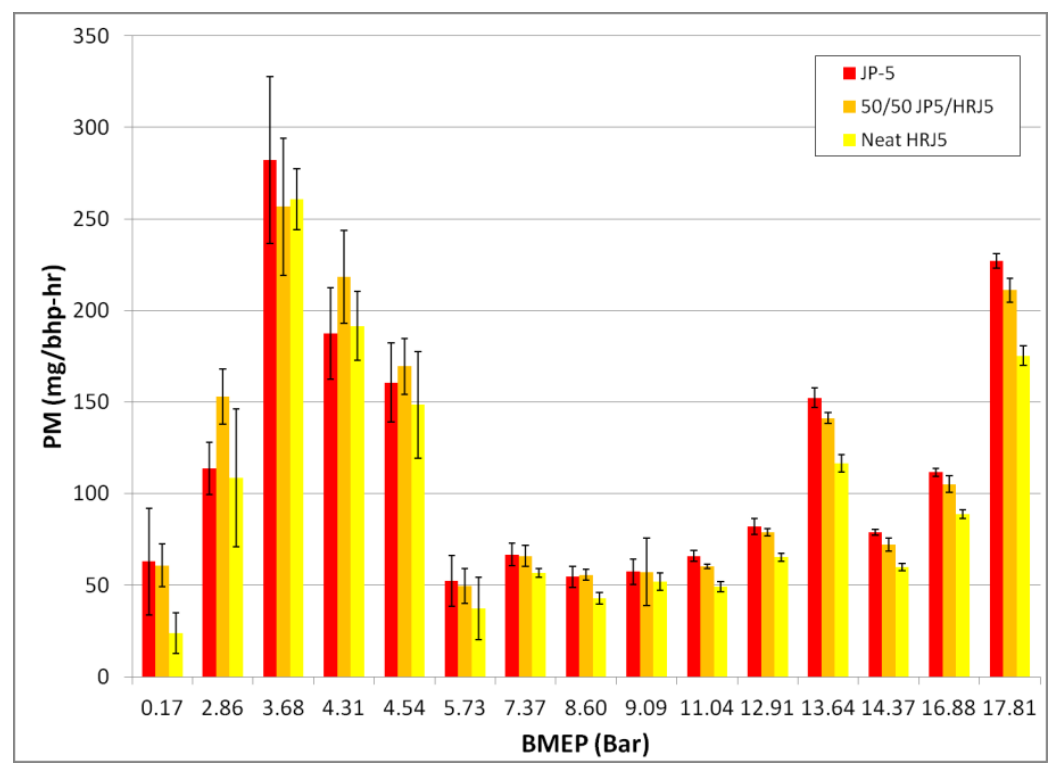

Figure 5-21: Brake Specific PM Emissions for JP-5 Fuels

\subsubsection{Fuel Economy}

Fuel economy is reported as brake specific fuel consumption (bsFC) and was calculated from the fuel mass measured by the carbon balance method explained previously. The fuel consumption reported by the fuel meter and scale are not presented here. Figure 5-22 shows the total bsFC for each test fuel; modest reductions in bsfc were noticed with operation on both biofuels. The decrease in bsFC was more evident for Neat HRJ5 and was attributed to the higher cetane number and mass based heating value of the biofuels [28]. Percent reductions in bsFC of $\sim 1.3$ to $2.3 \%$ for $50 / 50$ JP5/HRJ5 and $\sim 2.5$ to $5 \%$ for Neat HRJ5 were noticed. Data in Table 8-15 supports the claim that as cetane number increases bsFC decreases slightly. 


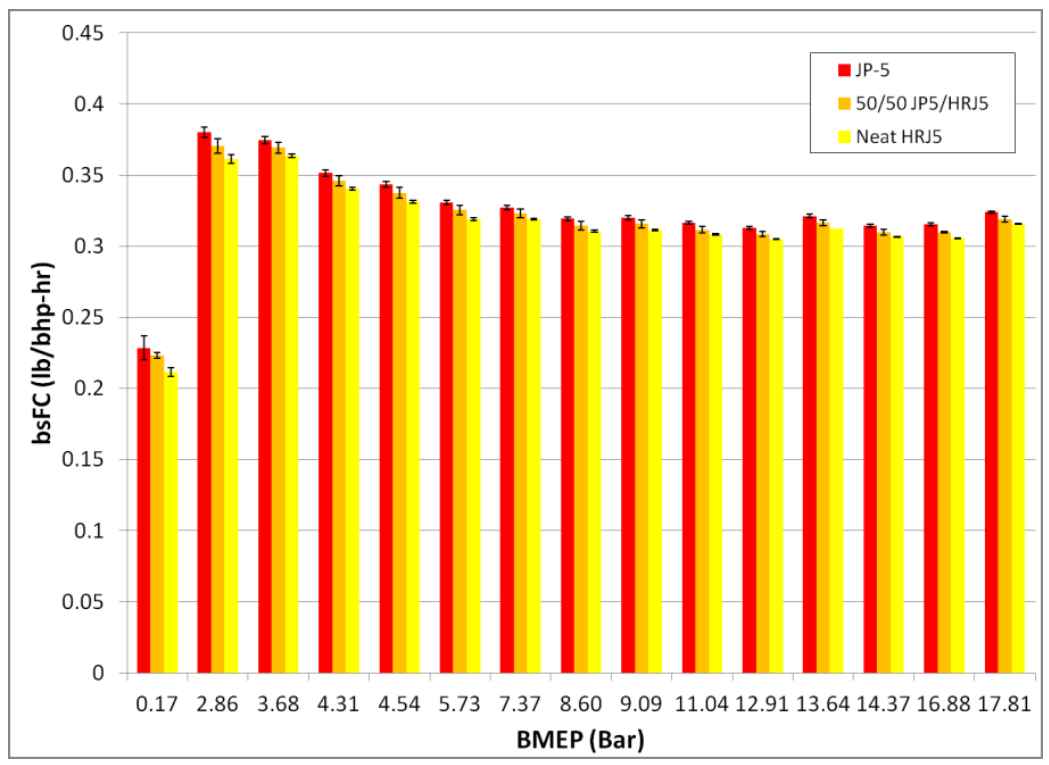

Figure 5-22: Brake Specific Fuel Consumption for JP-5 Fuels

\subsubsection{Transient Tests}

Idle to full power step tests were conducted to examine the performance of the JP-5 test fuels under transient operating conditions. Data is reported for two tests of both JP-5 and Neat HRJ5; only one test was collected, and reported, for 50/50 JP5/HRJ5. Table 8-16 presents the combustion data for each fuel as minimum, maximum, and average values recorded during the entire test cycle. Maximum values typically occurred during full power operation or during the transition to or from full power. Average values were calculated from the entire test cycle. Emission constituents were measured across the entire test cycle and are reported as brake specific values in Table 8-17. Due to the nature of the test cycle greater variations in measurements and calculations were noticed throughout the test cycle since multiple tests were not collected and averaged together. For this reason some of the reported results must be taken lightly.

During the idle modes the magnitude of most combustion parameters was relatively low compared to the full power modes. For this reason, parameters that could have adverse affects on combustion and engine performance are reported as maximum values. This also helps to understand the performance of each fuel's maximum performance potential. The maximum heat released for each fuel is consistent with the heat released during the steady state tests at the same engine load and speed. Slight reductions were noticed for both 50/50 JP5/HRJ5 and Neat HRJ5. The reductions were more evident with Neat HRJ5. The maximum HRR for both 50/50 JP5/HRJ5 and Neat HRJ5 was also lower than for JP-5. It should be noted that the maximum HRR occurred during the transition from idle to full power. Although the magnitudes are higher the reductions are consistent with the steady state test results. The 
results for the maximum values of heat released and HRR are supported by the reduction in the average values for the candidate biofuels in Table 8-16.

The maximum pressure occurred during the transition from full power to idle for each test fuel. Although the candidate biofuels showed reductions in maximum pressure during transient testing; the maximum pressure reached during the transient tests was significantly lower $(\sim 200 \mathrm{kPa})$ than the pressure reached during the steady state tests. The maximum pressure rise rate occurred during the transition from idle to full power; significant reductions were noticed for both biofuels. The maximum PRR during transient testing was much higher than during steady state testing. It should be noted that the steady state values were averaged, while the transient values were the maximum achieved. The maximum in-cylinder temperature achieved during the transient test cycle for Neat HRJ5 was moderately lower ( $\sim 100$ to $150 \mathrm{~K})$ than for JP-5 and 50/50 JP5/HRJ5 was $\sim 60$ to $70 \mathrm{~K}$ lower than the JP-f fuel.

As expected, from the literature and steady state results presented here, brake specific emissions (Table 8-17) were reduced for each constituent for both 50/50 JP5/HRJ5 and Neat HRJ5. Slight reductions in bsHC emissions were achieved for both biofuels. These reductions are minimal due to the already low magnitude of bsHC emissions. Brake specific mass emissions for both NOx and CO also showed minimal reductions for both biofuels. Reductions of $\sim 7$ to $10 \mathrm{~g} / \mathrm{bhp}-\mathrm{hr}$ and $\sim 20 \mathrm{~g} / \mathrm{bhp}-\mathrm{hr}$ of $\mathrm{bsCO}_{2}$ for 50/50 JP5/HRJ5 and for Neat HRJ5, respectively. Brake specific emissions of PM were also reduced for both fuels: $\sim 5$ to $10 \mathrm{mg} / \mathrm{bhp}-\mathrm{hr}$ for 50/50 JP5/HRJ5 and $\sim 20$ to $26 \mathrm{mg} / \mathrm{bhp}-\mathrm{hr}$. Along with reductions in $\mathrm{bsCO}_{2}$ emissions, bsFC was also reduced for both biofuels. The change in emissions was attributed to the same fuel properties discussed for the steady state tests.

\subsection{F-76 Fuels}

Six alternative candidate biofuels: Neat HRD76, 50/50 F76/HRD76, Neat DSH76, 50/50 F76/DSH76, 80/20 F76/DSH76, and 80/20 F76/HDCD76 were tested and compared to the reference fuel (F-76). The engine was mapped to yield a full power torque curve on F-76. This baseline torque curve was used throughout the test program for the F-76 test fuels only. The test evaluation of the F-76 fuel consisted of a 15 mode steady state test only. Figure 5-23 shows the engine map for each fuel along with the set points for each mode. It is noted that the three full load set points for F-76 were increased by 100 $\mathrm{ft}-\mathrm{lb}$ to ensure that full power is reached for each fuel. Data for modes 5 and 12 is presented as heat release rate, pressure, and temperature curves to illustrate the performance differences between the fuels. Some data is also presented as a function of brake mean effective pressure (BMEP) in ascending order; Table 5-2 shows the relationship between the modal set points and BMEP for the F-76 test cycle. 
Table 5-2: Relationship between BMEP and modal set points for F-76 test cycle

\begin{tabular}{|c|c|c|c|c|c|c|c|c|c|c|c|c|c|c|c|}
\hline BMEP (bar) & 0.15 & 3.27 & 6.53 & 4.75 & 4.63 & 4.00 & 9.50 & 9.26 & 7.99 & 14.24 & 13.88 & 11.99 & 18.85 & 17.80 & 15.41 \\
\hline Mode (-) & 1 & 2 & 3 & 4 & 5 & 6 & 7 & 8 & 9 & 10 & 11 & 12 & 13 & 14 & 15 \\
\hline Set Speed (rpm) & 601 & 900 & 900 & 1189 & 1416 & 1644 & 1189 & 1416 & 1644 & 1189 & 1416 & 1644 & 1189 & 1416 & 1644 \\
\hline Set Torque (ft-lb) & 0 & 244 & 488 & 355 & 346 & 299 & 710 & 692 & 597 & 1064 & 1037 & 896 & 1533 & 1497 & 1306 \\
\hline
\end{tabular}

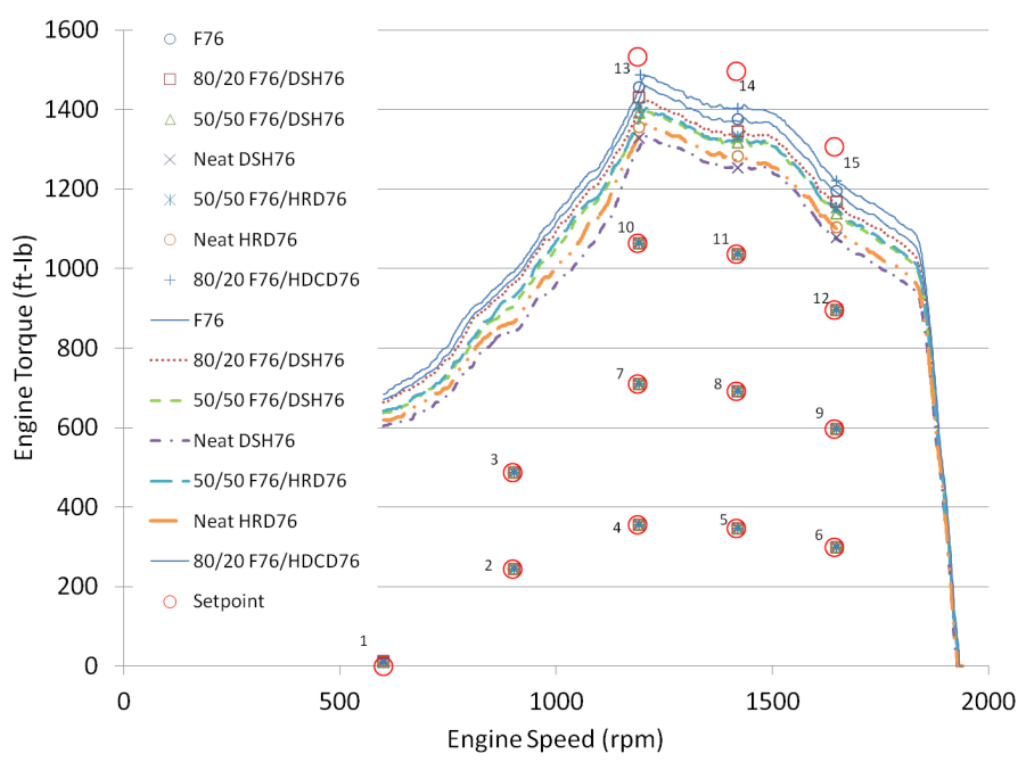

Figure 5-23: Engine Map and Set Points for F-76 Test Fuels

\subsubsection{In-Cylinder Combustion Parameters}

Several in-cylinder combustion parameters were recorded and calculated through the in-cylinder pressure analysis. The following sections will present the data for: heat release and heat release rate, incylinder pressure and temperature, fuel injection timing, ignition delay, and combustion phasing for all F76-based test fuels. The values for a given parameter and fuel were obtained by averaging the values for each mode from each test cycle. The F-76 candidate biofuels were compared to the reference fuel (F-76) using a percent difference and/or an absolute difference. A percent difference was used for parameters for non-crank angle location parameters; a negative percent difference indicates a reduction in a particular parameter and a positive percent difference shows an increase. Absolute difference was used for values related to crank angle location, such as injection timing, combustion phasing, locations of maximum values, etc. A positive difference shows retardation and a negative difference shows advancement in location compared to F-76.

\subsubsection{Heat Release and Heat Release Rate}

Investigation into parameters such as net heat released, maximum heat release rate and its location, as well as heat released during premix and diffusion provided means to understand performance differences between each test fuel. Figure 5-24 and Figure 5-25 illustrate the heat release rate curves at 
modes 5 and 12, respectively for F-76 and each candidate biofuel. From these figures it was obvious that the maximum HRR for all of the fuels, except 80/20 F76/HDCD76, was lower than baseline at both modes. The other test modes showed similar results across the test cycle (Figure 5-26). Across the test cycle, Neat HRD76 and 50/50 F76/HRD76 showed reductions in HRR of up to 46 and 28\%, respectively. Neat DSH76 and 50/50 F76/DSH76 showed reduction in maximum HRR of up to 28 and $\sim 15 \%$, while a smaller difference $(<7 \%)$ was noticed for $80 / 20$ F76/DSH76. Maximum HRR reductions became less significant as the engine load increased. The reduction in maximum HRR for these fuels was attributed to their higher cetane number, which promotes earlier ignition and therefore a smaller premix spike. Except at idle and full engine load 80/20 F76/HDCD76 showed an increase in maximum HRR of at least $10 \%$. Similar to the JP-5-based fuels, maximum HRR decreased as cetane number increased and as fuel density and aromatic content decreased, this is evident in Table 8-18.

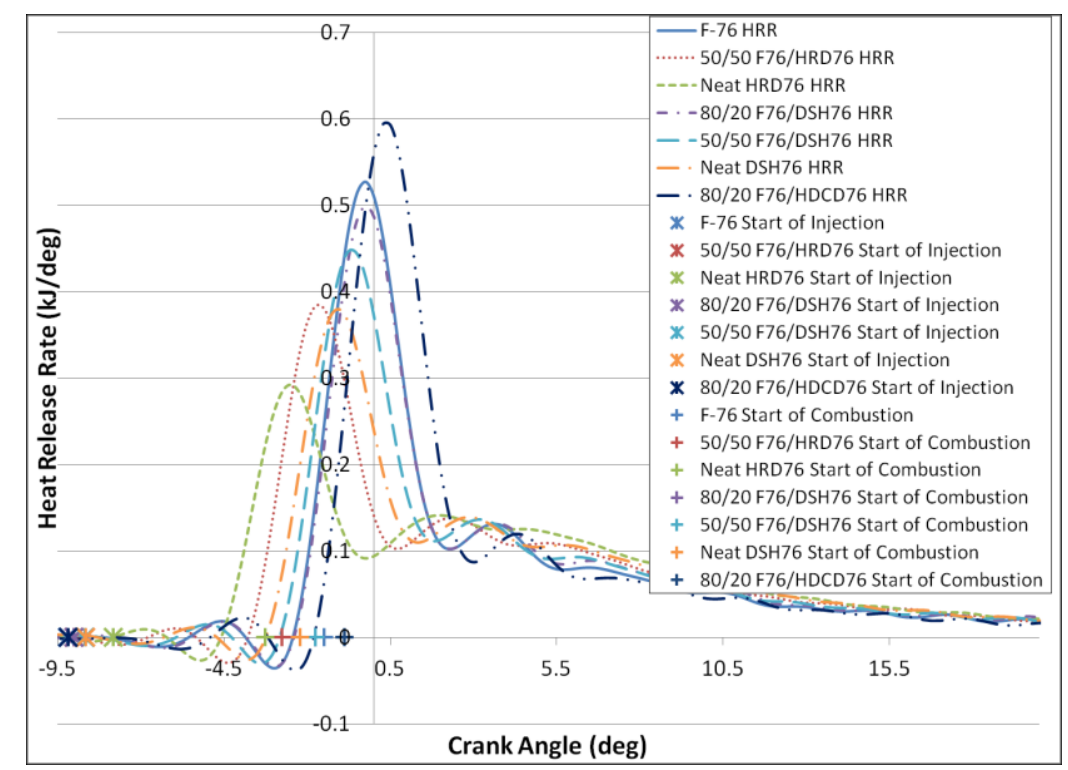

Figure 5-24: Heat Release Rate Curve at Mode 5 (25\% Engine Load and 1416 rpm) for F-76 Test Fuels 


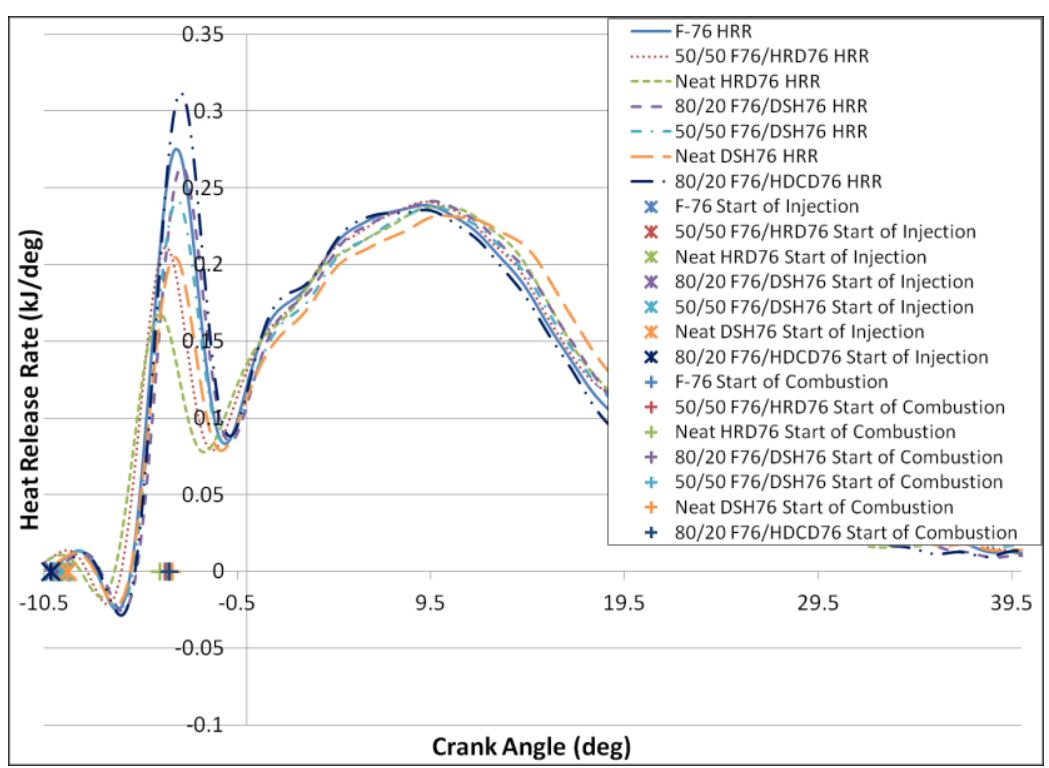

Figure 5-25: Heat Release Rate Curve at Mode 12 (75\% Engine Load and 1644 rpm) for F-76 Test Fuels

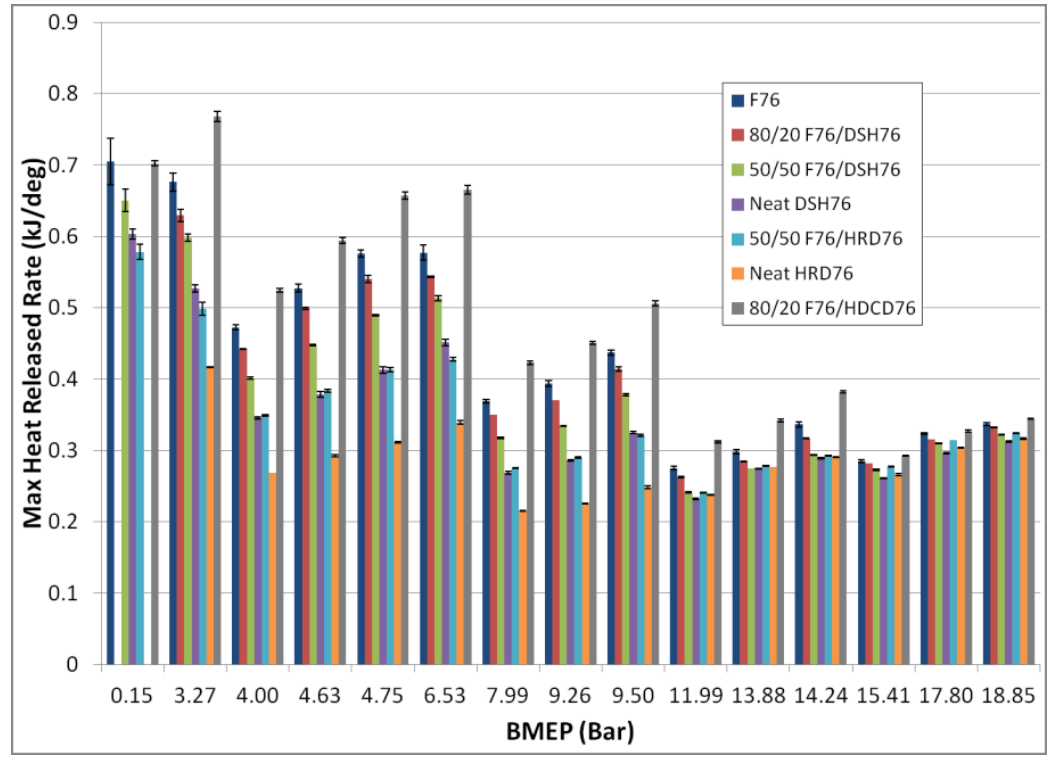

Figure 5-26: Maximum Heat Release Rate at each Test Mode for F-76 Test Fuels

Figure 5-27 shows the net heat released during the combustion period of each mode for all F-76 test fuels. Except at high BMEP (>15.4 bar) it is difficult to notice any significant differences in net heat released for any fuel. It was noted that data for 80/20 F76/DSH and Neat HRD76 was invalid at mode 1, due to lack of fuel injection into the cylinder. Mode 2 showed a slight difference in heat released for 80/20 F76/DSH76, Neat HRD76, and Neat DSH76. Except at modes 1 and 2 candidate biofuels showed less than 2\% difference in net heat released at BMEP less than 14.24 bar. At high BMEP ( $>15.4$ bar) slight reductions ( $\sim 1.5$ to $2.25 \%$ ) were noticed for $80 / 20$ F76/DSH76. Net heat released decreased as the 
amount of Neat DSH76 in the fuel increased: $\sim 3.8$ to $4.5 \%$ for 50/50 F76/DSH76 and $\sim 8.3$ to $9 \%$ for Neat DSH76. The 50/50 F76/HRD76 and Neat HRD76 fuels showed slightly lower reductions than the DSH fuels: $\sim 2.9$ to $3.9 \%$ and $\sim 6.4$ to $7 \%$, respectively. All of the fuels except 80/20 F76/HDCD76 showed reductions in heat released, which showed an increase of $\sim 1.5$ to $2 \%$ at BMEP of 15.4 bar and higher. As with the JP-5-based fuels the fuel density, cetane number, and aromatic content do not appear to have a significant effect on net released as indicated by the small slope or " $m$ " values in Table 8-19. The variation in net heat released could be attributed to the different heating values of the biofuels.

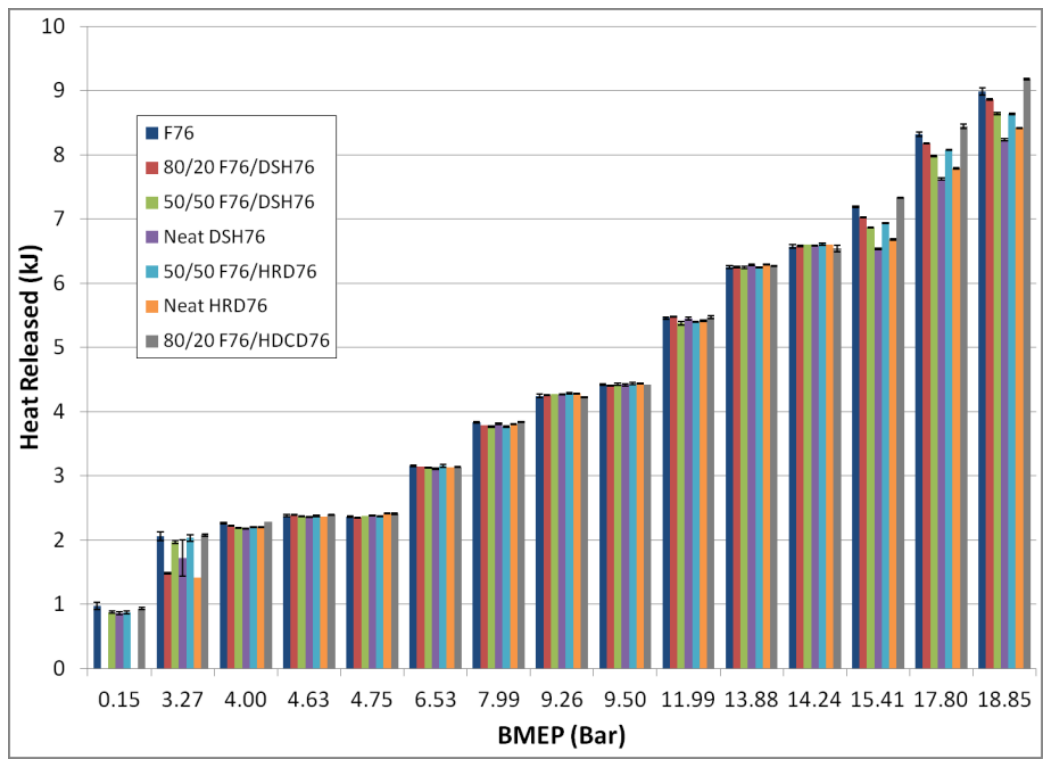

Figure 5-27: Net Heat Released for F-76 Test Fuels

\subsubsection{In-Cylinder Pressure and Pressure Rise Rate}

The in-cylinder pressure curves for modes 5 and 12 are shown in Figure 5-28 and Figure 5-29, respectively. The pressure curve at both modes indicates a reduction in maximum pressure for all of the candidate biofuels except 80/20 F76/HDCD76. The reduction in maximum pressure was most evident with Neat HRD76 and Neat DSH76; 2 to $13 \%$ and $\sim 3.5$ to $9.4 \%$, respectively. As the amount of Neat HRD76 and Neat DSH76 in the fuel blends decreased the difference in maximum in-cylinder pressure decreased. Across the test cycle the reduction in maximum pressure was only $\sim 1$ to $5 \%$ for $50 / 50$ F76/HRD76, 2 to 5.2\% for 50/50 F76/DSH76, and below 3\% for 80/20 F76/DSH76 except for mode 2. Except for idle, the maximum pressure for 80/20 F76/HDCD76 increased up to $\sim 2 \%$. The most significant differences were noticed at high (75 to 100\%) engine load, where the magnitude of in-cylinder pressure is greatest. Maximum pressure rise rates can be determined by examining the slope of the 
pressure curves but it is more practical to plot them as shown in Figure 5-30. The only fuel to achieve an increase in maximum PRR was 80/20 F76/HDCD76 ( 7 to 13\%). Neat HRD76 achieved the greatest reduction ( 25 to $42 \%$ ) in maximum PRR compared to F-76. Both Neat DSH76 and 50/50 F76/HRD76 achieved reductions in maximum PRR of $\sim 16$ to $26 \%$. The 50/50 F76/DSH76 and 80/20 F76/DSH76 fuels only achieved reductions up to $\sim 14$ and $8 \%$, respectively. Reductions in maximum PRR were greatest at low engine speed and load, where the magnitude of the PRR was greatest due to larger premix spikes. The in-cylinder pressure was significantly affected by the fuel density, cetane number, and aromatic content of the biofuels. This is evident in Table 8-20, indicated by the large slopes or " $m$ " values the maximum in-cylinder pressure decreased as cetane number increased and as density and aromatic content decreased. Therefore reductions of in-cylinder pressure were attributed to higher cetane number, lower density, and lower aromatic content of the biofuels. The opposite can be said for 80/20 F76/HDCD76, which showed an increase in maximum in-cylinder pressure. Table 8-21 shows that pressure rise rates were affected similarly by changes in fuel density, cetane number, and aromatic content.

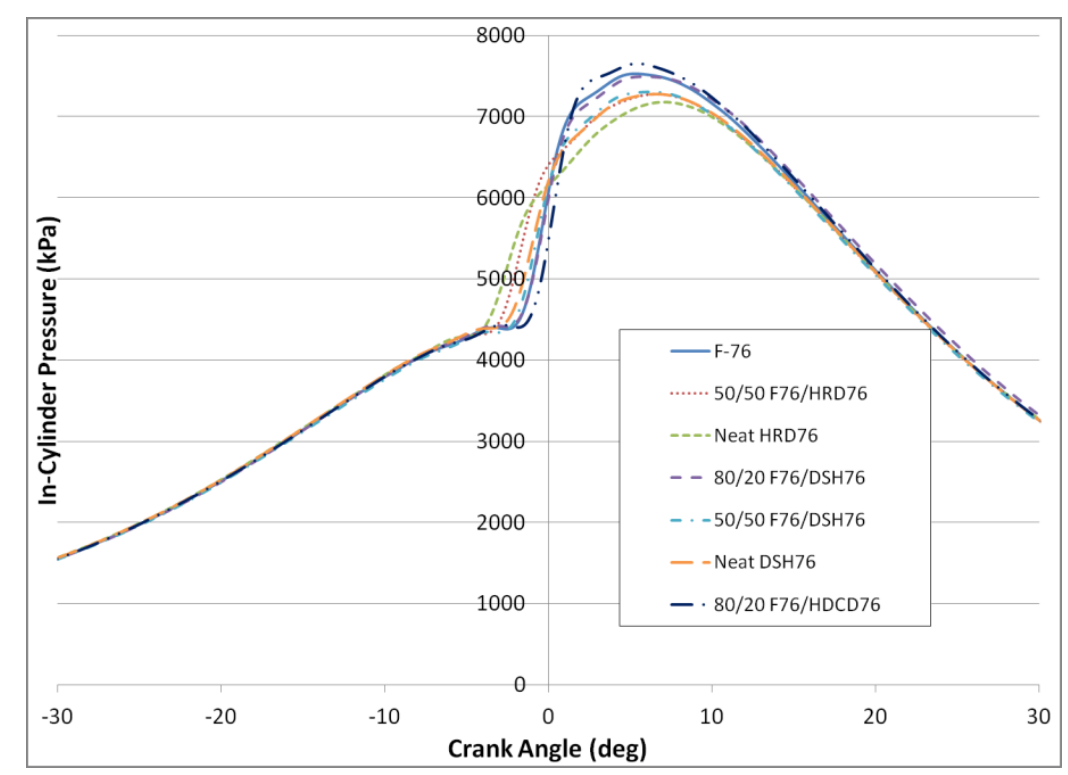

Figure 5-28: In-Cylinder Pressure Curve at Mode 5 (25\% Engine Load and 1430 rpm) for F-76 Test Fuels 


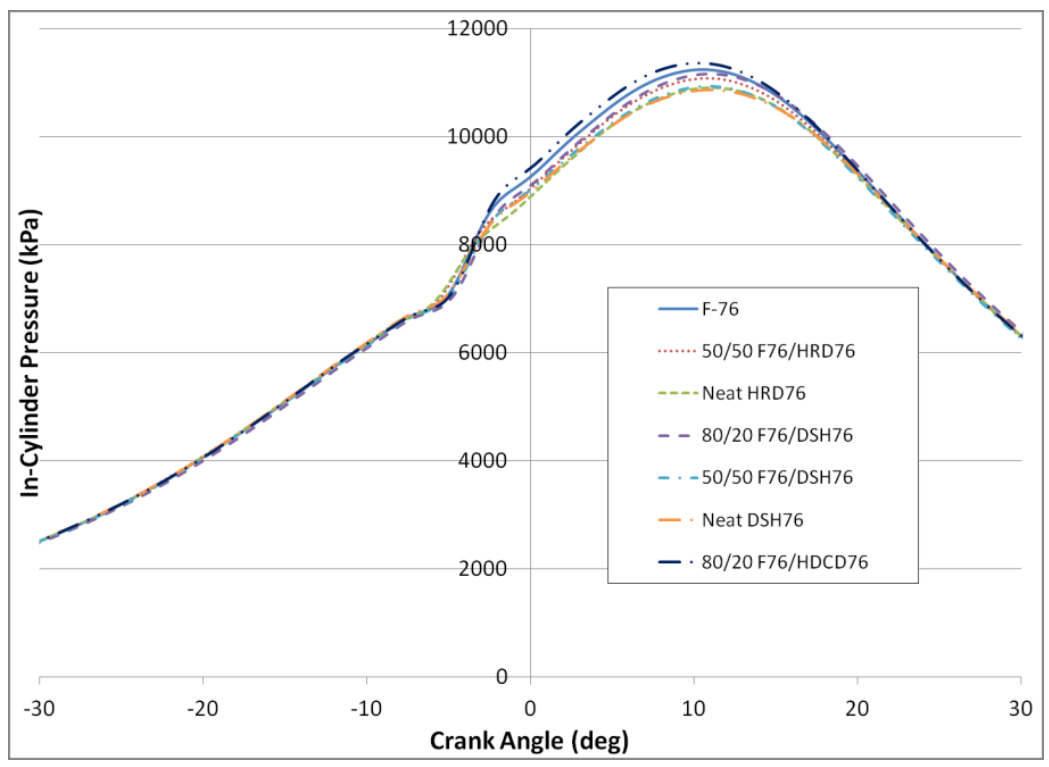

Figure 5-29: In-Cylinder Pressure Curve at Mode 12 (75\% Engine Load and 1644 rpm) for F-76 Test Fuels

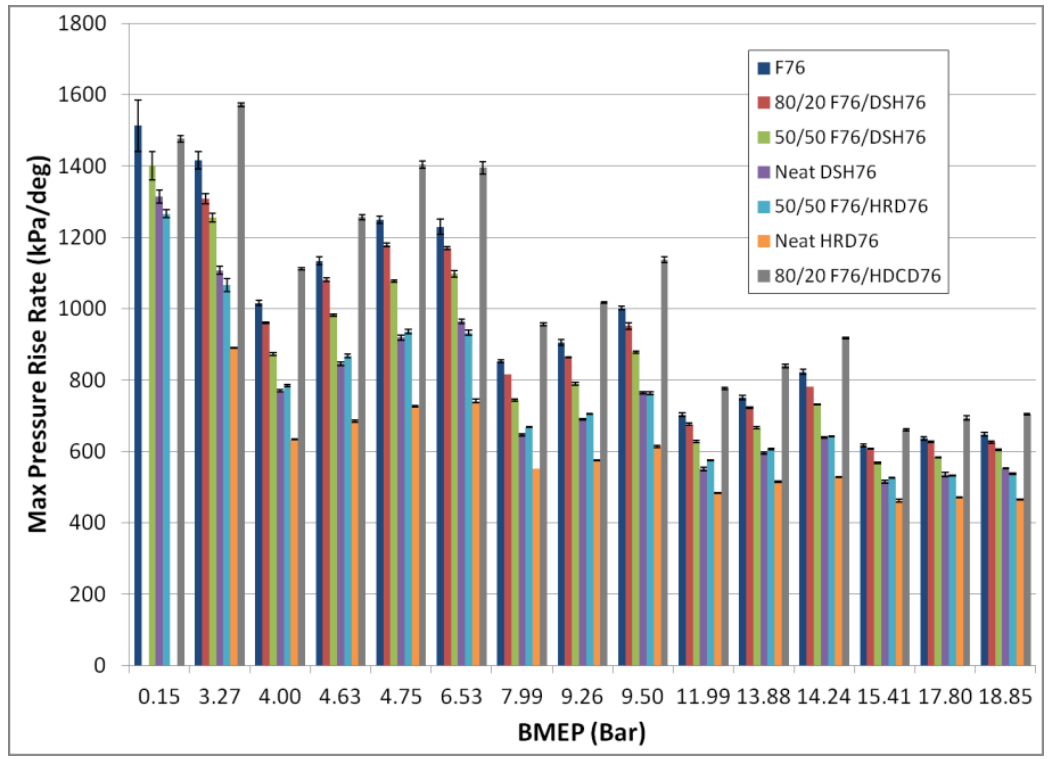

Figure 5-30: Maximum Pressure Rise Rate for F-76 Test Fuels

\subsubsection{In-Cylinder Temperature}

The maximum in-cylinder temperature was very similar for each test fuel at every mode. Mode 5, shown in Figure 5-31, showed a slight $(<2 \%)$ drop in maximum temperature for Neat HRD76, 50/50 F76/HRD76, Neat DSH76, 50/50F76/DSH76, and 80/20 F76/DSH76 compared to F-76. The 80/20 F76/HDCD76 blend showed a slight $(<1.5 \%)$ increase at every mode except idle. The difference of maximum in-cylinder temperature between the candidate biofuels and F-76 was even less at mode 12 (Figure 5-32). Temperatures were very similar across the test cycle for each fuel. This was attributed to 
the similar heating values of the candidate biofuels and F-76 and indicates that the different fuel properties do not significantly affect in-cylinder temperature. The maximum in-cylinder temperature decreased as cetane number increased and as fuels density and aromatic content decreased. This is indicated by the negative slope or " $m$ " values for cetane number and positive values for density and aromatics in Table 8-22.

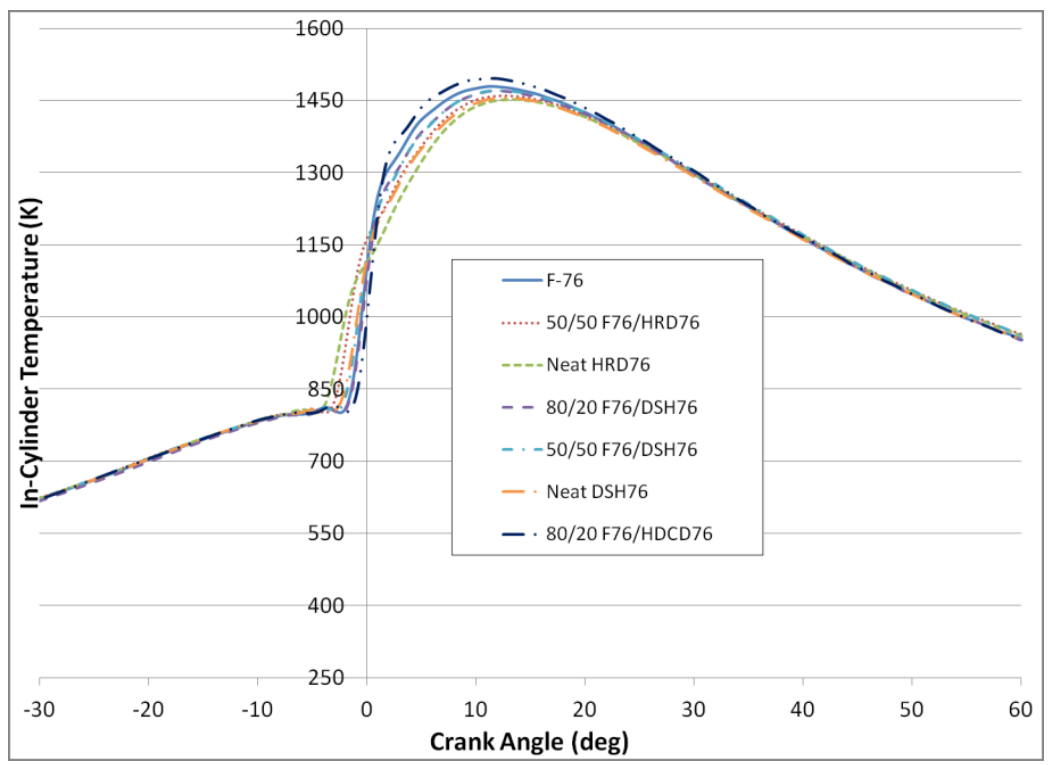

Figure 5-31: In-Cylinder Temperature Curve at Mode 5 (25\% Engine Load and $1430 \mathrm{rpm}$ ) for F-76 Test Fuels

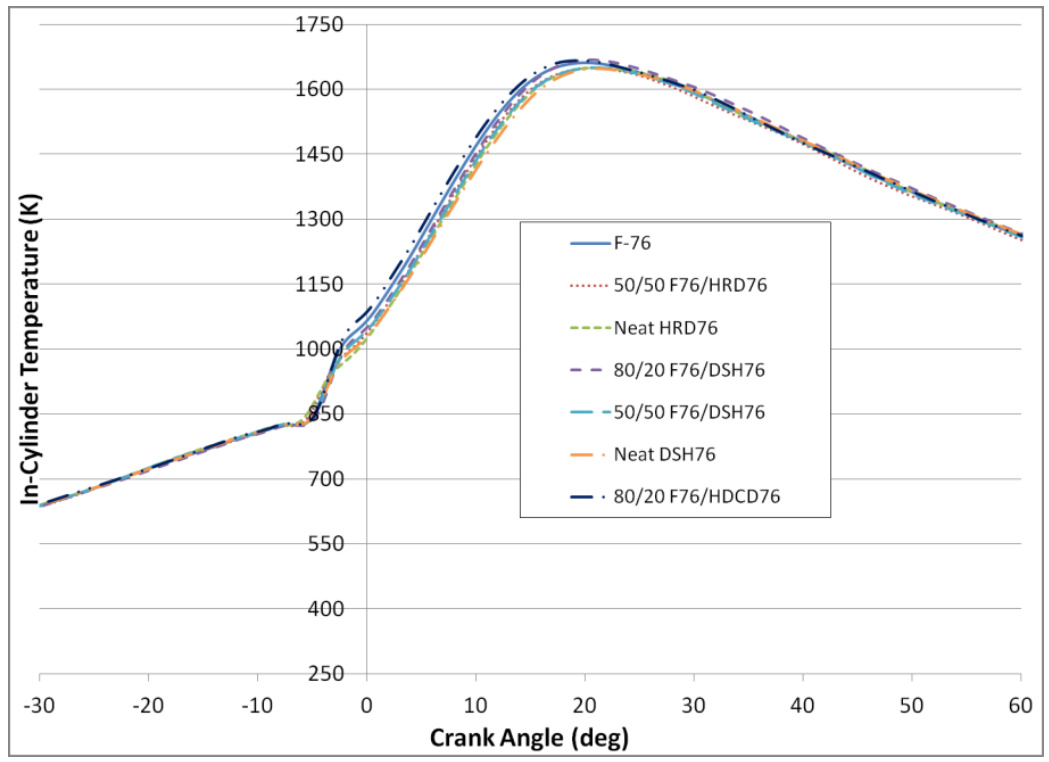

Figure 5-32: In-Cylinder Temperature Curve at Mode 12 (75\% Engine Load and 1644 rpm) for F-76 Test Fuels 


\subsubsection{Start of Fuel Injection and Ignition Delay}

Start of fuel injection and start of combustion is indicated in Figure 5-33 and Figure 5-34 for modes 5 and 12, respectively. The crank angle period between the start of fuel injection and start of combustion is the ignition delay. Start of combustion was determined based on the location of 5\% mass fraction burned. At mode 5 (Figure 5-33), the fuel injection was slightly retarded for all candidate biofuels, except 80/20 F76/HDCD76, and start of combustion was advanced compared to F-76. Ignition delay was shorter by: 3.1 degrees for Neat HRD76, 1.45 degrees for 50/50 F76/HRD76, 1.25 degrees for Neat DSH76, 0.8 degrees for 50/50 F76/DSH76, and 0.45 degrees for 80/20 F76/DSH76. Ignition delay for 80/20 F76/HDCD76 at mode 5 was $\sim 1.4$ degrees longer compared to F-76. Similar results are noticed in Figure 5-34 for mode 12. Across the entire test cycle ignition delay was usually shorter for Neat HRD76, 50/50 F76/HRD76, Neat DSH76, 80/20 F76/DSH76, and 50/50 F76/DSH76; and longer for 80/20 F76/HDCD76.

The effects of fuel density, cetane number, and aromatic content on start of injection and start of combustion are presented in Table 8-23and Table 8-24, respectively. The effects of fuel viscosity were also examined for start of fuel injection. Stated previously, the literature [27] suggests that fuel injection is slightly retarded due to higher viscosities. Similar results were found in this study except for the $80 / 20$ F76/HDCD76 fuel. The later injection due to higher viscosity is indicated by the negative slope or " $\mathrm{m}$ " values in Table 8-23. Retarded fuel injection could also be attributed to the lower fuel density of the biofuels. The advanced start of combustion is most likely attributed to the higher cetane number of the biofuels. This is indicated by the negative slope or " $m$ " values for cetane number in Table 8-24.

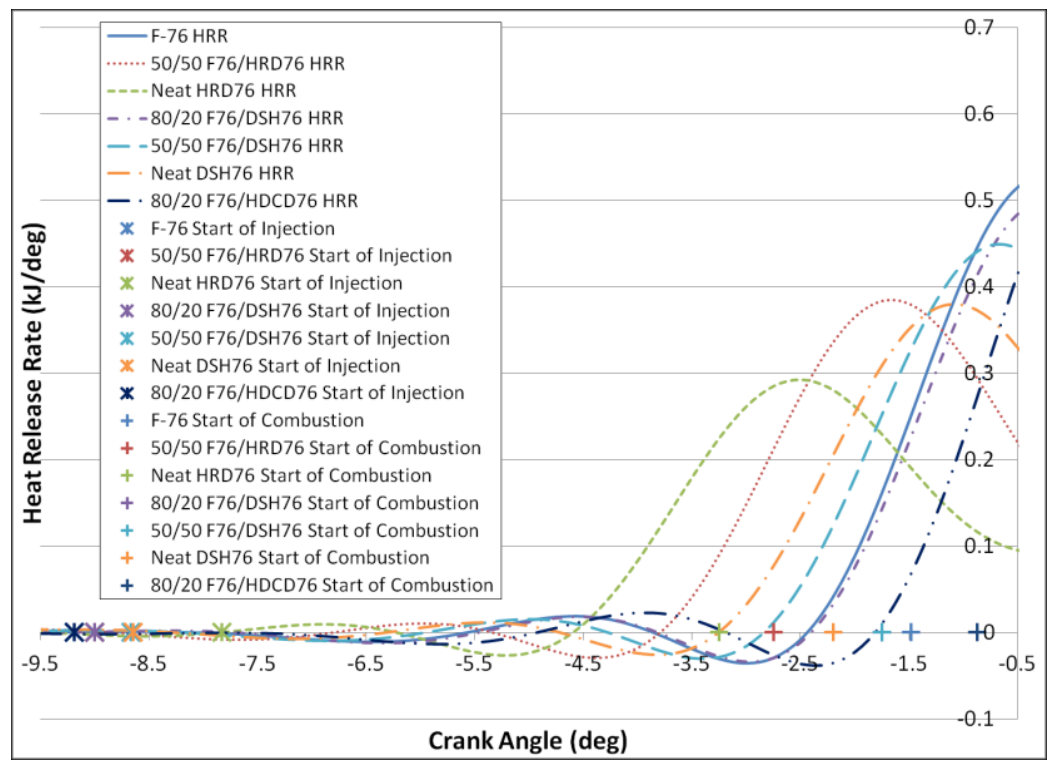

Figure 5-33: Heat Release Rate Curve at Mode 5 Indicating Start of Fuel Injection and Start of Combustion for F-76 Test Fuels 


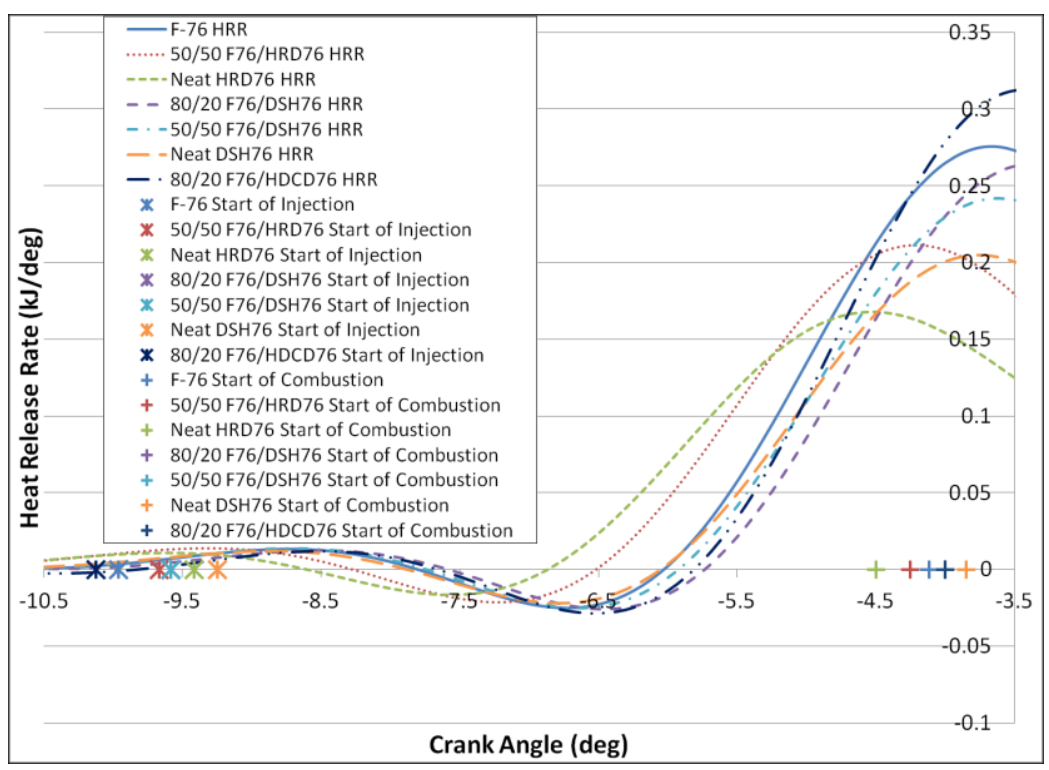

Figure 5-34: Heat Release Rate Curve at Mode 12 Indicating Start of Fuel Injection and Start of Combustion for F-76 Test Fuels

\subsubsection{Premix and Diffusion Fraction}

Figure 5-24 and Figure 5-25 indicated that at low loads the combustion period is predominantly premix fraction and diffusion fraction at high load. Premix was indicated by the sudden large spike in HRR, diffusion was indicated by the slower more controlled change in HRR. Figure 5-35 and Figure 5-36 illustrate the length of the premix and diffusion fractions at each test mode, respectively. The premix fraction was shorter for all of the candidate biofuels except 80/20 F76/HDCD76 and 80/20 F76/DSH76. Although length of the premix fraction for 80/20 F76/DSH76 was shorter at most modes it was not consistently shorter and the difference from F-76 was minimal, less than 0.14 degrees. The 80/20 F76/HDCD76 fuel showed a slight increase, up to $\sim 0.27$ degrees, in premix fraction length. The change in premix fraction length for the 80/20 F76/DSH76 and 80/20 F76/HDCD76 fuel blends may not be significant due to the 0.25 degree resolution of the pressure DAQ system. The rest of the fuels showed a consistent decrease in premix fraction length. Premix fraction length was only slightly decreased, up to $\sim 0.24$ degrees, for 50/50 F76/DSH76 and moderately shorter, up to $\sim 0.39$ degrees, for Neat DSH76. The 50/50 F76/HRD76 fuel showed a slightly more pronounce difference than Neat DSH76, up to $\sim 0.52$ degrees compared to F-76. The decrease in premix fraction length was most pronounced for Neat HRD76; up to $\sim 1$ degree shorter at full power. The length of the diffusion fraction was generally longer for the biofuels, except 80/20 F76/HDCD76. Between BMEP of 4 and 13.88 bar the diffusion fraction length was longer for: Neat HRD76 (2 to 5.2 degrees), 50/50 F76/HRD76 (0.75 to 3.8 degrees), Neat DSH76 (2.4 to 3.8), 50/50 F76/DSH76 (0.3 to 1.9 degrees), and 80/20 F76/DSH76 (0.1 to 1.2 degrees). Within this range the difference in diffusion fraction length generally decreased as BMEP increased. Above this range it was difficult to determine any significant differences because results varied and 
diffusion length was usually no more than 0.6 degrees different. The diffusion fraction length for 80/20 F76/HDCD76 was consistently shorter by about one degree but showed a maximum and minimum difference of 0.1 and 2.9 degrees, respectively. Slight effects of density, cetane number, and aromatic content on the premix and diffusion fraction lengths were noticed based on the small slope values in Table 8-25 and Table 8-26, respectively. Although effects were small, reductions in premix fraction length were attributed to lower density, lower aromatic content, and higher cetane number. Increases in diffusion fraction length were attributed to an increase in cetane number and a decrease in density and aromatic content.

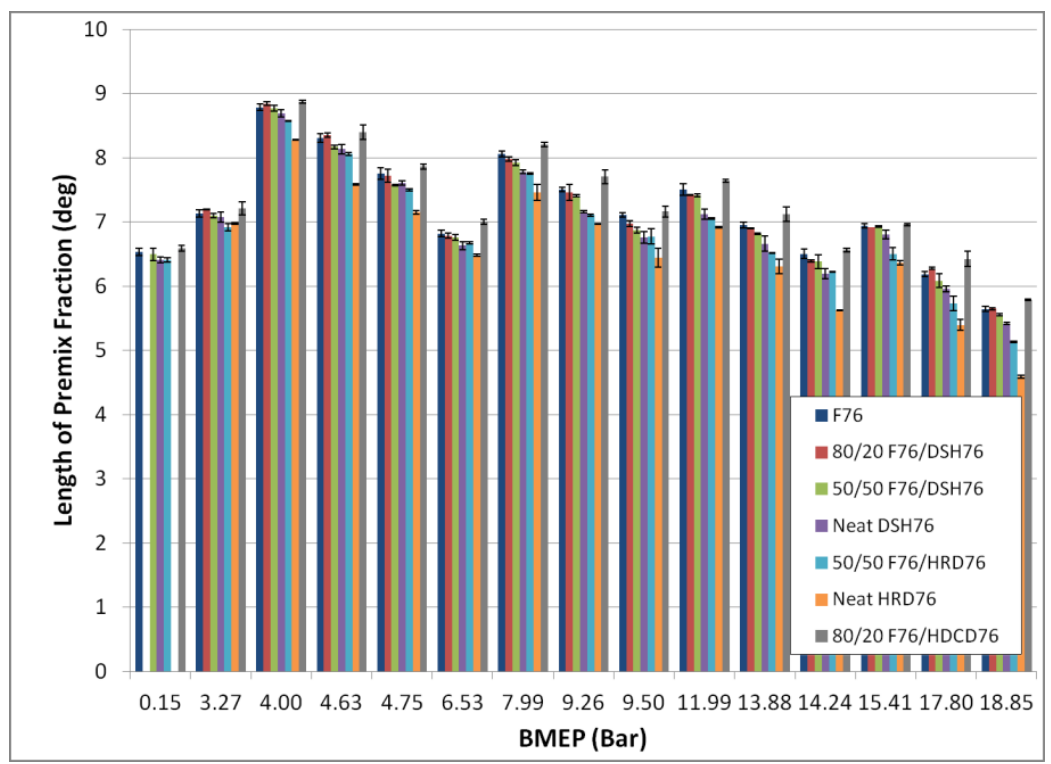

Figure 5-35: Length of Premix Fraction for F-76 Test Fuels 


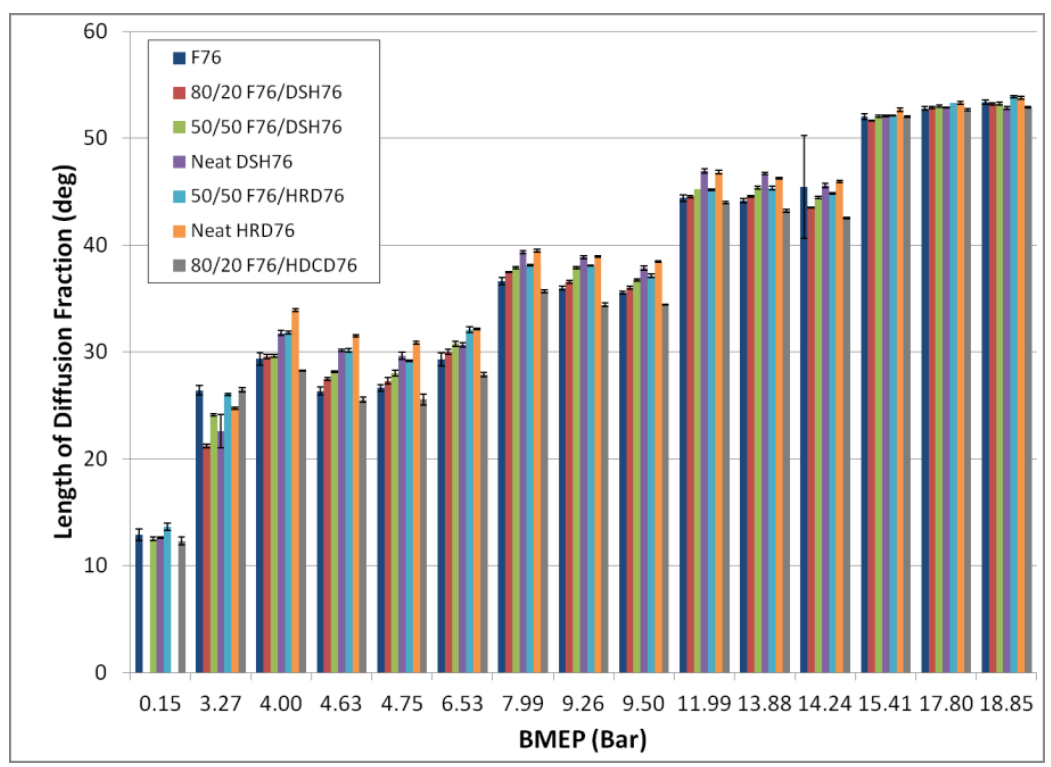

Figure 5-36: Length of Diffusion Fraction for F-76 Test Fuels

\subsubsection{Emissions}

The emission results for the F-76 test fuels during steady state tests are presented in the following sections. These results include the brake specific mass emissions of $\mathrm{HC}, \mathrm{NOx}, \mathrm{CO}, \mathrm{CO}_{2}$, and $\mathrm{PM}$, as well as brake specific fuel consumption. The brake specific values were obtained by averaging the data for each mode of all the tests for a given fuel. The candidate biofuels were compared to F-76 by using a percent difference. A negative percent difference shows a reduction in a particular emission constituent from F-76 and a positive percent difference shows an increase. Any variation in small numbers would show up as a large percent difference. Some of this variation in small values could be attributed to the emissions analyzer ranges. It is important to note that variations also occurred at mode 1 (idle), so this information must be taken lightly since all the data for the idle mode were small values due to the selected tunnel flow rate and analyzer full-scale range selected to capture the highest concentrations during testing. Note that the idle mode, mode 1 , data is provided on a mass rate basis while the other 14 modes are on a brake-specific mass basis. The effect of fuel density, cetane number, and aromatic content on exhaust emissions were examined by applying a linear curve fit to each emission constituent against a given fuel property. This was explained in more detail in Section 5.2.2 covering emissions of the JP-5 test fuels.

\subsubsection{HC}

Brake specific HC emissions for F-76 test fuels are displayed in Figure 5-37 for all 15 test modes. Although large percent reductions were noticed for Neat HRD76 (up to 52\%), 50/50 F76/HRD76 (up to 49\%), and Neat DSH76 and 50/50 F76/DSH76 (up to 25\%); the absolute difference is relatively small due to the low magnitude of bsHC emissions. The 80/20 F76/DSH76 fuel showed reductions less than $10 \%$ at 
most modes but also showed a slight increase at modes 3, 7, 8, and 10. The 80/20 F76/HDCD76 fuel showed a consistent increase in bsHC emissions up to $16 \%$. The difference in bsHC emissions are most significant under a BMEP of 4.75 bar, beyond this BMEP the magnitude is low and it is difficult to determine the significance of the percent difference in bsHC emissions for the biofuels. Based on the curve fit analysis in Table 8-27, the decrease in bsHC emissions was attributed to the lower fuel density, lower aromatic content, and higher cetane number of the biofuels. The 80/20 F76/HDCD76 fuel, which had a higher fuel density, higher aromatic content, and lower cetane number, further supported this claim as its operation resulted in an increase in bsHC emissions. At high loads the effects of fuel properties is negligible, indicated by the small slope or " $m$ " values in Table 8-27.

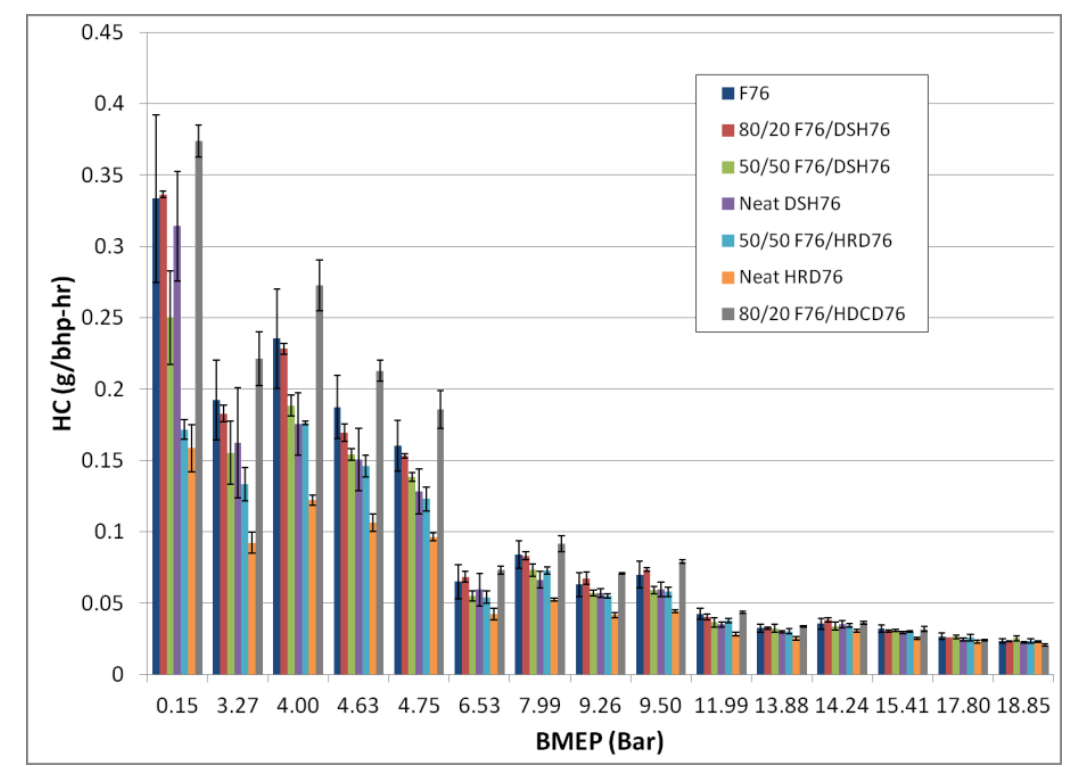

Figure 5-37: Brake Specific HC Emisions for F-76 Test Fuels

\subsubsection{NOx}

Brake specific NOx emissions (Figure 5-38) were lower at every mode for each candidate biofuel except 80/20 F76/HDCD76. The 80/20 F76/HDCD76 fuel showed an increase in bsNOx up to $10 \%$ at $25 \%$ engine load. The increase bsNOx for this fuel became less evident as engine load and BMEP increased; less than 5\% increase from 50\% to 100\% engine load (BMEP of 7.99 to 18.85 bar). The most significant reductions in bsNOx were noticed at low loads, where the magnitude of bsNOx emissions was greatest. The two neat biofuels showed the greatest reduction of bsNOx emissions; $\sim 9$ to $26 \%$ for Neat HRD76 and $\sim 11$ to $23 \%$ for Neat DSH76. NOx emissions were reduced by: $\sim 3$ to $15.6 \%$ for $50 / 50$ F76/HRD76, $\sim 1.6$ to $10.5 \%$ for 50/50 F76/DSH76, and $\sim 3.3$ to $5.5 \%$ for 80/20 F76/DSH76. The reductions in NOx emissions were attributed to the lower fuel density, lower aromatic content, and higher cetane number of the biofuels; which led to earlier ignition, shorter premix fraction, longer diffusion 
fraction, and therefore lower combustion temperatures. This was verified by the analysis in Table 8-28, where increasing cetane number resulted in decreasing bsNOx, while increasing fuel density and aromatics resulted in increasing bsNOx.

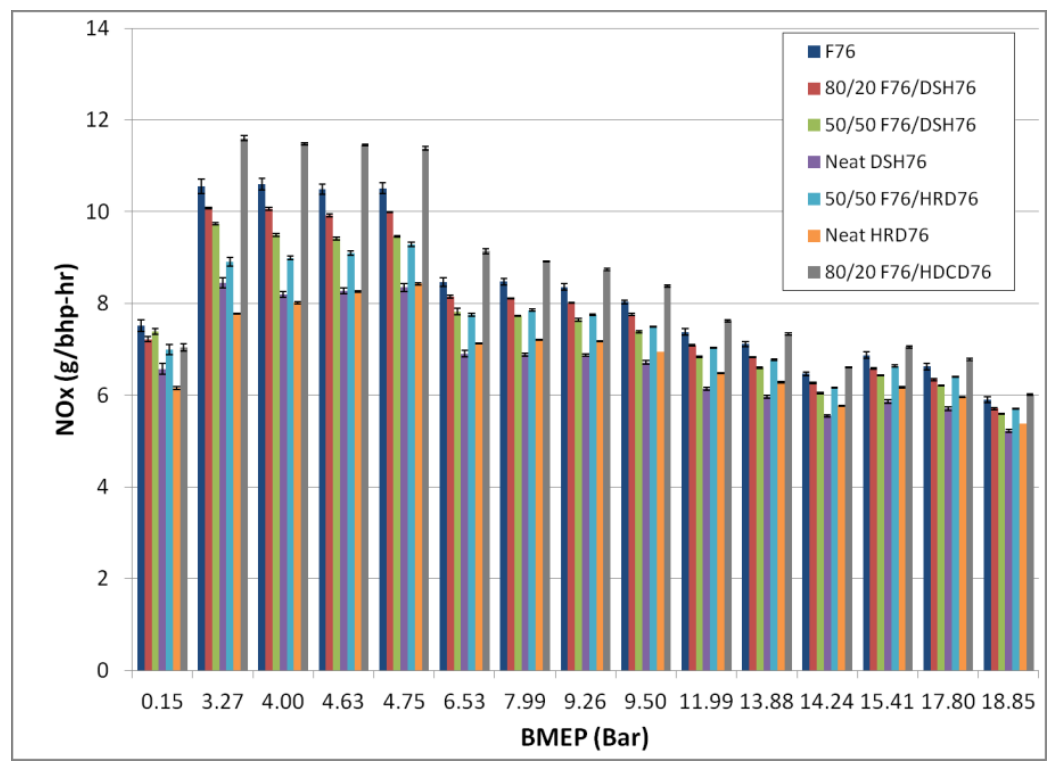

Figure 5-38: Brake Specific NOx Emissions for F-76 Test Fuels

\subsubsection{CO}

Brake specific CO emissions are displayed in Figure 5-39. Relatively large percent differences in bsCO emissions were achieved with the biofuels; however, due to the relatively low magnitude of bsCO emissions, especially at low to medium engine load, it is difficult to determine how significant the differences are. At high engine load (BMEP $>14.24$ bar) the difference in bsCO emissions is evident and significant for some candidate biofuels. The difference in this range is most noticeable for Neat HRD76 and 50/50 F76/HRD76, which showed reduction in bsCO of $\sim 6.2$ to $13.7 \%$ and $\sim 5.5$ to $12.5 \%$, respectively. Neat DSH76 also showed slight reductions in bsCO of $\sim 1.3$ to $7.9 \%$. Except at idle the 50/50 F76/DSH76 fuel showed up to a 16\% difference in bsCO emissions, while 80/20 F76/DSH76 showed an increase of $\sim 2.4$ to $9.2 \%$. An increase of up to $5.4 \%$ in bsCO was noticed for $80 / 20$ F76/HDCD76 in this range. Table 8-29 indicates that there is no significant and/or consistent relationship between density, cetane number, or aromatic content and bsCO emissions. 


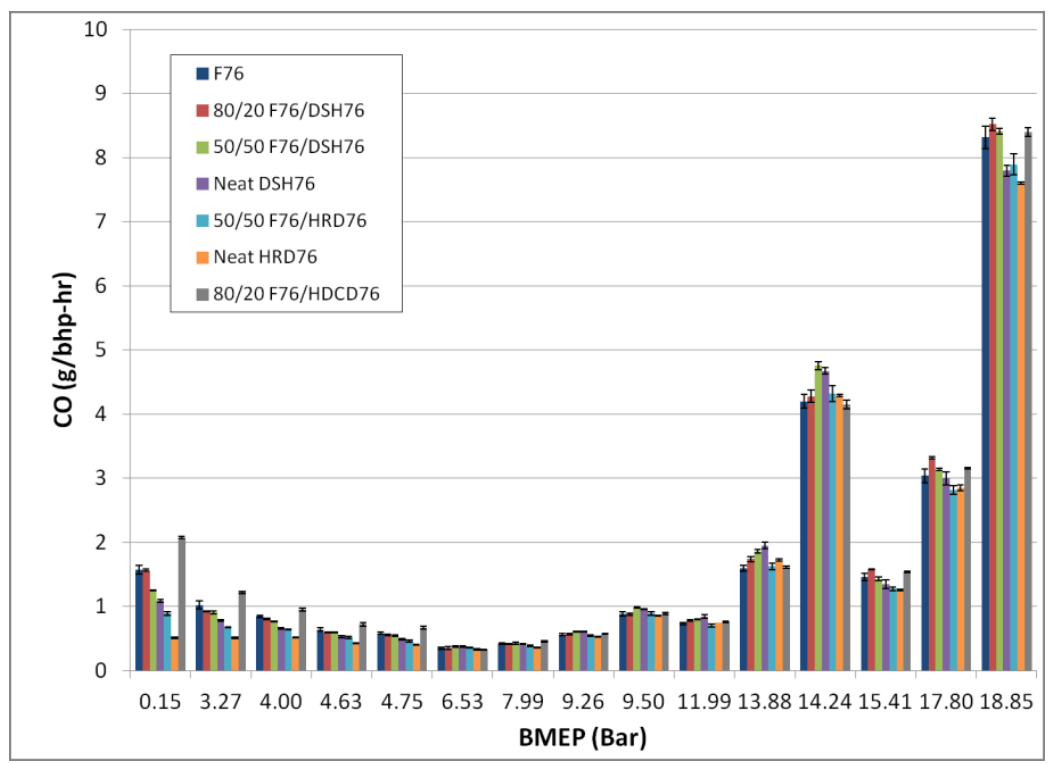

Figure 5-39: Brake Specific Emissions of CO for F-76 Test Fuels

\subsubsection{4 $\mathrm{CO}_{2}$}

Consistent reductions in brake specific $\mathrm{CO}_{2}$ were noticed for all candidate biofuels except 80/20 F76/HDCD76, which showed a consistent increase. This is evident in Figure 5-40, which shows the magnitude of $\mathrm{bsCO}_{2}$ emissions at each test mode. Aside from idle, Neat HRD76 and Neat DSH76 showed very similar reductions in $\mathrm{bsCO}_{2}$ between 3.8 and $6.2 \%$. Brake specific $\mathrm{CO}_{2}$ emissions were reduced by: $\sim 1.9$ to $2.8 \%$ for $50 / 50$ F76/DSH76, $\sim 1.6$ to $2.2 \%$ for $50 / 50$ F76/HRD76, and $\sim 0.5$ to $1.8 \%$ for $80 / 20 \mathrm{~F} 76 / \mathrm{DSH} 76$. Operation of $80 / 20 \mathrm{~F} 76 / \mathrm{HDCD} 76$ resulted in an increase of $\mathrm{bsCO}_{2}$ by $\sim 1.1$ to $1.5 \%$. It was obvious that as the amount of $\mathrm{F}-76$ in the fuel increased the difference in $\mathrm{bsCO}_{2}$ emissions decreased. Table 8-30 provides an analysis of fuel property effects on $\mathrm{bsCO}_{2}$. From this analysis it was concluded that reductions in $\mathrm{bsCO}_{2}$ were achieved due to lower fuel density, lower aromatic content, and higher cetane number. In the literature $\mathrm{CO}_{2}$ reductions were attributed to a higher $\mathrm{H} / \mathrm{C}$ ratio hydrotreated fuels [6]. 


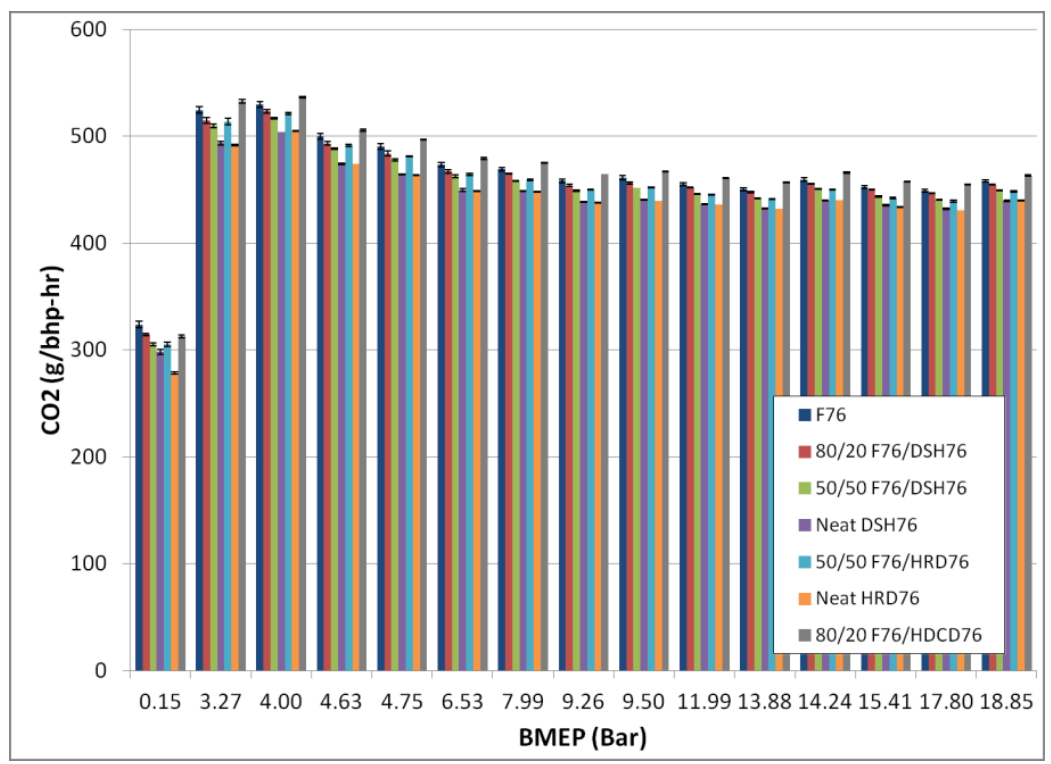

Figure 5-40: Brake Specific Emissions of $\mathrm{CO}_{2}$ for F-76 Test Fuels

\subsubsection{PM}

The biofuels generally showed reductions in brake specific PM (Figure 5-41) across the test cycle. However, 50/50 F76/DSH76 showed an increase in bsPM at a BMEP of 13.88 and 14.24 bar and 80/20 F76/DSH76 showed an increase above 13.88 bar. The rest of the candidate biofuels showed consistent reductions in bsPM across the entire test cycle. Reductions in bsPM were most evident for Neat HRD76 and Neat DSH76 and became less evident as the amount of F-76 in the fuel increased. Reductions in bsPM ranged from: $\sim 20$ to $60 \%$ for Neat HRD76, 8.4 to 50\% for 50/50 F76/HRD76, 4 to $60 \%$ for Neat DSH76, and $\sim 2$ to $22 \%$ for $80 / 20$ F76/HDCD76. Below a BMEP of 13.88 bar, 50/50 F76/DSH76 showed a reduction in bsPM of $\sim 9.8$ to $31.5 \%$ and $\sim 0.73$ to $18 \%$ for $80 / 20$ F76/DSH76. Table 8-31 indicates that as fuel density and aromatic content increase, bsPM emissions increase; and as cetane number increases, bsPM emissions decrease. Therefore, reductions in bsPM were attributed to higher cetane number and lower fuel density and aromatic content. 


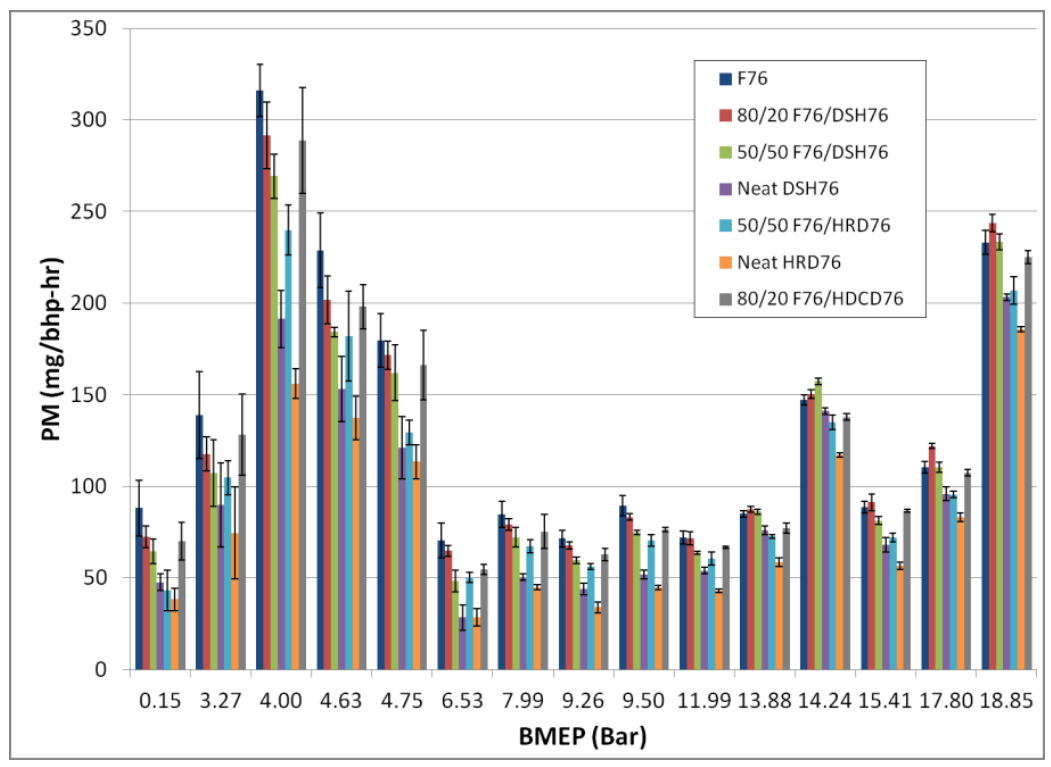

Figure 5-41: Brake Specific PM Emissions for F-76 Test Fuels

\subsubsection{Fuel Economy}

Brake specific fuel consumption for each fuel is presented in Figure 5-42. As expected the bsFC for all of the candidate biofuels, except 80/20 F76/HDCD76, was slightly reduced. Brake specific FC for $80 / 20$ F76/HDCD76 increased by about $1 \%$ at every mode except idle. Differences were magnified at idle due to the already low bsFC for every fuel. Reductions in bsFC were most evident with Neat HRD76 $(\sim 1.8$ to $4.2 \%)$ and Neat DSH76 ( 1.8 to $4 \%)$. The 80/20 F76/DSH76 fuel showed relatively lower reductions of less than $1.5 \%, 50 / 50$ F76/DSH76 was only slightly better with reductions less than $2.2 \%$. The 50/50 F76/HRD76 fuel also showed lowered reductions in bsFC, less than 1.4\%. Although changes in fuel consumption were modest, they were attributed to the higher cetane number, lower fuel density, and lower aromatic content. This claim is supported by the analysis in Table 8-32, which shows that bsFC decreases as cetane number increases and fuel density and aromatic content decrease. 


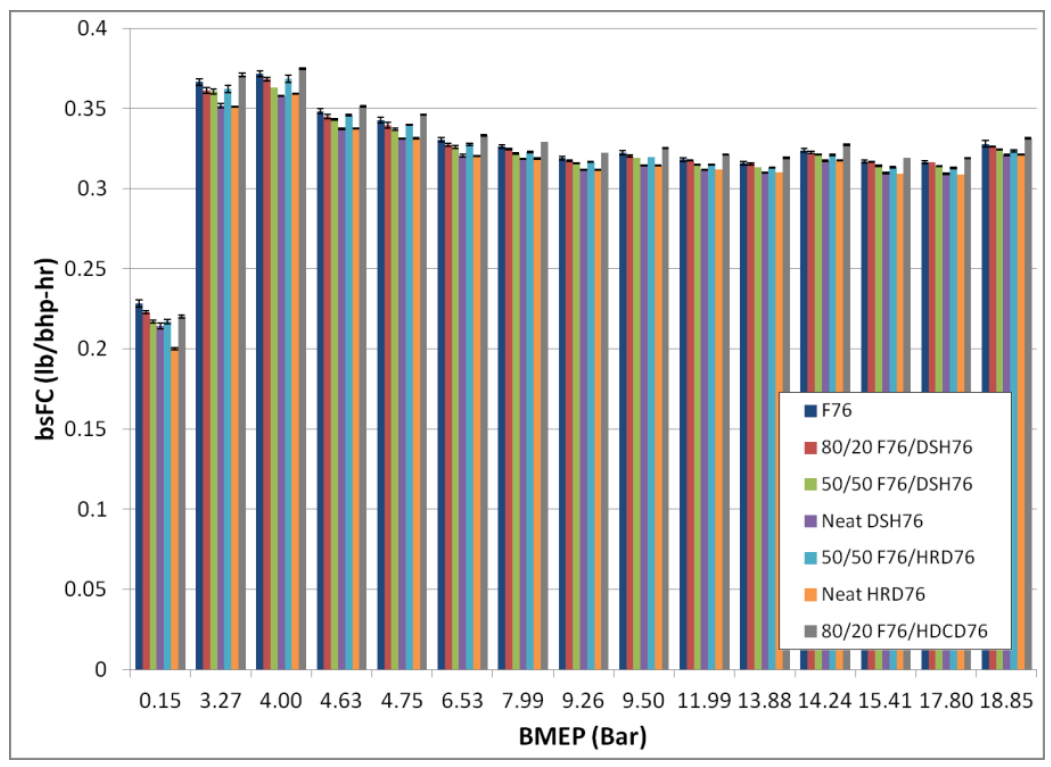

Figure 5-42: Brake Specific Fuel Consumption for F-76 Test Fuels

\subsection{Uncertainty of Data}

The experimental measurements, and data derived from these measurements, have an uncertainty associated with each measurement. It is recognized that a propagation of error analysis, or similar analytical approach, could be performed to quantify the possible error in each measurement. However, a different approach was taken in this work to provide an indication of the uncertainty. First, historical data were available for this engine in the laboratory. Preliminary tests, not reported here, were compared to this historical data and these data showed consistency with the prior data. It is noted that this comparison does not necessarily mean the data presented herein is accurate or precise but does indicate that the engine did operate, along with the emissions and in-cylinder pressure data, consistently with prior data.

Secondly, a comparison of the fuel consumed and fuel recovered through a dilute emissions carbon balance was examined. From this comparison, it was observed that the direct fuel consumption and carbon balance fuel consumption were within 5\%. Based on this comparison, the emissions data are assumed to be within $5 \%$ of the true value. 


\section{Chapter 6: Conclusions and Recommendations}

\subsection{Conclusions}

Eight different biofuels, from four different base fuels, were investigated on a 1992 Series 60 DDC engine. The biofuels were split into two groups based on their reference fuels (JP-5 and F-76). The engines were exercised over a 15 mode steady state test, with in-cylinder pressure and needle lift data collected. The emissions of $\mathrm{CO}, \mathrm{CO}_{2}, \mathrm{HC}, \mathrm{NOx}$, and TPM were also collected. The in-cylinder pressure and needle lift data was used to determine in-cylinder combustion parameters, fuel injection timing, and combustion phasing. In addition to the steady state test, a transient idle to full power step test was conducted for the JP-5 fuel set. Combustion, emission, and engine performance of the candidate biofuels were compared to the respective reference fuel.

- Differences in maximum heat release rate for both fuels sets were most evident at low to medium load. Both JP-5 candidate biofuels showed reductions up to 25 and 43\% for 50/50 JP5/HRJ5 and Neat HRJ5, respectively. Maximum heat release rate was reduced up to: $28 \%$ for Neat DSH76, $\sim 15 \%$ for $50 / 50$ F76/DSH76, $7 \%$ for $80 / 20$ F76/DSH76, $46 \%$ for Neat HRD76, and $\sim 28 \%$ for 50/50 F76/HRD76. The reduction in maximum heat release for these fuels was attributed to their higher cetane number, which promotes earlier ignition and therefore a smaller premix spike. Again, 80/20 F76/HDCD76 was the only fuel to show an increase (up to $16 \%$ ) and was attributed to its lower cetane number, which led to a larger premix spike.

- The maximum in-cylinder pressure for both Neat HRJ5 and 50/50 HRJ5 was slightly lower at all modes; up to $7 \%$ for Neat HRJ5 and 5\% for 50/50 JP5/HRJ5. The F-76 fuel set showed similar results for the HRD and DSH fuels. Neat HRD76 and Neat DSH76 showed a more significant drop in in-cylinder pressure of up to 13 and $9.4 \%$, respectively. The blended fuels containing DSH76 and HRD76 showed a less significant reduction in maximum in-cylinder pressure of up to $\sim 5 \%$. The peak pressure increased up to $2 \%$ for $80 / 20$ F76/HDCD76 and showed advancement up to 0.85 degrees in location.

- The maximum pressure rise rate was reduced by: $\sim 16$ to $39 \%$ for Neat HRJ5, 6 to $22 \%$ for $50 / 50$ HRJ5/JP5, 25 to $42 \%$ for Neat HRD76, and $\sim 16$ to $26 \%$ for Neat DSH76 and 50/50 F76/HRD76. The 50/50 F76/DSH76 and 80/20 F76/DSH76 fuels showed moderate reductions up 14 and $8 \%$, respectively.

- The maximum in-cylinder temperature for both Neat HRJ5 and 50/50 JP5/HRJ5 was reduced up to $4 \%$ compared to the JP-5 fuel. The F-76 fuel set showed similar results with maximum drop in 
peak temperature of about 2\%, excluding the second mode. Also, 80/20 F76/HDCD76 showed a slight $(<1.5 \%)$ increase in peak temperature. The reduced in-cylinder peak temperature was attributed to the lower peak pressure and heat release rate due to the higher cetane number and lower heating value of the biofuels.

- For all of the candidate biofuels, with the exception of 80/20 F76/HDCD76, premix fraction length was shorter, heat released during premix was lower, diffusion fraction length was longer, and heat released during diffusion was higher. This was due to the lower rate of pressure rise and heat release of the biofuels caused by the difference in cetane number and heating value. These fuel properties, among others, also led to more efficient and overall longer combustion of the biofuels compared to JP-5 and F-76.

- Start of fuel injection was retarded for all biofuels except 80/20 F76/HDCD76; which was only slightly advanced compared to F-76. The start of injection for the other fuels was retarded by: $\sim 0.2$ to 0.59 degrees for Neat HRJ5, less than 0.25 degrees for 50/50 JP5/HRJ5, 0.55 and 0.95 for Neat DSH76, $\sim 0.15$ to 0.85 degrees for $50 / 50$ F76/DSH76, $\sim 0.05$ to 0.6 degrees for $80 / 20$ F76/DSH76, and $\sim 2$ to 1.3 degrees for Neat HRD76 and 50/50 F76/HRD76. Differences in fuel injection timing were attributed primarily to fuel density and viscosity.

- Start of combustion was typically advanced for all of the candidate biofuels, except 80/20 F76/HDCD76. This resulted in a shorter ignition delay for most of the biofuels. The shortest ignition delays were achieved with the neat fuel blends (Neat HRJ5, Neat HRD76, and Neat DSH76) and increased as the amount of the reference fuel (JP-5 or F-76) in the fuel blend increased.

- Emission constituents were reported as brake specific values for each mode of the steady state test. Most of the results were consistent with the literature $[2,6,7,8,28,29]$. The emissions of HC, NOx, $\mathrm{CO}, \mathrm{CO}_{2}$, and PM showed percent reductions of 6.7 to $49.7 \%, 4.3$ to $31.3 \%, 2.6$ to $72.7 \%$, 4.1 to $7.5 \%$, and 4.7 to $62.2 \%$, respectively for Neat HRJ5, and 2.3 to $35.2 \%, 2.5$ to $18.5 \%, 0.16$ to $52.4 \%, 1.7$ to $2.8 \%$, and 0.3 to $9.0 \%$, respectively for 50/50 JP5/HRJ5. The 50/50 JP5/HRJ5 fuel also showed a percent increase in TPM at modes 2, 4, 5, and 8 of 34.4, 16.5, 5.5, and 2.1\%, respectively. The F-76 candidate biofuels performed similarly except for 80/20 F76/HDCD76; which showed percent increase in $\mathrm{HC}, \mathrm{NOx}, \mathrm{CO}$, and $\mathrm{CO}_{2}$ of 1.7 to $15.9 \%, 1.8$ to $9.9 \%, 0.78$ to $32.2 \%$, and 1.1 to $1.5 \%$, respectively, and a 2.0 to $22.5 \%$ reduction in PM. The rest of the F-76 biofuels showed varying results between percent increase and decrease of $\mathrm{CO}$ emissions; this is not a major concern due to the already low level of $\mathrm{CO}$ emissions. 
- Varying results were noticed for 80/20 F76/DSH76 for HC emissions and percent reductions in NOx, $\mathrm{CO}_{2}$, and $\mathrm{PM}$ of 3.1 to $5.5 \%, 0.45$ to 2.9 , and 0.73 to $18.0 \%$, respectively. However, at high BMEP ( $\geq 13.88)$ PM emissions increased by 2.2 to $10.4 \%$.

- Emissions of $\mathrm{HC}, \mathrm{NOx}, \mathrm{CO}_{2}$, and TPM showed percent reductions of: 3.3 to $52.5 \%, 8.9$ to $26.3 \%, 4.0$ to $13.9 \%$, and 20.4 to $59.7 \%$, respectively for Neat HRD76, 3.0 to $48.5 \%, 3.3$ to $15.6 \%, 1.6$ to $5.7 \%$, and 8.3 to $51.1 \%$, for $50 / 50$ F76/HRD76, 0.38 to $25.4 \%, 11.6$ to $22.7 \%, 3.8$ to $7.9 \%$, and 4.1 to $59.7 \%$, for Neat DSH76, and 1.5 to $25.0 \%, 1.6$ to $10.5 \%, 1.9$ to $5.7 \%$, and 0.17 to $31.5 \%$, for $50 / 50 \mathrm{~F} 76 / \mathrm{DSH} 76$.

- Reduction in all emission constituents were also related to the candidate biofuels' lower density and aromatic content, as well as their higher cetane number.

- The biofuels achieved lower brake specific fuel consumption. Percent reductions of bsFC for Neat HRJ5, 50/50 JP5/HRJ5, Neat HRD76, 50/50 F76/HRD76, Neat DSH76, 50/50 F76/DSH76, and $80 / 20$ F76/HRD76 were: 2.8 to $7.4 \%, 1.3$ to $2.6 \%, 1.8$ to $12.4 \%, 0.69$ to $5.0 \%, 1.8$ to $6.1 \%$, 0.8 to $4.9 \%$, and 0.02 to $2.4 \%$, respectively. The $80 / 20$ F76/HDCD76 fuel showed a percent increase of 0.75 to $1.2 \%$ in bsFC. As with the emission constituents, the effects of the biofuels on bsFC were attributed to their respective values for cetane number, fuel density, and aromatic content.

Based on the results of this study, it appears that most of the biofuels evaluated have no adverse combustion effects. In some cases combustion and engine operation may even be improved with the use of these biofuels. The majority of the fuels showed similar combustion and engine operation attributes as well as reduced emissions; however, further testing needs to be conducted to determine if the fuels would be suitable replacement for JP-5 and F-76; however, I would recommend the use of 50/50 JP5/HRJ5 and 50/50 F76/HRD76 because they demonstrate suitable combustion characteristics, reduced emissions, and displace $50 \%$ of the petroleum based fuel. 


\subsection{Recommendations}

In order to make additional conclusions about this study and the performance of the tested hydrotreated biofuels, the following suggestions will be made:

- Additional test engines should be used to broaden the evaluation to include newer technology and larger displacement engines. This would allow more conclusions to be drawn about the effectiveness of these biofuels.

- Additional transient tests should be completed for both fuel sets to further understand the performance of the fuels under transient operating conditions.

- A further regression should be performed to the relate combustion parameters to exhaust emissions. This would allow for conclusions to be drawn about the mechanisms of pollutant formation.

- Test cycles should be created to simulate engine operation aboard a U.S. Navy vessel and implemented in the laboratory evaluation of these fuels.

- Shipboard testing should be conducted for the F-76 biofuels to evaluate the performance of the biofuels in the environment that they will be used. This would help to determine how suitable the fuels are for use in a U.S. Navy vessel.

- The JP-5 biofuels should be tested in a turbine jet engine. This would allow further conclusions to be drawn about whether or not the fuels are suitable for use in a jet engine. 


\section{Chapter 7: References}

[1] Great Green Fleet. 2013. Article. 30 January 2013. <http://greenfleet.dodlive.mil/energy/greatgreen-fleet/>

[2] Sujit, G. and T. Risley. Alternative Fuel for Marine Application - Final Report. Technical Report. U.S. Maritime Administration. Washington, DC, 2012. Document. 30 January 2014. $<$ http://www.marad.dot.gov/documents/MARAD_ALT_FUEL_FINAL_REPORT_\%28R EVISED_3-22-12\%29.pdf $>$.

[3] Goldstein, E. Military Alternative Fuels Research: The Navy's Great Green Fleet, and Opposition from Congress. 6 September 2013. Article. 19 September 2013.

$<$ http://www.defensemedianetwork.com/stories/military-alternative-fuels-research-thenavys-great-green-fleet/>.

[4] Xue, J., Grift, T., and Hansen, A. "Effect of biodiesel on engine performances and emissions," Renewable and Sustainable Energy Reviews 15 (2011): 1098-1116 Web

[5] ASTM Standard D6751, 2012, "Standard Specification for Biodiesel Fuel Blend Stock (B100) for Middle Distillate Fuels," ASTM International, West Conshohocken, PA, 2012, DOI: 10.1520/D6751-12, www.astm.org.

[6] Kuronen, M., Mikkonen, S., Aakko, P., and Murtonen, T. "Hydrotreated vegetable oil as fuel for heavy duty diesel engines," SAE 2007-01-4031, SAE International, Warrendale, PA, 2007

[7] No, S. "Application of hydrotreated vegetable oil from triglyceride based biomass to CI engines A review," Fuel 115 (2014): 88-96

[8] Rantanen, L., Linnaila, R., Aakko, P., and Harju, T. "NExBTL - Biodiesel Fuel of the Second Generation,” SAE 2005-01-3771, SAE International, Warrendale, PA, 2005

[9] Atadashi, I.M., Aroua, M.K., and Aziz, A.Abdul. "Biodiesel seperation and purification: A review,” Renewable Energy 36 (2011): 437-443. Web

[10] Yamane, K., Kato, T., and Okutani, H. "Effect of Refining Process in Biodiesel Fuel Production on Fuel Properties, Diesel Engine Performance and Emissions," SAE 2003-01-1930, SAE International, Warrendale, PA, 2003

[11] Wang, Y., Wang, X., Liu, Y., Ou, S., Tan, Y., and Tang, S. "Refining of biodiesel by ceramic membrane separation," Fuel Processing Technology 90 (2009): 422-427. Web

[12] ASTM Standard D975, 2013, "Standard Specification for Diesel Fuel Oils," ASTM International, West Conshohocken, PA, 2013, DOI: 10.1520/D0975-13, www.astm.org.

[13] O’Rourke, R. "Navy Ship Propulsion Technologies: Options for Reducing Oil Use - Background for Congress," 11 December 2006 
[14] Bartis, J., and Bibber, L. “Alternative Fuels for Military Applications,” RAND National Defense Research Institute, 2011

[15] Dipasquale, C., and Weiss, D. “'Great Green Fleet' Sails Toward Pentagon's Reduction in Oil Use,” Think Progress, n.p. 19 Sep. 2013 Web. 10 July 2012. $<$ http://thinkprogress.org/climate/2012/07/10/513635/great-green-fleet-sails-towardpentagons-reduction-in-oil-use/>

[16] Diesel Propulsion Overview. 27 Febuary 1999. Document. 12 October 2013. $<$ http://www.fas.org/man/dod-101/navy/docs/swos/eng/62n-110.htm>.

[17] Heywood, J., Internal Combustion Engine Fundamentals. New York City: McGraw-Hill, 1988.

[18] Nuszkowski, J., "The Effects of Fuel Additive on Diesel Engine Emissions during Steady State and Transient Operation," PhD Dissertation, Department of Mechanical and Aerospace Engineering, West Virginia University, Morgantown, WV, 2008

[19] Lloyd, A., and Cackette, T. "Diesel Engines: Environmental Impact and Control," Journal of the Air \& Waste Management Association 51 (2001): 809-847. Web

[20] Owen, K. and Coley, T., Automotive Fuels Reference Book, Second Edition, SAE Publications, Warrendale, PA, 1995

[21] Particulate Matter (PM). U.S. Environmental Protection Agency, 18 March 2013, EPA, 15 February 2014, < http://www.epa.gov/airquality/particlepollution/>.

[22] Heavy-Duty Vehicles: GHG Emissions \& Fuel Economy. DieselNet. September 2011. 15 February 2014. <http://www.dieselnet.com/standards/us/fe_hd.php>.

[23] Tincher, R., "Evaluation of Heavy Duty Diesel Engines Regulated Emissions Based on Variation of Fuel Properties by Use of Additives," M.S. Thesis, Department of Mechanical and Aerospace Engineering, West Virginia University, Morgantown, WV, 2007

[24] Tan, P., Zhao, J., Hu, Z., Lou, D., and Du, A. "Effects of fuel properties on exhaust emissions from diesel engines," Journal of Fuel Chemistry and Technology 41(3) (2013): 347-355. Web

[25] Hulkkonen, T., Hillam, H., Sarjovaara, T., and Larmi, M. "Experimental Study of Spray Characteristics between Hydrotreated Vegetable Oil (HVO) and Crude Oil Based EN 590 Diesel Fuel," SAE 2011-24-0042, SAE International, Warrendale, PA, 2011 
[26] Legg J. M., Narvaez A. A., and McDonell V. G., "Atomization and Combustion Performance of Renewable Liquid Fuels in a Swirl Stabilized Research Combustor," ICLASS (2012), $24^{\text {th }}$ Annual Conference on Liquid Atomization and Spray Systems, San Antonio, TX

[27] Caton, P., Williams, S., Kamin, R., Luning-Prak, D., Hamilton, L., and Cowart, J., "Hydrotreated Algae Renewable Fuel Performance in a Military Diesel Engine,” ICES 2012-81048, ASME, 2012

[28] Aatola, H., Larmi, M., Sarjovaara, T., and Mikkonen, S. "Hydrotreated Vegetable Oil (HVO) as a Renewable Diesel Fuel: Trade-off between NOx, Particulate Emission, and Fuel Consumption of a Heavy Duty Engine,” SAE 2008-01-2500, SAE International, Warrendale, PA, 2008

[29] Sugiyama, K., Goto, I., Kitano, K., Mogi, K., and Honkanen, M. "Effects of Hydrotreated Vegetable Oil (HVO) as Renewable Diesel Fuel on Combustion and Exhaust Emissions in Diesel Engine,” SAE 2011-01-1954, SAE International, Warrendale, PA, 2011

[30] Military Specification MIL-DTL-5624MIL-DTL-5624V, 11 July 2013, “Turbine Fuel, Aviation Grades JP-4 and JP-5," Detail Specification.

[31] Military Specification MIL-DTL-16884M, 14 August 2012, "Fuel, Naval Distillate," Detail Specification.

[32] Code of Federal Regulations, Title 40 CFR Part 1065, Washington, D.C., Office of Federal Register National Archive and Records Administration, 2012.

[33] Brunt, M. and Pond, C., "Evaluation of Techniques for Absolute Cylinder Pressure Correction," SAE Paper No. 970036, SAE International, Warrendale, PA, 1997 


\section{Chapter 8: Appendices}

\subsection{JP-5 Fuels Data}

Table 8-1: Effects of fuel density, cetane number, and aromatic content on maximum heat release rate for JP-5 test fuels

\begin{tabular}{|c|c|c|c|c|c|c|c|c|c|c|c|c|}
\hline \multirow[b]{2}{*}{ Mode } & \multicolumn{3}{|c|}{ Max Heat Release Rate $(\mathrm{kJ} / \mathrm{deg})$} & \multicolumn{3}{|c|}{ Density } & \multicolumn{3}{|c|}{ Cetane Number } & \multicolumn{3}{|c|}{ Aromatics } \\
\hline & $J P-5$ & Neat HRJ5 & $\begin{array}{c}50 / 50 \\
\text { JP5/HRJ5 }\end{array}$ & $\mathrm{m}$ & $\mathrm{b}$ & $\mathrm{R}^{2}$ & $\mathrm{~m}$ & $\mathrm{~b}$ & $\mathrm{R}^{2}$ & $\mathrm{~m}$ & $\mathrm{~b}$ & $\mathrm{R}^{2}$ \\
\hline 1 & 0.749 & 0.605 & 0.683 & 0.0030 & -1.6823 & 0.9981 & -0.0079 & 1.0941 & 0.9932 & 0.0076 & 0.6052 & 0.9985 \\
\hline 2 & 0.820 & 0.537 & 0.673 & 0.0059 & -3.9531 & 0.9993 & -0.0154 & -3.9531 & 0.9993 & 0.0149 & 0.5320 & 0.9990 \\
\hline 3 & 0.828 & 0.471 & 0.619 & 0.0074 & -5.2048 & 0.9897 & -0.0193 & -5.2048 & 0.9897 & 0.0188 & 0.4566 & 0.9887 \\
\hline 4 & 0.706 & 0.413 & 0.547 & 0.0061 & -4.2418 & 0.9973 & -0.0159 & -4.2418 & 0.9973 & 0.0154 & 0.4054 & 0.9967 \\
\hline 5 & 0.627 & 0.380 & 0.495 & 0.0051 & -3.5536 & 0.9982 & -0.0135 & -3.5536 & 0.9982 & 0.0130 & 0.3737 & 0.9978 \\
\hline 6 & 0.523 & 0.340 & 0.431 & 0.0038 & -2.5694 & 0.9999 & -0.0100 & -2.5694 & 0.9999 & 0.0096 & 0.3375 & 0.9998 \\
\hline 7 & 0.568 & 0.326 & 0.424 & 0.0050 & -3.5297 & 0.9879 & -0.0131 & -3.5297 & 0.9879 & 0.0128 & 0.3154 & 0.9868 \\
\hline 8 & 0.500 & 0.292 & 0.378 & 0.0043 & -3.0091 & 0.9900 & -0.0112 & -3.0091 & 0.9900 & 0.0109 & 0.2836 & 0.9890 \\
\hline 9 & 0.470 & 0.273 & 0.355 & 0.0041 & -2.8482 & 0.9906 & -0.0106 & -2.8482 & 0.9906 & 0.0103 & 0.2654 & 0.9896 \\
\hline 10 & 0.444 & 0.281 & 0.332 & 0.0034 & -2.3106 & 0.9540 & -0.0086 & -2.3106 & 0.9540 & 0.0086 & 0.2693 & 0.9519 \\
\hline 11 & 0.393 & 0.257 & 0.295 & 0.0028 & -1.9023 & 0.9397 & -0.0072 & -1.9023 & 0.9397 & 0.0071 & 0.2457 & 0.9373 \\
\hline 12 & 0.363 & 0.222 & 0.275 & 0.0029 & -2.0290 & 0.9812 & -0.0076 & -2.0290 & 0.9812 & 0.0074 & 0.2142 & 0.9798 \\
\hline 13 & 0.334 & 0.308 & 0.310 & 0.0005 & -0.1040 & 0.7937 & -0.0013 & -0.1040 & 0.7937 & 0.0014 & 0.3041 & 0.7897 \\
\hline 14 & 0.298 & 0.292 & 0.291 & 0.0001 & 0.1928 & 0.6415 & -0.0003 & 0.1928 & 0.6415 & 0.0003 & 0.2906 & 0.6368 \\
\hline 15 & 0.285 & 0.254 & 0.256 & 0.0006 & -0.2359 & 0.7818 & -0.0016 & -0.2359 & 0.7818 & 0.0016 & 0.2492 & 0.7777 \\
\hline
\end{tabular}

Table 8-2: Effects of fuel density, cetane number, and aromatic content on net heat released for JP-5 test fuels

\begin{tabular}{|c|c|c|c|c|c|c|c|c|c|c|c|c|}
\hline \multirow[b]{2}{*}{ Mode } & \multicolumn{3}{|c|}{ Net Heat Released (kJ) } & \multicolumn{3}{|c|}{ Density } & \multicolumn{3}{|c|}{ Cetane Number } & \multicolumn{3}{|c|}{ Aromatics } \\
\hline & $J P-5$ & Neat HRJ5 & $\begin{array}{c}50 / 50 \\
\text { JP5/HRJ5 }\end{array}$ & $\mathrm{m}$ & b & $R^{2}$ & $\mathrm{~m}$ & b & $\mathrm{R}^{2}$ & $\mathrm{~m}$ & b & $R^{2}$ \\
\hline 1 & 0.926 & 0.889 & 0.878 & 0.0008 & 0.2906 & 0.5531 & -0.0018 & 0.9915 & 0.4270 & 0.0019 & 0.8786 & 0.5482 \\
\hline 2 & 1.728 & 1.818 & 1.614 & -0.0019 & 3.2055 & 0.1970 & 0.0062 & 3.2055 & 0.1970 & -0.0048 & 1.7672 & 0.2009 \\
\hline 3 & 2.774 & 2.754 & 2.770 & 0.0004 & 2.4332 & 0.9073 & -0.0012 & 2.4332 & 0.9073 & 0.0011 & 2.7554 & 0.9101 \\
\hline 4 & 2.262 & 2.289 & 2.267 & -0.0006 & 2.7198 & 0.8757 & 0.0016 & 2.7198 & 0.8757 & -0.0014 & 2.2866 & 0.8789 \\
\hline 5 & 2.224 & 2.221 & 2.220 & 0.0001 & 2.1656 & 0.5078 & -0.0002 & 2.1656 & 0.5078 & 0.0002 & 2.2198 & 0.5029 \\
\hline 6 & 2.036 & 2.036 & 2.032 & 0.0000 & 2.0209 & 0.0287 & 0.0000 & 2.0209 & 0.0287 & 0.0000 & 2.0342 & 0.0271 \\
\hline 7 & 4.224 & 4.226 & 4.199 & 0.0000 & \begin{tabular}{l|l}
4.2492 \\
\end{tabular} & 0.0042 & 0.0003 & 4.2492 & 0.0042 & \begin{tabular}{l|l|}
-0.0001 \\
\end{tabular} & 4.2177 & 0.0049 \\
\hline 8 & 3.990 & 3.988 & 3.980 & 0.0000 & 3.9503 & 0.0445 & 0.0000 & 3.9503 & 0.0445 & 0.0001 & 3.9847 & 0.0425 \\
\hline 9 & 3.532 & 3.515 & 3.514 & 0.0004 & 3.2437 & 0.6960 & -0.0008 & 3.2437 & 0.6960 & 0.0009 & 3.5120 & 0.6915 \\
\hline 10 & 6.256 & 6.334 & 6.287 & -0.0016 & 7.5707 & 0.9852 & 0.0043 & 7.5707 & 0.9852 & 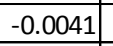 & 6.3326 & 0.9864 \\
\hline 11 & 5.802 & 5.819 & 5.797 & -0.0003 & 6.0780 & 0.5551 & 0.0010 & 6.0780 & 0.5551 & -0.0009 & 5.8145 & 0.5600 \\
\hline 12 & 4.979 & 5.037 & 4.971 & -0.0012 & 5.9473 & 0.6454 & 0.0035 & 5.9473 & 0.6454 & -0.0031 & 5.0258 & 0.6501 \\
\hline 13 & 8.346 & 8.113 & 8.170 & 0.0048 & 4.4038 & 0.9196 & -0.0122 & 4.4038 & 0.9196 & 0.0122 & 8.0908 & 0.9169 \\
\hline 14 & 7.803 & 7.539 & 7.648 & 0.0055 & 3.3319 & 0.9897 & -0.0143 & 3.3319 & 0.9897 & 0.0139 & 7.5277 & 0.9887 \\
\hline 15 & 6.656 & 6.388 & 6.486 & 0.0055 & 2.1234 & 0.9761 & -0.0144 & 2.1234 & 0.9761 & 0.0141 & 6.3732 & 0.9746 \\
\hline
\end{tabular}


Table 8-3: Effects of fuel density, cetane number, and aromatic content on maximum in-cylinder pressure for JP-5 test fuels

\begin{tabular}{|c|c|c|c|c|c|c|c|c|c|c|c|c|}
\hline \multirow[b]{2}{*}{ Mode } & \multicolumn{3}{|c|}{ Max In-Cylinder Pressure ( $\mathrm{kPa})$} & \multicolumn{3}{|c|}{ Density } & \multicolumn{3}{|c|}{ Cetane Number } & \multicolumn{3}{|c|}{ Aromatics } \\
\hline & JP-5 & Neat HRJ5 & \begin{tabular}{c|}
$50 / 50$ \\
JP5/HRJ5
\end{tabular} & $\mathrm{m}$ & $\mathrm{b}$ & $\mathrm{R}^{2}$ & $\mathrm{~m}$ & $\mathrm{~b}$ & $\mathrm{R}^{2}$ & $\mathrm{~m}$ & $\mathrm{~b}$ & $\mathrm{R}^{2}$ \\
\hline 1 & 5388.71 & 5141.60 & 5265.00 & 5.116 & 1219.875 & 1.000 & -13.505 & 5971.865 & 0.984 & 13.005 & 5138.518 & 1.000 \\
\hline 2 & 6370.33 & 5989.00 & 6053.40 & 7.891 & -101.953 & 0.872 & -19.820 & -101.953 & 0.872 & 20.023 & 5942.689 & 0.868 \\
\hline 3 & 7278.22 & 6762.60 & 6993.80 & 10.675 & -1428.535 & 0.996 & -27.966 & -1428.535 & 0.996 & 27.127 & 6747.503 & 0.996 \\
\hline 4 & 7438.22 & 6994.80 & 7174.20 & 9.179 & -55.408 & 0.988 & -23.893 & -55.408 & 0.988 & 23.322 & 6975.411 & 0.987 \\
\hline 5 & 7465.89 & 7033.00 & 7254.20 & 8.963 & 164.580 & 1.000 & -23.698 & 164.580 & 1.000 & 22.785 & 7029.260 & 1.000 \\
\hline 6 & 7278.67 & 6891.40 & 7070.40 & 8.018 & 740.975 & 0.998 & -21.048 & 740.975 & 0.998 & 20.376 & 6881.826 & 0.998 \\
\hline 7 & 9199.11 & 8835.00 & 8951.80 & 7.537 & 3036.320 & 0.958 & -19.372 & 3036.320 & 0.958 & 19.139 & 8809.018 & 0.956 \\
\hline 8 & 9211.11 & 8868.60 & 8990.80 & 7.090 & 3417.744 & 0.973 & -18.323 & 3417.744 & 0.973 & 18.008 & 8848.225 & 0.971 \\
\hline 9 & 8904.33 & 8583.20 & 8702.20 & 6.648 & 3473.934 & 0.978 & -17.215 & 3473.934 & 0.978 & 16.886 & 8565.556 & 0.976 \\
\hline 10 & 10862.11 & 10705.20 & 10751.40 & 3.248 & 8205.015 & 0.946 & -8.315 & 8205.015 & 0.946 & 8.246 & 10692.640 & 0.944 \\
\hline 11 & 10903.44 & 10747.60 & 10792.60 & 3.226 & 8264.136 & 0.943 & -8.251 & 8264.136 & 0.943 & 8.190 & 10734.833 & 0.941 \\
\hline 12 & 10444.22 & 10250.20 & 10307.80 & 4.016 & 7158.843 & 0.947 & -10.285 & 7158.843 & 0.947 & 10.197 & 10234.826 & 0.945 \\
\hline 13 & 12678.00 & 12277.60 & 12441.00 & 8.289 & 5911.862 & 0.989 & -21.586 & 5911.862 & 0.989 & 21.059 & 12260.556 & 0.988 \\
\hline 14 & 12810.33 & 12386.80 & 12562.40 & 8.768 & 5654.136 & 0.990 & -22.856 & 5654.136 & 0.990 & 22.277 & 12369.681 & 0.989 \\
\hline 15 & 12034.78 & 11640.40 & 11802.60 & 8.164 & 5370.797 & 0.989 & -21.272 & 5370.797 & 0.989 & 20.743 & 11624.027 & 0.988 \\
\hline
\end{tabular}

Table 8-4: Effects of fuel density, cetane number, and aromatic content on maximum pressure rise rate for JP-5 test fuels

\begin{tabular}{|c|c|c|c|c|c|c|c|c|c|c|c|c|}
\hline \multirow[b]{2}{*}{ Mode } & \multicolumn{3}{|c|}{ Max Pressure Rise Rate (kPa/deg) } & \multicolumn{3}{|c|}{ Density } & \multicolumn{3}{|c|}{ Cetane Number } & \multicolumn{3}{|c|}{ Aromatics } \\
\hline & $\mathrm{JP}-5$ & Neat HRJ5 & $\begin{array}{c}50 / 50 \\
\text { JP5/HRJ5 } \\
\end{array}$ & $\mathrm{m}$ & $\mathrm{b}$ & $\mathrm{R}^{2}$ & $\mathrm{~m}$ & $\mathrm{~b}$ & $\mathrm{R}^{2}$ & $\mathrm{~m}$ & $\mathrm{~b}$ & $\mathrm{R}^{2}$ \\
\hline 1 & 1552.571 & 1301.000 & 1459.333 & 5.2094 & -2681.2963 & 0.9785 & -14.0134 & 2171.0028 & 0.9996 & 13.2521 & 1308.6475 & 0.9799 \\
\hline 2 & 1624.778 & 1126.800 & 1375.400 & 10.3101 & -6776.1719 & 1.0000 & -27.2143 & -6776.1719 & 1.0000 & 26.2082 & 1120.5657 & 1.0000 \\
\hline 3 & 1650.333 & 999.200 & 1286.400 & 13.4799 & -9346.1344 & 0.9952 & -35.2776 & -9346.1344 & 0.9952 & 34.2547 & 978.5650 & 0.9945 \\
\hline 4 & 1461.444 & 19.800 & 1175.800 & 11.2137 & -7680.6419 & 0.9989 & -29.4840 & -7680.6419 & 0.9989 & 28.5011 & 908.2710 & 0.9986 \\
\hline 5 & 1280.444 & 846.800 & 1057.600 & 8.9780 & \begin{tabular}{|l|}
-6036.9596 \\
\end{tabular} & 0.9997 & -23.6525 & -6036.9596 & 0.9997 & 22.8203 & 839.4970 & 0.9995 \\
\hline 6 & 059.222 & 9.400 & 918.200 & 2077 & \begin{tabular}{|l|}
-3995.9826 \\
\end{tabular} & 0.9989 & -16.4590 & \begin{tabular}{|l|}
-3995.9826 \\
\end{tabular} & 0.9989 & 15.7828 & 758.6547 & 0.9992 \\
\hline 7 & 1238.667 & 767.200 & 964.400 & 9.7601 & \begin{tabular}{|l|}
-6726.8965 \\
\end{tabular} & 0.9909 & -25.4564 & -6726.8965 & 0.9909 & 24.7989 & 748.7131 & 0.9900 \\
\hline 8 & 1088.889 & 692.200 & 862.400 & 8.2122 & \begin{tabular}{|l|}
-5611.9534 \\
\end{tabular} & 0.9931 & -21.4535 & -5611.9534 & 0.9931 & 20.8672 & 678.0556 & 0.9923 \\
\hline 9 & 1008.889 & 50.600 & 805.600 & 7.4173 & -5042.9068 & 0.9938 & -19.3871 & -5042.9068 & 0.9938 & 18.8477 & 638.2454 & 0.9930 \\
\hline 10 & 1022.667 & 643.600 & 800.200 & 7.8472 & \begin{tabular}{|l|}
-5382.3788 \\
\end{tabular} & 0.9898 & -20.4516 & \begin{tabular}{|l|}
-5382.3788 \\
\end{tabular} & 0.9898 & 19.9380 & 628.0926 & 0.9888 \\
\hline 11 & 911.889 & 595.200 & 724.200 & 6.5559 & -4439.7353 & 0.9884 & -17.0713 & -4439.7353 & 0.9884 & 16.6564 & 581.6408 & 0.9874 \\
\hline 12 & 841.889 & 559.400 & 679.400 & 5.8480 & \begin{tabular}{|l|}
-3930.2682 \\
\end{tabular} & 0.9923 & -15.2677 & \begin{tabular}{|l|}
-3930.2682 \\
\end{tabular} & 0.9923 & 14.8594 & 548.9311 & 0.9914 \\
\hline 13 & 822.778 & 550.400 & 662.600 & 5.6386 & \begin{tabular}{|l|}
-3779.6588 \\
\end{tabular} & 0.9895 & -14.6928 & -3779.6588 & 0.9895 & 14.3263 & 539.1501 & 0.9885 \\
\hline 14 & 756.667 & 524.000 & 620.200 & 4.8165 & $\mid-3174.6499$ & 0.9899 & -12.5536 & -3174.6499 & 0.9899 & 12.2377 & 514.5084 & 0.9889 \\
\hline 15 & 718.667 & 513.000 & 602.000 & 4.2577 & -2755.2053 & 0.9938 & -11.1289 & -2755.2053 & 0.9938 & 10.8191 & 505.9168 & 0.9930 \\
\hline
\end{tabular}


Table 8-5: Effects of fuel density, cetane number, and aromatic content on maximum in-cylinder temperature for JP-5 test fuels

\begin{tabular}{|c|c|c|c|c|c|c|c|c|c|c|c|c|}
\hline \multirow[b]{2}{*}{ Mode } & \multicolumn{3}{|c|}{ Max In-Cylinder Temperature (K) } & \multicolumn{3}{|c|}{ Density } & \multicolumn{3}{|c|}{ Cetane Number } & \multicolumn{3}{|c|}{ Aromatics } \\
\hline & $J P-5$ & Neat HRJ5 & $\begin{array}{c}50 / 50 \\
\text { JP5/HRJ5 }\end{array}$ & $\mathrm{m}$ & b & $R^{2}$ & $\mathrm{~m}$ & b & $\mathrm{R}^{2}$ & $\mathrm{~m}$ & b & $\mathrm{R}^{2}$ \\
\hline 1 & 1186.86 & 1142.80 & 1162.67 & 0.912 & 442.946 & 0.997 & -2.390 & 1289.210 & 0.966 & 2.318 & 1141.547 & 0.996 \\
\hline 2 & 1400.33 & 1359.80 & 1337.60 & 0.838 & 703.345 & 0.405 & -1.872 & 703.345 & 0.405 & 2.118 & 1345.300 & 0.400 \\
\hline 3 & 1578.78 & 1514.40 & 1546.60 & 1.333 & 492.735 & 1.000 & -3.519 & 492.735 & 1.000 & 3.388 & 1513.614 & 1.000 \\
\hline 4 & 1490.22 & 1441.20 & 1460.40 & 1.015 & 661.573 & 0.984 & -2.636 & 661.573 & 0.984 & 2.578 & 1438.848 & 0.983 \\
\hline 5 & 1476.33 & 1419.60 & 1443.20 & 1.174 & 517.767 & 0.990 & -3.062 & 517.767 & 0.990 & 2.984 & 1417.333 & 0.989 \\
\hline 6 & 1429.56 & 1376.60 & 1403.20 & 1.096 & 536.239 & 1.000 & -2.895 & 536.239 & 1.000 & 2.787 & 1375.991 & 1.000 \\
\hline 7 & 1711.56 & 1674.40 & 1682.60 & 0.769 & 1081.521 & 0.905 & -1.947 & 1081.521 & 0.905 & 1.952 & 1670.522 & 0.902 \\
\hline 8 & 1653.56 & 1619.80 & 1629.40 & 0.699 & 1081.842 & 0.941 & -1.786 & 1081.842 & 0.941 & 1.774 & 1616.986 & 0.939 \\
\hline 9 & 1592.22 & 1557.40 & 1571.60 & 0.721 & 1003.777 & 0.989 & -1.877 & 1003.777 & 0.989 & 1.831 & 1555.914 & 0.987 \\
\hline 10 & 1781.78 & 1787.00 & 1778.40 & -0.108 & 1868.015 & 0.364 & 0.334 & 1868.015 & 0.364 & -0.277 & 1785.089 & 0.369 \\
\hline 11 & 1704.11 & 1703.20 & 1694.40 & 0.019 & 1685.865 & 0.007 & 0.025 & 1685.865 & 0.007 & 0.045 & 1700.137 & 0.006 \\
\hline 12 & 1631.56 & 1633.60 & 1621.40 & -0.043 & 1662.572 & 0.025 & 0.202 & 1662.572 & 0.025 & -0.112 & 1629.939 & 0.026 \\
\hline 13 & 1835.78 & 1833.00 & 1827.80 & 0.057 & 1786.870 & 0.117 & -0.098 & 1786.870 & 0.117 & 0.144 & 1830.793 & 0.114 \\
\hline 14 & 1749.33 & 1744.60 & 1738.00 & 0.098 & 1666.696 & 0.172 & -0.186 & 1666.696 & 0.172 & 0.246 & 1741.585 & 0.168 \\
\hline 15 & 1681.22 & 1676.20 & 1670.40 & 0.104 & 1593.915 & 0.214 & \begin{tabular}{|c|}
-0.207 \\
\end{tabular} & 1593.915 & 0.214 & 0.261 & 1673.398 & 0.210 \\
\hline
\end{tabular}

Table 8-6: Effects of fuel density, cetane number, aromatic content, and viscosity on start of fuel injection for JP-5 test fuels

\begin{tabular}{|c|c|c|c|c|c|c|c|c|c|c|c|c|c|c|c|}
\hline \multirow[b]{2}{*}{ Mode } & \multicolumn{3}{|c|}{ Start of Fuel Injection (deg) } & \multicolumn{3}{|c|}{ Density } & \multicolumn{3}{|c|}{ Cetane Number } & \multicolumn{3}{|c|}{ Aromatics } & \multicolumn{3}{|c|}{ Viscosity } \\
\hline & $J P-5$ & Neat HRJ5 & \begin{tabular}{|c|}
$50 / 50$ \\
JP5/HRJ5
\end{tabular} & $\mathrm{m}$ & b & $\mathrm{R}^{2}$ & $\mathrm{~m}$ & b & $\mathrm{R}^{2}$ & $\mathrm{~m}$ & b & $\mathrm{R}^{2}$ & $\mathrm{~m}$ & b & $\mathrm{R}^{2}$ \\
\hline 1 & -2.55 & -2.06 & -2.58 & -0.0101 & 5.5880 & 0.7000 & 0.0289 & -3.9104 & 0.8083 & -0.0258 & -2.1479 & 0.7045 & 0.1982 & -3.6669 & 0.9286 \\
\hline 2 & -3.75 & -3.17 & -3.56 & -0.0121 & 6.0584 & 0.9597 & 0.0327 & 6.0584 & 0.9597 & -0.0307 & -3.1939 & 0.9616 & 0.2089 & -4.8297 & 0.9886 \\
\hline 3 & -3.50 & -3.00 & -3.31 & \begin{tabular}{|c|}
-0.0104 \\
\end{tabular} & 4.9155 & 0.9799 & 0.0278 & 4.9155 & 0.9799 & -0.0263 & -3.0145 & 0.9813 & 0.1757 & -4.3952 & 0.9724 \\
\hline 4 & -8.00 & -7.50 & -7.75 & -0.0104 & 0.4349 & 1.0000 & 0.0273 & 0.4349 & 1.0000 & -0.0263 & -7.4939 & 1.0000 & 0.1679 & -8.8246 & 0.9067 \\
\hline 5 & -8.71 & -8.38 & -8.56 & -0.0069 & -3.0915 & 0.9950 & 0.0184 & -3.0915 & 0.9950 & -0.0176 & -8.3778 & 0.9957 & 0.1145 & -9.2816 & 0.9443 \\
\hline 6 & -9.42 & -8.92 & -9.63 & -0.0104 & -1.1241 & 0.4728 & 0.0310 & -1.1241 & 0.4728 & -0.0265 & -9.0617 & 0.4777 & 0.2249 & -10.7589 & 0.7673 \\
\hline 7 & -7.96 & -7.50 & -7.75 & -0.0095 & -0.2328 & 0.9974 & 0.0252 & -0.2328 & 0.9974 & -0.0241 & -7.5012 & 0.9979 & 0.1565 & -8.7378 & 0.9349 \\
\hline 8 & -8.71 & -8.50 & -8.50 & -0.0043 & -5.1614 & 0.7490 & 0.0105 & -5.1614 & 0.7490 & -0.0109 & -8.4631 & 0.7447 & 0.0570 & -8.9343 & 0.4515 \\
\hline 9 & -9.25 & -8.75 & -9.44 & -0.0104 & -0.9510 & 0.4960 & 0.0309 & -0.9510 & 0.4960 & -0.0265 & -8.8881 & 0.5009 & 0.2223 & -10.5687 & 0.7866 \\
\hline 10 & -7.75 & -7.50 & -7.75 & -0.0052 & -3.5714 & 0.7510 & 0.0147 & -3.5714 & 0.7510 & -0.0132 & -7.5382 & 0.7552 & 0.0995 & -8.3035 & 0.9552 \\
\hline 11 & -8.58 & -8.25 & -8.44 & -0.0069 & -2.9665 & 0.9950 & 0.0184 & -2.9665 & 0.9950 & -0.0176 & -8.2528 & 0.9957 & 0.1145 & -9.1566 & 0.9443 \\
\hline 12 & -9.08 & -8.75 & -9.13 & -0.0069 & -3.5248 & 0.6587 & 0.0199 & -3.5248 & 0.6587 & -0.0176 & -8.8146 & 0.6633 & 0.1379 & -9.8684 & 0.9042 \\
\hline 13 & -7.75 & -7.44 & -7.63 & -0.0065 & -2.4879 & 0.9871 & 0.0173 & -2.4879 & 0.9871 & -0.0165 & -7.4440 & 0.9882 & 0.1088 & -8.3007 & 0.9623 \\
\hline 14 & -8.63 & -8.13 & -8.50 & -0.0104 & -0.2289 & 0.9237 & 0.0283 & -0.2289 & 0.9237 & -0.0264 & -8.1601 & 0.9263 & 0.1835 & -9.5908 & 0.9991 \\
\hline 15 & -9.00 & -8.63 & -9.00 & -0.0078 & -2.7321 & 0.7510 & 0.0220 & -2.7321 & 0.7510 & -0.0198 & -8.6822 & 0.7552 & 0.1493 & -9.8302 & 0.9552 \\
\hline
\end{tabular}


Table 8-7: Effects of fuel density, cetane number, and aromatic content on start of combustion for JP-5 test fuels

\begin{tabular}{|c|c|c|c|c|c|c|c|c|c|c|c|c|}
\hline \multirow[b]{2}{*}{ Mode } & \multicolumn{3}{|c|}{ Start of Combustion (deg) } & \multicolumn{3}{|c|}{ Density } & \multicolumn{3}{|c|}{ Cetane Number } & \multicolumn{3}{|c|}{ Aromatics } \\
\hline & $J P-5$ & Neat HRJ5 & $\begin{array}{c}50 / 50 \\
\text { JP5/HRJ5 }\end{array}$ & $\mathrm{m}$ & b & $R^{2}$ & $\mathrm{~m}$ & b & $R^{2}$ & $\mathrm{~m}$ & b & $R^{2}$ \\
\hline 1 & 2.14 & 1.00 & 1.25 & 0.0237 & -17.2369 & 0.9039 & -0.0599 & 4.5970 & 0.8173 & 0.0600 & 0.8800 & 0.9010 \\
\hline 2 & 3.08 & 1.35 & 2.05 & 0.0359 & -26.2096 & 0.9876 & -0.0934 & -26.2096 & 0.9876 & 0.0912 & 1.2738 & 0.9865 \\
\hline 3 & 2.81 & 1.25 & 1.80 & 0.0322 & -23.5073 & 0.9718 & -0.0832 & -23.5073 & 0.9718 & 0.0818 & 1.1558 & 0.9702 \\
\hline 4 & 0.28 & -2.00 & -1.00 & 0.0472 & -38.1912 & 0.9949 & -0.1234 & -38.1912 & 0.9949 & 0.1198 & -2.0737 & 0.9942 \\
\hline 5 & 0.50 & -2.00 & -0.95 & 0.0518 & -41.7369 & 0.9913 & -0.1350 & -41.7369 & 0.9913 & 0.1315 & -2.0966 & 0.9904 \\
\hline 6 & 0.47 & -2.25 & -1.05 & 0.0564 & -45.5014 & 0.9952 & -0.1475 & -45.5014 & 0.9952 & 0.1432 & -2.3365 & 0.9945 \\
\hline 7 & -1.00 & -2.50 & -2.00 & 0.0310 & -26.3825 & 0.9638 & -0.0800 & -26.3825 & 0.9638 & 0.0789 & -2.6008 & 0.9620 \\
\hline 8 & -1.11 & -2.90 & -2.25 & 0.0370 & -31.3654 & 0.9753 & -0.0958 & -31.3654 & 0.9753 & 0.0941 & -3.0025 & 0.9738 \\
\hline 9 & -1.08 & -3.10 & -2.25 & 0.0417 & -35.1535 & 0.9916 & -0.1089 & -35.1535 & 0.9916 & 0.1061 & -3.1769 & 0.9907 \\
\hline 10 & -2.22 & -3.00 & -2.75 & 0.0161 & -15.3864 & 0.9587 & -0.0414 & -15.3864 & 0.9587 & 0.0409 & -3.0553 & 0.9568 \\
\hline 11 & -2.25 & -3.25 & -3.00 & 0.0207 & -19.1976 & 0.9224 & -0.0526 & -19.1976 & 0.9224 & 0.0525 & -3.3447 & 0.9198 \\
\hline 12 & -2.50 & -3.75 & -3.25 & 0.0259 & -23.6262 & 0.9866 & -0.0673 & -23.6262 & 0.9866 & 0.0657 & -3.8065 & 0.9854 \\
\hline 13 & -2.75 & -2.75 & -2.85 & 0.0000 & -2.7811 & 0.0000 & 0.0008 & -2.7811 & 0.0000 & 0.0000 & -2.7830 & 0.0000 \\
\hline 14 & -3.08 & -3.30 & -3.45 & 0.0045 & -6.8187 & 0.3442 & -0.0098 & -6.8187 & 0.3442 & 0.0113 & -3.3878 & 0.3396 \\
\hline 15 & -3.28 & -3.95 & -3.75 & 0.0139 & -14.6604 & 0.9476 & -0.0356 & -14.6604 & 0.9476 & 0.0353 & -4.0031 & 0.9454 \\
\hline
\end{tabular}

Table 8-8: Effects of fuel density, cetane number, and aromatic content on premix fraction length for JP-5 test fuels

\begin{tabular}{|c|c|c|c|c|c|c|c|c|c|c|c|c|}
\hline \multirow[b]{2}{*}{ Mode } & \multicolumn{3}{|c|}{ Premix Fraction Length (deg) } & \multicolumn{3}{|c|}{ Density } & \multicolumn{3}{|c|}{ Cetane Number } & \multicolumn{3}{|c|}{ Aromatics } \\
\hline & $\mathrm{JP}-5$ & Neat HRJ5 & $\begin{array}{c}50 / 50 \\
\text { JP5/HRJ5 } \\
\end{array}$ & $\mathrm{m}$ & $\mathrm{b}$ & $\mathrm{R}^{2}$ & $\mathrm{~m}$ & $\mathrm{~b}$ & $\mathrm{R}^{2}$ & $\mathrm{~m}$ & $\mathrm{~b}$ & $\mathrm{R}^{2}$ \\
\hline 1 & 6.66 & 6.53 & 6.50 & 0.0027 & 4.4279 & 0.6113 & -0.0064 & 6.8987 & 0.4858 & 0.0068 & 6.4967 & 0.6065 \\
\hline 2 & 7.37 & 7.06 & 7.26 & 0.0064 & 2.1381 & 0.9737 & -0.0174 & 2.1381 & 0.9737 & 0.0164 & 7.0689 & 0.9753 \\
\hline 3 & 7.28 & 6.70 & 7.00 & 0.0121 & -2.5873 & 0.9998 & -0.0320 & -2.5873 & 0.9998 & 0.0308 & 6.6913 & 0.9999 \\
\hline 4 & 7.97 & 7.61 & 7.75 & 0.0075 & 1.8479 & 0.9843 & -0.0195 & 1.8479 & 0.9843 & 0.0191 & 7.5946 & 0.9831 \\
\hline 5 & 8.54 & 8.11 & 8.38 & 0.0090 & 1.1978 & 0.9819 & -0.0243 & 1.1978 & 0.9819 & 0.0230 & 8.1197 & 0.9832 \\
\hline 6 & 9.14 & 8.75 & 8.89 & 0.0080 & 2.5761 & 0.9744 & -0.0208 & 2.5761 & 0.9744 & 0.0204 & 8.7314 & 0.9728 \\
\hline 7 & 7.41 & 6.80 & 7.15 & 0.0127 & -2.9526 & 0.9939 & -0.0340 & -2.9526 & 0.9939 & 0.0324 & 6.8025 & 0.9946 \\
\hline 8 & 7.87 & 7.35 & 7.61 & 0.0107 & -0.8321 & 0.9999 & -0.0282 & -0.8321 & 0.9999 & 0.0271 & 7.3470 & 1.0000 \\
\hline 9 & 8.53 & 7.82 & 8.11 & 0.0147 & -3.4856 & 0.9885 & -0.0383 & -3.4856 & 0.9885 & 0.0374 & 7.7897 & 0.9875 \\
\hline 10 & 6.96 & 6.26 & 6.56 & 0.0144 & -4.8100 & 0.9943 & -0.0377 & -4.8100 & 0.9943 & 0.0366 & 6.2366 & 0.9935 \\
\hline 11 & 7.29 & 6.69 & 6.99 & 0.0125 & -2.9010 & 1.0000 & -0.0330 & -2.9010 & 1.0000 & 0.0318 & 6.6806 & 1.0000 \\
\hline 12 & 7.94 & 7.30 & 7.57 & 0.0133 & -2.9079 & 0.9914 & -0.0347 & -2.9079 & 0.9914 & 0.0338 & 7.2753 & 0.9905 \\
\hline 13 & 6.40 & 5.48 & 5.91 & 0.0191 & -9.1821 & 0.9981 & -0.0502 & -9.1821 & 0.9981 & 0.0486 & 5.4556 & 0.9977 \\
\hline 14 & 6.79 & 6.06 & 6.49 & 0.0151 & -5.4686 & 0.9887 & -0.0403 & -5.4686 & 0.9887 & 0.0383 & 6.0735 & 0.9897 \\
\hline 15 & 7.39 & 6.85 & 7.11 & 0.0111 & -1.6910 & 0.9994 & -0.0293 & -1.6910 & 0.9994 & 0.0283 & 6.8437 & 0.9991 \\
\hline
\end{tabular}


Table 8-9: Effects of fuel density, cetane number, and aromatic content on diffusion fraction length for JP-5 test fuels

\begin{tabular}{|c|c|c|c|c|c|c|c|c|c|c|c|c|}
\hline \multirow[b]{2}{*}{ Mode } & \multicolumn{3}{|c|}{ Diffusion Fraction Length (deg) } & \multicolumn{3}{|c|}{ Density } & \multicolumn{3}{|c|}{ Cetane Number } & \multicolumn{3}{|c|}{ Aromatics } \\
\hline & JP-5 & Neat HRJ5 & $\begin{array}{c}50 / 50 \\
\text { JP5/HRJ5 }\end{array}$ & $\mathrm{m}$ & $\mathrm{b}$ & $\mathrm{R}^{2}$ & $\mathrm{~m}$ & $\mathrm{~b}$ & $\mathrm{R}^{2}$ & $\mathrm{~m}$ & $\mathrm{~b}$ & $\mathrm{R}^{2}$ \\
\hline 1 & 22.66 & 13.01 & 11.08 & 0.1998 & -142.3690 & 0.6041 & -0.4732 & 40.3468 & 0.4784 & 0.5058 & 10.6601 & 0.5993 \\
\hline 2 & 16.28 & 23.33 & 18.73 & -0.1460 & 134.9149 & 0.9705 & 0.3941 & 134.9149 & 0.9705 & -0.3716 & 23.0630 & 0.9722 \\
\hline 3 & 20.16 & 27.79 & 24.09 & -0.1579 & 148.8942 & 0.9996 & 0.4160 & 148.8942 & 0.9996 & -0.4015 & 27.9239 & 0.9994 \\
\hline 4 & 20.89 & 29.04 & 24.89 & -0.1689 & 158.4597 & 0.9999 & 0.4464 & 158.4597 & 0.9999 & -0.4293 & 29.1164 & 1.0000 \\
\hline 5 & 21.72 & 29.46 & 24.78 & -0.1604 & 152.1109 & 0.9860 & 0.4298 & 152.1109 & 0.9860 & -0.4079 & 9.2906 & 0.9871 \\
\hline 6 & 23.93 & 31.34 & 27.46 & -0.1534 & 148.8846 & 0.9993 & 0.4064 & 148.8846 & 0.9993 & -0.3901 & 31.3692 & 0.9996 \\
\hline 7 & 32.39 & 37.49 & 35.52 & -0.1055 & 118.5760 & 0.9824 & 0.2739 & 118.5760 & 0.9824 & -0.2681 & 37.7414 & 0.9811 \\
\hline 8 & 33.18 & 38.05 & 36.37 & -0.1008 & 115.5719 & 0.9687 & 0.2601 & 115.5719 & 0.9687 & -0.2560 & 38.3560 & 0.9670 \\
\hline 9 & 33.05 & 38.10 & 35.75 & -0.1046 & 118.3363 & 0.9982 & 0.2747 & 118.3363 & 0.9982 & -0.2658 & 38.2200 & 0.9977 \\
\hline 10 & 43.23 & 45.27 & 47.01 & -0.0421 & 78.4816 & 0.2900 & 0.0891 & 78.4816 & 0.2900 & -0.1063 & 46.2055 & 0.2856 \\
\hline 11 & 43.76 & 45.73 & 45.07 & -0.0408 & 77.0781 & 0.9638 & 0.1050 & 77.0781 & 0.9638 & -0.1035 & 45.8624 & 0.9619 \\
\hline 12 & 42.71 & 45.23 & 43.92 & -0.0523 & 85.3097 & 0.9996 & 0.1385 & 85.3097 & 0.9996 & -0.1330 & 45.2489 & 0.9997 \\
\hline 13 & 52.05 & 52.95 & 52.72 & -0.0186 & 67.2813 & 0.9270 & 0.0474 & 67.2813 & 0.9270 & -0.0472 & 53.0347 & 0.9245 \\
\hline 14 & 52.59 & 53.34 & 53.27 & -0.0156 & 65.3719 & 0.8163 & 0.0386 & 65.3719 & 0.8163 & -0.0395 & 53.4528 & 0.8125 \\
\hline 15 & 50.68 & 51.48 & 51.27 & -0.0166 & 64.2518 & 0.9279 & 0.0422 & 64.2518 & 0.9279 & -0.0421 & 51.5553 & 0.9254 \\
\hline
\end{tabular}


Table 8-10: Effects of fuel density, cetane number, and aromatic content on bsHC emissions for JP-5 test fuels

\begin{tabular}{|c|c|c|c|c|c|c|c|c|c|c|c|c|}
\hline & \multicolumn{3}{|c|}{ bsHC (g/bhp-hr) } & \multicolumn{3}{|c|}{ Density } & \multicolumn{3}{|c|}{ Cetane Number } & \multicolumn{3}{|c|}{ Aromatics } \\
\hline Mode & $J P-5$ & \begin{tabular}{l|} 
Neat \\
HRJ5
\end{tabular} & \begin{tabular}{|c|}
$50 / 50$ \\
JP5/HRJ5 \\
\end{tabular} & $\mathrm{m}$ & $b$ & $\mathrm{R}^{2}$ & $\mathrm{~m}$ & b & $\mathrm{R}^{2}$ & $\mathrm{~m}$ & b & $\mathrm{R}^{2}$ \\
\hline $1^{*}$ & 0.659 & 0.331 & \begin{tabular}{|l|}
0.427 \\
\end{tabular} & 0.0068 & -4.8981 & 0.9449 & -0.0174 & 1.3822 & 0.8736 & 0.0172 & 0.3046 & 0.9426 \\
\hline 2 & 0.374 & 0.204 & 0.279 & 0.0035 & -2.4926 & 0.9954 & -0.0092 & -2.4926 & 0.9954 & 0.0089 & 0.1989 & 0.9948 \\
\hline 3 & 0.111 & 0.081 & 0.100 & 0.0006 & -0.3976 & 0.9768 & -0.0017 & -0.3976 & 0.9768 & 0.0016 & 0.0820 & 0.9782 \\
\hline 4 & 0.201 & 0.148 & 0.183 & 0.0011 & -0.7000 & 0.9674 & -0.0030 & -0.7000 & 0.9674 & 0.0028 & 0.1499 & 0.9692 \\
\hline 5 & 0.216 & 0.166 & 0.208 & 0.0010 & -0.6279 & 0.8690 & -0.0029 & -0.6279 & 0.8690 & 0.0027 & 0.1705 & 0.8723 \\
\hline 6 & 0.278 & 0.199 & 0.227 & 0.0016 & -1.0626 & 0.9751 & -0.0042 & -1.0626 & 0.9751 & 0.0042 & 0.1942 & 0.9736 \\
\hline 7 & 0.082 & 0.069 & 0.080 & 0.0003 & -0.1367 & 0.8580 & -0.0008 & -0.1367 & 0.8580 & 0.0007 & 0.0706 & 0.8614 \\
\hline 8 & 0.082 & 0.063 & 0.077 & 0.0004 & -0.2364 & 0.9532 & -0.0011 & -0.2364 & 0.9532 & 0.0010 & 0.0644 & 0.9553 \\
\hline 9 & 0.095 & 0.078 & 0.090 & 0.0004 & -0.1992 & 0.9529 & -0.0010 & -0.1992 & 0.9529 & 0.0009 & 0.0786 & 0.9549 \\
\hline 10 & 0.047 & 0.039 & 0.043 & 0.0002 & -0.0948 & 1.0000 & -0.0005 & -0.0948 & 1.0000 & 0.0004 & 0.0386 & 0.9999 \\
\hline 11 & 0.045 & 0.038 & 0.042 & 0.0002 & -0.0865 & 0.9948 & -0.0004 & -0.0865 & 0.9948 & 0.0004 & 0.0376 & 0.9955 \\
\hline 12 & 0.055 & 0.043 & 0.047 & 0.0003 & -0.1535 & 0.9660 & -0.0007 & -0.1535 & 0.9660 & 0.0006 & 0.0420 & 0.9642 \\
\hline 13 & 0.030 & 0.028 & 0.029 & 0.0000 & -0.0038 & 0.9996 & -0.0001 & -0.0038 & 0.9996 & 0.0001 & 0.0284 & 0.9998 \\
\hline 14 & 0.036 & 0.029 & 0.032 & 0.0001 & -0.0813 & 0.9971 & -0.0004 & -0.0813 & 0.9971 & 0.0004 & 0.0290 & 0.9966 \\
\hline 15 & 0.039 & 0.032 & 0.035 & 0.0001 & -0.0769 & 0.9768 & -0.0004 & -0.0769 & 0.9768 & 0.0004 & 0.0317 & 0.9753 \\
\hline * Values ar & eported & a mass & 5 rate & & & & & & & & & \\
\hline
\end{tabular}

Table 8-11: Effects of fuel density, cetane number, and aromatic content on bsNOx emissions for JP-5 test fuels

\begin{tabular}{|c|c|c|c|c|c|c|c|c|c|c|c|c|}
\hline & \multicolumn{3}{|c|}{ bsNOx (g/bhp-hr) } & \multicolumn{3}{|c|}{ Density } & \multicolumn{3}{|c|}{ Cetane Number } & \multicolumn{3}{|c|}{ Aromatics } \\
\hline Mode & $J P-5$ & \begin{tabular}{l|} 
Neat \\
HRJ5
\end{tabular} & \begin{tabular}{|c|}
$50 / 50$ \\
JP5/HRJ5 \\
\end{tabular} & $\mathrm{m}$ & b & $\mathrm{R}^{2}$ & $\mathrm{~m}$ & $b$ & $\mathrm{R}^{2}$ & $\mathrm{~m}$ & b & $\mathrm{R}^{2}$ \\
\hline $1^{*}$ & 6.815 & 6.519 & \begin{tabular}{|l|}
7.140 \\
\end{tabular} & 0.0062 & 1.9575 & 0.2289 & -0.0200 & 7.8736 & 0.3426 & 0.0158 & 6.6710 & 0.2330 \\
\hline 2 & 12.731 & 8.752 & 10.799 & 0.0824 & -54.3851 & 0.9998 & -0.2180 & -54.3851 & 0.9998 & 0.2095 & 8.7218 & 0.9999 \\
\hline 3 & 10.226 & 7.048 & 8.334 & 0.0658 & -43.4730 & 0.9878 & -0.1712 & -43.4730 & 0.9878 & 0.1671 & 6.9093 & 0.9867 \\
\hline 4 & 11.820 & 8.321 & 9.756 & 0.0724 & -47.3112 & 0.9891 & -0.1887 & -47.3112 & 0.9891 & 0.1841 & 8.1743 & 0.9880 \\
\hline 5 & 11.696 & 8.153 & 9.682 & 0.0734 & -48.1532 & 0.9936 & -0.1917 & -48.1532 & 0.9936 & 0.1864 & 8.0297 & 0.9928 \\
\hline 6 & 11.868 & 8.229 & 9.957 & 0.0753 & -49.5393 & 0.9991 & -0.1981 & -49.5393 & 0.9991 & 0.1915 & 8.1544 & 0.9988 \\
\hline 7 & 8.170 & 6.782 & 7.372 & 0.0287 & -15.2745 & 0.9924 & -0.0750 & -15.2745 & 0.9924 & 0.0730 & 6.7305 & 0.9915 \\
\hline 8 & 8.299 & 6.832 & 7.471 & 0.0304 & -16.4680 & 0.9943 & -0.0794 & -16.4680 & 0.9943 & 0.0771 & 6.7830 & 0.9935 \\
\hline 9 & 8.579 & 6.923 & 7.620 & 0.0343 & -19.4043 & 0.9915 & -0.0895 & -19.4043 & 0.9915 & 0.0871 & 6.8594 & 0.9906 \\
\hline 10 & 6.222 & 5.608 & 5.919 & 0.0127 & -4.1346 & 1.0000 & -0.0336 & -4.1346 & 1.0000 & 0.0323 & 5.6015 & 1.0000 \\
\hline 11 & 6.601 & 5.936 & 6.273 & 0.0138 & -4.6115 & 1.0000 & -0.0364 & -4.6115 & 1.0000 & 0.0350 & 5.9295 & 1.0000 \\
\hline 12 & 6.906 & 6.146 & 6.536 & 0.0157 & -5.9160 & 0.9998 & -0.0416 & -5.9160 & 0.9998 & 0.0400 & 6.1400 & 0.9999 \\
\hline 13 & 5.591 & 5.210 & 5.424 & 0.0079 & -0.8379 & 0.9952 & -0.0210 & -0.8379 & 0.9952 & 0.0201 & 5.2126 & 0.9959 \\
\hline 14 & 5.966 & 5.545 & 5.817 & 0.0087 & -1.1102 & 0.9729 & -0.0235 & -1.1102 & 0.9729 & 0.0222 & 5.5605 & 0.9745 \\
\hline 15 & 6.249 & 5.761 & 6.053 & 0.0101 & -1.9635 & 0.9872 & -0.0270 & -1.9635 & 0.9872 & 0.0257 & 5.7711 & 0.9882 \\
\hline * Values ar & eported & $s$ a mass & s rate & & & & & & & & & \\
\hline
\end{tabular}


Table 8-12: Effects of fuel density, cetane number, and aromatic content on bsCO emissions for JP-5 test fuels

\begin{tabular}{|c|c|c|c|c|c|c|c|c|c|c|c|c|}
\hline & \multicolumn{3}{|c|}{ bsCO (g/bhp-hr) } & \multicolumn{3}{|c|}{ Density } & \multicolumn{3}{|c|}{ Cetane Number } & \multicolumn{3}{|c|}{ Aromatics } \\
\hline Mode & $J P-5$ & \begin{tabular}{l|} 
Neat \\
HRJ5
\end{tabular} & \begin{tabular}{|c|}
$50 / 50$ \\
JP5/HRJ5
\end{tabular} & $\mathrm{m}$ & $\mathrm{b}$ & $\mathrm{R}^{2}$ & $\mathrm{~m}$ & $\mathrm{~b}$ & $\mathrm{R}^{2}$ & $\mathrm{~m}$ & $b$ & $\mathrm{R}^{2}$ \\
\hline $1 *$ & 3.980 & 1.084 & \begin{tabular}{|l|}
1.893 \\
\end{tabular} & 0.0599 & -45.0769 & 0.9385 & -0.1531 & 10.3326 & 0.8645 & 0.1522 & 0.8379 & 0.9361 \\
\hline 2 & 2.637 & 0.953 & 1.480 & 0.0349 & -25.8657 & 0.9548 & -0.0895 & -25.8657 & 0.9548 & 0.0885 & 0.8288 & 0.9528 \\
\hline 3 & 0.369 & 0.359 & 0.365 & 0.0002 & 0.2073 & 0.9771 & -0.0005 & 0.2073 & 0.9771 & 0.0005 & 0.3596 & 0.9785 \\
\hline 4 & 0.810 & 0.520 & 0.615 & 0.0060 & -4.0915 & 0.9614 & -0.0154 & -4.0915 & 0.9614 & 0.0152 & 0.5003 & 0.9595 \\
\hline 5 & 0.938 & 0.583 & 0.714 & 0.0073 & -5.0591 & 0.9773 & -0.0190 & -5.0591 & 0.9773 & 0.0186 & 0.5633 & 0.9758 \\
\hline 6 & 1.360 & 0.751 & 0.903 & 0.0126 & -8.9556 & 0.9227 & -0.0320 & -8.9556 & 0.9227 & 0.0320 & 0.6935 & 0.9201 \\
\hline 7 & 0.884 & 0.769 & 0.883 & 0.0024 & -1.0362 & 0.7601 & -0.0067 & -1.0362 & 0.7601 & 0.0061 & 0.7862 & 0.7643 \\
\hline 8 & 0.598 & 0.512 & 0.570 & 0.0018 & -0.8484 & 0.9588 & -0.0048 & -0.8484 & 0.9588 & 0.0045 & 0.5160 & 0.9607 \\
\hline 9 & 0.471 & 0.401 & 0.444 & 0.0015 & -0.7103 & 0.9841 & -0.0039 & -0.7103 & 0.9841 & 0.0037 & 0.4025 & 0.9853 \\
\hline 10 & 4.097 & 3.743 & 4.050 & 0.0073 & -1.8369 & 0.8472 & -0.0204 & -1.8369 & 0.8472 & 0.0187 & 3.7814 & 0.8507 \\
\hline 11 & 1.613 & 1.495 & 1.588 & 0.0024 & -0.3525 & 0.9001 & -0.0067 & -0.3525 & 0.9001 & 0.0062 & 1.5052 & 0.9030 \\
\hline 12 & 0.743 & 0.672 & 0.706 & 0.0015 & -0.4468 & 0.9993 & -0.0038 & -0.4468 & 0.9993 & 0.0037 & 0.6711 & 0.9991 \\
\hline 13 & 7.686 & 6.771 & 7.310 & 0.0189 & -7.7155 & 0.9897 & -0.0506 & -7.7155 & 0.9897 & 0.0482 & 6.7869 & 0.9906 \\
\hline 14 & 2.950 & 2.688 & 2.892 & 0.0054 & -1.4354 & 0.9062 & -0.0149 & -1.4354 & 0.9062 & 0.0138 & 2.7093 & 0.9090 \\
\hline 15 & 1.299 & 1.181 & 1.255 & 0.0024 & -0.6718 & 0.9784 & -0.0065 & -0.6718 & 0.9784 & 0.0062 & 1.1850 & 0.9798 \\
\hline
\end{tabular}

Table 8-13: Effects of fuel density, cetane number, and aromatic content on bs $\mathrm{CO}_{2}$ emissions for JP-5 test fuels

\begin{tabular}{|c|c|c|c|c|c|c|c|c|c|c|c|c|}
\hline & \multicolumn{3}{|c|}{$\mathrm{bsCO}_{2}$ (g/bhp-hr) } & \multicolumn{3}{|c|}{ Density } & \multicolumn{3}{|c|}{ Cetane Number } & \multicolumn{3}{|c|}{ Aromatics } \\
\hline Mode & JP-5 & $\begin{array}{l}\text { Neat } \\
\text { HRJ5 }\end{array}$ & \begin{tabular}{|c|}
$50 / 50$ \\
JP5/HRJ5
\end{tabular} & $\mathrm{m}$ & b & $\mathrm{R}^{2}$ & $\mathrm{~m}$ & b & $\mathrm{R}^{2}$ & $\mathrm{~m}$ & b & $\mathrm{R}^{2}$ \\
\hline $1 *$ & 316.91 & 293.01 & 311.43 & 0.4950 & -84.2537 & 0.9116 & -1.3586 & 378.2176 & 0.9695 & 1.2602 & 294.8500 & 0.9143 \\
\hline 2 & 536.51 & 503.61 & 521.52 & 0.6813 & -18.1033 & 0.9975 & -1.8102 & -18.1033 & 0.9975 & 1.7322 & 503.6862 & 0.9980 \\
\hline 3 & 472.92 & 448.18 & 461.70 & 0.5123 & 55.8724 & 0.9972 & -1.3617 & 55.8724 & 0.9972 & 1.3026 & 448.2542 & 0.9977 \\
\hline 4 & 487.66 & 462.94 & 476.52 & 0.5117 & 71.0925 & 0.9969 & -1.3607 & 71.0925 & 0.9969 & 1.3012 & 463.0410 & 0.9974 \\
\hline 5 & 500.19 & 477.02 & 489.40 & 0.4799 & 109.4394 & 0.9985 & -1.2732 & 109.4394 & 0.9985 & 1.2201 & 476.9935 & 0.9989 \\
\hline 6 & 532.77 & 509.70 & 522.33 & 0.4777 & 143.8985 & 0.9971 & -1.2698 & 143.8985 & 0.9971 & 1.2146 & 509.7735 & 0.9976 \\
\hline 7 & 454.45 & 434.59 & 445.12 & 0.4112 & 119.5880 & 0.9989 & -1.0903 & 119.5880 & 0.9989 & 1.0455 & 434.5427 & 0.9992 \\
\hline 8 & 454.97 & 435.18 & 445.06 & 0.4098 & 121.0891 & 1.0000 & -1.0816 & 121.0891 & 1.0000 & 1.0416 & 434.9322 & 1.0000 \\
\hline 9 & 466.81 & 447.34 & 457.30 & 0.4032 & 138.3872 & 0.9999 & -1.0661 & 138.3872 & 0.9999 & 1.0249 & 447.1707 & 0.9999 \\
\hline 10 & 452.51 & 432.95 & 442.39 & 0.4050 & 122.4191 & 0.9996 & -1.0664 & 122.4191 & 0.9996 & 1.0293 & 432.5956 & 0.9993 \\
\hline 11 & 445.44 & 426.79 & 435.87 & 0.3862 & 130.7035 & 0.9997 & -1.0174 & 130.7035 & 0.9997 & 0.9816 & 426.4786 & 0.9995 \\
\hline 12 & 451.66 & 432.93 & 441.60 & 0.3877 & 135.5480 & 0.9981 & -1.0178 & 135.5480 & 0.9981 & 0.9853 & 432.4749 & 0.9976 \\
\hline 13 & 451.13 & 432.46 & 441.17 & 0.3865 & 135.9854 & 0.9984 & -1.0153 & 135.9854 & 0.9984 & 0.9823 & 432.0277 & 0.9980 \\
\hline 14 & 444.11 & 425.67 & 435.22 & 0.3818 & 133.1031 & 0.9996 & -1.0106 & 133.1031 & 0.9996 & 0.9707 & 425.5526 & 0.9998 \\
\hline 15 & 448.19 & 429.50 & 438.17 & 0.3869 & 132.7015 & 0.9982 & -1.0160 & 132.7015 & 0.9982 & 0.9833 & 429.0454 & 0.9977 \\
\hline * Values a & reporte & as a mass & s rate & & & & & & & & & \\
\hline
\end{tabular}


Table 8-14: Effects of fuel density, cetane number, and aromatic content on bsPM emissions for JP-5 test fuels

\begin{tabular}{|c|c|c|c|c|c|c|c|c|c|c|c|c|}
\hline & \multicolumn{3}{|c|}{ bsPM (mg/bhp-hr) } & \multicolumn{3}{|c|}{ Density } & \multicolumn{3}{|c|}{ Cetane Number } & \multicolumn{3}{|c|}{ Aromatics } \\
\hline Mode & $J P-5$ & \begin{tabular}{l|} 
Neat \\
HRJ5
\end{tabular} & \begin{tabular}{|c|}
$50 / 50$ \\
JP5/HRJ5
\end{tabular} & $\mathrm{m}$ & $\mathrm{b}$ & $\mathrm{R}^{2}$ & $\mathrm{~m}$ & $b$ & $\mathrm{R}^{2}$ & $\mathrm{~m}$ & $\mathrm{~b}$ & $\mathrm{R}^{2}$ \\
\hline $1 *$ & 62.876 & 23.743 & 60.740 & 0.8107 & -591.8793 & 0.7918 & -2.2800 & 168.4390 & 0.8841 & 2.0660 & 29.0104 & 0.7957 \\
\hline 2 & 113.775 & 108.425 & 152.970 & 0.1120 & 36.5276 & 0.0124 & -0.6314 & 36.5276 & 0.0124 & 0.2970 & 122.1650 & 0.0135 \\
\hline 3 & 52.276 & 37.237 & 49.681 & 0.3115 & -199.8910 & 0.8757 & -0.8618 & -199.8910 & 0.8757 & 0.7933 & 38.6765 & 0.8789 \\
\hline 4 & 160.578 & 148.430 & 169.440 & 0.2520 & -39.7299 & 0.3328 & -0.7849 & -39.7299 & 0.3328 & 0.6449 & 153.2056 & 0.3374 \\
\hline 5 & 187.454 & 191.586 & 218.363 & -0.0847 & 266.1320 & 0.0149 & -0.0077 & 266.1320 & 0.0149 & -0.2068 & 201.1476 & 0.0137 \\
\hline 6 & 282.193 & 260.639 & 256.616 & 0.4458 & -86.0239 & 0.6129 & -1.0582 & -86.0239 & 0.6129 & 1.1289 & 255.4945 & 0.6081 \\
\hline 7 & 57.423 & 52.010 & 57.231 & 0.1121 & -33.0983 & 0.7774 & -0.3162 & -33.0983 & 0.7774 & 0.2858 & 52.7734 & 0.7815 \\
\hline 8 & 54.515 & 42.786 & 55.686 & 0.2430 & -141.1552 & 0.6769 & -0.6980 & -141.1552 & 0.6769 & 0.6199 & 44.9624 & 0.6815 \\
\hline 9 & 66.764 & 56.740 & 65.880 & 0.2077 & -101.0561 & 0.8165 & -0.5813 & -101.0561 & 0.8165 & 0.5291 & 57.9786 & 0.8203 \\
\hline 10 & 152.252 & 116.332 & 141.110 & 0.7439 & -451.5907 & 0.9547 & -2.0184 & -451.5907 & 0.9547 & 1.8930 & 118.1398 & 0.9567 \\
\hline 11 & 82.115 & 65.201 & 78.957 & 0.3504 & -201.5862 & 0.8851 & -0.9674 & -201.5862 & 0.8851 & 0.8922 & 66.7404 & 0.8881 \\
\hline 12 & 65.928 & 49.117 & 60.220 & 0.3481 & -216.8415 & 0.9672 & -0.9407 & \begin{tabular}{|l|}
-216.8415 \\
\end{tabular} & 0.9672 & 0.8858 & 49.7998 & 0.9690 \\
\hline 13 & 227.125 & 175.276 & 211.145 & 1.0738 & -644.4671 & 0.9537 & -2.9144 & -644.4671 & 0.9537 & 2.7325 & 177.9192 & 0.9558 \\
\hline 14 & 111.706 & 88.791 & 105.202 & 0.4746 & -273.3384 & 0.9419 & -1.2926 & \begin{tabular}{|l|}
-273.3384 \\
\end{tabular} & 0.9419 & 1.2079 & 90.1431 & 0.9442 \\
\hline 15 & 78.852 & 60.027 & 72.159 & 0.3898 & -237.8819 & 0.9733 & -1.0509 & -237.8819 & 0.9733 & 0.9918 & 60.6927 & 0.9749 \\
\hline & & & & & & & & & & & & \\
\hline
\end{tabular}

Table 8-15: Effects of fuel density, cetane number, and aromatic content on bsFC for JP-5 test fuels

\begin{tabular}{|c|c|c|c|c|c|c|c|c|c|c|c|c|}
\hline & \multicolumn{3}{|c|}{ bsFC (lb/bhp-hr) } & \multicolumn{3}{|c|}{ Density } & \multicolumn{3}{|c|}{ Cetane Number } & \multicolumn{3}{|c|}{ Aromatics } \\
\hline Mode & $J P-5$ & $\begin{array}{l}\text { Neat } \\
\text { HRJ5 }\end{array}$ & \begin{tabular}{|c|}
$50 / 50$ \\
JP5/HRJ5
\end{tabular} & $\mathrm{m}$ & $\mathrm{b}$ & $\mathrm{R}^{2}$ & $\mathrm{~m}$ & $\mathrm{~b}$ & $\mathrm{R}^{2}$ & $\mathrm{~m}$ & b & $\mathrm{R}^{2}$ \\
\hline $1 *$ & 0.228 & 0.211 & 0.223 & 0.0004 & -0.0572 & 0.9541 & -0.0010 & 0.2709 & 0.9920 & 0.0009 & 0.2122 & 0.9561 \\
\hline 2 & 0.380 & 0.361 & 0.370 & 0.0004 & 0.0596 & 0.9998 & -0.0010 & 0.0596 & 0.9998 & 0.0010 & 0.3608 & 0.9996 \\
\hline 3 & 0.331 & 0.319 & 0.325 & 0.0002 & 0.1297 & 0.9979 & -0.0007 & 0.1297 & 0.9979 & 0.0006 & 0.3189 & 0.9983 \\
\hline 4 & 0.343 & 0.331 & 0.337 & 0.0002 & 0.1400 & 1.0000 & -0.0007 & 0.1400 & 1.0000 & 0.0006 & 0.3312 & 1.0000 \\
\hline 5 & 0.351 & 0.340 & 0.346 & 0.0002 & 0.1671 & 0.9996 & -0.0006 & 0.1671 & 0.9996 & 0.0006 & 0.3403 & 0.9998 \\
\hline 6 & 0.374 & 0.364 & 0.369 & 0.0002 & 0.1919 & 0.9996 & -0.0006 & 0.1919 & 0.9996 & 0.0006 & 0.3635 & 0.9998 \\
\hline 7 & 0.320 & 0.311 & 0.316 & 0.0002 & 0.1724 & 0.9996 & -0.0005 & 0.1724 & 0.9996 & 0.0005 & 0.3112 & 0.9998 \\
\hline 8 & 0.319 & 0.311 & 0.315 & 0.0002 & 0.1724 & 0.9981 & -0.0005 & 0.1724 & 0.9981 & 0.0005 & 0.3103 & 0.9976 \\
\hline 9 & 0.327 & 0.319 & 0.323 & 0.0002 & 0.1869 & 0.9993 & -0.0005 & 0.1869 & 0.9993 & 0.0004 & 0.3188 & 0.9991 \\
\hline 10 & 0.321 & 0.312 & 0.316 & 0.0002 & 0.1734 & 0.9962 & -0.0005 & 0.1734 & 0.9962 & 0.0005 & 0.3121 & 0.9956 \\
\hline 11 & 0.313 & 0.305 & 0.308 & 0.0002 & 0.1778 & 0.9947 & -0.0004 & 0.1778 & 0.9947 & 0.0004 & 0.3046 & 0.9939 \\
\hline 12 & 0.316 & 0.308 & 0.311 & 0.0002 & 0.1818 & 0.9847 & -0.0004 & 0.1818 & 0.9847 & 0.0004 & 0.3079 & 0.9834 \\
\hline 13 & 0.324 & 0.316 & 0.319 & 0.0002 & 0.1828 & 0.9895 & -0.0005 & 0.1828 & 0.9895 & 0.0004 & 0.3152 & 0.9885 \\
\hline 14 & 0.315 & 0.305 & 0.310 & 0.0002 & 0.1492 & 0.9921 & -0.0005 & 0.1492 & 0.9921 & 0.0005 & 0.3051 & 0.9912 \\
\hline 15 & 0.314 & 0.307 & 0.310 & 0.0002 & 0.1847 & 0.9839 & -0.0004 & 0.1847 & 0.9839 & 0.0004 & 0.3062 & 0.9827 \\
\hline
\end{tabular}


Table 8-16: Transient Combustion Data for JP-5 Test Fuels

\begin{tabular}{|c|c|c|c|c|c|c|c|c|c|c|c|c|c|c|c|c|}
\hline \multirow[b]{3}{*}{ Fuel } & & \multicolumn{5}{|c|}{ Minimum } & \multicolumn{5}{|c|}{ Maximum } & \multicolumn{5}{|c|}{ Average } \\
\hline & & & $50 / 50$ & & & & & $50 / 50$ & & & & & $50 / 50$ & & & \\
\hline & & JP.5 لر & JP5//RR/5 & \begin{tabular}{l|l} 
JP.5 & $\mathrm{N}$ \\
\end{tabular} & Neat HR55 $\mathrm{N}$ & Neat HRI5 & JP.5 & JP5/HR/5 & JP.5 & Neat HRI5 & Neat HRI5 & PP.5 If & Pp5/HRN5 & JP.5 & Neat HRl5 & Neat HRl5 \\
\hline Time & $\sec$ & 0.23 & 0.22 & 0.21 & 0.21 & 0.21 & 612.51 & 621.30 & 626.28 & \begin{tabular}{|r|}
629.20 \\
\end{tabular} & 619.15 & 309.41 & 310.07 & 316.31 & $1 \quad 318.09$ & 310.42 \\
\hline Engine Speed & $\mathrm{rpm}$ & 306.56 & 578.64 & 576.28 & 575.57 & 568.65 & 1880.05 & 1883.45 & 1924.45 & 1899.34 & 1866.05 & 1498.75 & 1497.18 & 1491.83 & \begin{tabular}{|l|l|}
3 & 1488.66 \\
\end{tabular} & 1495.07 \\
\hline Heat Released & $\mathrm{kJ}$ & 0.00 & 0.00 & 0.00 & 0.00 & 0.00 & 7.26 & 7.19 & 7.29 & 7.12 & 7.13 & 5.01 & 4.82 & 4.97 & \begin{tabular}{|l|l|}
7 & 4.77 \\
\end{tabular} & 4.68 \\
\hline Max Heat Release Rate & $\mathrm{k} / \mathrm{deg}$ & 0.03 & 0.18 & 0.18 & -0.64 & 0.10 & 1.11 & 1.03 & 1.33 & 0.98 & 0.68 & 0.35 & 0.30 & 0.36 & 0.29 & 0.23 \\
\hline Location of Max Heat Release Rate & $\operatorname{deg}$ & -155.25 & -155.25 & -155.25 & -155.25 & -155.25 & 143.25 & 144.75 & 144.75 & 143.25 & 144.75 & 13.14 & 15.24 & $4 \quad 14.63$ & 15.11 & 6.81 \\
\hline Max Pressure & $\mathrm{kPa}$ & 3713.60 & 3839.81 & 3988.54 & 3953.05 & 3781.51 & 10071.97 & 9937.26 & 10057.00 & \begin{tabular}{|l|}
9773.29 \\
\end{tabular} & 9736.99 & 8273.43 & 7991.96 & 8280.45 & \begin{tabular}{|l|l|}
5 & 7890.00 \\
\end{tabular} & 7709.04 \\
\hline Location of Max Pressure & $\operatorname{deg}$ & -0.50 & -1.25 & -1.25 & -1.25 & -1.25 & 15.25 & 13.75 & 16.25 & 14.75 & 14.50 & 7.39 & 6.65 & 7.47 & \begin{tabular}{|l|l|}
7 & 6.15 \\
\end{tabular} & 5.40 \\
\hline Max Pressure Rise & $\mathrm{KPa} / \mathrm{deg}$ & \begin{tabular}{|l|}
109.71 \\
\end{tabular} & 132.66 & 133.81 & 139.42 & 119.65 & 2091.13 & 1722.21 & 2293.61 & 1512.33 & 1288.06 & 553.42 & 453.03 & 577.05 & 461.27 & 278.04 \\
\hline Location of Max Pressure Rise & deg & -16.75 & -23.00 & -23.25 & -22.50 & -21.50 & 12.50 & 10.75 & 12.50 & 7.75 & 8.75 & -5.57 & -7.93 & -4.87 & -8.79 & $-11,71$ \\
\hline Max Temperature & K & 819.56 & 816.64 & 817.36 & 824.02 & 822.68 & 2066.15 & 2002.93 & 2075.32 & \begin{tabular}{|l|}
1907.54 \\
\end{tabular} & 1999.86 & 1419.11 & 1399.14 & A 1419.71 & \begin{tabular}{|l|l|}
1405.77 \\
\end{tabular} & 1370.61 \\
\hline Location of Max Tempera & deg & -0.50 & -1.50 & -1.50 & -1.25 & -1.50 & 43.25 & 43.00 & 43.25 & 46.00 & 43.25 & 28.98 & 28.84 & $4 \quad 28.91$ & \begin{tabular}{|l|l|} 
& 28.73 \\
\end{tabular} & 27.67 \\
\hline Average Temperature & $K$ & 446.43 & 442.14 & 433.08 & 445.24 & 446.76 & 968.54 & 983.87 & 979.35 & 954.13 & 958.34 & 754.32 & 747.94 & 4751.55 & 750.72 & 740.92 \\
\hline Pressure at Start of Combustion & K & 177.85 & 168.19 & 171.59 & 170.57 & 173.07 & 493.44 & 473.94 & 483.20 & 466.21 & 472.81 & 371.83 & 363.96 & 371.26 & 358.45 & 360.35 \\
\hline Temperature at S & K & 343.89 & 313.32 & 336.37 & 330.86 & 343.86 & 426.76 & 421.99 & 438.25 & 430.12 & 417.56 & 378.15 & 378.30 & 377.94 & 378.15 & 381.74 \\
\hline Intake Gas & K & 304.43 & 304.76 & 300.72 & 305.39 & 308.84 & 314.49 & 314.94 & 315.47 & 314.46 & 325.64 & 310.36 & 310.22 & 309.61 & 310.42 & 312.58 \\
\hline Exhaust Gas Temperature & K & 407.34 & 372.09 & 406.91 & 398.81 & 355.39 & 829.52 & 822.94 & 826.79 & 821.57 & 820.28 & 733.42 & 723.88 & 728.19 & 724.04 & 718.58 \\
\hline Start of Injection & $\operatorname{deg}$ & & $\cdot \cdot$ & $\cdot$ & \begin{tabular}{l|l}
$\cdot$ \\
\end{tabular} & $\cdot$ & $\cdot$ & 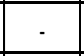 & & & \begin{tabular}{l|l}
$\cdot$ & \\
\end{tabular} & \begin{tabular}{|l|}
$\cdot$ \\
\end{tabular} & \begin{tabular}{|l|}
$\cdot$ \\
\end{tabular} & \begin{tabular}{|l|}
$\cdot$ \\
\end{tabular} & & $\cdot$ \\
\hline Stop of Injection & deg & - & - & - & - & - & 89.50 & 89.50 & 89.50 & 89.50 & 89.50 & 23.67 & 19.70 & 19.68 & 15.99 & 22.88 \\
\hline Start of Combustion & deg & . & - & . & . & - & 29.00 & 28.50 & 29.75 & 29.50 & 32.50 & 4.75 & 1.98 & 3.59 & 2.09 & -2.79 \\
\hline Location & $\operatorname{deg}$ & - & . & - & . & - & 29.00 & 28.50 & 29.75 & 29.50 & 32.50 & 4.75 & 1.98 & 3.59 & 2.09 & -2.79 \\
\hline Location of 10\% Mass Fraction Burned & $\operatorname{deg}$ & . & . & . & . & . & 29.00 & 28.50 & 29.75 & 29.50 & 32.50 & 6.02 & 4.06 & 4.98 & 4.69 & 0.04 \\
\hline Location of 50\% Mass Fraction Burned & $\operatorname{deg}$ & - & - & - & - & - & 29.00 & 28.50 & 29.75 & 32.00 & 32.50 & 17.57 & 15.63 & 16.45 & 15.93 & 13.17 \\
\hline Location of $90 \%$ Mass Fraction Burned & $\operatorname{deg}$ & - & - & - & - & - & 49.25 & 51.25 & 50.75 & 127.00 & 50.75 & 32.26 & 30.41 & 30.55 & 31.18 & 28.63 \\
\hline Location of 95\% Mass Fract & $\operatorname{deg}$ & - & - & - & . & - & 67.25 & 108.50 & 115.75 & 133.50 & 65.50 & 39.40 & 37.99 & 37.61 & 38.21 & 35.40 \\
\hline Estimated End 0 & $\operatorname{deg}$ & $\cdot$ & 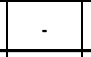 &. & $\cdot$ & - & 144.50 & 144.75 & 144.75 & 144.75 & 144.75 & 100.92 & 99.01 & 99.02 & 98.95 & 90.80 \\
\hline Mass Flow Of Cylinder Charge & $\mathrm{kg} / \mathrm{min}$ & 0.35 & 0.65 & 0.66 & 0.66 & 0.63 & 5.14 & 4.99 & 5.11 & 4.97 & 4.95 & 3.69 & 3.61 & 3.68 & 3.54 & 3.53 \\
\hline Mass Flow Of Fuel & $\mathrm{kg} / \mathrm{min}$ & 0.00 & 0.00 & 0.00 & 0.00 & 0.00 & 0.15 & 0.14 & 0.14 & 0.14 & 0.14 & 0.10 & 0.10 & 0.10 & 0.09 & 0.09 \\
\hline Mass AF Ratio &. & 22.79 & 23.39 & 22.52 & 24.91 & 24.53 & 1018284.73 & 65535.00 & 65535.00 & 65535.00 & 65535.00 & 907.606 & 65535.00 & 65535.00 & 06535.00 & 65535.00 \\
\hline Manifold Air Pressure & $\mathrm{kPa}$ & 94.57 & 91.71 & 93.61 & 93.90 & 94.02 & 239.84 & 239.48 & 246.18 & 234.58 & 233.10 & 191.14 & 186.83 & 190.44 & \begin{tabular}{|l|l|}
4 & 184.31 \\
\end{tabular} & 184.72 \\
\hline Gross Indicated Mean Effective Pressure & $\mathrm{kPa}$ & $\cdot$ & $\cdot$ & $\cdot$ & $\cdot$ & $\cdot$ & $\cdot$ & $\cdot$ & \begin{tabular}{|l|}
$\cdot$ \\
\end{tabular} & . & $\cdot$ & \begin{tabular}{|l|}
$\cdot$ \\
\end{tabular} & $\cdot$ & $\cdot$ & $\cdot$ & $\cdot$ \\
\hline Brake Torque & N-m & & - & . & . & - & - & . & . & & . & . & . & - & 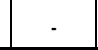 & - \\
\hline Energy Conversion Efficiency & $\%$ & - & . & . & . & . & . & - & . & . & . & - & - & - & - & . \\
\hline Length of Premix Fraction & deg & - & $\cdot$ & - & - & - & 30.00 & 29.30 & 30.00 & 30.00 & 30.00 & 7.44 & 6.13 & 7.64 & 6.56 & 6.05 \\
\hline Length of Diffustion Fraction & deg & - & - & - & - & - & 99.64 & 62.44 & 100.00 & 87.12 & 62.89 & 44.01 & 41.92 & 43.64 & 43.80 & 42.57 \\
\hline Heat Released during Premix & $\mathrm{kJ}$ & - & . & - & . & - & 2.19 & 1.77 & 2.44 & 1.76 & 1.49 & 0.52 & 0.31 & 0.54 & 0.27 & 0.23 \\
\hline Heat Released during Diffusion & $\mathrm{kJ}$ & - &. & - & - & - & 6.65 & 6.41 & 8.26 & 6.44 & 6.47 & 4.18 & 4.11 & 4.15 & 4.15 & 4.16 \\
\hline Premix Shape Factor &. & - & 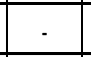 & . & . & . & 20.00 & 17.73 & 20.00 & 20.00 & 18.20 & 7.57 & 4.62 & 7.85 & 5.96 & 4.50 \\
\hline Diffusion Shape Factor &. & $\cdot$ & $\cdot$ & $\cdot$ & $\cdot$ & . & 43.08 & 49.97 & 50.00 & 50.00 & 49.99 & 3.11 & 2.02 & 3.35 & 2.57 & 2.07 \\
\hline Fresh Air & $\mathrm{kg} / \mathrm{min}$ & 0.35 & 0.65 & 0.66 & 0.66 & 0.63 & 5.14 & 4.99 & 5.11 & 4.97 & 4.95 & 3.69 & 3.61 & 3.68 & 3.54 & 3.53 \\
\hline Mass Fraction Burned at 950 K & . & -99.21 & -545.34 & -855.25 & -807.44 & .702 .41 & 3.71 & 340.80 & 105.91 & 61.44 & 8600.38 & 0.16 & & & & \\
\hline
\end{tabular}


Table 8-17: Transient Emissions Data for JP-5 Test Fuels

\begin{tabular}{|l|r|r|r|r|r|}
\hline & \multicolumn{1}{|c|}{ JP-5 } & $\mathbf{5 0 - 5 0 ~ J P 5 - H R J 5}$ & JP-5 & Neat HR5 & Neat HRJ5 \\
\hline Average Speed (RPM) & 1206.98 & 1210.91 & 1213.10 & 1212.70 & 1211.13 \\
\hline Average Torque (ft-lb) & 499.28 & 484.79 & 500.37 & 477.55 & 473.48 \\
\hline Total Work (hp-hr) & 29.047 & 28.173 & 29.075 & 27.740 & 27.500 \\
\hline HC (g/bhp-hr) & 0.06553 & 0.05833 & 0.06677 & 0.05179 & 0.05515 \\
\hline NOx (g/bhp-hr) & 3.4511 & 3.2933 & 3.4282 & 3.0915 & 3.0342 \\
\hline CO (g/bhp-hr) & 1.44150 & 1.38277 & 1.37461 & 1.36977 & 1.33432 \\
\hline CO2 (g/bhp-hr) & 524.59 & 514.03 & 521.08 & 502.08 & 502.60 \\
\hline PM (mg/bhp-hr) & 160.5 & 149.0 & 154.6 & 134.4 & 132.1 \\
\hline Fuel mass carbon balance (g) & 4766.5 & 4560.7 & 4741.9 & 4430.0 & 4393.7 \\
\hline Fuel mass gravimetric (g) & 4770.0 & 4510.0 & 0.0 & 4490.0 & 4470.0 \\
\hline Fuel mass meter (g) & 4706.2 & 4589.2 & 4779.2 & 4441.2 & 4492.1 \\
\hline NOx Kh (avg) () & 0.952 & 0.950 & 0.955 & 0.946 & 0.945 \\
\hline PM Vmix (SCF) & 3.379 & 3.366 & 3.380 & 3.381 & 3.372 \\
\hline PM Sample Flow (SCF) & 0.002 & 0.002 & 0.002 & 0.002 & 0.002 \\
\hline bsFC (lb/bhp-hr) & 0.162 & 0.155 & 0.161 & 0.150 & 0.149 \\
\hline
\end{tabular}




\subsection{F-76 Fuels Data}

Table 8-18: Effects of fuel density, cetane number, and aromatic content on maximum heat release rate for F-76 test fuels

\begin{tabular}{|c|c|c|c|c|c|c|c|c|c|c|c|c|c|c|c|}
\hline & \multicolumn{6}{|c|}{ Max Heat Release Rate (kJ/deg) } & \multicolumn{3}{|c|}{ Density } & \multicolumn{3}{|c|}{ Cetane Number } & \multicolumn{3}{|c|}{ Aromatics } \\
\hline Mode & F-76 & Neat HRD76 & $\begin{array}{c}50 / 50 \\
\text { F76/HRD76 }\end{array}$ & Neat DSH76 & $\begin{array}{c}50 / 50 \\
\text { F76/DSH76 }\end{array}$ & \begin{tabular}{c|}
$80 / 20$ \\
F76/HDCD76
\end{tabular} & $\mathrm{m}$ & b & $\mathrm{R}^{2}$ & $\mathrm{~m}$ & b & $\mathrm{R}^{2}$ & $\mathrm{~m}$ & b & $\mathrm{R}^{2}$ \\
\hline 1 & 0.705 & N/A & 0.578 & 0.603 & 0.650 & \begin{tabular}{|l|}
0.702 \\
\end{tabular} & 0.0013 & -0.4261 & 0.6349 & -0.0071 & 1.0159 & 0.9225 & 0.0053 & 0.5814 & 0.5902 \\
\hline 2 & 0.676 & 0.417 & 0.498 & 0.527 & 0.598 & 0.768 & 0.0032 & -2.0063 & 0.7924 & -0.0120 & 1.2361 & 0.9081 & 0.0129 & 0.4448 & 0.7796 \\
\hline 3 & 0.577 & 0.339 & 0.428 & 0.451 & 0.513 & 0.665 & 0.0029 & -1.8376 & 0.7827 & -0.0109 & 1.0912 & 0.9105 & 0.0117 & 0.3725 & 0.7767 \\
\hline 4 & 0.576 & 0.311 & 0.413 & 0.413 & 0.489 & 0.657 & 0.0032 & -2.1462 & 0.8441 & -0.0119 & 1.1270 & 0.9270 & 0.0131 & 0.3386 & 0.8323 \\
\hline 5 & 0.527 & 0.292 & 0.383 & 0.379 & 0.448 & 0.594 & 0.0028 & -1.8781 & 0.8550 & -0.0104 & 1.0092 & 0.9313 & 0.0115 & 0.3156 & 0.8423 \\
\hline 6 & 0.472 & 0.269 & 0.349 & 0.346 & 0.401 & 0.524 & 0.0024 & -1.5646 & 0.8525 & -0.0089 & 0.8807 & 0.9421 & 0.0097 & 0.2907 & 0.8381 \\
\hline 7 & 0.437 & 0.248 & 0.321 & 0.325 & 0.378 & 0.506 & 0.0024 & -1.5442 & 0.8319 & -0.0087 & 0.8437 & 0.9130 & 0.0095 & 0.2687 & 0.8202 \\
\hline 8 & 0.394 & 0.225 & 0.290 & 0.286 & 0.334 & 0.451 & 0.0021 & -1.3937 & 0.8596 & -0.0077 & 0.7513 & 0.9168 & 0.0086 & 0.2396 & 0.8423 \\
\hline 9 & 0.369 & 0.215 & 0.275 & 0.269 & 0.317 & 0.423 & 0.0020 & -1.2832 & 0.8657 & -0.0071 & 0.6984 & 0.9110 & 0.0079 & 0.2275 & 0.8523 \\
\hline 10 & 0.336 & 0.291 & 0.292 & 0.289 & 0.294 & 0.382 & 0.0009 & -0.4532 & 0.7903 & -0.0030 & 0.4762 & 0.6316 & 0.0036 & 0.2759 & 0.6942 \\
\hline 11 & 0.298 & 0.277 & 0.278 & 0.274 & 0.275 & 0.342 & 0.0006 & -0.2220 & 0.7027 & -0.0019 & 0.3932 & 0.5025 & 0.0024 & 0.2652 & 0.6159 \\
\hline 12 & 0.275 & 0.238 & 0.241 & 0.232 & 0.241 & 0.312 & 0.0008 & -0.3913 & 0.8279 & -0.0024 & 0.3898 & 0.6271 & 0.0031 & 0.2240 & 0.7376 \\
\hline 13 & 0.337 & 0.316 & 0.324 & 0.312 & 0.322 & 0.344 & 0.0003 & 0.0494 & 0.9817 & -0.0010 & 0.3817 & 0.7107 & 0.0013 & 0.3118 & 0.9250 \\
\hline 14 & 0.323 & 0.304 & 0.314 & 0.296 & 0.310 & 0.327 & 0.0003 & 0.0541 & 0.9638 & -0.0009 & 0.3610 & 0.6096 & 0.0013 & 0.2989 & 0.9304 \\
\hline 15 & 0.285 & 0.266 & 0.277 & 0.261 & 0.273 & 0.293 & 0.0003 & 0.0087 & 0.9809 & -0.0009 & 0.3271 & 0.6481 & 0.0013 & 0.2618 & 0.9487 \\
\hline
\end{tabular}

Table 8-19: Effects of fuel density, cetane number, and aromatic content on net heat released for F-76 test fuels

\begin{tabular}{|c|c|c|c|c|c|c|c|c|c|c|c|c|c|c|c|}
\hline & \multicolumn{6}{|c|}{ Net Heat Released (kJ) } & \multicolumn{3}{|c|}{ Density } & \multicolumn{3}{|c|}{ Cetane Number } & \multicolumn{3}{|c|}{ Aromatics } \\
\hline Mode & F-76 & Neat HRD76 & $\begin{array}{c}50 / 50 \\
\text { F76/HRD76 }\end{array}$ & Neat DSH76 & $\begin{array}{c}50 / 50 \\
\text { F76/DSH76 }\end{array}$ & \begin{tabular}{c|}
$80 / 20$ \\
F76/HDCD76
\end{tabular} & $\mathrm{m}$ & b & $\mathrm{R}^{2}$ & $\mathrm{~m}$ & b & $\mathrm{R}^{2}$ & $\mathrm{~m}$ & b & $\mathrm{R}^{2}$ \\
\hline 1 & 0.976 & N/A & 0.873 & 0.859 & 0.876 & \begin{tabular}{|l|}
0.932 \\
\end{tabular} & 0.0012 & -0.0637 & 0.6899 & -0.0061 & 1.2171 & 0.8989 & 0.0045 & 0.8468 & 0.5736 \\
\hline 2 & 2.058 & 1.415 & 2.032 & 1.716 & 1.967 & 2.077 & 0.0060 & -2.9823 & 0.6585 & -0.0217 & 3.0659 & 0.7029 & 0.0257 & 1.6060 & 0.7337 \\
\hline 3 & 3.154 & 3.126 & 3.150 & 3.108 & 3.128 & 3.136 & 0.0003 & 2.8673 & 0.4784 & -0.0008 & 3.1750 & 0.2064 & 0.0013 & 3.1196 & 0.4677 \\
\hline 4 & 2.366 & 2.411 & 2.366 & 2.380 & 2.375 & 2.408 & 0.0000 & 2.4084 & 0.0027 & 0.0006 & 2.3541 & 0.0765 & -0.0002 & 2.3868 & 0.0107 \\
\hline 5 & 2.379 & 2.366 & 2.376 & 2.360 & 2.368 & 2.392 & 0.0003 & 2.1287 & 0.8919 & -0.0008 & 2.4174 & 0.5095 & 0.0012 & 2.3611 & 0.8334 \\
\hline 6 & 2.264 & 2.197 & 2.196 & 2.178 & 2.188 & 2.284 & 0.0011 & 1.2963 & 0.8303 & -0.0035 & 2.4084 & 0.6354 & 0.0043 & 2.1727 & 0.7048 \\
\hline 7 & 4.422 & 4.433 & 4.435 & 4.416 & 4.425 & 4.420 & 0.0000 & 4.4567 & 0.0338 & 0.0004 & 4.4017 & 0.3301 & -0.0001 & 4.4264 & 0.0226 \\
\hline 8 & 4.244 & 4.279 & 4.284 & 4.266 & 4.269 & 4.219 & -0.0006 & 4.7156 & 0.6487 & 0.0021 & 4.1476 & 0.7093 & -0.0021 & 4.2827 & 0.5625 \\
\hline 9 & 3.832 & 3.801 & 3.761 & 3.806 & 3.762 & 3.836 & 0.0004 & 3.4488 & 0.2214 & $\mid-0.0017$ & 3.8956 & 0.2949 & 0.0013 & 3.7863 & 0.1151 \\
\hline 10 & 6.570 & 6.600 & 6.606 & 6.583 & 6.600 & 6.542 & -0.0005 & 6.9801 & 0.5138 & 0.0018 & 6.4826 & 0.5931 & -0.0018 & 6.6022 & 0.4083 \\
\hline 11 & 6.254 & 6.291 & 6.245 & 6.281 & 6.243 & 6.267 & -0.0003 & 6.4792 & 0.2307 & 0.0009 & 6.2141 & 0.2140 & -0.0013 & 6.2773 & 0.3448 \\
\hline 12 & 5.456 & 5.413 & 5.395 & 5.446 & 5.377 & 5.465 & 0.0004 & 5.0710 & 0.1899 & -0.0020 & 5.5365 & 0.3321 & 0.0012 & 5.4125 & 0.0919 \\
\hline 13 & 8.986 & 8.414 & 8.637 & 8.233 & 8.642 & 9.173 & 0.0097 & 0.7764 & 0.9822 & -0.0283 & 10.2351 & 0.6778 & 0.0390 & 8.2690 & 0.9522 \\
\hline 14 & 8.316 & 7.783 & 8.075 & 7.621 & 7.983 & 8.443 & 0.0087 & 0.9994 & 0.9805 & -0.0247 & 9.3923 & 0.6491 & 0.0348 & 7.6695 & 0.9547 \\
\hline 15 & 7.187 & 6.684 & 6.934 & 6.532 & 6.863 & 7.330 & 0.0083 & 0.1335 & 0.9848 & -0.0240 & 8.2377 & 0.6605 & 0.0335 & 6.5686 & 0.9516 \\
\hline
\end{tabular}

Table 8-20: Effects of fuel density, cetane number, and aromatic content on maximum in-cylinder pressure for F-76 test fuels

\begin{tabular}{|c|c|c|c|c|c|c|c|c|c|c|c|c|c|c|c|}
\hline & \multicolumn{6}{|c|}{ Max In-Cylinder Pressure (kPa) } & \multicolumn{3}{|c|}{ Density } & \multicolumn{3}{|c|}{ Cetane Number } & \multicolumn{3}{|c|}{ Aromatics } \\
\hline Mode & F-76 & Neat HRD76 & $\begin{array}{c}50 / 50 \\
\text { F76/HRD76 }\end{array}$ & Neat DSH76 & $\begin{array}{c}50 / 50 \\
\text { F76/DSH76 }\end{array}$ & $\begin{array}{c}80 / 20 \\
\text { F76/HDCD76 }\end{array}$ & $\mathrm{m}$ & b & $R^{2}$ & $\mathrm{~m}$ & b & $R^{2}$ & $\mathrm{~m}$ & b & $R^{2}$ \\
\hline 1 & 5400.38 & $\mathrm{~N} / \mathrm{A}$ & 5122.67 & \begin{tabular}{|l|}
5170.67 \\
\end{tabular} & 5217.33 & 5329.00 & 2.5325 & 3170.4186 & 0.5926 & -14.4589 & 5996.9811 & 0.9525 & 9.8185 & 5125.6717 & 0.5004 \\
\hline 2 & 6424.00 & 5593.67 & 6158.00 & 6003.80 & 6250.00 & 6550.25 & 8.4380 & \begin{tabular}{|l|}
-699.3618 \\
\end{tabular} & 0.7856 & -31.9114 & 7913.0958 & 0.9115 & 35.2221 & 5791.6928 & 0.8228 \\
\hline 3 & 7380.85 & 7037.33 & 7124.33 & 7080.40 & 7134.00 & 7515.00 & 5.0751 & 3084.3834 & 0.8986 & -16.9465 & 8141.2198 & 0.8128 & 19.6945 & 7004.2085 & 0.8134 \\
\hline 4 & 7355.92 & 7077.00 & 7140.33 & 7106.20 & 7163.00 & 7513.50 & 4.5268 & 3544.3630 & 0.8823 & -14.8760 & 8041.6924 & 0.7729 & 17.6310 & 7039.9854 & 0.8045 \\
\hline 5 & 7528.00 & 7175.67 & 7275.67 & 7226.20 & 7306.67 & 7647.50 & 5.0005 & 3293.0331 & 0.9188 & -16.8643 & 8284.6736 & 0.8477 & 19.6148 & 7153.0136 & 0.8498 \\
\hline 6 & 7406.38 & 6990.00 & 7100.67 & 7076.00 & 7163.67 & 7538.25 & 5.6569 & 2611.7518 & 0.8957 & -19.6262 & 8288.6627 & 0.8746 & 22.2357 & 6977.9077 & 0.8319 \\
\hline 7 & 9345.62 & 9096.67 & 9196.33 & 9021.20 & 9139.33 & 9469.75 & 4.5807 & 5486.0010 & 0.9545 & -13.2164 & 9936.1797 & 0.6446 & 17.9700 & 9021.8998 & 0.8829 \\
\hline 8 & 9579.23 & 9326.33 & 9449.33 & 9225.80 & 9355.00 & 9665.25 & 4.5058 & 5768.9361 & 0.9475 & -12.5580 & 10122.0901 & 0.5971 & 17.6819 & 9246.9474 & 0.8771 \\
\hline 9 & 9315.00 & 9033.67 & 9118.00 & 8948.20 & 9049.67 & 9455.25 & 5.2050 & \begin{tabular}{|l|}
4920.0862 \\
\end{tabular} & 0.9260 & -15.1755 & 9985.4204 & 0.6385 & 20.1558 & 8940.6530 & 0.8346 \\
\hline 10 & 11375.31 & 11101.00 & 11228.33 & 10978.60 & 11131.67 & 11462.25 & 4.9244 & \begin{tabular}{|l|}
7207.8803 \\
\end{tabular} & 0.9453 & \begin{tabular}{|l|}
-13.6189 \\
\end{tabular} & 11959.6278 & 0.5865 & 19.3485 & 11008.7327 & 0.8772 \\
\hline 11 & 11726.92 & 11477.67 & 11609.67 & 11310.00 & 11476.33 & 11834.00 & 5.0701 & \begin{tabular}{|l|l|}
7448.9141 \\
\end{tabular} & 0.9026 & -13.1906 & 12295.7181 & 0.4956 & 19.8934 & 11362.5559 & 0.8352 \\
\hline 12 & 11234.85 & 10904.67 & 11078.67 & 10771.20 & 10933.33 & 11361.50 & 6.0122 & 6157.6100 & 0.9385 & -16.6054 & 11957.8988 & 0.5807 & 23.5596 & 10798.8152 & 0.8662 \\
\hline 13 & 13588.92 & 12665.67 & 13122.67 & 12392.80 & 12940.67 & 13837.25 & 15.2151 & \begin{tabular}{|l|}
716.9172 \\
\end{tabular} & 0.9816 & -43.7645 & 15491.0831 & 0.6588 & 60.6324 & 12451.6568 & 0.9369 \\
\hline 14 & 13855.54 & 12962.00 & 13461.00 & 12616.20 & 13207.67 & 14118.50 & 15.4287 & 821.9689 & 0.9652 & -42.8822 & 15721.5275 & 0.6048 & 61.6089 & 12720.1767 & 0.9250 \\
\hline 15 & 13118.08 & 12214.00 & 12692.33 & 11889.40 & $\begin{array}{l}12435.67 \\
\end{array}$ & 13406.25 & 15.6431 & -96.5463 & 0.9683 & $\begin{array}{l}-43.9214 \\
\end{array}$ & 15034.3096 & 0.6192 & 62.1665 & 11970.0976 & 0.9192 \\
\hline
\end{tabular}


Table 8-21: Effects of fuel density, cetane number, and aromatic content on maximum pressure rise rate for F-76 test fuels

\begin{tabular}{|c|c|c|c|c|c|c|c|c|c|c|c|c|c|c|c|}
\hline & \multicolumn{6}{|c|}{ Max Pressure Rise Rate $(\mathrm{kPa} / \mathrm{deg})$} & \multicolumn{3}{|c|}{ Density } & \multicolumn{3}{|c|}{ Cetane Number } & \multicolumn{3}{|c|}{ Aromatics } \\
\hline Mode & F-76 & Neat HRD76 & $\begin{array}{c}50 / 50 \\
\text { F76/HRD76 } \\
\end{array}$ & Neat DSH76 & \begin{tabular}{c|}
$50 / 50$ \\
F76/DSH76 \\
\end{tabular} & $\begin{array}{c}80 / 20 \\
\text { F76/HDCD76 }\end{array}$ & $\mathrm{m}$ & $\mathrm{b}$ & $R^{2}$ & $\mathrm{~m}$ & $\mathrm{~b}$ & $R^{2}$ & $\mathrm{~m}$ & $\mathrm{~b}$ & $\mathrm{R}^{2}$ \\
\hline & 1512.46 & $N / A$ & 1266.00 & 1314.00 & \begin{tabular}{|l|}
1400.67 \\
\end{tabular} & 1476.75 & 2.3083 & -499.7324 & 0.5904 & -12.9153 & 2062.9892 & 0.9113 & 9.3496 & 1277.4791 & 0.5440 \\
\hline 2 & 1416.31 & 891.00 & 1066.33 & 1107.20 & 1255.33 & 1572.00 & 6.2553 & -3869.3776 & 0.8056 & -23.5372 & 2508.6516 & 0.9253 & 25.3478 & 950.6098 & 0.7952 \\
\hline 3 & 1229.62 & 1.33 & 932.33 & 4.40 & 1097.67 & 1394.50 & 5.8123 & -3667.1319 & 0.7968 & -21.9340 & 2262.6915 & 0.9205 & 23.6554 & 810.4104 & 0.7934 \\
\hline 4 & 1249.31 & 6.33 & 5.00 & 9.00 & 1077.67 & 1404.00 & 6.3736 & -4131.8018 & 0.8567 & -23.2926 & 2329.0956 & 0.9282 & 25.8472 & \begin{tabular}{|l|l|}
779.1967 \\
\end{tabular} & 0.8469 \\
\hline 5 & 1133.85 & & 7.67 & 5.40 & 982.00 & 1256.25 & 5.4251 & -3450.5732 & 0.8658 & -19.7760 & 2046.0777 & 0.9333 & 21.9966 & 729.6296 & 0.8556 \\
\hline 6 & 1015.92 & 633.00 & 784.67 & 770.00 & 873.00 & 1111.75 & 4.5718 & -2853.5116 & 0.8668 & -16.7276 & 1781.9545 & 0.9414 & 18.4477 & \begin{tabular}{|l|l|}
670.1006 \\
\end{tabular} & 0.8483 \\
\hline 7 & 1001.62 & 4.00 & 763.67 & 764.40 & \begin{tabular}{|l|}
878.33 \\
\end{tabular} & 1136.75 & \begin{tabular}{|l|}
4.8307 \\
\end{tabular} & -3068.9811 & 0.8419 & -17.6872 & 1829.6438 & 0.9155 & 19.5709 & \begin{tabular}{|l|l|}
653.3214 \\
\end{tabular} & 0.8306 \\
\hline 8 & 906.00 & & & 9.40 & \begin{tabular}{|l|}
789.33 \\
\end{tabular} & 1017.00 & 4.1889 & -2626.5245 & 0.8704 & -15.0808 & 1607.2775 & 0.9152 & 16.9281 & \begin{tabular}{|l|l|}
601.7525 \\
\end{tabular} & 0.8544 \\
\hline 9 & \begin{tabular}{|l|}
852.62 \\
\end{tabular} & \begin{tabular}{|l|}
551.67 \\
\end{tabular} & $\begin{array}{l}667.67 \\
\end{array}$ & |646.60 & \begin{tabular}{|l|l|}
744.00 \\
\end{tabular} & \begin{tabular}{|l|}
956.25 \\
\end{tabular} & 3.8895 & -2426.8544 & 0.8824 & -13.8456 & 1495.6695 & 0.9070 & 15.7112 & 570.7136 & 0.8654 \\
\hline 10 & 822.69 & & & & 731.00 & 917.75 & 3.6295 & -2238.3114 & 0.8468 & -13.2813 & 1441.8311 & 0.9199 & 14.7328 & \begin{tabular}{|l|l|}
58.1427 \\
\end{tabular} & 0.8387 \\
\hline 11 & 750.46 & & 606.67 & 5.80 & \begin{tabular}{|l|}
665.67 \\
\end{tabular} & 839.50 & 3.0625 & -1828.5660 & 0.8703 & -10.9527 & 1262.7528 & 0.9029 & 12.3525 & \begin{tabular}{|l|l|}
51.8637 \\
\end{tabular} & 0.8510 \\
\hline 12 & 702.69 & 3.67 & 4.33 & 550.80 & \begin{tabular}{|l|}
627.67 \\
\end{tabular} & 777.00 & 2.8309 & -1682.9761 & 0.8922 & -10.0134 & 1168.4261 & 0.9056 & 11.4776 & \begin{tabular}{|l|l|} 
\\
\end{tabular} & 0.8816 \\
\hline 13 & & & & & 48.33 & 703.75 & 2.1001 & -1123.0049 & 0.7764 & $\begin{array}{l}-8.0411 \\
\end{array}$ & \begin{tabular}{|l|}
1025.9361 \\
\end{tabular} & 0.9233 & 8.5930 & \begin{tabular}{|l|l|}
494.3616 \\
\end{tabular} & 0.7812 \\
\hline 14 & 636.08 & 471.33 & 532.33 & 535.00 & 583.00 & 694.00 & 2.0593 & -1099.5428 & 0.8379 & -7.5506 & 989.3150 & 0.9137 & 8.3341 & \begin{tabular}{|l|l|}
487.3663 \\
\end{tabular} & 0.8249 \\
\hline 15 & 616.69 & \begin{tabular}{|l|}
461.33 \\
\end{tabular} & 526.67 & 515.20 & 567.00 & 660.50 & 1.8970 & -984.9271 & 0.8720 & -6.8675 & \begin{tabular}{|c|}
934.4692 \\
\end{tabular} & 0.9271 & 7.7160 & \begin{tabular}{|c|}
476.4951 \\
\end{tabular} & 0.8672 \\
\hline
\end{tabular}

Table 8-22: Effects of fuel density, cetane number, and aromatic content on maximum in-cylinder temperature for F-76 test fuels

\begin{tabular}{|c|c|c|c|c|c|c|c|c|c|c|c|c|c|c|c|}
\hline & \multicolumn{6}{|c|}{ Max In-Cylinder Temperature (K) } & \multicolumn{3}{|c|}{ Density } & \multicolumn{3}{|c|}{ Cetane Number } & \multicolumn{3}{|c|}{ Aromatics } \\
\hline Mode & F-76 & Neat HRD76 & $\begin{array}{c}50 / 50 \\
\text { F76/HRD76 }\end{array}$ & Neat DSH76 & $\begin{array}{c}50 / 50 \\
\text { F76/DSH76 }\end{array}$ & $\begin{array}{c}80 / 20 \\
\text { F76/HDCD76 }\end{array}$ & $\mathrm{m}$ & b & $R^{2}$ & $\mathrm{~m}$ & b & $\mathrm{R}^{2}$ & $\mathrm{~m}$ & b & $\mathrm{R}^{2}$ \\
\hline 1 & 1187.38 & N/A & 1148.67 & 1149.00 & 1163.33 & 1171.25 & 0.3585 & 869.7876 & 0.5873 & -1.9592 & 1265.4159 & 0.8648 & 1.4408 & 1145.9747 & 0.5328 \\
\hline 2 & 1425.15 & 1247.00 & 1404.33 & 1336.00 & 1409.33 & 1441.75 & 1.7031 & -7.8790 & 0.6847 & -6.3195 & 1723.7823 & 0.7648 & 7.3390 & 1299.8349 & 0.7643 \\
\hline 3 & 1595.69 & 1572.00 & 1578.00 & 1566.00 & 1583.33 & 1613.25 & 0.4675 & 1204.5214 & 0.9285 & -1.3972 & 1661.3279 & 0.6729 & 1.8734 & 1564.9479 & 0.8964 \\
\hline 4 & 1478.54 & 1468.33 & 1464.33 & 1459.80 & 1474.00 & 1500.75 & 0.3520 & 1188.0155 & 0.7398 & -0.9997 & 1529.1101 & 0.4841 & 1.4064 & 1459.4552 & 0.7099 \\
\hline 5 & 1479.31 & 1451.33 & 1459.00 & 1451.20 & 1470.00 & 1496.25 & 0.4745 & 1081.9265 & 0.9097 & -1.5209 & 1551.2428 & 0.7581 & 1.9269 & 1447.5202 & 0.9017 \\
\hline 6 & 1442.00 & 1402.67 & 1410.67 & 1402.00 & 1423.00 & 1459.00 & 0.6226 & 916.8902 & 0.9236 & -2.0222 & 1534.1078 & 0.7905 & 2.4920 & 1396.9317 & 0.8895 \\
\hline 7 & 1719.92 & 1707.00 & 1711.33 & 1697.40 & 1717.00 & 1733.00 & 0.3192 & 1454.6975 & 0.8781 & -0.8649 & 1761.7002 & 0.5230 & 1.3177 & 1700.3746 & 0.8996 \\
\hline 8 & 1665.85 & 1654.33 & 1657.00 & 1644.60 & 1660.00 & 1677.00 & 0.2906 & 1423.4317 & 0.8916 & -0.7780 & 1702.4587 & 0.5184 & 1.1779 & 1647.3695 & 0.8804 \\
\hline 9 & 1603.23 & 1582.67 & 1583.33 & 1574.60 & 1585.00 & 1611.00 & 0.3727 & 1286.8714 & 0.9027 & -1.1123 & 1650.9645 & 0.6524 & 1.4470 & 1574.7055 & 0.8181 \\
\hline 10 & 1819.46 & 1818.00 & 1813.67 & 1803.20 & 1815.67 & 1827.25 & 0.1751 & 1673.8276 & 0.6241 & -0.3551 & 1835.6785 & 0.2083 & 0.6988 & 1808.8349 & 0.5977 \\
\hline 11 & 1743.54 & 1744.67 & 1736.33 & 1729.60 & 1736.33 & 1754.00 & 0.1691 & 1603.2000 & 0.5014 & -0.3333 & 1759.0201 & 0.1580 & 0.6354 & 1734.0423 & 0.4254 \\
\hline 12 & 1661.77 & 1649.33 & 1648.67 & 1644.40 & 1649.67 & 1666.00 & 0.2231 & 1471.8895 & 0.8708 & -0.6722 & 1690.1636 & 0.6415 & 0.8572 & 1644.2624 & 0.7730 \\
\hline 13 & 1871.92 & 1859.00 & 1862.67 & 1846.40 & 1861.67 & 1881.25 & 0.3150 & 1607.5881 & 0.8972 & -0.8122 & 1908.3528 & 0.4837 & 1.2594 & 1850.5308 & 0.8618 \\
\hline 14 & 1786.77 & 1768.67 & 1775.00 & 1755.60 & 1773.67 & 1790.00 & 0.3354 & 1502.1401 & 0.9135 & -0.8925 & 1823.8883 & 0.5246 & 1.3485 & 1760.7239 & 0.8873 \\
\hline 15 & 1712.00 & 1695.33 & 1700.33 & 1679.40 & 1701.00 & 1720.25 & 0.3735 & 1397.5963 & 0.8946 & -0.9631 & 1754.1955 & 0.4825 & 1.5109 & 1685.4464 & 0.8798 \\
\hline
\end{tabular}

Table 8-23: Effects of fuel density, cetane number, aromatic content, and viscosity on start of fuel injection for F-76 test fuels

\begin{tabular}{|c|c|c|c|c|c|c|c|c|c|c|c|c|c|c|c|c|c|c|}
\hline \multirow[b]{2}{*}{ Mode } & \multicolumn{6}{|c|}{ Start of Fuel Injection (deg) } & \multicolumn{3}{|c|}{ Density } & \multicolumn{3}{|c|}{ Cetane Number } & \multicolumn{3}{|c|}{ Aromatics } & \multicolumn{3}{|c|}{ Viscosity } \\
\hline & \begin{tabular}{l|l}
$F-76$ & 1 \\
\end{tabular} & Neat HRD76 & $\begin{array}{c}50 / 50 \\
\text { F76/HRD76 } \\
\end{array}$ & Neat DSH76 & $\begin{array}{c}50 / 50 \\
\text { F76/DSH76 } \\
\end{array}$ & $\begin{array}{c}80 / 20 \\
\text { F76/HDCD76 } \\
\end{array}$ & $\mathrm{m}$ & $\mathrm{b}$ & $\mathrm{R}^{2}$ & $\mathrm{~m}$ & $\mathrm{~b}$ & $\mathrm{R}^{2}$ & $\mathrm{~m}$ & $\mathrm{~b}$ & $\mathrm{R}^{2}$ & $\mathrm{~m}$ & $\mathrm{~b}$ & $\mathrm{R}^{2}$ \\
\hline 1 & -3.17 & \begin{tabular}{r|}
$\mathrm{N} / \mathrm{A}$ \\
\end{tabular} & -2.50 & \begin{tabular}{|r|}
-2.58 \\
\end{tabular} & -3.00 & \begin{tabular}{|r|}
-2.50 \\
\end{tabular} & -0.0015 & -1.5294 & 0.0272 & 0.0159 & -3.5770 & 0.1539 & -0.0073 & -2.6602 & 0.0369 & -0.2392 & -2.0671 & 0.2514 \\
\hline 2 & -4.42 & -3.25 & -3.92 & -3.50 & -4.00 & -4.50 & -0.0134 & 6.9557 & 0.9319 & 0.0461 & -6.4589 & 0.8962 & -0.0550 & -3.3514 & 0.9455 & -0.6402 & -2.1605 & 0.6694 \\
\hline 3 & -4.15 & -3.50 & -3.75 & -3.25 & -3.50 & -4.31 & -0.0112 & 5.3317 & 0.9252 & 0.0316 & -5.4793 & 0.6033 & -0.0432 & -3.2890 & 0.8320 & -0.5438 & -2.2399 & 0.6900 \\
\hline 4 & -8.46 & -8.00 & -8.08 & -7.65 & -8.00 & -8.44 & -0.0079 & -1.6426 & 0.8577 & 0.0213 & -9.2729 & 0.4996 & -0.0311 & -7.7775 & 0.7885 & -0.4012 & -6.9954 & 0.6867 \\
\hline 5 & -9.19 & -7.83 & -9.00 & -8.65 & -8.67 & -9.19 & -0.0114 & 0.5281 & 0.6328 & 0.0450 & -11.2222 & 0.7977 & -0.0466 & -8.2628 & 0.6354 & -0.5320 & -7.2832 & 0.4317 \\
\hline 6 & -10.21 & -9.50 & -9.83 & -9.40 & -9.75 & -10.56 & -0.0122 & 0.0658 & 0.9782 & 0.0365 & -11.8803 & 0.7093 & -0.0486 & -9.3636 & 0.9290 & -0.5601 & -8.3268 & 0.6449 \\
\hline 7 & -8.13 & -8.00 & -7.33 & -7.45 & -7.67 & -8.25 & -0.0064 & -2.5694 & 0.3693 & 0.0172 & -8.7512 & 0.2148 & -0.0230 & -7.5627 & 0.2844 & -0.4385 & -6.5925 & 0.5381 \\
\hline 8 & -8.88 & -8.00 & -8.42 & -8.05 & -8.50 & -9.13 & -0.0124 & 1.6198 & 0.9839 & 0.0402 & -10.6984 & 0.8322 & -0.0504 & -7.9640 & 0.9722 & -0.5859 & -6.8749 & 0.6858 \\
\hline 9 & -10.21 & -9.58 & -9.17 & -9.30 & -9.58 & -10.00 & -0.0083 & -2.9145 & 0.5411 & 0.0283 & -11.1938 & 0.5147 & -0.0310 & -9.3141 & 0.4559 & -0.5868 & -8.0173 & 0.8555 \\
\hline 10 & -8.13 & -7.42 & -7.50 & -7.35 & -7.58 & -8.25 & -0.0104 & 0.7309 & 0.9135 & 0.0337 & -9.5547 & 0.7830 & -0.0403 & -7.2807 & 0.8284 & -0.5656 & -6.1409 & 0.8530 \\
\hline 11 & -8.69 & -8.17 & -7.83 & -7.90 & \begin{tabular}{|l|}
-7.83 \\
\end{tabular} & -8.94 & -0.0106 & 0.3981 & 0.6251 & 0.0327 & -10.0229 & 0.4835 & -0.0382 & -7.8247 & 0.4863 & -0.6504 & -6.4277 & 0.7385 \\
\hline 12 & -9.96 & -9.42 & -9.67 & -9.25 & -9.58 & -10.13 & -0.0091 & -2.2303 & 0.9826 & 0.0264 & -11.1135 & 0.6632 & -0.0364 & -9.2828 & 0.9379 & -0.4218 & -8.5002 & 0.6567 \\
\hline 13 & \begin{tabular}{l|l|}
-7.88 \\
\end{tabular} & -7.58 & -6.58 & -7.25 & $\begin{array}{l}-7.42 \\
\end{array}$ & -8.25 & -0.0090 & -0.1913 & 0.3159 & 0.0309 & -9.1890 & 0.3041 & -0.0326 & -7.1494 & 0.2500 & -0.6473 & -5.7022 & 0.5157 \\
\hline 14 & -8.87 & -7.92 & -8.25 & -7.90 & -8.58 & -8.88 & -0.0118 & 1.1922 & 0.8988 & 0.0392 & -10.5457 & 0.8041 & -0.0489 & -7.8821 & 0.9305 & -0.5841 & -6.7825 & 0.6925 \\
\hline 15 & -9.73 & -9.33 & -9.50 & -9.10 & -9.58 & -9.50 & -0.0046 & -5.7211 & 0.5645 & 0.0126 & -10.1514 & 0.3470 & -0.0196 & -9.2508 & 0.6196 & -0.2211 & -8.8463 & 0.4105 \\
\hline
\end{tabular}


Table 8-24: Effects of fuel density, cetane number, and aromatic content on start of combustion for F-76 test fuels

\begin{tabular}{|c|c|c|c|c|c|c|c|c|c|c|c|c|c|c|c|}
\hline \multirow[b]{2}{*}{ Mode } & \multicolumn{6}{|c|}{ Start of Combustion (deg) } & \multicolumn{3}{|c|}{ Density } & \multicolumn{3}{|c|}{ Cetane Number } & \multicolumn{3}{|c|}{ Aromatics } \\
\hline & F-76 & Neat HRD76 & $\begin{array}{c}50 / 50 \\
\text { F76/HRD76 }\end{array}$ & Neat DSH76 & $\begin{array}{c}50 / 50 \\
\text { F76/DSH76 }\end{array}$ & $\begin{array}{c}80 / 20 \\
\text { F76/HDCD76 }\end{array}$ & $\mathrm{m}$ & b & $\mathrm{R}^{2}$ & $\mathrm{~m}$ & b & $R^{2}$ & $\mathrm{~m}$ & b & $R^{2}$ \\
\hline 1 & 0.56 & N/A & 0.25 & $\begin{array}{r}0.50 \\
\end{array}$ & 0.33 & 1.50 & 0.0097 & -7.3527 & 0.4531 & -0.0446 & 2.9364 & 0.4688 & 0.0377 & 0.1582 & 0.3827 \\
\hline 2 & 1.08 & 0.50 & 0.58 & 1.20 & 1.00 & 1.56 & 0.0063 & -4.1211 & 0.3190 & -0.0305 & 2.6582 & 0.6092 & 0.0247 & 0.7261 & 0.2974 \\
\hline 3 & 0.83 & 0.00 & 0.25 & 1.00 & 1.00 & 1.00 & 0.0048 & -3.2034 & 0.1482 & -0.0316 & 2.4095 & 0.5251 & 0.0211 & 0.4570 & 0.1738 \\
\hline 4 & -1.40 & -3.00 & -2.50 & -2.00 & -1.50 & -1.00 & 0.0160 & -14.9109 & 0.5808 & -0.0681 & 1.8329 & 0.8536 & 0.0669 & -2.6065 & 0.6108 \\
\hline 5 & -1.48 & -3.25 & -2.75 & -2.20 & -1.75 & -0.88 & 0.0194 & -17.8683 & 0.6406 & -0.0797 & 2.3165 & 0.8717 & 0.0798 & -2.8933 & 0.6490 \\
\hline 6 & -1.58 & -3.50 & -2.75 & -2.25 & -1.75 & -1.25 & 0.0178 & -16.6443 & 0.5759 & -0.0772 & 2.0548 & 0.8808 & 0.0745 & -2.9658 & 0.6079 \\
\hline 7 & $\begin{array}{l}-2.50 \\
\end{array}$ & \begin{tabular}{|l|}
-3.33 \\
\end{tabular} & \begin{tabular}{|l|}
-3.17 \\
\end{tabular} & -2.55 & -2.50 & -2.06 & 0.0084 & -9.5204 & 0.3979 & -0.0395 & -0.5218 & 0.7116 & 0.0346 & -3.0503 & 0.4052 \\
\hline 8 & -2.75 & \begin{tabular}{|l|}
-4.00 \\
\end{tabular} & -3.50 & -3.00 & -3.00 & -2.44 & 0.0112 & -12.2548 & 0.5171 & -0.0511 & -0.3132 & 0.8669 & 0.0458 & -3.5973 & 0.5151 \\
\hline 9 & -3.00 & \begin{tabular}{|l|}
-4.17 \\
\end{tabular} & -3.75 & -3.25 & -3.00 & -2.75 & 0.0101 & -11.5370 & 0.4511 & -0.0472 & -0.7293 & 0.7998 & 0.0427 & -3.7703 & 0.4851 \\
\hline 10 & -3.23 & -3.25 & -3.50 & -3.05 & \begin{tabular}{|c|}
-3.08 \\
\end{tabular} & $\begin{array}{l}-3.00 \\
\end{array}$ & 0.0006 & -3.7137 & 0.0159 & -0.0064 & -2.8325 & 0.1269 & 0.0027 & -3.2137 & 0.0159 \\
\hline 11 & -3.75 & \begin{tabular}{|l|}
-4.08 \\
\end{tabular} & \begin{tabular}{|l|}
-4.00 \\
\end{tabular} & -3.65 & -3.75 & \begin{tabular}{|l|}
-3.63 \\
\end{tabular} & 0.0022 & -5.6083 & 0.1745 & -0.0139 & \begin{tabular}{|c|}
-3.0498 \\
\end{tabular} & 0.5560 & 0.0090 & -3.9051 & 0.1752 \\
\hline 12 & -4.12 & -4.50 & -4.25 & -3.85 & -4.00 & -4.00 & 0.0013 & -5.1527 & 0.0390 & -0.0132 & -3.3966 & 0.3399 & 0.0060 & -4.1829 & 0.0528 \\
\hline 13 & -3.25 & -2.50 & -3.00 & -2.75 & -3.00 & -3.25 & -0.0076 & 3.2088 & 0.8545 & 0.0273 & -4.4539 & 0.8967 & -0.0314 & -2.6275 & 0.8783 \\
\hline 14 & -4.00 & -3.58 & -3.92 & -3.50 & -3.83 & -4.13 & -0.0066 & 1.5441 & 0.9441 & 0.0187 & -4.8523 & 0.6148 & -0.0273 & -3.5386 & 0.9685 \\
\hline 15 & -4.50 & -4.25 & -4.33 & -3.95 & -4.25 & -4.50 & -0.0051 & -0.1469 & 0.7924 & 0.0122 & -4.9650 & 0.3661 & -0.0203 & -4.0828 & 0.7554 \\
\hline
\end{tabular}

Table 8-25: Effects of fuel density, cetane number, and aromatic content on premix fraction length for F-76 test fuels

\begin{tabular}{|c|c|c|c|c|c|c|c|c|c|c|c|c|c|c|c|}
\hline \multirow[b]{2}{*}{ Mode } & \multicolumn{6}{|c|}{ Premix Fraction Length (deg) } & \multicolumn{3}{|c|}{ Density } & \multicolumn{3}{|c|}{ Cetane Number } & \multicolumn{3}{|c|}{ Aromatics } \\
\hline & $F-76$ & Neat HRD76 & $\begin{array}{c}50 / 50 \\
\text { F76/HRD76 }\end{array}$ & Neat DSH76 & $\begin{array}{c}50 / 50 \\
\text { F76/DSH76 }\end{array}$ & \begin{tabular}{c|}
$80 / 20$ \\
F76/HDCD76
\end{tabular} & $\mathrm{m}$ & b & $\mathrm{R}^{2}$ & $\mathrm{~m}$ & b & $\mathrm{R}^{2}$ & $\mathrm{~m}$ & b & $R^{2}$ \\
\hline 1 & 6.53 & \begin{tabular}{|l|}
$\mathrm{N} / \mathrm{A}$ \\
\end{tabular} & 6.41 & $\begin{array}{r}6.40 \\
\end{array}$ & 6.49 & $\begin{array}{r}6.59 \\
\end{array}$ & 0.0020 & 4.8131 & 0.7847 & -0.0095 & 6.9747 & 0.8345 & 0.0086 & 6.3777 & 0.7823 \\
\hline 2 & 7.13 & 6.97 & 6.92 & 7.08 & 7.09 & 7.21 & 0.0019 & 5.5382 & 0.4042 & -0.0083 & 7.5234 & 0.6431 & 0.0074 & 6.9887 & 0.3782 \\
\hline 3 & 6.82 & 6.48 & 6.67 & 6.63 & 6.76 & 7.01 & 0.0046 & 3.0053 & 0.8309 & -0.0163 & 7.6200 & 0.8533 & 0.0188 & 6.5285 & 0.8458 \\
\hline 4 & 7.75 & 7.15 & 7.50 & 7.60 & 7.57 & 7.86 & 0.0053 & 3.2399 & 0.5966 & -0.0231 & 8.8417 & 0.9119 & 0.0215 & 7.3463 & 0.5859 \\
\hline 5 & 8.31 & 7.58 & 8.06 & 8.13 & 8.17 & 8.40 & 0.0060 & 3.2065 & 0.5628 & -0.0265 & 9.5650 & 0.8849 & 0.0250 & 7.8457 & 0.5828 \\
\hline 6 & 8.79 & 8.27 & 8.58 & 8.69 & 8.77 & 8.87 & 0.0041 & 5.3108 & 0.4680 & -0.0191 & 9.7106 & 0.8174 & 0.0176 & 8.4765 & 0.5129 \\
\hline 7 & 7.11 & 6.44 & 6.77 & 6.76 & 6.87 & 7.16 & 0.0066 & 1.5117 & 0.7942 & -0.0257 & 8.2621 & 0.9860 & 0.0267 & 6.5720 & 0.7863 \\
\hline 8 & 7.50 & 6.96 & 7.11 & 7.16 & 7.41 & 7.70 & 0.0069 & 1.7297 & 0.7747 & -0.0255 & 8.7027 & 0.8662 & 0.0282 & 7.0091 & 0.7879 \\
\hline 9 & 8.05 & 7.46 & 7.76 & 7.78 & 7.92 & 8.21 & 0.0064 & 2.6631 & 0.7643 & -0.0249 & 9.2258 & 0.9382 & 0.0263 & 7.5849 & 0.7770 \\
\hline 10 & 6.50 & 5.63 & 6.22 & 6.19 & 6.38 & 6.56 & 0.0075 & 0.1851 & 0.6176 & -0.0313 & 7.9627 & 0.8840 & 0.0315 & 5.9134 & 0.6649 \\
\hline 11 & 6.95 & 6.31 & 6.52 & 6.66 & 6.82 & 7.12 & 0.0068 & 1.1722 & 0.6858 & -0.0277 & 8.2455 & 0.9123 & 0.0280 & 6.4335 & 0.6909 \\
\hline 12 & 7.51 & 6.92 & 7.05 & 7.12 & 7.42 & 7.64 & 0.0069 & 1.6685 & 0.7360 & -0.0263 & 8.7158 & 0.8676 & 0.0286 & 6.9734 & 0.7602 \\
\hline 13 & 5.64 & 4.59 & 5.13 & 5.42 & 5.55 & 5.79 & 0.0085 & -1.5850 & 0.4865 & -0.0396 & 7.5264 & 0.8520 & 0.0359 & 4.9739 & 0.5186 \\
\hline 14 & 6.19 & 5.40 & 5.73 & 5.96 & 6.08 & 6.43 & 0.0078 & -0.4035 & 0.5952 & -0.0334 & 7.7975 & 0.8814 & 0.0323 & 5.6222 & 0.6106 \\
\hline 15 & 6.94 & 6.37 & 6.50 & 6.80 & 6.93 & 6.96 & 0.0042 & 3.3024 & 0.3547 & -0.0216 & 7.9313 & 0.7457 & 0.0180 & 6.5586 & 0.3848 \\
\hline
\end{tabular}

Table 8-26: Effects of fuel density, cetane number, and aromatic content on diffusion fraction length for F-76 test fuels

\begin{tabular}{|c|c|c|c|c|c|c|c|c|c|c|c|c|c|c|c|}
\hline \multirow[b]{2}{*}{ Mode } & \multicolumn{6}{|c|}{ Diffusion Fraction Length (deg) } & \multicolumn{3}{|c|}{ Density } & \multicolumn{3}{|c|}{ Cetane Number } & \multicolumn{3}{|c|}{ Aromatics } \\
\hline & F-76 & Neat HRD76 & $\begin{array}{c}50 / 50 \\
\text { F76/HRD76 }\end{array}$ & Neat DSH76 & $\begin{array}{c}50 / 50 \\
\text { F76/DSH76 }\end{array}$ & \begin{tabular}{c|}
$80 / 20$ \\
F76/HDCD76
\end{tabular} & $\mathrm{m}$ & b & $\mathrm{R}^{2}$ & $\mathrm{~m}$ & b & $R^{2}$ & $\mathrm{~m}$ & b & $R^{2}$ \\
\hline 1 & 12.91 & N/A & 13.65 & 12.62 & 12.51 & \begin{tabular}{|r|}
12.28 \\
\end{tabular} & -0.0028 & 15.0546 & 0.0331 & 0.0299 & 11.2449 & 0.1919 & -0.0119 & 12.9416 & 0.0347 \\
\hline 2 & 26.39 & 24.73 & 26.02 & 22.60 & 24.09 & 26.44 & 0.0356 & -3.8707 & 0.6868 & -0.0771 & 29.2734 & 0.2619 & 0.1387 & 23.5827 & 0.6286 \\
\hline 3 & 29.27 & 32.15 & 32.08 & 30.65 & 30.77 & 27.87 & -0.0370 & 60.5886 & 0.6341 & 0.1460 & 22.4583 & 0.7990 & -0.1432 & 31.9741 & 0.5699 \\
\hline 4 & 26.62 & 30.84 & 29.17 & 29.64 & 28.03 & 25.54 & -0.0524 & 70.8932 & 0.8936 & 0.1865 & 18.0779 & 0.9197 & -0.2130 & 30.5528 & 0.8887 \\
\hline 5 & 26.34 & 31.51 & 30.13 & 30.14 & 28.15 & 25.53 & -0.0610 & 78.2814 & 0.8472 & 0.2240 & 16.3515 & 0.9254 & -0.2475 & 31.2458 & 0.8373 \\
\hline 6 & 29.33 & 33.91 & 31.79 & 31.77 & 29.63 & 28.26 & $\begin{array}{l}-0.0498 \\
\end{array}$ & 71.2781 & 0.7289 & 0.1925 & 20.2289 & 0.8836 & $\begin{array}{l}-0.2102 \\
\end{array}$ & 33.0004 & 0.7806 \\
\hline 7 & 35.55 & 38.47 & 37.10 & 37.83 & 36.72 & 34.42 & -0.0405 & 69.6124 & 0.9409 & 0.1365 & 29.1946 & 0.8681 & -0.1635 & 38.4074 & 0.9227 \\
\hline 8 & 35.96 & 38.92 & 38.05 & 38.86 & 37.88 & 34.41 & -0.0486 & 76.8905 & 0.9299 & 0.1554 & 28.8285 & 0.7703 & -0.1912 & 39.3655 & 0.8648 \\
\hline 9 & 36.61 & 39.46 & 38.13 & 39.34 & 37.89 & 35.68 & -0.0415 & 71.6381 & 0.9840 & 0.1330 & 30.5591 & 0.8181 & -0.1680 & 39.6241 & 0.9674 \\
\hline 10 & 45.45 & 45.95 & 44.81 & 45.58 & 44.45 & 42.52 & -0.0253 & 65.3477 & 0.5282 & 0.0714 & 40.8747 & 0.3424 & -0.1085 & 45.9367 & 0.5848 \\
\hline 11 & 44.17 & 46.25 & 45.33 & 46.67 & 45.38 & 43.20 & -0.0360 & 74.4691 & 0.9836 & 0.1067 & 39.3124 & 0.7003 & -0.1444 & 46.6893 & 0.9498 \\
\hline 12 & 44.40 & 46.81 & 45.15 & 46.90 & 45.22 & 43.97 & -0.0333 & 72.5227 & 0.9576 & 0.1017 & 39.8302 & 0.7229 & -0.1383 & 46.8659 & 0.9900 \\
\hline 13 & 53.36 & 53.77 & 53.88 & 52.83 & 53.25 & 52.90 & -0.0024 & 55.3041 & 0.0398 & 0.0226 & 52.0946 & 0.2796 & -0.0092 & 53.4297 & 0.0348 \\
\hline 14 & 52.78 & 53.30 & 53.30 & 52.87 & 52.97 & 52.65 & -0.0046 & 56.7575 & 0.3761 & 0.0228 & 51.7255 & 0.7357 & -0.0180 & 53.1667 & 0.3377 \\
\hline 15 & 51.99 & 52.66 & 52.12 & 52.08 & 52.03 & 52.01 & -0.0042 & 55.5369 & 0.3447 & 0.0207 & 51.0144 & 0.6909 & -0.0182 & 52.3419 & 0.3968 \\
\hline
\end{tabular}


Table 8-27: Effects of fuel density, cetane number, and aromatic content on bsHC emissions for F-76 test fuels

\begin{tabular}{|c|c|c|c|c|c|c|c|c|c|c|c|c|c|c|c|}
\hline & \multicolumn{6}{|c|}{ bsHC (g/bhp-hr) } & \multicolumn{3}{|c|}{ Density } & \multicolumn{3}{|c|}{ Cetane Number } & \multicolumn{3}{|c|}{ Aromatics } \\
\hline Mode & $F-76$ & Neat HRD76 & $\begin{array}{c}50 / 50 \\
\text { F76/HRD76 }\end{array}$ & Neat DSH76 & $\begin{array}{c}50 / 50 \\
\text { F76/DSH76 }\end{array}$ & $\begin{array}{c}80 / 20 \\
\text { F76/HDCD76 }\end{array}$ & $\mathrm{m}$ & $b$ & $\mathrm{R}^{2}$ & $\mathrm{~m}$ & $b$ & $\mathrm{R}^{2}$ & $\mathrm{~m}$ & $b$ & $\mathrm{R}^{2}$ \\
\hline $1^{*}$ & 0.334 & 0.159 & 0.172 & 0.314 & 0.250 & 0.374 & 0.0015 & -0.9444 & 0.3593 & -0.0075 & 0.6758 & 0.7306 & 0.0056 & 0.2077 & 0.3069 \\
\hline 2 & 0.192 & 0.092 & 0.133 & 0.162 & 0.155 & 0.221 & 0.0010 & -0.6594 & 0.6351 & -0.0042 & 0.3915 & 0.9099 & 0.0040 & 0.1173 & 0.6013 \\
\hline 3 & 0.065 & 0.042 & 0.054 & 0.059 & 0.055 & 0.073 & 0.0002 & -0.1328 & 0.6327 & -0.0010 & 0.1112 & 0.8740 & 0.0009 & 0.0484 & 0.5847 \\
\hline 4 & 0.160 & 0.096 & 0.123 & 0.128 & 0.139 & 0.186 & 0.0008 & \begin{tabular}{l|}
-0.4936 \\
\end{tabular} & 0.7923 & -0.0029 & 0.2993 & 0.9129 & 0.0031 & 0.1057 & 0.7703 \\
\hline 5 & 0.187 & 0.106 & 0.146 & 0.151 & 0.154 & 0.213 & 0.0009 & -0.5820 & 0.7831 & -0.0035 & 0.3512 & 0.9337 & 0.0036 & 0.1212 & 0.7483 \\
\hline 6 & 0.235 & 0.122 & 0.176 & 0.176 & 0.188 & 0.273 & 0.0013 & -0.8946 & 0.8304 & -0.0050 & 0.4680 & 0.9293 & 0.0054 & 0.1386 & 0.7971 \\
\hline 7 & 0.070 & 0.044 & 0.058 & 0.059 & 0.059 & 0.079 & 0.0003 & -0.1749 & 0.7612 & -0.0011 & 0.1228 & 0.9129 & 0.0012 & 0.0493 & 0.7219 \\
\hline 8 & 0.063 & 0.041 & 0.055 & 0.057 & 0.057 & 0.071 & 0.0002 & -0.1236 & 0.6685 & -0.0009 & 0.1068 & 0.8875 & 0.0009 & 0.0479 & 0.6616 \\
\hline 9 & 0.084 & 0.053 & 0.073 & 0.066 & 0.073 & 0.091 & 0.0004 & -0.2151 & 0.8655 & -0.0013 & 0.1438 & 0.9209 & 0.0014 & 0.0581 & 0.8640 \\
\hline 10 & 0.035 & 0.031 & 0.034 & 0.035 & 0.034 & 0.036 & 0.0000 & 0.0065 & 0.3779 & -0.0002 & 0.0434 & 0.7331 & 0.0001 & 0.0328 & 0.3608 \\
\hline 11 & 0.032 & 0.025 & 0.030 & 0.030 & 0.032 & 0.034 & 0.0001 & -0.0228 & 0.6177 & -0.0003 & 0.0453 & 0.8384 & 0.0003 & 0.0276 & 0.6885 \\
\hline 12 & 0.042 & 0.028 & 0.038 & 0.035 & 0.036 & 0.044 & 0.0001 & \begin{tabular}{l|l|}
-0.0761 \\
\end{tabular} & 0.8110 & -0.0005 & 0.0659 & 0.9325 & 0.0006 & 0.0313 & 0.7960 \\
\hline 13 & 0.024 & 0.023 & 0.024 & 0.022 & 0.025 & 0.021 & 0.0000 & 0.0339 & 0.0927 & 0.0000 & 0.0211 & 0.0499 & 0.0000 & 0.0234 & 0.0377 \\
\hline 14 & 0.027 & 0.023 & 0.026 & 0.024 & 0.026 & 0.024 & 0.0000 & 0.0123 & 0.1455 & -0.0001 & 0.0291 & 0.2586 & 0.0001 & 0.0242 & 0.2052 \\
\hline 15 & 0.032 & 0.025 & 0.030 & 0.029 & 0.031 & 0.032 & 0.0001 & -0.0140 & 0.6001 & -0.0002 & 0.0423 & 0.8641 & 0.0002 & 0.0274 & 0.6494 \\
\hline Values & ported & as a mass rate & & & & & & & & & & & & & \\
\hline
\end{tabular}

Table 8-28: Effects of fuel density, cetane number, and aromatic content on bsNOx emissions for F-76 test fuels

\begin{tabular}{|c|c|c|c|c|c|c|c|c|c|c|c|c|c|c|c|}
\hline & \multicolumn{6}{|c|}{ bsNOx (g/bhp-hr) } & \multicolumn{3}{|c|}{ Density } & \multicolumn{3}{|c|}{ Cetane Number } & \multicolumn{3}{|c|}{ Aromatics } \\
\hline Mode & $F-76$ & Neat HRD76 & $\begin{array}{c}50 / 50 \\
\text { F76/HRD76 }\end{array}$ & Neat DSH76 & $\begin{array}{c}50 / 50 \\
\text { F76/DSH76 }\end{array}$ & $\begin{array}{c}80 / 20 \\
\text { F76/HDCD76 }\end{array}$ & $\mathrm{m}$ & b & $\mathrm{R}^{2}$ & $\mathrm{~m}$ & b & $R^{2}$ & $\mathrm{~m}$ & b & $R^{2}$ \\
\hline $1^{*}$ & 7.511 & 6.156 & 6.993 & 6.569 & 7.390 & \begin{tabular}{|l|}
7.037 \\
\end{tabular} & 0.0101 & -1.2405 & 0.4968 & -0.0400 & 9.1354 & 0.6365 & 0.0447 & 6.4713 & 0.5890 \\
\hline 2 & 10.558 & 7.777 & 8.908 & 8.448 & 9.738 & 11.600 & 0.0378 & -21.2056 & 0.9037 & -0.1305 & 16.6583 & 0.8751 & 0.1542 & 7.8779 & 0.9058 \\
\hline 3 & 8.464 & 7.126 & 7.758 & 6.905 & 7.823 & 9.140 & 0.0231 & -10.9557 & 0.9813 & -0.0691 & 11.6605 & 0.7104 & 0.0936 & 6.8813 & 0.9651 \\
\hline 4 & 10.513 & 8.429 & 9.291 & 8.347 & 9.463 & 11.379 & 0.0330 & -17.2620 & 0.9806 & -0.1031 & 15.2261 & 0.7774 & 0.1326 & 8.1715 & 0.9521 \\
\hline 5 & 10.490 & 8.254 & 9.097 & 8.270 & 9.408 & 11.457 & 0.0350 & -18.9810 & 0.9668 & -0.1115 & 15.6111 & 0.7956 & 0.1407 & 8.0122 & 0.9378 \\
\hline 6 & 10.600 & 8.014 & 8.995 & 8.195 & 9.490 & 11.484 & 0.0375 & \begin{tabular}{|l}
-21.0739 \\
\end{tabular} & 0.9616 & -0.1229 & 16.2033 & 0.8361 & 0.1517 & 7.8630 & 0.9431 \\
\hline 7 & 8.031 & 6.944 & 7.486 & 6.712 & 7.384 & 8.380 & 0.0177 & -6.8960 & 0.9935 & -0.0521 & 10.3451 & 0.6987 & 0.0710 & 6.7398 & 0.9634 \\
\hline 8 & 8.360 & 7.174 & 7.749 & 6.873 & 7.647 & 8.735 & 0.0196 & -8.1648 & 0.9908 & -0.0572 & 10.8908 & 0.6853 & 0.0787 & 6.9264 & 0.9616 \\
\hline 9 & 8.474 & 7.206 & 7.854 & 6.881 & 7.732 & 8.922 & 0.0213 & -9.4649 & 0.9897 & -0.0618 & 11.2351 & 0.6775 & 0.0857 & 6.9410 & 0.9640 \\
\hline 10 & 6.467 & 5.771 & 6.162 & 5.548 & 6.044 & 6.609 & 0.0112 & -2.9959 & 0.9745 & -0.0318 & 7.8423 & 0.6380 & 0.0452 & 5.6237 & 0.9550 \\
\hline 11 & 7.116 & 6.277 & 6.772 & 5.972 & 6.598 & 7.329 & 0.0140 & -4.7288 & 0.9684 & -0.0392 & 8.8252 & 0.6129 & 0.0566 & 6.0797 & 0.9493 \\
\hline 12 & 7.379 & 6.480 & 7.038 & 6.133 & 6.833 & 7.622 & 0.0153 & -5.5000 & 0.9617 & -0.0422 & 9.2278 & 0.5962 & 0.0618 & 6.2623 & 0.9470 \\
\hline 13 & 5.905 & 5.375 & 5.708 & 5.220 & 5.593 & 6.013 & 0.0084 & -1.1982 & 0.9690 & -0.0238 & 6.9402 & 0.6302 & 0.0340 & 5.2767 & 0.9552 \\
\hline 14 & \begin{tabular}{|l|}
6.628 \\
\end{tabular} & 5.959 & 6.395 & 5.710 & 6.216 & \begin{tabular}{|l|}
6.778 \\
\end{tabular} & 0.0111 & -2.7241 & 0.9547 & -0.0306 & 7.9571 & 0.5902 & 0.0448 & 5.8082 & 0.9404 \\
\hline 15 & 6.870 & 6.166 & 6.635 & 5.864 & 6.428 & 7.055 & 0.0121 & -3.3470 & 0.9460 & -0.0329 & 8.3047 & 0.5648 & 0.0490 & 5.9858 & 0.9320 \\
\hline & & & & & & & & & & & & & & & \\
\hline
\end{tabular}

Table 8-29: Effects of fuel density, cetane number, and aromatic content on bsCO emissions for F-76 test fuels

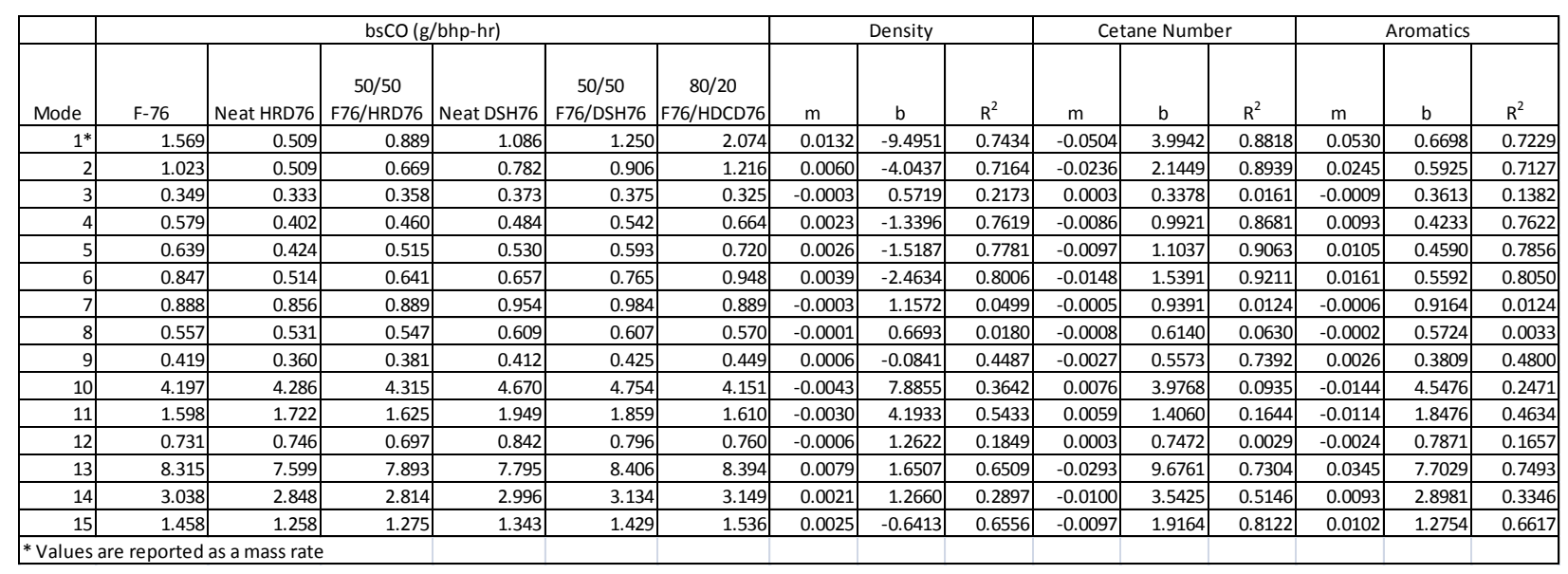


Table 8-30: Effects of fuel density, cetane number, and aromatic content on bsCO $_{2}$ emissions for F-76 test fuels

\begin{tabular}{|c|c|c|c|c|c|c|c|c|c|c|c|c|c|c|c|}
\hline \multirow[b]{2}{*}{ Mode } & \multicolumn{6}{|c|}{$\mathrm{bsCO}_{2}(\mathrm{~g} / \mathrm{bhp}-\mathrm{hr})$} & \multicolumn{3}{|c|}{ Density } & \multicolumn{3}{|c|}{ Cetane Number } & \multicolumn{3}{|c|}{ Aromatics } \\
\hline & $F-76$ & Neat HRD76 & $\begin{array}{c}50 / 50 \\
\text { F76/HRD76 }\end{array}$ & Neat DSH76 & $\begin{array}{c}50 / 50 \\
\text { F76/DSH76 }\end{array}$ & $\begin{array}{c}80 / 20 \\
\text { F76/HDCD76 }\end{array}$ & $\mathrm{m}$ & b & $\mathrm{R}^{2}$ & $\mathrm{~m}$ & $\mathrm{~b}$ & $\mathrm{R}^{2}$ & $\mathrm{~m}$ & b & $\mathrm{R}^{2}$ \\
\hline $1^{*}$ & 323.61 & 278.37 & 305.30 & \begin{tabular}{|r|}
298.05 \\
\end{tabular} & 305.00 & 312.32 & 0.3443 & 23.7732 & 0.6552 & -1.4063 & 380.8881 & 0.8869 & 1.4080 & 288.9201 & 0.6588 \\
\hline 2 & 524.42 & 491.81 & 513.31 & 493.46 & 509.70 & 532.34 & 0.4522 & 143.0938 & 0.9846 & -1.4122 & 588.2757 & 0.7790 & 1.8410 & 491.4188 & 0.9810 \\
\hline 3 & 473.15 & 448.33 & 464.16 & \begin{tabular}{|l|}
449.48 \\
\end{tabular} & 462.37 & 479.10 & 0.3440 & 182.9915 & 0.9862 & -1.0780 & 521.8781 & 0.7857 & 1.4029 & 447.9648 & 0.9859 \\
\hline 4 & 490.21 & 463.52 & 481.13 & 464.03 & 477.77 & 496.51 & 0.3744 & 174.3559 & 0.9862 & -1.1575 & 542.3329 & 0.7647 & 1.5234 & 462.7906 & 0.9814 \\
\hline 5 & 499.79 & 474.01 & 491.37 & 474.16 & 488.00 & 505.73 & 0.3625 & 194.0072 & 0.9837 & -1.1142 & 549.9364 & 0.7537 & 1.4779 & \begin{tabular}{|l|}
473.2507 \\
\end{tabular} & 0.9827 \\
\hline 6 & 529.65 & 505.00 & 521.18 & 503.70 & 516.67 & 536.15 & 0.3634 & 223.1699 & 0.9892 & -1.0952 & 578.7764 & 0.7288 & 1.4705 & 503.2092 & 0.9735 \\
\hline 7 & 460.91 & 439.32 & 451.97 & 440.11 & 451.60 & 467.04 & 0.3080 & 201.3657 & 0.9907 & -0.9681 & 504.9118 & 0.7942 & 1.2536 & 438.6004 & 0.9868 \\
\hline 8 & 458.19 & 437.51 & 449.74 & 438.26 & 448.77 & 464.45 & 0.2984 & 206.8125 & 0.9920 & -0.9350 & 500.7537 & 0.7901 & 1.2109 & 436.7106 & 0.9820 \\
\hline 9 & 469.00 & 447.97 & 459.14 & 448.44 & 458.17 & 474.87 & 0.3025 & 213.5401 & 0.9958 & -0.9526 & 511.8294 & 0.8008 & 1.2182 & 446.7440 & 0.9705 \\
\hline 10 & 459.36 & 439.84 & 449.96 & 439.98 & 450.30 & 465.96 & 0.2909 & 214.3120 & 0.9923 & -0.9122 & 500.9217 & 0.7916 & 1.1773 & 438.4800 & 0.9769 \\
\hline 11 & 450.16 & 431.76 & 441.19 & 432.24 & 441.67 & 456.56 & 0.2733 & 220.0035 & 0.9898 & -0.8622 & 489.5405 & 0.7992 & 1.1053 & 430.6034 & 0.9731 \\
\hline 12 & 454.77 & 435.94 & 445.13 & 436.50 & 445.70 & 460.76 & 0.2753 & 222.5373 & 0.9903 & -0.8742 & 494.4009 & 0.8098 & 1.1107 & 434.7494 & 0.9686 \\
\hline 13 & 457.98 & 439.59 & 448.30 & 439.54 & 449.30 & 463.20 & 0.2677 & 231.9211 & 0.9925 & -0.8461 & 496.0465 & 0.8043 & 1.0826 & 438.2295 & 0.9755 \\
\hline 14 & 449.10 & 430.41 & 439.12 & 431.64 & 440.60 & 454.71 & 0.2661 & 224.5407 & 0.9831 & -0.8596 & 488.0639 & 0.8324 & 1.0751 & 429.5885 & 0.9648 \\
\hline 15 & 452.31 & 433.68 & 442.32 & 435.12 & 443.47 & 457.59 & 0.2617 & 231.2648 & 0.9832 & -0.8492 & 490.6470 & 0.8401 & 1.0546 & 432.9538 & 0.9600 \\
\hline & & rate & & & & & & & & & & & & & \\
\hline
\end{tabular}

Table 8-31: Effects of fuel density, cetane number, and aromatic content on bsPM emissions for F-76 test fuels

\begin{tabular}{|c|c|c|c|c|c|c|c|c|c|c|c|c|c|c|c|}
\hline & \multicolumn{6}{|c|}{ bsPM (mg/bhp-hr) } & \multicolumn{3}{|c|}{ Density } & \multicolumn{3}{|c|}{ Cetane Number } & \multicolumn{3}{|c|}{ Aromatics } \\
\hline Mode & $F-76$ & Neat HRD76 & $\begin{array}{c}50 / 50 \\
\text { F76/HRD76 }\end{array}$ & Neat DSH76 & $\begin{array}{c}50 / 50 \\
\text { F76/DSH76 }\end{array}$ & $\begin{array}{c}80 / 20 \\
\text { F76/HDCD76 }\end{array}$ & $\mathrm{m}$ & b & $R^{2}$ & $\mathrm{~m}$ & b & $R^{2}$ & $\mathrm{~m}$ & b & $R^{2}$ \\
\hline 1* & 88.11 & \begin{tabular}{|r|}
38.21 \\
\end{tabular} & 43.08 & 47.64 & 64.40 & $\begin{array}{r}69.96 \\
\end{array}$ & 0.4192 & -282.3983 & 0.6162 & -1.7090 & 152.2758 & 0.8307 & 1.6802 & 40.8410 & 0.5949 \\
\hline 2 & 138.93 & 74.56 & 104.71 & 89.69 & 107.33 & 128.31 & 0.6185 & -395.7747 & 0.8577 & -2.2629 & 231.3360 & 0.9314 & 2.4940 & 80.9411 & 0.8383 \\
\hline 3 & 70.53 & 28.44 & 50.32 & 28.43 & 48.30 & 288.77 & 2.1999 & -1703.4041 & 0.6061 & -6.2620 & 429.1617 & 0.3983 & 8.6603 & -5.5678 & 0.5645 \\
\hline 4 & 179.63 & 113.36 & 129.29 & 121.11 & 161.90 & 198.15 & 0.9035 & -584.2494 & 0.8719 & -3.1150 & 321.3805 & 0.8408 & 3.7065 & 111.4696 & 0.8820 \\
\hline 5 & 228.72 & 137.36 & 181.92 & 153.20 & 184.20 & 166.12 & 0.5478 & -270.2715 & 0.3818 & -2.2317 & 297.6260 & 0.5140 & 2.2723 & 151.2803 & 0.3948 \\
\hline 6 & 316.06 & 155.93 & 239.89 & 191.28 & 269.23 & 54.62 & -0.2790 & 431.4088 & 0.0115 & -0.6149 & 238.2203 & 0.0045 & -0.6554 & 211.4156 & 0.0038 \\
\hline 7 & 89.50 & 44.71 & 70.52 & 51.87 & 74.67 & 75.35 & 0.3939 & -252.5763 & 0.7190 & -1.4117 & 145.1750 & 0.7492 & 1.6585 & 50.2720 & 0.7662 \\
\hline 8 & 71.48 & 33.86 & 56.12 & 43.87 & 59.70 & 62.75 & 0.3290 & -212.9630 & 0.7430 & -1.2223 & 121.6533 & 0.8318 & 1.3803 & 40.0678 & 0.7859 \\
\hline 9 & 84.63 & 44.93 & 67.32 & 50.40 & 72.13 & 76.40 & 0.3875 & -249.1572 & 0.8060 & -1.3512 & 140.0594 & 0.7951 & 1.6258 & 48.8158 & 0.8529 \\
\hline 10 & 147.22 & 117.11 & 134.89 & 141.12 & 157.30 & 66.70 & -0.4186 & 467.8574 & 0.2090 & 0.6733 & 90.4697 & 0.0439 & -1.4706 & 142.9050 & 0.1550 \\
\hline 11 & 84.89 & 58.65 & 72.71 & 75.93 & 86.07 & 77.16 & 0.1444 & -41.5669 & 0.2682 & $\begin{array}{l}-0.7638 \\
\end{array}$ & 117.7805 & 0.6085 & 0.6629 & 68.9074 & 0.3396 \\
\hline 12 & 72.13 & 43.02 & 60.67 & 53.92 & 63.83 & 137.81 & 0.7908 & -571.2962 & 0.6972 & -2.4470 & 206.0748 & 0.5415 & 3.1586 & 38.5744 & 0.6685 \\
\hline 13 & 233.14 & 185.63 & 207.05 & 203.18 & 233.53 & 86.80 & $\begin{array}{l}-0.6669 \\
\end{array}$ & 733.9320 & 0.1897 & 1.2842 & 121.1367 & 0.0571 & -2.4035 & 216.9124 & 0.1481 \\
\hline 14 & 110.45 & 83.11 & 95.53 & 95.91 & 110.40 & 107.32 & 0.2227 & -80.6603 & 0.5317 & -0.9500 & 152.5444 & 0.7849 & 0.9749 & 90.1685 & 0.6125 \\
\hline 15 & 88.58 & 56.56 & 72.04 & 68.04 & 81.23 & 225.07 & 1.3663 & -1012.5958 & \begin{tabular}{l|}
0.5982 \\
\end{tabular} & \begin{tabular}{|l|}
-4.0779 \\
\end{tabular} & 322.1949 & 0.4323 & 5.4191 & 41.4165 & 0.5657 \\
\hline Values & orted & ass rate & & & & & & & & & & & & & \\
\hline
\end{tabular}

Table 8-32: Effects of fuel density, cetane number, and aromatic content on bsFC for F-76 test fuels

\begin{tabular}{|c|c|c|c|c|c|c|c|c|c|c|c|c|c|c|c|}
\hline & \multicolumn{6}{|c|}{ bsFC (Ib/bhp-hr) } & \multicolumn{3}{|c|}{ Density } & \multicolumn{3}{|c|}{ Cetane Number } & \multicolumn{3}{|c|}{ Aromatics } \\
\hline Mode & $F-76$ & Neat HRD76 & $\begin{array}{c}50 / 50 \\
\text { F76/HRD76 }\end{array}$ & Neat DSH76 & $\begin{array}{c}50 / 50 \\
\text { F76/DSH76 }\end{array}$ & $\begin{array}{c}80 / 20 \\
\text { F76/HDCD76 }\end{array}$ & $\mathrm{m}$ & b & $R^{2}$ & $\mathrm{~m}$ & b & $R^{2}$ & $\mathrm{~m}$ & b & $\mathrm{R}^{2}$ \\
\hline $1^{*}$ & 0.228 & 0.217 & 0.217 & $\begin{array}{l}0.214 \\
\end{array}$ & 0.217 & $\begin{array}{l}0.200 \\
\end{array}$ & \begin{tabular}{l|}
-0.0001 \\
\end{tabular} & 0.2599 & 0.0459 & 0.0001 & 0.2115 & 0.0070 & \begin{tabular}{l|}
-0.0002 \\
\end{tabular} & 0.2180 & 0.0494 \\
\hline 2 & 0.367 & 0.362 & 0.362 & 0.352 & 0.361 & 0.351 & 0.0000 & 0.3561 & 0.0004 & 0.0001 & 0.3553 & 0.0127 & 0.0000 & 0.3588 & 0.0010 \\
\hline 3 & 0.330 & 0.328 & 0.368 & 0.320 & 0.326 & 0.320 & 0.0000 & 0.3319 & 0.0000 & 0.0004 & 0.3115 & 0.0440 & 0.0001 & 0.3314 & 0.0011 \\
\hline 4 & 0.343 & 0.340 & 0.346 & 0.331 & 0.337 & 0.331 & 0.0000 & 0.3326 & 0.0015 & 0.0001 & 0.3321 & 0.0322 & 0.0000 & 0.3376 & 0.0024 \\
\hline 5 & 0.348 & 0.346 & 0.340 & 0.337 & 0.343 & 0.338 & 0.0000 & 0.3362 & 0.0030 & 0.0000 & 0.3411 & 0.0012 & 0.0000 & 0.3417 & 0.0011 \\
\hline 6 & 0.371 & 0.368 & 0.328 & 0.358 & 0.363 & 0.359 & 0.0000 & 0.3400 & 0.0025 & -0.0003 & 0.3732 & 0.0323 & 0.0000 & 0.3578 & 0.0000 \\
\hline 7 & 0.322 & 0.320 & 0.323 & 0.314 & 0.319 & 0.314 & 0.0000 & 0.3124 & 0.0055 & 0.0000 & 0.3166 & 0.0111 & 0.0000 & 0.3183 & 0.0089 \\
\hline 8 & 0.319 & 0.317 & 0.317 & 0.312 & 0.316 & 0.312 & 0.0000 & 0.3092 & 0.0075 & 0.0000 & 0.3144 & 0.0024 & 0.0000 & 0.3148 & 0.0086 \\
\hline 9 & 0.326 & 0.323 & 0.320 & 0.318 & 0.322 & 0.319 & 0.0000 & 0.3088 & 0.0327 & 0.0000 & 0.3238 & 0.0249 & 0.0001 & 0.3207 & 0.0224 \\
\hline 10 & 0.324 & 0.321 & 0.315 & 0.317 & 0.321 & 0.318 & 0.0000 & 0.3093 & 0.0171 & -0.0001 & 0.3231 & 0.0442 & 0.0000 & 0.3188 & 0.0130 \\
\hline 11 & 0.316 & 0.313 & 0.313 & 0.310 & 0.313 & 0.310 & 0.0000 & 0.3034 & 0.0341 & 0.0000 & 0.3139 & 0.0122 & 0.0000 & 0.3121 & 0.0359 \\
\hline 12 & 0.318 & 0.315 & 0.321 & 0.312 & 0.315 & 0.312 & 0.0000 & 0.3040 & 0.0196 & 0.0000 & 0.3147 & 0.0013 & 0.0001 & 0.3147 & 0.0264 \\
\hline 13 & 0.328 & 0.323 & 0.313 & 0.321 & 0.324 & 0.321 & 0.0000 & 0.3036 & 0.0268 & -0.0002 & 0.3302 & 0.0989 & 0.0001 & 0.3211 & 0.0182 \\
\hline 14 & 0.316 & 0.313 & 0.313 & 0.309 & 0.314 & 0.309 & 0.0000 & 0.3058 & 0.0094 & 0.0000 & 0.3130 & 0.0019 & 0.0000 & 0.3119 & 0.0152 \\
\hline 15 & 0.317 & 0.313 & 0.323 & 0.310 & 0.314 & 0.309 & 0.0000 & 0.3093 & 0.0019 & 0.0001 & 0.3106 & 0.0186 & 0.0000 & 0.3140 & 0.0064 \\
\hline & & & & & & & & & & & & & & & \\
\hline
\end{tabular}


